Bruno Madio

\title{
Purificação e caracterização da fração \\ neurotóxica da peçonha da anêmona do mar Anthopleura cascaia
}

Purification and characterization of the neurotoxic fraction from the venom of the sea anemone Anthopleura cascaia 


\section{Bruno Madio}

Versão corrigida conforme a Resolução CoPGr: 5890

Original encontra-se disponível no Instituto de Biociências da Universidade de São Paulo

\section{Purificação e caracterização da fração neurotóxica da peçonha da anêmona do mar Anthopleura cascaia}

Purification and characterization of the neurotoxic fraction from the venom of the sea anemone Anthopleura cascaia

Dissertação apresentada ao Instituto de Biociências da Universidade de São Paulo, para a obtenção do Título de Mestre em Ciências, na Área de Fisiologia Geral.

Orientador: José Eduardo

Pereira Wilken Bicudo 


\section{Bruno Madio}

\section{Madio, Bruno}

Purificação e caracterização da fração neurotóxica da peçonha da anêmona do mar Anthopleura cascaia. 169 páginas.

Dissertação (Mestrado) - Instituto de Biociências da Universidade de São Paulo. Departamento de Fisiologia Geral.

1. Toxinologia 2. Neurotoxinas 3. Anêmonas do mar. Universidade de São Paulo. Instituto de Biociências. Departamento de Fisiologia.

Comissão Julgadora:

Prof. Dr. José Eduardo Pereira Wilken Bicudo

Prof.(a) Dr. (a)

Prof.(a) Dr. (a) 
"...se alguém pensa que sabe alguma coisa, não a conhece ainda como convém conhecer..."

I Corinthios 8:2 
Por ter a certeza de que ciência não é construída de forma solitária e por ter obtido os resultados da minha dissertação por meio de favores e colaborações. Por esses e outros motivos gostaria de agradecer:

Primeiramente a minha família, que sempre me amaram e me apoiaram incondicionalmente. Mesmo distantes do meu trabalho, em outras palavras, sem entender nada sempre me apoiaram e confiaram nas minhas metas.

Ao Prof. José Carlos de Freitas, inicialmente meu orientador, por ter aberto as portas de seu laboratório. Mesmo ausente, me incentivou pela excelência de seus trabalhos publicados.

Ao meu atual orientador, Prof. José Eduardo Pereira Wilken Bicudo, muito obrigado por assumir a complicada obrigação de me orientar.

Ao Diego Jose Orts y Belato obrigado por desde a graduação estar ao meu lado nessa batalha. Não vejo como seria possível enfrentar tudo o que passamos sozinho.

Ao professor Dr. Jan Tytgat e ao Laboratório de Toxicologia por me receber tão bem em seu país e por dar suporte para conseguir realisar tantos experimentos em tão pouco tempo.

Ao Álvaro Rossan de Brandão Prieto da Silva, mesmo sem "vínculo" institucional, sempre esteve disposto em me ajudar. Obrigado por ser uma referência para mim como cientista e pessoa.

A todos os amigos do departamento de fisiologia, não preciso citar nomes, pois quem me apoiou, compartilhou discussões, cafés, festas, almoços, etc. sabe que sou grato e terei muitos como amigos pelo resto da vida.

Aos funcionários do Instituto de Biociências e do Departamento de Fisiologia Geral, muito obrigado por darem suporte para poder desenvolver meu trabalho.

Ao CNPq e ao Instituto de Biociências da USP, obrigado pelo apoio financeiro.

Agradeço a todos aqueles que de forma direta e indireta contribuíram para realização deste trabalho. 


\section{Índice}

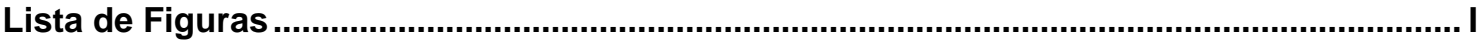

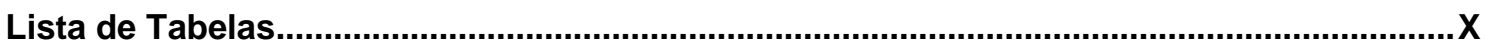

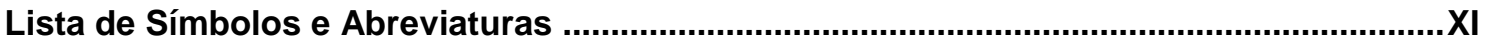

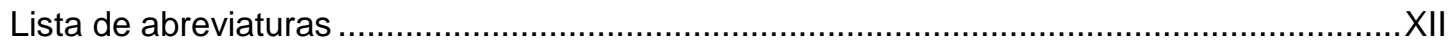

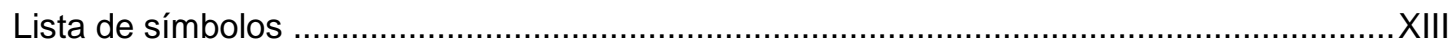

Lista de abreviatura dos aminoácidos................................................................................. XIV

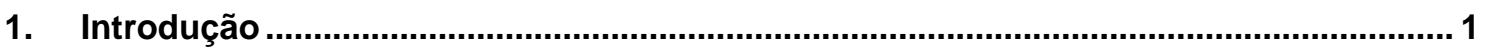

1.1 Anêmonas do mar - aspectos zoológicos ……….............................................. 2

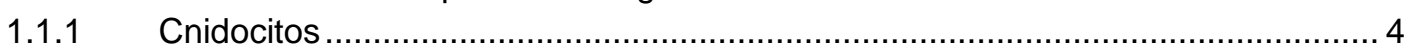

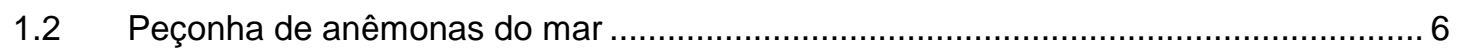

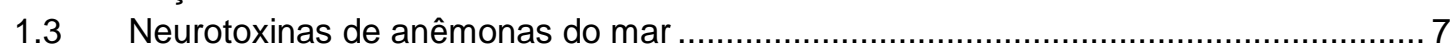

1.4 Toxinas de anêmonas do mar e canais para potássio sensíveis à voltagem ................ 8

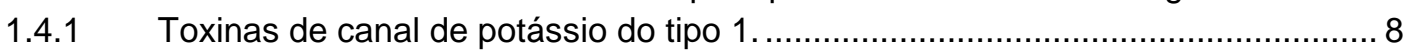

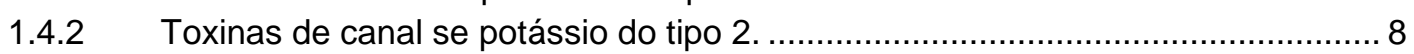

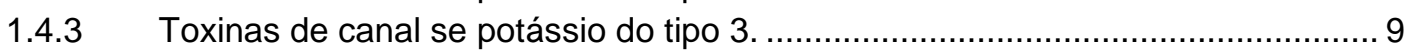

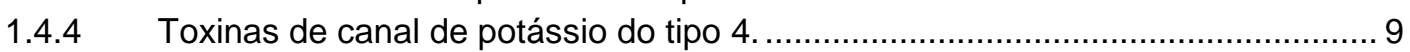

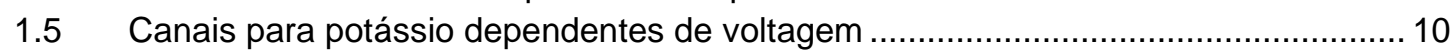

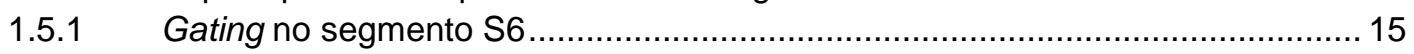

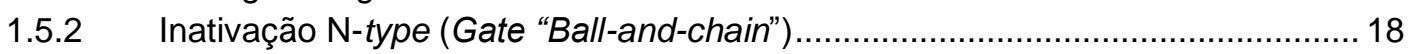

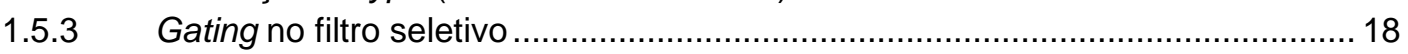

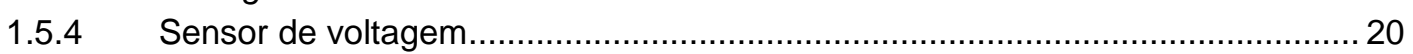

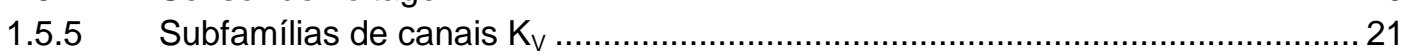

1.6 Toxinas de anêmonas do mar e canais para sódio sensíveis à voltagem.................... 26

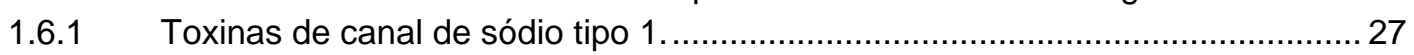

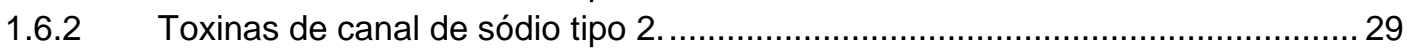

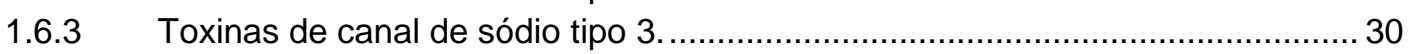

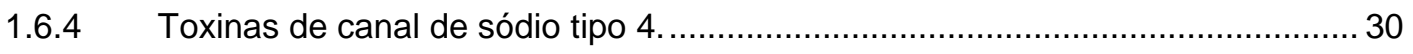

1.6.5 Superfície bioativa de toxinas de anêmonas do mar que atuam em canal de

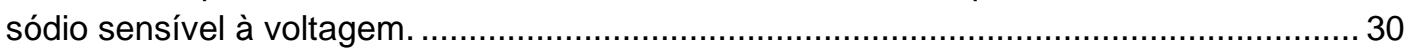

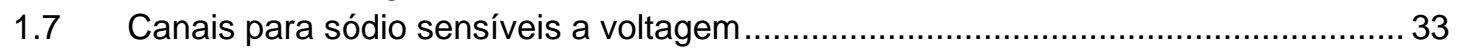

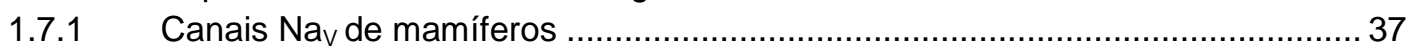

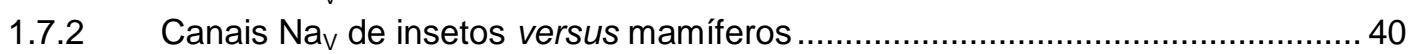

$1.8 \quad$ Novas classes de toxinas de anêmonas do mar.................................................... 43

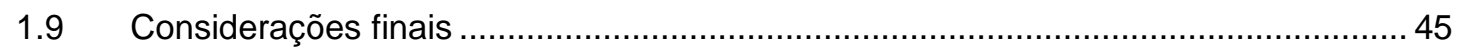

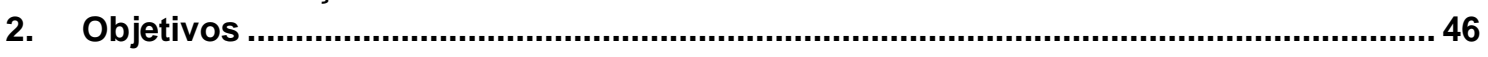

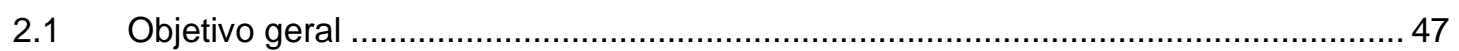

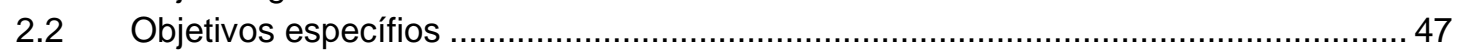

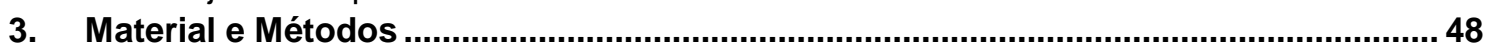

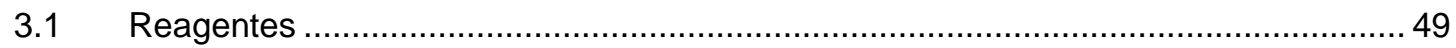

3.2 Captura e manutenção das anêmonas do mar ...................................................... 49

3.3 Obtenção da peçonha de Anthopleura cascaia ....................................................... 49

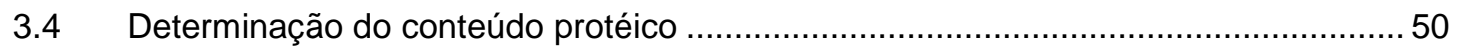

3.5 Purificação da peçonha de Anthopleura cascaia ..................................................... 50

3.5.1 Purificação por gel-filtração em gel de Sephadex G-50.....................................50

3.5.2 Purificação por cromatografia de fase reversa (RP-HPLC) da fração neurotóxica

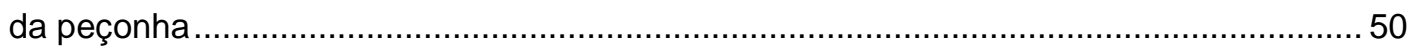

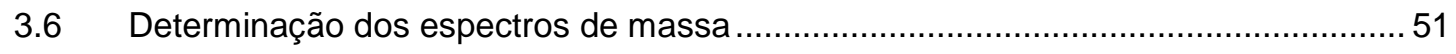

3.7 Determinação da sequência $\mathrm{N}$-terminal ....................................................................... 51 
3.8 Pesquisa de homologia dos peptídeos neurotóxicos ……....................................... 52

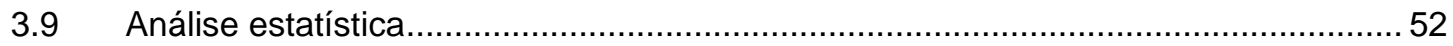

3.10 Medidas eletrofisiológicas em oócitos de Xenopus laevis - Técnica de voltage clamp

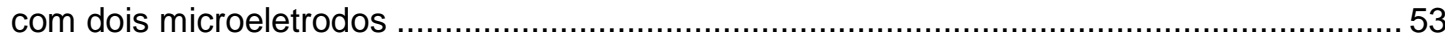

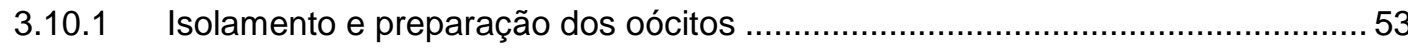

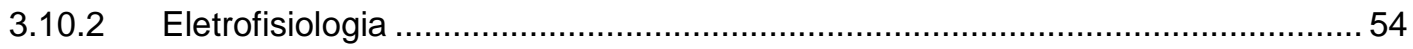

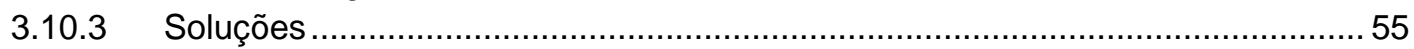

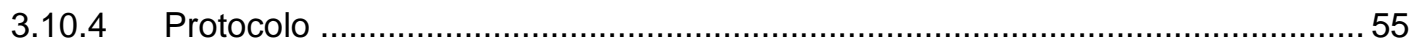

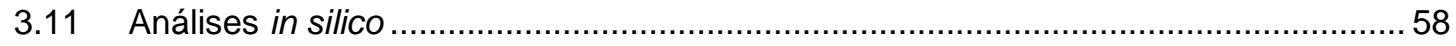

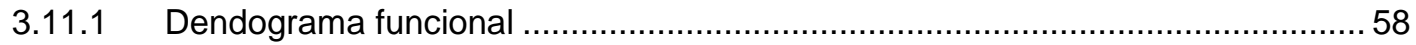

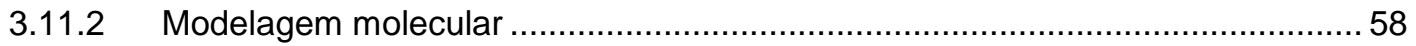

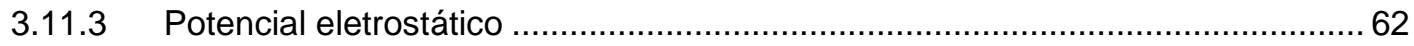

3.11.4 Predição da interação entre canal e toxina - "Docking Molecular" ...................... 62

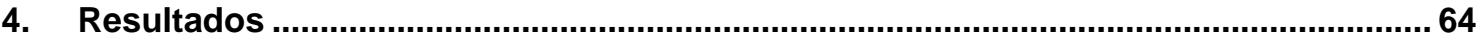

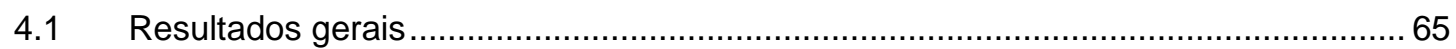

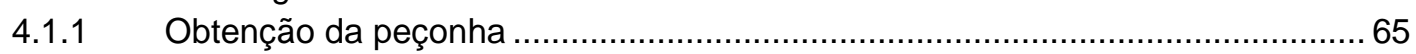

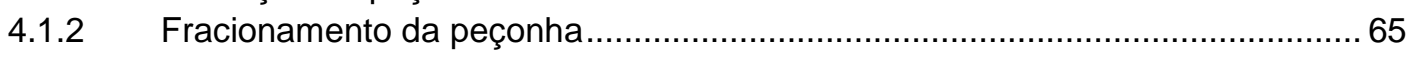

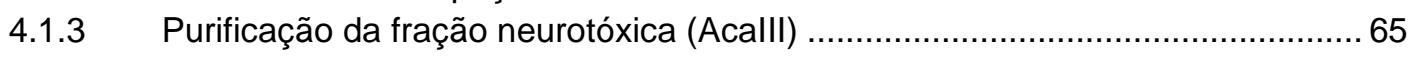

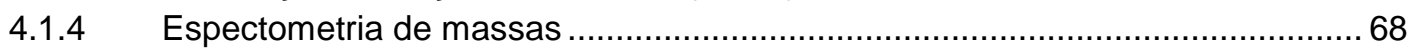

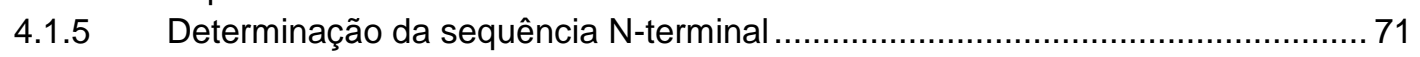

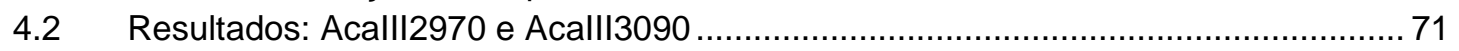

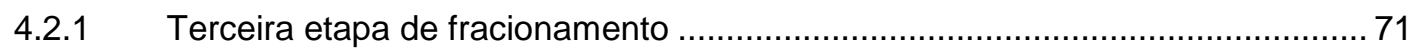

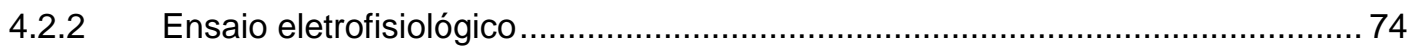

4.2.3 Determinação da sequência N-terminal e busca por similaridades .................... 77

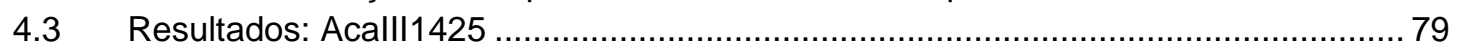

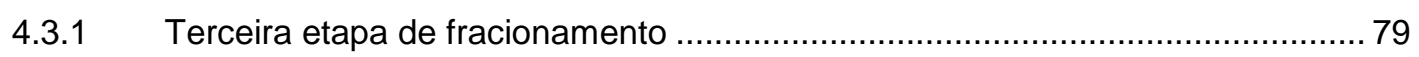

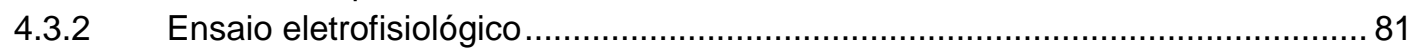

4.3.3 Determinação da sequência $\mathrm{N}$-terminal e busca por similaridades ..................... 87

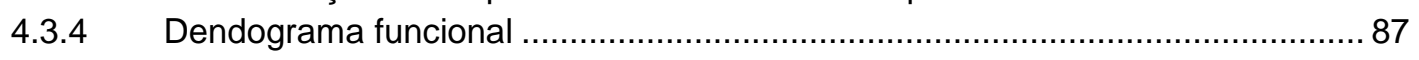

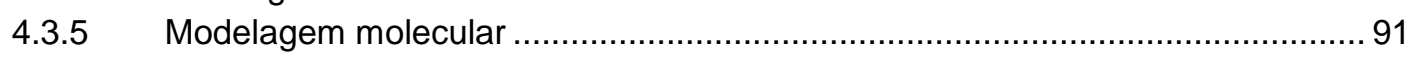

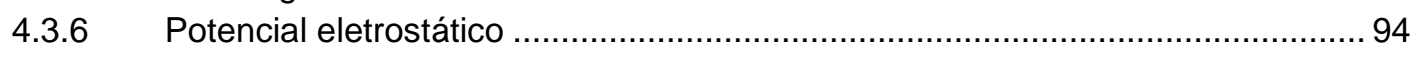

4.3.7 Predição da interação entre canal e toxina - Docking........................................ 95

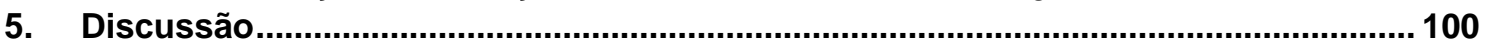

5.1 Obtenção da peçonha de Anthopleura cascaia ….................................................. 101

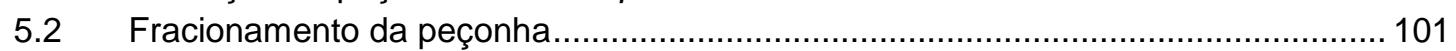

5.3 Purificação da fração neurotóxica (AcallI) …....................................................... 101

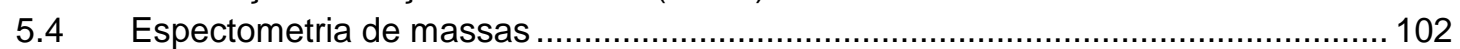

5.5 Determinação da sequência N-terminal e busca por similaridades ................................ 102

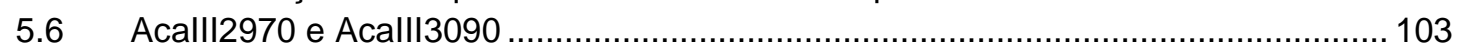

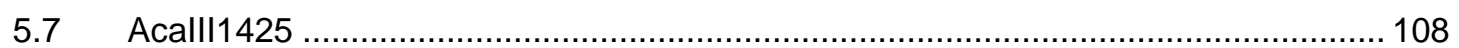

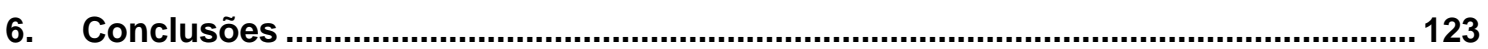

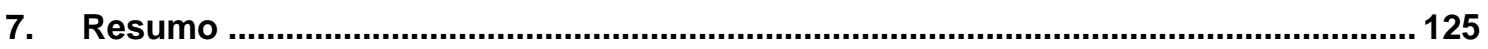

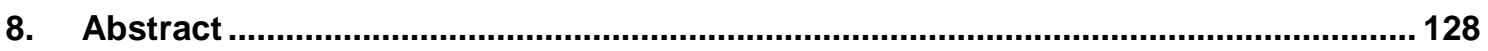

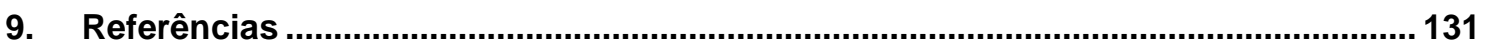




\section{Lista de Figuras}

FIGURA 1 - CLADOGRAMA HIPOTÉTICO DOS ORGANISMOS COM SIMETRIA BILATERAL. AS ERAS GEOLÓGICAS ESTÃO INDICADAS NA LATERAL ESQUERDA DO CLADOGRAMA. O FILO DOS CNIDÁRIOS ENCONTRA-SE CIRCULADO EM VERMELHO. FIGURA ADAPTADA DE BRUSCA \& BRUSCA (2003) ............................... 3

FIGURA 2 - ANATOMIA DE ANÊMONAS DO MAR. FIGURA ADAPTADA DE BRUSCA \& BRUSCA (2003).

FIGURA 3 - ORGANIZAÇÃO INTRACELULAR DE UM CNIDÓCITO CARREGADO (A) E DESCARREGADO (B). FIGURA ADAPTADA DE ANDERSON \& BOUCHARD (2009)...... 6

FIGURA 4 - NO LADO ESQUERDO TEMOS UM ESQUEMA DE UMA SUBUNIDADE A DO CANAL PARA POTÁSSIO. OS 6 SEGMENTOS TRANSMEMBRANA DE UMA ÚNICA SUBUNIDADE DO CANAL ENCONTRAM-SE EM EVIDÊNCIA. EXISTEM APENAS DUAS HÉLICES TRANSMEMBRANA: A HÉLICE EXTERNA É HOMÓLOGA AO S5 E A HÉLICE INTERNA AO S6. NA FIGURA DO LADO DIREITO TEMOS: O INTERIOR DA PROTEÍNA ESTÁ EM VERDE ESCURO, COM AS ESTRUTURAS SECUNDÁRIAS REPRESENTADAS POR FITAS, PARA AS TRÊS DAS QUATRO SUBUNIDADES, E A SUPERFÍCIE DA PROTEÍNA EXPOSTA À ÁGUA ENCONTRA-SE COLORIDA EM CINZA. O FILTRO SELETIVO É VISTO NO TOPO, COM O “LOOP” DO FILTRO SELETIVO APOIADO PELAS HÉLICES DO PORO. AS QUATRO ESFERAS MARCAM OS QUATRO SÍTIOS DE LIGAÇÃO PARA ÍONS $\mathrm{K}^{+}$; ESSES SÃO COMUMENTE OCUPADOS POR ÍONS ALTERNATIVOS AO K+ E MOLÉCULAS DE ÁGUA (MORAISCABRAL ET AL, 2001). AS QUATRO HÉLICES INTERNAS CRUZAM-SE PARA AFUNILAR O CANAL EM SUA PORÇÃO INFERIOR (O "CAMINHO DE PASSAGEM"). ENTRE O FILTRO SELETIVO E O CAMINHO DE PASSAGEM ENCONTRA-SE UMA CAVIDADE COM ÁGUA. FIGURA MODIFICADA DE YELLEN (2002). 10

FIGURA 5 - O CENTRO DA SUBFAMÍLIA $\mathrm{K}_{\mathrm{v}} 1 . X-\mathrm{K}_{\mathrm{v}} 4 . X$ TEM NO SEU N-TERMINAL UM "DOMÍNIO TETRAMERIZADO" (T1, ROXO) QUE DETERMINA A ESPECIFICIDADE DO CONJUNTO DE SUBUNIDADES E TAMBÉM SERVE COMO UMA PLATAFORMA PARA A MONTAGEM DAS SUBUNIDADES B (EM AZUL CLARO) E PARA OUTRAS INTERAÇÕES PROTEÍNA-PROTEÍNA. FIGURA MODIFICADA DE YELLEN (2002)......11

FIGURA 6 - REPRESENTAÇÃO DE CANAL TETRAMÉRICOS 6TM. ESSES POSSUEM UM DOMÍNIO ESTRUTURAL DIFERENTE, CARACTERIZADO PELA AUSÊNCIA DE UM DOMÍNIO T1 E A PRESENÇA DE UM DOMÍNIO SENSOR NO C-TERMINAL (VERDE). ALGUNS MEMBROS DESSA FAMÍLIA POSSUEM NO N-TERMINAL UMA REGIÃO TRANSMEMBRANA ADICIONAL (SO) (ROXO). FIGURA MODIFICADA DE YELLEN (2002).

FIGURA 7 - CARACTERÍSTICAS ARQUITETÔNICAS DOS CANAIS DE K IMPORTANTES PARA A PERMEABILIDADE DE ÍONS. APROXIMAÇÃO DE UM CORTE TRANSVERSAL DE UM CANAL DE $K^{+}$ABERTO, BASEADO NA ESTRUTURA DO CANAL MTHK 
(ESQUERDA) (JIANG ET AL., 2002). O VESTÍBULO INTRACELULAR ABERTO E OS POROS DOS DIPOLOS DAS HÉLICES ESTÃO REALÇADOS. O DIAGRAMA DA DIREITA É UMA REPRESENTAÇÃO DERIVADA DA ESTRUTURA DE ALTA RESOLUÇÃO DO CANAL KCSA (ZHOU ET AL., 2001), MOSTRANDO UM ACESSO ESTREITO, PROVAVELMENTE FECHADO, PARA A CAVIDADE CHEIA DE ÁGUA NO CENTRO DA PROTEÍNA DE MEMBRANA. UM ÍON K+ APRISIONADO (ESFERA ROXA) E SUAS OITO MOLÉCULAS DE ÁGUA DE HIDRATAÇÃO (ESFERAS VERDES); OS OXIGÊNIOS DE SUPORTE DO FILTRO SELETIVO (ESFERAS VERMELHAS) FORNECEM UMA BOA CORRESPONDÊNCIA PARA ESSE AMBIENTE DE HIDRATAÇÃO PARA OS ÍONS POTÁSSIO. A OCUPAÇÃO DO PORO POR MÚLTIPLOS ÍONS $\mathrm{K}^{+}$APRESENTA UM PAPEL IMPORTANTE NA SELETIVIDADE E EM OUTRAS PROPRIEDADES DO CANAL (MORAIS-CABRAL ET AL., 2001; HODGKIN \& KEYNES, 1955; HILLE \& SCHWARZ, 1978; SPASSOVA \& LU, 1998). ESSA ARQUITETURA BÁSICA TAMBÉM PODE PRODUZIR CANAIS CATIÔNICOS NÃO SELETIVOS (HEGINBOTHAM ET AL., 1992) OU CANAIS SELETIVOS PARA ÍONS NA+ OU $\mathrm{CA}^{2+}$ (REN ET AL., 2001). ESFERAS NA COR LARANJA INDICAM CADEIAS LATERAIS DE ÁTOMOS DE OXIGÊNIO. FIGURA MODIFICADA DE DOYLE E COLABORADORES (1998).

FIGURA 8 - MUDANÇAS CONFORMACIONAIS QUE ABREM E FECHAM O PORO DO CANAL DE $K^{+}$. O DIAGRAMA CENTRAL MOSTRA A ESTRUTURA DO CENTRO DE UM CANAL DE K ${ }^{+}$ABERTO, COM BASE NA ESTRUTURA DE MTHK (JIANG ET AL, 2002B). O FILTRO SELETIVO (EM VERDE) É REPRESENTADO COM UM CORTE PARA MOSTRAR O PORO ESTREITO. AS HÉLICES EXTERNAS NÃO ESTÃO REPRESENTADAS PARA PODER MOSTRAR AS HÉLICES INTERNAS, CORRESPONDENTES AO S6. NO ESTADO ABERTO OS SEGMENTOS S6 ESTÃO ESPALHADOS PARA FORA, COMO NA ESTRUTURA DE MTHK, UTILIZANDO A DOBRADIÇA CONSERVADA DE GLICINA PRÓXIMA AO FILTRO SELETIVO. O DIAGRAMA SUPERIOR MOSTRA UM CANAL DE $\mathrm{K}^{+}$NO ESTADO FECHADO, COM BASE NA ESTRUTURA DE KCSA (DOYLE ET AL, 1998). OS QUATRO SEGMENTOS TRANSMEMBRANA S6 BALANÇAM EM CONJUNTO PARA PRODUZIR UM FECHAMENTO DO CAMINHO DE PASSAGEM (DEL CAMINO \& YELLEN, 2001). ISSO CORTA O FLUXO DE ÍONS E PODE PRENDER BLOQUEADORES ORGÂNICOS DOS CANAIS NA CAVIDADE FECHADA. O ANEL EM VERDE E O EM VERMELHO ILUSTRAM O ESTADO ABERTO E FECHADO, RESPECTIVAMENTE, DO GATE S6. ALTERNATIVAMENTE, O CANAL PODE DE SER FECHADO NO FILTRO SELETIVO (DIAGRAMA DA DIREITA NO CANTO INFERIOR), OU POR LIGAÇÃO DE UM PEPTÍDEO AUTO-INIBITÓRIO (DIAGRAMA DA ESQUERDA NO CANTO INFERIOR) QUANDO O SÍTIO DE LIGAÇÃO NO PORO É EXPOSTO PELA ABERTURA DO GATE S6. FIGURA MODIFICADA DE JIANG E COLABORADORES (2002). 
FIGURA 9 - ÁRVORE FILOGENÉTICA PARA AS FAMÍLIAS Kv1-9: ALINHAMENTOS DAS SEQUÊNCIAS DE AMINOÁCIDOS DAS PROTEÍNAS DE CANAIS $K_{v}$ DE HUMANO FORAM CRIADOS POR MEIO DA UTILIZAÇÃO DA FERRAMENTA CLUSTALW E DA ANÁLISE POR MÁXIMA PARCIMÔNIA, UTILIZANDO PAUP. COMO RESULTADO, FOI CRIADA UMA ÁRVORE SEM RAIZ COMPREENDENDO AS FAMÍLIAS $K_{\mathrm{v}} 1-K_{\mathrm{v}} 6 \mathrm{E} \mathrm{K}_{\mathrm{v}} 8-$ $\mathrm{K}_{\mathrm{v}} 9$ QUE APARECERAM ANTERIORMENTE. AS SEQUÊNCIAS DE K $\mathrm{K}_{\mathrm{V}}$ 7.1-7.5, $\mathrm{K}_{\mathrm{v}} 6.4 \mathrm{E}$ $K_{V} 8.2$ FORAM ADICIONADAS AO ALINHAMENTO EXISTENTE, E ESSAS NOVAS SEQUÊNCIAS FORAM INCORPORADAS NA TOPOLOGIA DA ÁRVORE JÁ EXISTENTE UTILIZANDO UMA COMBINAÇÃO DE MÁXIMA PARCIMÔNIA E ANÁLISE NEIGHBORJOINING. SOMENTE OS NÚCLEOS HIDROFÓBICOS (S1-S6) FORAM UTILIZADOS PARA ANÁLISE. OS NOMES DADOS PELA IUPHAR E PELA HGNC ESTÃO MOSTRADOS JUNTO COM A LOCALIZAÇÃO DO GENE NO CROMOSSOMO E OUTROS NOMES COMUMENTE UTILIZADOS. FIGURA MODIFICADA DE GUTMAN E COLABORADORES (2003). 25

FIGURA 10 - ÁRVORE FILOGENÉTICA PARA AS FAMÍLIAS KV10-12: ESTA ÁRVORE SEM RAIZ FOI CRIADA COMO DESCRITO NA FIGURA 9. OS NOMES DADOS PELA IUPHAR E PELA HGNC ESTÃO MOSTRADOS JUNTO COM A LOCALIZAÇÃO DO GENE NO CROMOSSOMO E OUTROS NOMES COMUMENTE UTILIZADOS. FIGURA MODIFICADA DE GUTMAN E COLABORADORES (2003).

FIGURA 11 - ARRANJO TRANSMEMBRANA DA SUBUNIDADE A DOS CANAIS PARA SÓDIO EVIDENCIANDO OS PRINCIPAIS SÍTIOS DE INTERAÇÃO COM TOXINAS. FONTE: CESTELE \& CATTERALL, 2000.

FIGURA 12 - COMPARAÇÃO DA SUPERFÍCIE BIOATIVA DE TOXINAS QUE LIGAM AO SÍTIO 3. OS REÍDUOS QUE CONSTITUEM A SUPERFÍCIE "INSETICIDA" DE ESCORPIÃO A-TOXINA LQHAIT (KARBAT ET AL, 2004), A TOXINA DE ANÊMONA DO MAR DO TIPO 1 AV2 (MORAN ET AL, 2006), ASSIM COMO OS QUE COMPÕEM A SUPERFÍCIE BIOATIVA PARA NA ${ }_{V} S$ CARDÍACOS DA TOXINA DE ANÊMONA DO MAR DO TIPO 1 APB (BLUMENTHAL \& SEIBERT, 2003; SEIBERT ET AL, 2004) ESTÃO REPRESENTADAS POR STICKS DAS CADEIAS LATERAIS E POR RIBBON DA ESTRUTURA DO CA. AS ENTRADAS PARA DO PDB PARA AS ESTRUTURAS DA LQHAIT E APB SÃO, RESPECTIVAMENTE, 1LQI E 1APF. AMINOÁCIDOS AROMÁTICOS ESTÃO REPRESENTADOS EM MAGENTA; OS ALIFÁTICOS EM VERDE; POLARES EM LARANJA; POSITIVOS EM AZUL E NEGATIVOS EM VERMELHO. FIGURA MODIFICADA DE MORAN E COLABORADORES (2009). 33

FIGURA 13 - REPRESENTAÇÃO DOS ESTADOS DE UM CANAL VOLTAGEMDEPENDENTE DE SÓDIO. AS SETAS REPRESENTAM A TRANSIÇÃO DE UM ESTADO PARA OUTRO. AS SETAS EM VERMELHO INDICAM QUE NÃO OCORRE A PASSAGEM DE UM ESTADO PARA O OUTRO.

FIGURA 14 - REPRESENTAÇÃO ESQUEMÁTICA DA TOPOLOGIA DA MEMBRANA DE CANAIS NA $A_{V}$ A SUBUNIDADE-A (DI-IV) FORMADORA DE PORO ESTÁ 
REPRESENTADA NO CENTRO, FLANQUEADA POR DUAS SUBUNIDADES-B $\left(\mathrm{B}_{1} \mathrm{E}_{\mathrm{B}}\right)$ AUXILIARES. OS SEGMENTOS S1-S3 ESTÃO COLORIDOS EM VERMELHO; S5 E S6 ESTÃO COLORIDOS EM VERDE. OS RESÍDUOS DEKA E EEDD NO LINKER S5-S6, QUE FORMAM OS ANÉIS INTERNO E EXTERNO DO FILTRO SELETIVO, ESTÃO REPRESENTADOS POR CÍRCULOS BRANCOS. OS RESÍDUOS IFM NO GATE DE INATIVAÇÃO ESTÃO REPRESENTADOS POR CÍRCULOS AMARELOS; OS POSSÍVEIS LOCAIS QUE FORMAM O RECEPTOR DO GATE DE INATIVAÇÃO ESTÃO INDICADOS POR SETAS AMARELAS. ADAPTADO DE KING E COLABORADORES (2008A) E YU \& CATTERALL (2003). 36

FIGURA 15 - GATE DE INATIVAÇÃO DE CANAIS NAV PELO MECANISMO DE TAMPA ARTICULADA. PARA MELHOR VISUALIZAÇÃO SOMENTE TRÊS DOMÍNIOS HOMÓLOGOS DA SUBUNIDADE-A (DII-DIV) ESTÃO REPRESENTADOS. O LOOP INTRACELULAR ENTRE DIII E DIV ESTÁ DESCRITO COMO FORMADOR DE UMA TAMPA ARTICULADA COM OS RESÍDUOS CRÍTICOS IFM (CÍRCULOS AMARELOS). ESTES INTERAGEM OCLUINDO A BOCA INTERNA DO PORO DURANTE O PROCESSO DE INATIVAÇÃO. OS CÍRCULOS EM AZUL, VERMELHO E VERDE REPRESENTAM OS SEGMENTOS TRANSMEMBRANA, DE ACORDO COM A FIGURA 14. FIGURA ADAPTADA DE YU \& CATTERALL (2003). 37

FIGURA 16 - ÁRVORE FILOGENÉTICA DA SUBUNIDADE-A DE CANAL NAV DE MAMÍFERO. AS SEQUÊNCIAS DE AMINOÁCIDOS PARA NA $V$ DE RATOS FORAM ALINHADAS UTILIZANDO CLUSTALW E A ÁRVORE FOI CONSTRUÍDA UTILIZANDO PAUP. OS CROMOSSOMOS HUMANOS, NOS QUAIS O ORTÓLOGO HUMANO CORRESPONDENTE DE CADA GENE DE RATO É ENCONTRADO ESTÃO REPRESENTADOS NO LADO DIREITO. FIGURA MODIFICADA DE CATTERALL E COLABORRADORES (2005)...

FIGURA 17 - ALINHAMENTO DAS SEQUÊNCIAS DA REGIÃO DO PORO DE CANAIS DE SÓDIO DE INSETOS E MAMÍFEROS E CANAIS DE CÁLCIO DE INSETO BSC1/DSC1. O ALINHAMENTO MOSTRA A SEQUÊNCIA DE AMINOÁCIDOS DO LOOP P DOS QUATRO DOMÍNIOS (DI-IV) DE NA $V$ DE CANAIS NA ${ }_{V}$ PARA-TYPE DE MOSCA DE FRUTA, BARATA ALEMÃ E MOSCA CASEIRA (TOPO), CANAIS NA 1 DE RATO (MEIO) E CANAIS BSC1/DSC1 DE MOSCA DA FRUTA E BARATA ALEMÃ (INFERIOR). RESÍDUOS DE AMINOÁCIDOS IDÊNTICOS COM AQUELES DE DMNA 1 ESTÃO REPRESENTADOS COM O FUNDO CINZA CLARO. RESÍDUOS DA SEQUÊNCIA ASSINATURA (DEKA EM CANAIS NA ) ESTÃO REPRESENTADOS COM O FUNDO PRETO. RESÍDUOS GLU DO DIII DE CANAIS BSC1/DSC1-TYOE ESTÃO REPRESENTADOS COM O FUNDO CINZA ESCURO. RESÍDUOS IMPORTANTES PARA RESISTÊNCIA A TTX (CYS E SER) ESTÃO EM NEGRITO. FIGURA RETIRADA DE KING E COLABORADORES (2008A).

FIGURA 18 - ISOLAMENTO E PREPARAÇÃO DOS OÓCITOS DE XENOPUS LAEVIS. (A) EXEMPLAR DO XENOPUS LAEVIS. (B) OVARIOTECTOMIA PARCIAL PARA A 
RETIRADA DOS OÓCITOS. (C) SELEÇÃO DOS OÓCITOS. (D) INJEÇÃO DO CRNA DOS CANAIS DE INTERESSE NOS OÓCITOS. FOTOS CEDIDAS POR EVA CUYPERS, DO LABORATÓRIO DE TOXICOLOGIA DA UNIVERSIDADE CATÓLICA DE LEUVEN, BÉLGICA. .54

FIGURA 19 - PROTOCOLO DE PULSOS DE VOLTAGEM UTILIZADO PARA OS REGISTROS DAS CORRENTES DE POTÁSSIO E DE SÓDIO EM OÓCITOS DE X. LAEVIS. (A) PROTOCOLO UTILIZADO PARA ISOFORMAS $K_{V} 1.1-6$. O POTENCIAL DE MEMBRANA DOS OÓCITOS FOI MANTIDO EM -90 MV E RAPIDAMENTE DESPOLARIZADOS PARA $0 \mathrm{MV}$, SEGUIDO DE UMA REPOLARIZAÇÃO PARA -50 MV. O TEMPO TOTAL DO PROTOCOLO FOI DE 1 SEGUNDO. (B) PROTOCOLO UTILIZADO PARA ISOFORMA KV3.1. OÓCITOS FORAM MANTIDOS A UM POTENCIAL DE -90 MV, DESPOLARIZADOS A 30 MV POR 500 MILISSEGUNDOS. (C) PROTOCOLO UTILIZADO PARA ISOFORMA HERG. OS OÓCITOS FORAM MANTIDOS A UM POTENCIAL DE -90 MV, DESPOLARIZADOS A 40 MV POR 2,5 SEGUNDOS, SEGUIDO DE UM POTENCIAL DE -120 MV POR MAIS 2,5 SEGUNDOS. O TEMPO TOTAL DO PROTOCOLO FOI DE 5 SEGUNDOS. (D) PROTOCOLO UTILIZADO PARA ISOFORMAS $N A_{v}$ 1.2-8 E DMNA 1 1. OS OÓCITOS FORAM MANTIDOS A UM POTENCIAL DE -90 MV E DESPOLARIZADOS A 0 MV POR $100 \mathrm{MS}$. 57

FIGURA 20 - REPRESENTAÇÃO DE UMA PARTE DE UMA CADEIA POLIPEPTÍDICA COM OS GRAUS DE TORÇÃO DOS ÂNGULOS DIEDROS $\Psi$ E Ф. FIGURA RETIRADA DE LASKOWSKI ET AL. (1993). 60

FIGURA 21 - DIAGRAMA DE RAMACHANDRAN. A REGIÃO COLORIDA EM VERMELHO REPRESENTA A REGIÃO "PERMITIDA", EM MARROM A REGIÃO "ADICIONALMENTE PERMITIDA" E EM AMARELO A REGIÃO "NÃO PERMITIDA". FIGURA ADAPTADA DE RAMACHANDRAN (1963).

FIGURA 22 - CROMATOGRAMA DA PEÇONHA DA ANÊMONA DO MAR A. CASCAIA OBTIDO ATRAVÉS DE UMA COLUNA EMPACOTADA COM SEPHADEX G-50. A CROMATOGRAFIA FOI MONITORADA À 280 NM. O PERFIL OBTIDO RESULTOU EM 4 FRAÇÕES, SENDO SUAS ATIVIDADES BIOLÓGICAS CONHECIDAS COMO: FOSFOLIPÁSICA (ACAI), HEMOLÍTICA (ACAII), NEUROTÓXICA (ACAIII) E COMPOSTOS DE BAIXA MASSA MOLECULAR (ACAIV).

FIGURA 23 - CROMATOGRAMA REPRESENTATIVO DA ACAIII $(500 \mu \mathrm{G})$. OS NÚMEROS ACIMA DOS PICOS FORAM DADOS CONFORME OS TEMPOS DE ELUIÇÃO. AS ESCALAS DAS ORDENADAS MOSTRAM AS UNIDADES ARBITRÁRIAS DE ABSORBÂNCIA À 214 NM (ESQUERDA) E O PERCENTUAL DE SOLVENTE B $\left(\mathrm{CH}_{3} \mathrm{CN} /\right.$ $0,1 \%$ TFA) EMPREGADO NA PURIFICAÇÃO. A LINHA TRACEJADA MOSTRA A VARIAÇÃO DO GRADIENTE EMPREGADO NA PURIFICAÇÃO. O GRADIENTE FOI DE 10 A 60\% DE TAMPÃO B EM UM FLUXO DE 2,5 ML / MIN POR 40 MINUTOS.

FIGURA 24 - GRÁFICO DE MASSAS MOLECULARES VERSUS \%ACN NECESSÁRIA PARA ELUIÇÃO DOS COMPONENTES DA FRAÇÃO ACAIII 
FIGURA 25 - PERFIL CROMATOGRÁFICO DA FASE REVERSA (RP-HPLC) DA FRAÇÃO ACAIII2970. COLUNA: CAPCELL PAK C-18 (4,6 X 250 MM) EQUILIBRADA COM ELUENTE A (ÁGUA). A ACAIII2970 FOI ELUÍDA NO MODO ISOCRÁTICO DO ELUENTE B (30\% DE ACETONITRILA). AMOSTRA: $200 \mu \mathrm{G}$ DE PROTEÍNAS. FLUXO: 1,0 ML/MIN. A ELUIÇÃO FOI MONITORADA PELA ABSORBÂNCIA A 214 NM. .72

FIGURA 26 - PERFIL CROMATOGRÁFICO DA FASE REVERSA (RP-HPLC) DA FRAÇÃO ACAIII3090. COLUNA: CAPCELL PAK C-18 (4,6 X 250 MM) EQUILIBRADA COM ELUENTE A (ÁGUA). A ACAIII3090 FOI ELUÍDA NO MODO ISOCRÁTICO DO ELUENTE B (30\% DE ACETONITRILA). AMOSTRA: $200 \mu \mathrm{G}$ DE PROTEÍNAS. FLUXO: 1,0 ML/MIN. A ELUIÇÃO FOI MONITORADA PELA ABSORBÂNCIA A 214 NM.

FIGURA 27 - EFEITO DAS TOXINAS ACAIII2970 E ACAIII3090 NOS DIFERENTES SUBTIPOS DE NA . OS PERFIS REPRESENTAM A SITUAÇÃO CONTROLE E QUANDO APLICADOS $5 \mu \mathrm{M}$ DA TOXINA (MARCADO COM *). CADA SUBTIPO FOI TESTADO EM QUADRUPLICATA $(\mathrm{N}=4)$. 75

FIGURA 28 - A: CURVA DOSE-RESPOSTA DA TOXINA ACAIII2970 NOS SUBTIPOS

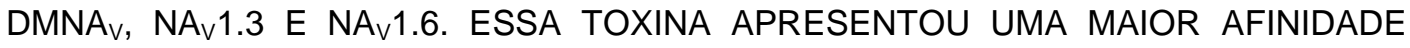
PARA O SUBTIPO DMNA $A_{V}$ DO QUE PARA OS SUBTIPOS NA 1.3 E NA 1.6 . B: CURVA DOSE-RESPOSTA DA TOXINA ACAIII3090 NOS SUBTIPOS DMNA, NA 1.3 E NA 1.6. COMO A ACAIII2970, A ACAIII3090 TAMBÉM APRESENTOU UMA MAIOR AFINIDADE PARA O SUBTIPO DMNA $A_{V}$ DO QUE PARA OS SUBTIPOS NA 1.3 E NA 1.6. 76

FIGURA 29 - ALINHAMENTO DAS TOXINAS ACAIII2970 E ACAIII3090. ESTAS APRESENTARAM HOMOLOGIA COM OUTRAS TOXINAS DE ANÊMONAS DO MAR COMO: NEUROTOXIN-5 (P01529) E NEUROTOXIN-2 (P01528) DE ANEMONIA SULCATA; HK2 (P0C5F4), HK7 (P0C5F5), HK8 (P0C5F6) E HK16 (P0C5F7) DE ANTHOPLEURA SP. (STRAIN 'ZHANJIANG'); APE1-1 (P0C1F0), APE1-2 (P0C1F1), APE2-1 (P0C1F2), APE2-2 (P0C1F3) E ANTHOPLEURIN-C (P01532) DE ANTHOPLEURA ELEGANTÍSSIMA; CGNA (P0C280) DE CONDYLACTIS GIGANTEA; NEUROTOXIN-1 (P10453) E NEUROTOXIN-2 (P10454) DE ANTHOPLEURA FUSCOVIRIDIS; RC-1 (POC5G5) DE HETERACTIS CRISPA; DELTA-AITX-BCG1A (P86459) E DELTA-AITX-BCG1B (P86460) DE BUNODOSOMA CANGICUM; PCR1 (P0C5F8), PCR4 (P0C5G1), PCR5 (P0C5G2), PCR7 (P0C5G4) E ANTHOPLEURIN-A (P01530) DE ANTHOPLEURA XANTHOGRAMMICA. AS LINHAS PONTILHADAS ACIMA DO ALINHAMENTO REPRESENTA O PADRÃO DE PONTES DISSULFETO PARA TOXINAS DE ANÊMONA DO MAR DO TIPO 1 DE CANAL DE SÓDIO. .78 FIGURA 30 - PERFIL CROMATOGRÁFICO DA FASE REVERSA (HPLC) DA FRAÇÃO ACAll1425. COLUNA: CAPCELL PAK C-18 (4,6 X 250 MM) EQUILIBRADA COM ELUENTE A (ÁGUA). A ACAIII1425 FOI ELUÍDA NO MODO ISOCRÁTICO DO ELUENTE B (12\% DE ACETONITRILA). AMOSTRA: $200 \mu \mathrm{G}$ DE PROTEÍNAS. FLUXO: 1,0 ML/MIN. A ELUIÇÃO FOI MONITORADA PELA ABSORBÂNCIA A 214 NM. .80 
FIGURA 31 - SCREENING DA ACAIII1425 EM CANAIS KVS. OS PERFIS REPRESENTAM A SITUAÇÃO CONTROLE E QUANDO APLICADOS $5 \mu \mathrm{M}$ DA TOXINA (MARCADO COM *). CADA SUBTIPO FOI TESTADO EM QUADRUPLICATA $(N=4)$. ESSA TOXINA APRESENTOU SELETIVIDADE PARA OS CANAIS DO SUBTIPO $\mathrm{K}_{v} 1.1 \mathrm{E} \mathrm{K}_{\mathrm{v}} 1.6$. .82

FIGURA 32 - EFEITO DA TOXINA ACAIII1425 NOS DIFERENTES SUBTIPOS DE NAv. OS PERFIS REPRESENTAM A SITUAÇÃO CONTROLE E QUANDO APLICADOS $5 \mu \mathrm{M}$ DA TOXINA (MARCADO COM *). CADA SUBTIPO FOI TESTADO EM QUADRUPLICATA (N $=4)$. ESSA TOXINA NÃO APRESENTOU ATIVIDADE NOS SUBTIPOS DE NAVS TESTADOS. .83

FIGURA 33 - CURVA DOSE-RESPOSTA DA TOXINA ACAIII1425. ESSA TOXINA APRESENTOU UMA MAIOR AFINIDADE PARA O SUBTIPO $\mathrm{K}_{V} 1.6$ DO QUE PARA O SUBTIPO $K_{V} 1.1$ 84

FIGURA 34 - CURVAS DA RELAÇÃO ENTRE CORRENTE E VOLTAGEM (IV). OS CÍRCULOS FECHADOS REPRESENTAM O CONTROLE E OS CÍRCULOS ABERTOS NA PRESENÇA DE 250 NM DE TOXINA ACAIII1425. EM "A", CURVA IV EM SOLUÇÃO ND96. A CURVA IV, NO CONTROLE E NA PRESENÇA DE 250 NM DE TOXINA ACAIII1425, FOI CARACTERIZADA POR UM VALOR DE $V_{1 / 2}$ DE - -13,5 \pm 1,1 MV E -12,8 $\pm 1,1 \mathrm{MV}(\mathrm{N}=5)$, RESPECTIVAMENTE; EM "B", IV EM SOLUÇÃO HK, ONDE OS CÍRCULOS FECHADOS REPRESENTAM O CONTROLE E O OS CÍRCULOS ABERTOS NA PRESENÇA DE 250 NM DE TOXINA ACAIII1425. NÃO FORAM OBSERVADOS DESLOCAMENTOS SIGNIFICATIVOS .86

FIGURA 35 - ALINHAMENTO CONSTRUÍDO UTILIZANDO A FERRAMENTA ALIGN DO UNIPROT E REFINADO MANUALMENTE. TODAS AS TOXINAS UTILIZADAS APRESENTAM O MESMO PADRÃO DE PONTES DISSULFETO. OS RESPECTIVOS CÓDIGOS DE ACESSO DO UNIPROT, O NOME DA TOXINA E A ESPÉCIE DA QUAL FOI EXTRAÍDA A PEÇONHA ENCONTRAM-SE NA TABELA 8. 88

FIGURA 36 - DENDOGRAMA FUNCIONAL CONSTRUÍDO A PARTIR DO ALINHAMENTO DA FIGURA 35. A SETA INDICA A POSIÇÃO DA TOXINA ACAIII1425, EXTRAÍDA DA ANÊMONA DO MAR ANTHOPLEURA CASCAIA. A SETA TRACEJADA INDICA A DIVISÃO EM DOIS RAMOS PRINCIPAIS, UM COMPREENDENDO AS TOXINAS PROVENIENTES DE PEÇONHAS DE ARANHAS E OUTRO REPRESENTADO POR TOXINAS DE MOLUSCO DO GÊNERO CONUS E A ACAIII1425. OS RESPECTIVOS ALVOS DAS TOXINAS ESTÃO ESCRITOS AO LADO DESTAS. QUANDO TOXINAS DE UM MESMO RAMO APRESENTAM O MESMO ALVO, ESTAS FORAM AGRUPADAS EM UMA CAIXA.

FIGURA 37 - DIAGRAMA DE RAMACHANDRAN GERADO PELO PROCHECK PARA O MODELO DA TOXINA ACAIII1425.

FIGURA 38 - REPRESENTAÇÃO DA ESTRUTURA DA TOXINA ACAIII1425. A) ESTRUTURA PRIMÁRIA DA TOXINA ACAIII1425. LINHAS PONTILHADAS REPRESENTAM O POSSÍVEL PADRÃO DE PONTES DISSULFETO. ABAIXO DA ESTRUTURA PRIMÁRIA 
ENCONTRA-SE UMA REPRESENTAÇÃO DA ESTRUTURA SECUNDÁRIA, ONDE AS SETAS REPRESENTAM AS FITAS-B. B) ESQUEMA EM RIBBON DA ESTRUTURA SECUNDÁRIA DA TOXINA ACAIII1425. AS LINHAS EM AMARELO REPRESENTAM AS PONTES DISSULFETO. C) E D) REPRESENTAÇÃO DA SUPERFÍCIE DA TOXINA ACAIII1425 GERADO A PARTIR DO MODELO CONSTRUÍDO. OS RESÍDUOS BÁSICOS FORAM COLORIDOS EM AZUL, OS ÁCIDOS EM VERMELHO, OS APOLARES E HIDROFÓBICOS EM VERDE, OS POLARES SEM CARGA EM CINZA E OS AROMÁTICOS EM LARANJA. A REPRESENTAÇÃO DO LADO DIREITO DA FIGURA (D) É DECORRENTE DE UMA ROTAÇÃO DE $180^{\circ}$ DA REPRESENTAÇÃO DO LADO ESQUERDO (C).

FIGURA 39 - MAPA DO CONTORNO DO POTENCIAL ELETROSTÁTICO PARA O CANAL RKV1.6 E A TOXINA DA ANÊMONA DO MAR ANTHOPLEURA CASCAIA ACAIII1425 EM UMA FORÇA IÔNICA DE 0,15 M. O PONTILHADO VERMELHO REPRESENTA A ENERGIA DE POTENCIAL ELETROSTÁTICO IGUAL A -1 KT; O PONTILHADO AZUL REPRESENTA A ENERGIA DE POTENCIAL ELETROSTÁTICO IGUAL A 1 KT. A SETA EM VERDE INDICA A DIREÇÃO DO DIPOLO. 95

FIGURA 40 - A) REPRESENTAÇÃO DA VISTA LATERAL DA PARTE EXTRACELULAR DO MODELO DO CANAL RK 1.6 ; B) REPRESENTAÇÃO DA SUPERFÍCIE DO CANAL $R_{V} 1.6$ VISTO DE CIMA. A, B, C E D REPRESENTAM UM DOS QUATRO DOMÍNIOS QUE FORMAM O CANAL RKV1.6. ESSES DOMÍNIOS FORAM COLORIDOS CADA UM DE UMA COR, PARA MELHOR VISUALIZAÇÃO. C) FIGURA REPRESENTATIVA DA SUPERFÍCIE DO COMPLEXO TOXINA-CANAL DO MODELO 1 GERADO NO DOCKING. A SUPERFÍCIE DA TOXINA ACAIII1425 ESTÁ REPRESENTADA EM ROSA. D) EM MAIOR TAMANHO ESTÁ REPRESENTADA A FACE DE CONTATO DA TOXINA ACAIII1425 COM A SUPERFÍCIE DO CANAL RKv1.6. A FIGURA MENOR É A FACE OPOSTA, QUE É VISTA DE CIMA QUANDO OBSERVAMOS A FIGURA C). .97

FIGURA 41 - SUPERFÍCIE DA TOXINA ACAIII1425 E DO CANAL RKV1.6 REPRESENTADAS SEGUNDO A ESCALA DE HIDROFOBICIDADE PADRONIZADA POR HESSA E COLABORADORES (2005), ONDE VALORES MAIS NEGATIVOS REFLETEM MAIOR HIDROFOBICIDADE. EM A): SUPERFÍCIE DO COMPLEXO TOXINA-CANAL DO MODELO 1 GERADO NO DOCKING. A TOXINA ACAIII1425 ESTÁ CONTORNADA EM VERDE PARA PODERMOS IDENTIFICÁ-LA; B) CANAL RK 1.6 . OS PONTOS CIRCULADOS E NUMERADOS DE 1 A 5, MARCAM REGIÕES MAIS HIDROFÍLICAS DO CANAL QUE FAZEM CONTATOS COM REGIÕES DA TOXINA ACAIII1425, TAMBÉM HIDROFÍLICAS; C) FACE DE CONTATO DA TOXINA ACAIII1425 COM A SUPERFÍCIE DO CANAL RKV1.6. OS PONTOS QUE FORAM MARCADOS EM "B", TAMBÉM FORAM MARCADOS NA TOXINA. ESSAS REGIÕES TAMBÉM SÃO HIDROFÍLICAS E O CENTRO DA TOXINA É LEVEMENTE HIDROFÓBICO, COMO A REGIÃO DO PORO DO CANAL; D) FACE OPOSTA AO CONTATO DA TOXINA COM O CANAL. .98 
FIGURA 42 - ALINHAMENTO DA SEQUÊNCIA IVS3-S4 DE SUBTIPOS DE NA DE INSETOS E MAMÍFEROS. O ALINHAMENTO DOS AMINOÁCIDOS DOS SEGMENTOS TRANSMEMBRANA S3 E S4 DOS DIV HOMÓLOGOS ESTÃO CONECTADOS PELO LOOP EXTRACELULAR. AS DUAS SEQUÊNCIAS NO TOPO SÃO DE CANAIS DE INSETOS (MDNAV1 E DMNAV1; MD, MOSCA DOMÉSTICA; DM, MOSCA DE FRUTA). AS OUTRAS SEQUÊNCIAS SÃO DE SUBTIPOS DE CANAIS DE MAMÍFEROS (NAV1.1NAV1.9; R, RATO; M, CAMUNDONGO; H, HUMANO). OS SUBTIPOS DE CANAIS NA $V$ AFETADOS PELA ACAIII2970 E ACAIII3090 ESTÃO REPRESENTADOS COM O FUNDO CINZA. OS RESÍDUOS QUE DIFEREM DAS SEQUÊNCIAS DOS NAv1.1-3 ESTÃO COLORIDOS EM VERMELHO. OS CÓDIGOS DE ACESSO DOS RESÍDUOS DOS SUBTIPOS SÃO: MDNAV1, 1668 (UNIPROT: Q94615); DMNAV1, 1680 (P35500); RNAV1.1, 1602 (P04774); RNAV1.2, 1592 (P04775); RNAV1.3, 1538 (P08104); RNAV1.4, 1407 (P15390); HNAV1.5, 1589 (Q14524); MNAV1.6, 1581 (Q9WTU3); RNAV1.7, 1574 (O08562); RNAV1.8, 1538 (Q62968); RNAV1.9, 1407 (O88457). 108

FIGURA 43 - ESQUEMA REPRESENTATIVO DO MOTIVO ESTRUTURAL ICK. OS PONTOS LIGADOS REPRESENTAM AS CISTEÍNAS E SEU RESPECTIVO PADRÃO DE PONTES DISSULFETO. FIGURA MODIFICA DE PALLAGHY E COLABORADORES (1994). ..... 109

FIGURA 44 - ALINHAMENTO DA REGIÃO DO PORO DAS ISOFORMAS DE KV1. POSIÇÃO E A SEQUÊNCIA DOS AMINOÁCIDOS DOS CANAIS KV1.1-6 (H: HUMANO E R: RATO) NOS SEGMENTOS 5 E 6. OS AMINOÁCIDOS EM VERMELHO NO RKv1.6 ESTÃO ENVOLVIDOS NA INTERAÇÃO DA TOXINA ACAIII1425. AMINOÁCIDOS IDÊNTICOS ESTÃO COM O FUNDO COLORIDO DE PRETO E AMINOÁCIDOS SIMILARES EM CINZA. 116

FIGURA 45 - FIGURA REPRESENTATIVA DO COMPLEXO TOXINA-CANAL. A TOXINA ACAIII1425 E O CANAL RKV1.6 ESTÃO REPRESENTADOS COMO RIBBON. OS RESÍDUOS DE AMINOÁCIDOS TIDOS COMO IMPORTANTES PARA A FORMAÇÃO DESSE COMPLEXO FORAM DESTACADOS ATRAVÉS DA REPRESENTAÇÃO DE SUA CADEIA LATERAL E SUPERFÍCIE. EM VERMELHO, OS RESÍDUOS ÁCIDOS DO CANAL; EM AMARELO, OS RESÍDUOS AROMÁTICOS DO CANAL; EM AZUL, OS RESÍDUOS POSITIVOS DA TOXINA; E EM LARANJA, OS RESÍDUOS AROMÁTICOS DA TOXINA. OS RESÍDUOS CANDIDATOS À DÍADE FUNCIONAL SÃO A H25, QUE SE LIGA AO Y426 (A, B E D), E A Y27, QUE SE LIGA AO D428 (D). A K7, QUE SE LIGA AO D428 (C) E Y430 (C), E R29, QUE SE LIGA AO E399 (A) E D402 (A), POSSIVELMENTE SÃO IMPORTANTES PARA O ANCORAMENTO E SELETIVIDADE DA TOXINA......... 120 


\section{Lista de Tabelas}

TABELA 1 - OS NOMES DOS GENES DAS FAMÍLIAS DE CANAIS $K_{v}$ MOSTRADOS SÃO AQUELES ATRIBUÍDOS PELA IUPHAR E HGNC ALÉM DE ALGUNS OUTROS NOMES COMUMENTE USADOS. TABELA RETIRADA DE GUTMAN E COLABORADORES (2003).

TABELA 2 - SUBTIPOS DE CANAIS NA 1 DE MAMÍFERO. S, SENSÍVEL EM CONCENTRAÇÃO NA FAIXA DE NANOMOLAR DE TETRODOTOXINA (TTX); R, RESISTENTE ACIMA DE CONCENTRAÇÕES NA FAIXA DE MICROMOLAR DE TTX; CNS, SISTEMA NERVOSO CENTRAL; PNS, SISTEMA NERVOSO PERIFÉRICO. FIGURA MODIFICADA DE GOLDIN, 2001.

TABELA 3 - LISTA DE MASSAS MOLECULARES DAS SUBFRAÇÕES ELUÍDAS DA CROMATOGRAFIA DE FASE REVERSA DA FRAÇÃO ACAIII. ...................................69

TABELA 4 - SEQUÊNCIAS N-TERMINAIS OBTIDAS........................................................ 71

TABELA 5 - SUMÁRIO DOS VALORES DE IC ${ }_{50}$ OBTIDOS DA ACAIII2970 E ACAIII3090 EM CANAIS VOLTAGEM DEPENDENTES DE SÓDIO..................................................... 76

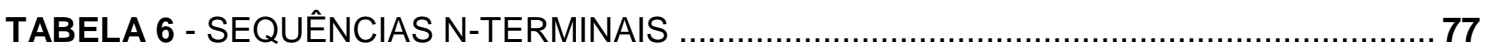

TABELA 7 - SEQUÊNCIA DE AMINOÁCIDOS DA TOXINA ACAIII1425 ..................................87

TABELA 8 - CÓDIGO DE ACESSO, NOME DAS TOXINAS E ESPÉCIE DA QUAL FORAM EXTRAÍDAS, REFERENTE ÀS TOXINAS UTILIZADAS NO ALINHAMENTO E NO DENDOGRAMA FUNCIONAL.

TABELA 9 - ANÁLISE DA QUALIDADE ESTEREOQUÍMICA PARA O MODELO DA TOXINA ACAIII1425.

TABELA 10 - AFINIDADE E DISTÂNCIA DO RMSD L.B. E U.B. DOS 20 MELHORES MODELOS DA INTERAÇÃO ENTRE A TOXINA DA ANÊMONA DO MAR ANTHOPLEURA CASCAIA E O CANAL RK 1.6 . DESSES 20 MODELOS FOI ESCOLHIDO O NÚMERO 1 PARA REPRESENTAR O COMPLEXO TOXINA-CANAL. .. 96

TABELA 11 - POSSÍVEIS LIGAÇÕES DE HIDROGÊNIO FORMADAS ENTRE A TOXINA ACAIII1425 DA ANÊMONA DO MAR ANTHOPLEURA CASCAIA E O CANAL RK 1.6 NO COMPLEXO TOXINA-CANAL. OS PARES DE INTERAÇÕES FORAM ORGANIZADOS DE ACORDO COM A LOCALIZAÇÃO NO CANAL RK $K_{v} 1.6$. .99 


\section{Lista de Símbolos e Abreviaturas}


Lista de abreviaturas

ASIC

canal sensível a acidez ("acid-sensing ion channel")

$\mathrm{BCA}$

4,4'-dicarboxi-2,2'-biquinolina ácido bicinconínico

BDS Blood Depressing Substances

BPTI inibidores da tripsina pancreática bovina

$\mathrm{Ca}^{2+}$ ion cálcio

Cav canal voltagem-dependente de cálcio

$\mathrm{CH}_{3} \mathrm{CN}$ acetonitrila

$\mathrm{Cl}^{2-} \quad$ íon cloro

DDT dichlorodiphenyltrichloroethano

EGFs fatores de crescimento de epiderme de mamíferos

$\mathrm{E}_{\mathrm{K}} \quad$ Potencial reverso para íons potássio

HPLC High Performance liquid Chromatography

I Corrente

$1^{125} \quad$ iodo 125

$I_{50} \quad$ Concentração inibitória para produzir $50 \%$ do efeito máximo

ICK Inhibitory Cystine Knot

$\mathrm{K}^{+} \quad$ íon potássio

$\mathrm{K}_{\mathrm{Ca}}$ 3.1 canal de potássio dependente de cálcio

$\mathrm{K}_{\mathrm{V}} \quad$ canal voltagem-dependente de potássio

mRNA ácido ribonucleico mensageiro

$\mathrm{Na}^{+} \quad$ íon sódio

$\mathrm{Na}$ canal voltagem-dependente de sódio

PDB Protein Data Bank

$r \quad$ Rattus norvegicus (rat)

RP-HPLC cromatografia de fase reversa

S1 a S6 segmentos transmembrana 1 a 6

RMN Ressonância Magnética Nuclear

TEA tetraetilamônio

TFA ácido trifluoroacético

tipE temperature-induced paralytic $E$ 
Lista de símbolos

$\begin{array}{ll}\text { A } & \text { Angstrom } \\ { }^{\circ} \mathrm{C} & \text { Grau (s) Celsius } \\ \mathrm{cm} & \text { Centímetro(s) } \\ \mathrm{g} & \text { Gramas/Gravidade } \\ \mathrm{G} \Omega & \text { Gigaohms } \\ \mathrm{h} & \text { Horas } \\ \mathrm{kDa} & \text { QuiloDalton(s) } \\ \mathrm{kHz} & \text { Quilohertz } \\ \mathrm{kvolts} & \text { Quilovolt(s) } \\ \mathrm{L} & \text { Litro(s) } \\ \mu \mathrm{L} & \text { Microlitro(s) } \\ \mu \mathrm{g} & \text { Micrograma(s) } \\ \mu \mathrm{M} & \text { Micromolar } \\ \mathrm{M} & \text { Molar } \\ \mathrm{mA} & \text { Miliamperer(s) } \\ \mathrm{M} \Omega & \text { Megaohm(s) } \\ \mathrm{mg} & \text { Miligrama(s) } \\ \mathrm{mL} & \text { Mililitro(s) } \\ \mathrm{min} & \text { Minuto(s) } \\ \mathrm{ms} & \text { Milisegundo(s) } \\ \mathrm{mM} & \text { Milimolar } \\ \mathrm{mV} & \text { Milivolt(s) } \\ \mathrm{nM} & \text { Nanomolar } \\ \mathrm{nm} & \text { Nanômetro(s) } \\ \mathrm{pA} & \text { Picoampere(s) } \\ \mathrm{pH} & \text { Potencial hidrogeniônico } \\ \mathrm{pl} & \text { Ponto isolétrico } \\ \mathrm{pmol} & \text { Picomol } \\ \mathrm{rpm} & \text { Rotações por minuto } \\ \mathrm{seg} & \text { Segundo(s) } \\ \mathrm{V} & \text { Volt(s) } \\ \mathrm{UV} & \text { Ultravioleta } \\ \mathrm{W} & \text { Watt(s) } \\ & \end{array}$


Lista de abreviatura dos aminoácidos

$\begin{array}{lll}\text { A } & \text { Ala } & \text { Alanina } \\ \text { C } & \text { Cys } & \text { Cisteína } \\ \text { D } & \text { Asp } & \text { Ácido Aspártico } \\ \text { E } & \text { Glu } & \text { Ácido Glutâmico } \\ \text { F } & \text { Phe } & \text { Fenilalanina } \\ \text { G } & \text { Gly } & \text { Glicina } \\ \text { H } & \text { His } & \text { Histidina } \\ \text { I } & \text { Ile } & \text { Isoleucina } \\ \text { K } & \text { Lys } & \text { Lisina } \\ \text { L } & \text { Leu } & \text { Leucina } \\ \text { M } & \text { Met } & \text { Metionina } \\ \text { N } & \text { Asn } & \text { Asparagina } \\ \text { P } & \text { Pro } & \text { Prolina } \\ \text { Q } & \text { Gln } & \text { Glutamina } \\ \text { R } & \text { Arg } & \text { Arginina } \\ \text { S } & \text { Ser } & \text { Serina } \\ \text { T } & \text { Thr } & \text { Treonina } \\ \text { V } & \text { Val } & \text { Valina } \\ \text { W } & \text { Trp } & \text { Triptofano } \\ \text { Y } & \text { Tyr } & \text { Tirosina }\end{array}$


Introdução 1

\section{Introdução}




\subsection{Anêmonas do mar - aspectos zoológicos}

O filo Cnidaria (Figura 1) é constituído por animais aquáticos bentônicos e pelágicos, divididos nas classes Anthozoa, Hydrozoa, Scyphozoa e Cubozoa. Apesar dos diferentes formatos e habitats, o corpo de todos os cnidários possuem simetria radial e são diploblásticos, ou seja, a ectoderme recobre a parte externa do corpo e a endoderme envolve a cavidade interior do corpo. Entre estas duas camadas celulares encontra-se a mesogléia. Os cnidários não possuem uma especialização celular em diferentes órgãos e o sistema nervoso é difundido ao longo do corpo. Atualmente existem cerca de 13000 espécies conhecidas (Turk \& Kem, 2009) que pertencem a este filo. Grande parte da diversidade exibida pelo grupo resulta de dois aspectos fundamentais do seu estilo de vida. O primeiro é a tendência de formar colônias por reprodução assexuada, podendo assim atingir formas e proporções impossíveis para indivíduos solitários. O segundo é a presença de um ciclo de vida dimórfico em muitas espécies, que inclui duas morfologias adultas completamente diferentes, pólipo e medusa.

As anêmonas do mar são pólipos sésseis, exclusivamente marinhos, que pertencem à classe Anthozoa e são agrupadas dentro da ordem Actiniaria, distribuídas em quatro subordens (Endocoelantheae, Nyantheae, Protantheae e Ptychodacteae), as quais englobam, pelo menos, 45 famílias, 512 gêneros e aproximadamente 1400 espécies. Os Anthozoários divergiram da linhagem dos animais com simetria bilateral (grupo Bilateria) logo no início do estágio evolutivo, há cerca de 600 milhões de anos (Ball et al., 2004). Esses são predadores que vivem no ambiente marinho, desde o costão rochoso até regiões oceânicas profundas. São animais solitários, podendo estar em simbiose com peixes, crustáceos, zooxantelas e dinoflagelados e estão amplamente distribuídos pelo mundo, podendo ser encontrados dos polos até a região do equador. 


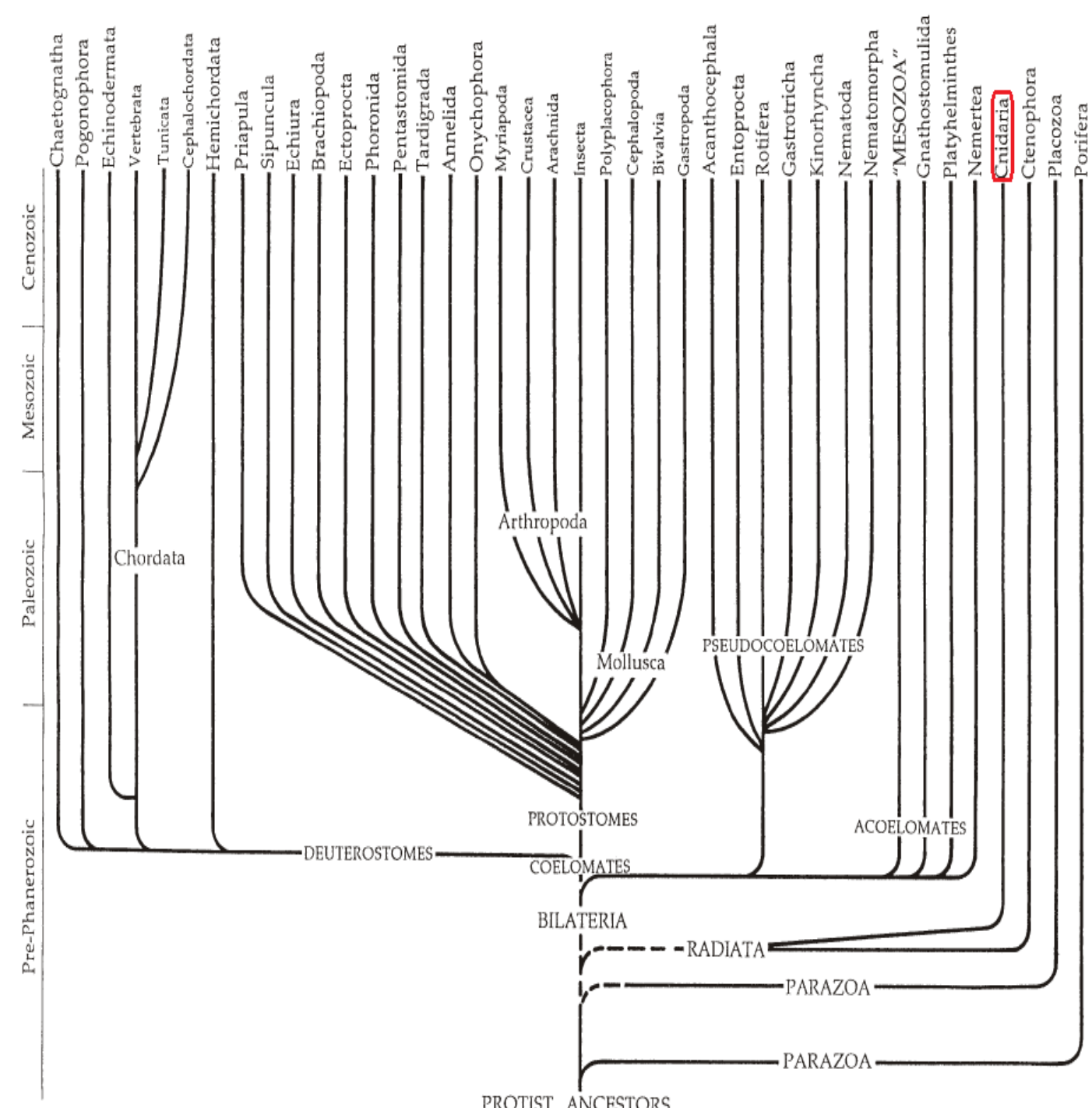

Figura 1 - Cladograma hipotético dos organismos com simetria bilateral. As eras geológicas estão indicadas na lateral esquerda do cladograma. O filo dos cnidários encontra-se circulado em vermelho. Figura adaptada de Brusca \& Brusca (2003).

O corpo das anêmonas do mar é formado por um pé adesivo, com uma coluna levando a um disco oral com tentáculos que circundam a abertura central da boca, sendo utilizados para capturar alimento e transportá-lo até a boca (a anatomia desses animais está mostrada na Figura 2). Nos tentáculos e em outras partes do corpo são encontradas cápsulas com "ferrão", denominadas de nematocistos, derivadas das organelas subcelulares conhecidas como cnidocistos (cnidae). 


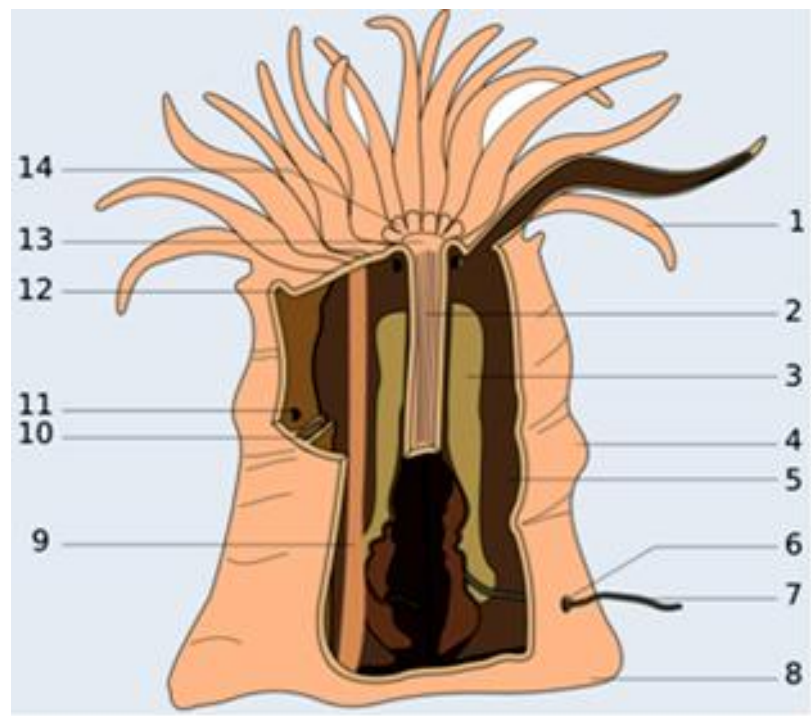

Anatomia de anêmonas do mar:

1. Tentáculo;

2. Faringe;

3. Tecido gametogênico (gônadas);

4. Parede externa da coluna;

5. Mesentério completo (septo);

6. Cinclide;

7. Acontium;

8. Disco pedal;

9. Músculo retrator,

10. Mesentério incompleto (septo):

11. Perfuração mesenterial (estômatos);

12. Colar (parapeito);

13. Boca;

14. Disco oral.

Figura 2 - Anatomia de anêmonas do mar. Figura adaptada de Brusca \& Brusca (2003).

\subsubsection{Cnidocitos}

Os cnidocistos ou nematocitos, exclusivos do filo Cnidaria, são uma das mais complexas células eucarióticas. Eles são originados de células embrionárias multipotentes localizadas no interstício e seu desenvolvimento é caracterizado pela montagem intracitoplasmática de uma membrana extensa e única e um túbulo (cnidocisto ou nematocisto), com subsequente inversão e enrolamento do mesmo junto com a peçonha e outras moléculas intracapsulares dentro do lúmen dessa célula. Do ponto de vista morfológico existem cerca de 30 tipos de nematocisto (Fautin, 2009), os quais podem ser agrupados em três tipos básicos. O primeiro é formado pelos "verdadeiros" nematocistos, cuja estrutura é composta por uma cápsula com paredes duplas contendo uma mistura tóxica e um túbulo reversível. Geralmente, esse túbulo é acompanhado por espinhos ou estiletes para facilitar a penetração e a fixação nos tecidos da vítima e é capaz de levar as toxinas até a mesma através do poro terminal existente no túbulo ou através da sua superfície (Brusca \& Brusca, 2003). O segundo tipo, o espirocisto, contém mucoproteínas ou glicoproteínas que aderem no corpo da vítima. Já o terceiro tipo, o pticocisto, é utilizado na fixação do próprio animal.

A complexidade estrutural do cnidocisto é refletida na sua complexidade funcional. O disparo de um cnidócito é, essencialmente, um evento explosivo que resulta na eversão do túbulo sendo expelido através do opérculo na região apical celular com, no caso de cnidocistos penetrantes, força suficiente para 
penetrar na cutícula ou pele de sua presa em menos de $3 \mathrm{~ms}$ (Anderson \& Bouchard, 2009).

Os mecanismos que tangem a geração de força necessária para o disparo do cnidócito ainda não são totalmente entendidos, mas cogita-se que existam fenômenos que podem ocorrer isolados ou em conjunto, como aumento da pressão hidrostática criada por um gradiente de pressão osmótica e energia mecânica armazenada no túbulo invertido; e, mais recentemente, sugere-se o aumento da pressão osmótica por um gradiente de prótons que atravessa a membrana que envolve o nematocisto (Anderson \& Bouchard, 2009). Estudos demonstram que esses fenômenos desencadeiam mudanças no potencial de membrana do cnidócito através da mudança de amplitude das correntes de $\mathrm{Na}^{+}$e K${ }^{+}$.

Segundo dados de Holstein \& Tardent, (1984) e Nüchter e colaboradores (2006), o processo de disparo dos cnidócitos pode ser dividido em 4 fases. A fase A é a fase inicial que compreende o intervalo entre a despolarização da membrana e a abertura do opérculo. $\mathrm{Na}$ fase $\mathrm{B}$, a cobertura da cápsula é aberta e a porção do estilete do túbulo é ejetada. Já a fase $C$ é uma fase intermediária e estacionária do processo de descarga. Na fase $D$ ocorre a evaginação da parte terminal do túbulo.

A demanda energética na criação de uma célula com tal complexidade se torna ainda mais marcante pelo fato de que os cnidocistos só podem ser usados uma única vez. Dessa maneira, essas células são altamente reguladas por uma variedade de quimiossensores, mecanossensores e vias endógenas para garantir que $O$ uso do cnidocisto seja feito apenas em condições adequadas (Anderson \& Bouchard, 2009). A integração desses vários fatores culmina na exocitose e disparo do cnidocisto. A Figura 3 mostra a organização intracelular de um cnidócito carregado e descarregado. 
(A)

Cnidócito carregado

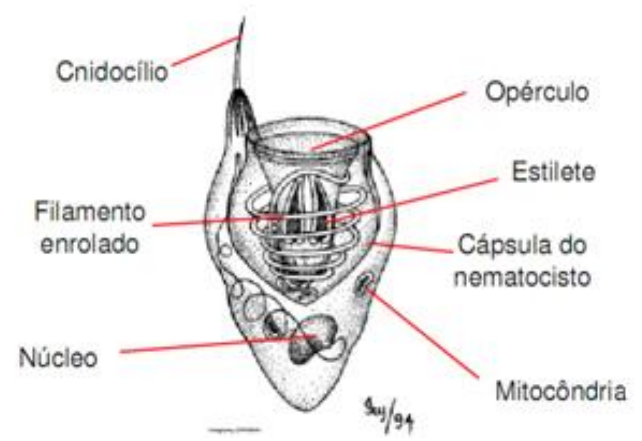

(B)

Cnidócito descarregado

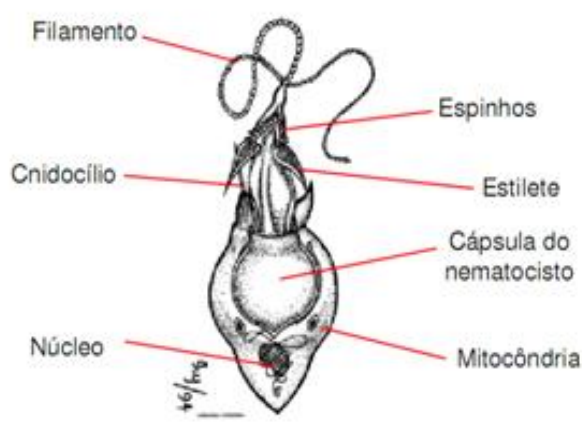

Figura 3 - Organização intracelular de um cnidócito carregado (A) e descarregado (B). Figura adaptada de Anderson \& Bouchard (2009).

\subsection{Peçonha de anêmonas do mar}

Desde a década de 70 as anêmonas do mar são investigadas no sentido de se entender qual o mecanismo de ação de suas toxinas. Trabalhos clássicos de vários autores (Barhanin et al., 1981; Beress \& Beress, 1975; Cariello et al., 1989) elucidaram os mecanismos de ação das toxinas ATX-I, II e III da anêmona do mar Anemonia sulcata, habitante do mar Mediterrâneo. No entanto, as anêmonas do mar brasileiras começaram a serem estudadas sob o aspecto fisiológico na década de 80 (Mendes, 1984), quando foram demonstradas inequívocas respostas da musculatura da coluna desses animais aos conhecidos neurotransmissores, acetilcolina, adrenalina e seus derivados.

Em geral, as peçonhas das anêmonas do mar são misturas complexas contendo proteínas e peptídeos com diferentes propriedades, além de componentes não proteicos, derivados do metabolismo secundário. Estes compostos divergem de uma espécie para outra, quanto a sua estrutura e seu potencial alvo de ação. Alguns são encontrados em várias peçonhas, enquanto que outros são espécie-específicos. A proporção com que estes compostos são encontrados nas diferentes espécies também pode variar de acordo com o estado alimentar e do estágio de desenvolvimento dos indivíduos (Rees, 1993).

Contudo, os componentes mais comuns e potentes presentes nas peçonhas de anêmonas do mar são: Fosfolipases A2, capazes de clivar fosfolipídios de membranas de células nervosas e musculares, produzindo 
ácido aracdônico e promovendo a inflamação (Nevalainen et al., 2004); Citolisinas (toxinas formadoras de poros) que atuam em membranas celulares e causam alterações na osmorregulação e consequentemente lise celular (Anderluh et al., 2003); Neurotoxinas que interferem na transmissão nervosa, afetando canais voltagem dependentes de $\mathrm{Na}^{+}$(Rogers et al.., 1996) e $\mathrm{K}^{+}$ (incluindo os canais das famílias hERG) e canais sensíveis a acidez ("acidsensing ion channels" - ASIC's) (Honma \& Shiomi, 2006; Norton, 1991); Compostos não protéicos (purinas, aminas terciárias, compostos de amônio quaternário e aminas biogênicas), os quais, acredita-se que estejam envolvidos na dor durante o envenenamento, servindo como proteção contra predadores e facilitando a absorção e distribuição dos componentes tóxicos da peçonha na presa (Welsh, 1964; Zaharenko et al., 2011). A seguir, descreveremos alguns tipos de neurotoxinas encontradas em anêmonas do mar, principal foco da investigação realizada.

\subsection{Neurotoxinas de anêmonas do mar}

Neurotoxinas são toxinas que interferem com a transmissão do impulso nervoso, modificando a função de algum tipo particular de canal na membrana do nervo ou músculo. As neurotoxinas constituem ferramentas importantes para o estudo dos diferentes tipos de canais presentes em membranas excitáveis e, por conseguinte, para investigar os mecanismos envolvidos durante a transmissão de impulsos nervosos. Algumas delas são muito seletivas e por isso têm permitido progressos rápidos na identificação e caracterização de novos receptores de membrana (Rees, 1993).

Os peptídeos neurotóxicos de anêmonas do mar possuem massas moleculares que variam entre 3 e $5 \mathrm{kDa}$ e têm como principal alvo os canais iônicos. Até o momento, o que mais se tem descrito na literatura são neurotoxinas que atuam sobre canais voltagem-dependentes de sódio $(\mathrm{Nav})$, potássio $\left(K_{\mathrm{V}}\right)$ e pouco sobre canais iônicos sensíveis à acidez (ASIC's). Até o momento, não existe descrita nenhuma toxina que interaja com canais de cloreto $\left(\mathrm{Cl}^{-}\right)$e de $\mathrm{Ca}^{2+}$ (Cav) dependentes de voltagem. 


\subsection{Toxinas de anêmonas do mar e canais para potássio sensíveis à voltagem}

Toxinas que interagem com os canais para potássio $\mathrm{K}_{\mathrm{V}}$, em geral, são peptídeos compactos, contendo em torno de 38 resíduos de aminoácidos estabilizados por 3 a 4 pontes dissulfeto. Esses peptídeos adotam usualmente um domínio estrutural conservado, conhecido como "motivo $\alpha \beta$ ". Trata-se de um motivo composto por uma $\alpha$-hélice ligada a uma fita $\beta$-antiparalela por meio de duas ou mais pontes dissulfeto (Bontems et al., 1991).

Toxinas que interagem com canais para potássio exercem sua ação de duas formas gerais: ligando-se à porção extracelular do poro condutor, ocluindo assim a passagem dos íons, ou pela modulação da parte sensível à voltagem (Garcia et al., 1991).

O segundo maior grupo de neurotoxinas de anêmonas do mar são as que atuam bloqueando os canais $\mathrm{K}_{\mathrm{v}}$. Atualmente são conhecidos pelo menos 13 diferentes peptídeos, sendo 11 purificados de seis espécies da família Actiniidae e os outros dois pertencem à família Stichodactylidae. Estas toxinas são classificadas de acordo com a similaridade da estrutura primária em quatro diferentes grupos (Honma \& Shiomi, 2006).

\subsubsection{Toxinas de canal de potássio do tipo 1.}

Esse grupo é composto por seis peptídeos que possuem entre 35 e 43 resíduos de aminoácidos. Representam este grupo: AETX-K, HmK, ShK, AeK, AsKs e BgK das anêmonas do mar Anemonia erythraea, Heteractis magnifica, Stichodactyla helianthus, Actinia equina, Anemonia sulcata e Bunodosoma granulifera, respectivamente. A toxina Shk atua em canais do tipo $\mathrm{K}_{\mathrm{v}} 1.1 \mathrm{a}$ $\mathrm{K}_{\mathrm{v}} 1.7$ e também liga-se em canais $\mathrm{K}_{\mathrm{Ca}} 3.1$ (canal de potássio dependente de cálcio) e $\mathrm{K}_{\mathrm{v}} 3$.2. Bgk se liga em $\mathrm{K}_{\mathrm{v}} 1.1$ a $\mathrm{K}_{\mathrm{v}} 1.6$ e também em $\mathrm{K}_{\mathrm{Ca}} 3$.1. As toxinas $\mathrm{HmK}$, AeK e AsKs se ligam á família dos canais $K_{v} 1$, porém os subtipos ainda não foram determinados.

\subsubsection{Toxinas de canal se potássio do tipo 2 .}

Os peptídeos geralmente conhecidos como Kalicludinas ou AsKCs (AsKC1, AsKC2 e AsKC3) da anêmona do mar A. sulcata representam este 
segundo grupo. Possuem 58 ou 59 aminoácidos, cuja ação biológica ocorre em canais da família $\mathrm{K}_{\mathrm{V}} 1$ com uma potência muito menor, se comparados aos peptídeos do grupo 1 (Schweitz et al., 1995). AsKCs também atuam como inibidores de protease, sendo que sua estrutura primária apresenta homologia com inibidores da tripsina pancreática bovina (BPTI). Entretanto, comparandose os resíduos lisina, alanina e isoleucina nas posições (K15, A16 e I19) da BPTI, que são importantes na ligação com a tripsina, as AsKCs apresentam uma substituição I19P, causando significativa perda em sua atividade inibitória.

\subsubsection{Toxinas de canal se potássio do tipo 3.}

Inicialmente, foram isoladas as toxinas BDS-I e BDS-II ("Blood Depressing Substances") da anêmona do mar A. sulcata, APETx1 da Anthopleura elegantissima e Am-II da Antheopsis maculata, compondo as toxinas do tipo 3, que possuem entre 42 e 46 aminoácidos. BDS-I e BDS-II atuam bloqueando especificamente canais do subtipo $\mathrm{K}_{\mathrm{v}} 3.4$. Recentemente, demonstrou-se que elas têm um fraco efeito sobre canais de sódio sensíveis a Tetrodotoxina, em neuroblastoma (Honma \& Shiomi, 2006).

APETx1 é seletivo para canais do tipo ERG1, pertencente à superfamília dos canais "ether-a-go-go" (EAG), a qual é subdividida em três subfamílias: EAG, ELK (EAG-like) e ERG, respectivamente, representadas pelas famílias dos canais $\mathrm{K}_{v} 10, \mathrm{~K}_{\mathrm{v}} 12$ e $\mathrm{K}_{\mathrm{v}} 11$ (Wanke \& Restano-Cassulini, 2007). Do ponto de vista biológico, APETx1 atua, aparentemente, na ativação e, possivelmente, na inativação dos canais $K_{v} 11$, sugerindo que este peptídeo se comporta como um modulador desses canais (Wanke \& Restano-Cassulini, 2007).

Segundo Honma e colaboradores (2005a), pressupõe-se que Am-II atue nos mesmos canais das toxinas BDS-I, BDS-II e APETx1, devido à identidade com estas toxinas (39\% com BDS-I e II e 37\% com APETx 1 ). Também apresenta $28 \%$ de identidade com APETx2 que atua bloqueando canais sensíveis à acidez (ASIC) (Diochot et al., 2004).

\subsubsection{Toxinas de canal de potássio do tipo 4 .}

As toxinas que representam este último tipo de toxinas de anêmonas do mar, que atuam em $K_{V}$, são formadas pelas toxinas SHTX-I e II (compostas por 28 aminoácidos) da anêmona do mar Stichodactyla haddoni. Ensaios de 
inibição competitiva indireta da ligação da $\alpha$-dendrotoxina marcada com $1^{125}$ (iodo), em membranas de sinaptossomas de rato, demonstraram que as toxinas SHTX-I e II ligam-se em canais voltagem-dependentes de $\mathrm{K}^{+}$e sugerem um possível bloqueio da corrente. Este tipo de toxina possui duas pontes dissulfeto que formam um pareamento do tipo C1-C3 e C2-C4 e têm massa molecular em torno de 2,7 kDa (Honma et al., 2008).

\subsection{Canais para potássio dependentes de voltagem}

Os canais voltagem-dependentes de $\mathrm{K}^{+}\left(\mathrm{K}_{\mathrm{V}}\right)$ são os protótipos de canais voltagem-dependentes. Um típico canal $\mathrm{K}_{\mathrm{V}}$ é um conjunto de quatro domínios transmembranais, idênticas ou similares, que circundam um poro central. Cada domínio possui seis segmentos transmembrana (S1-S6), com o N- e C-terminal voltados para o meio intracelular da membrana (Figura 4). A região mais estreita do poro, o filtro seletivo, é formada por um loop entre S5 e S6; o sensor de voltagem inclui o $\$ 4$, região com múltiplas cargas positivas.

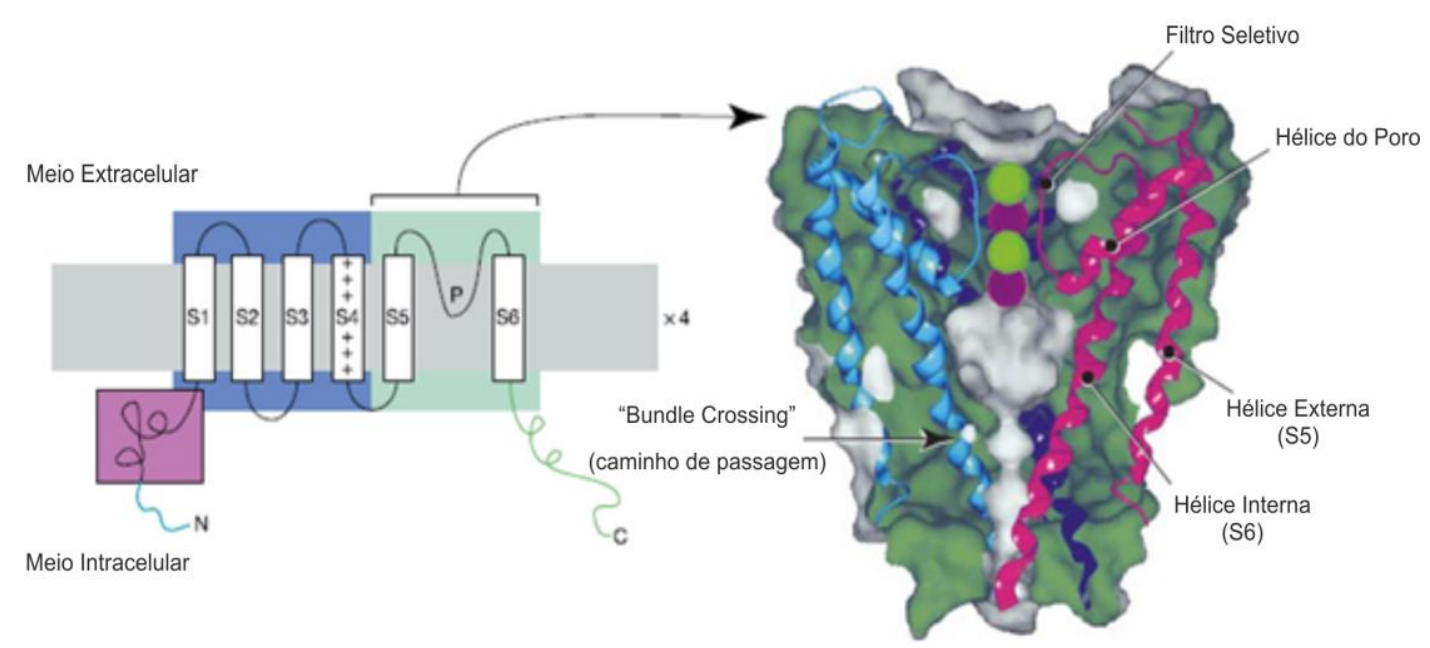

Figura 4 - No lado esquerdo temos um esquema de uma subunidade $\alpha$ do canal para potássio. Os 6 segmentos transmembrana de uma única subunidade do canal encontram-se em evidência. Existem apenas duas hélices transmembrana: a hélice externa é homóloga ao S5 e a hélice interna ao S6. Na figura do lado direito temos: o interior da proteína está em verde escuro, com as estruturas secundárias representadas por fitas, para as três das quatro subunidades, e a superfície da proteína exposta à água encontra-se colorida em cinza. $O$ filtro seletivo é visto no topo, com o "loop" do filtro seletivo apoiado pelas hélices do poro. As quatro esferas marcam os quatro sítios de ligação para íons $\mathrm{K}^{+}$; esses são comumente ocupados por íons alternativos ao $\mathrm{K}^{+}$e moléculas de água (Morais-Cabral et al, 2001). As quatro hélices internas cruzam-se para afunilar o canal em sua porção inferior (o "caminho de passagem"). Entre o filtro seletivo e o caminho de passagem encontra-se uma cavidade com água. Figura modificada de Yellen (2002).

Uma subunidade padrão de um canal $K_{V}$ contém seis regiões transmembrana (S1-S6), com o carboxi e amino terminal no meio intracelular 
da membrana (uma arquitetura tetramérica 6TM), um poro formado por S5-PS6 e um sensor de voltagem compreendendo S1-S4.

$\mathrm{O}$ centro da subfamília $\mathrm{K}_{\mathrm{v}} 1 . \mathrm{x}-\mathrm{K}_{\mathrm{v}} 4 . x$ (Figura 5 ) tem no seu $\mathrm{N}$-terminal um "domínio tetramerizado" (T1, em roxo) (Gulbis et al., 2000; Kreusch et al., 1998) que determina a especificidade do conjunto de subunidades (Shen \& Pfaffinger, 1995) e, também serve como uma plataforma para a montagem das subunidades $\beta$ e para outras interações proteína-proteína. Essas interações provavelmente modulam a atividade do canal e também podem proporcionar um caminho ao canal para sinalizar diretamente processos ao meio intracelular (Holmes et al., 1996). A extremidade $\mathrm{N}$-terminal pode prover a auto-inibição Ball-and-chain para a inativação do canal (será melhor detalhada ao longo do texto). O C-terminal (Figura 4, no lado esquerdo em verde) não possui um domínio estrutural evidente nessa subfamília, embora normalmente haja um motivo de ligação PDZ (Doyle et al., 1996) que determina a localização física do canal e da sua associação em grandes complexos de sinalização.

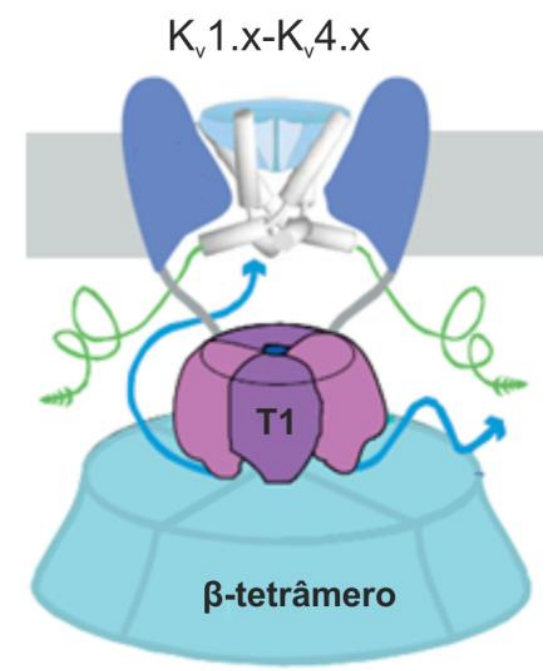

Figura 5 - $O$ centro da subfamília $\mathrm{K}_{\mathrm{v}} 1 . x-\mathrm{K}_{\mathrm{v}} 4 . x$ tem no seu $\mathrm{N}$-terminal um "domínio tetramerizado" (T1, roxo) que determina a especificidade do conjunto de subunidades e também serve como uma plataforma para a montagem das subunidades $\beta$ (em azul claro) e para outras interações proteínaproteína. Figura modificada de Yellen (2002).

Muitos outros canais tetraméricos 6TM possuem um domínio estrutural diferente, caracterizado pela ausência de um domínio T1 e a presença de um domínio sensor no C-terminal (Figura 6). Esses incluem os canais dependentes de voltagem KCNQ e eag/erg, bem como os canais coordenadamente dependentes de voltagem e ligantes (canais $\mathrm{BKCa}^{2+}$-ativados $\mathrm{e}$ 
hiperpolarização HCN, e canais nucleotídeos dependentes), e canais exclusivamente dependentes de ligantes intracelulares (canais CNG e canais SK). Em alguns casos o domínio sensor do C-terminal adota uma organização simétrica em tetrâmero, enquanto que em outros casos, eles podem funcionar como dímero de dímeros (Schumacher et al., 2001). Alguns membros da família possuem no $\mathrm{N}$-terminal uma região transmembrana adicional (S0) (Wallner et al., 1996) ou um domínio sensor a mais (Morais Cabral et al., 1998). Sabe-se que as subunidades que podem se associar com essa família (minK, $\mathrm{MiRP}, \mathrm{BKb})$ são transmembrana; elas aparentam estar inicialmente associadas com a região do poro (Knaus et al., 1994; Tapper \& George, 2001) e podem deslocar o sensor de voltagem ou interagir diretamente com ele.

CNG, $\mathrm{K}_{\mathrm{Ca}}, \mathrm{HCN}$, eag/erg, BK, SK

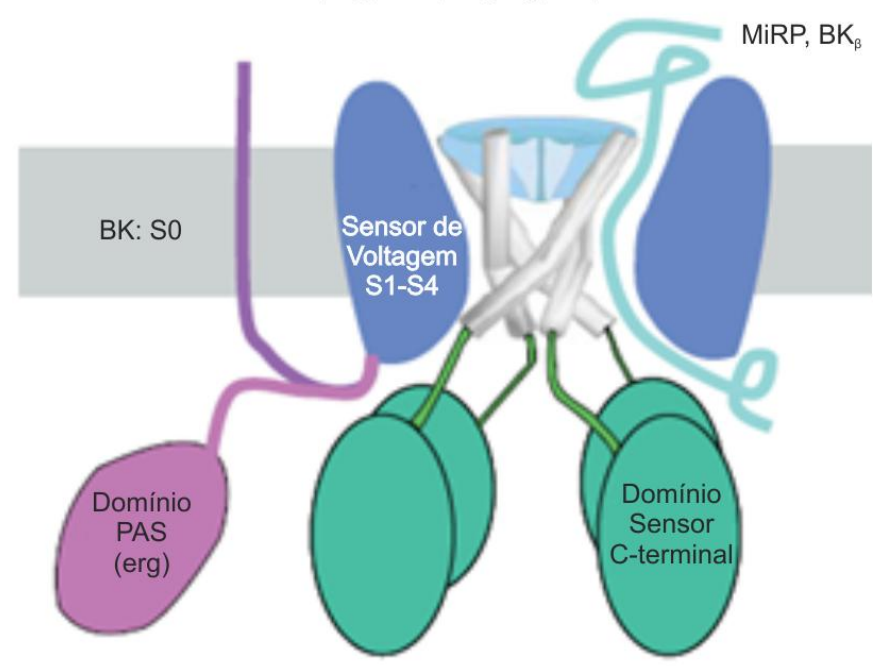

Figura 6 - Representação de canal tetraméricos 6TM. Esses possuem um domínio estrutural diferente, caracterizado pela ausência de um domínio T1 e a presença de um domínio sensor no Cterminal (verde). Alguns membros dessa família possuem no $\mathrm{N}$-terminal uma região transmembrana adicional (SO) (roxo). Figura modificada de Yellen (2002).

Os canais de $\mathrm{K}^{+}$são extremamente seletivos quanto aos íons que deixam passar. Contudo, eles permitem uma taxa de transporte perto do limite da difusão aquosa. Seletividade e velocidade são cruciais para a função biológica dos canais. Em neurônios e outras células, a especificidade dos canais a íons influência na diferença de concentração dos íons no meio intra e extracelular e determina a direção do fluxo da corrente. O fluxo de íons $\mathrm{Na}^{+} \mathrm{e}$ $\mathrm{Ca}^{2+}$ ocorrem do meio extracelular para o meio intracelular. Portanto, 
proporciona carga positiva para a célula. Como a maioria dos canais voltagemdependentes são ativados por uma voltagem positiva, isto promove a ativação dos canais e desencadeia a excitação regenerativa. Íons $\mathrm{K}^{+}$que fluem para o meio extracelular (ou íons $\mathrm{Cl}^{-}$fluindo para o meio intracelular) reduzem a carga positiva do meio intracelular e terminam (ou previnem) a excitação. Altas taxas de fluxo são essenciais para produzir essas rápidas mudanças de voltagem. Um típico potencial de ação em um neurônio de mamífero requer que milhões de íons fluam em milissegundos. Para conseguir isso sem o uso de milhões de proteínas exige que cada canal tenha um rendimento muito alto, enquanto mantêm uma elevada seletividade. A razão pela qual os íons necessitam de assistência para atravessar membranas lipídicas é que eles têm uma interação extremamente favorável com a água. Nas proximidades de um íon com carga positiva, como $\mathrm{K}^{+}$, as moléculas de água reorientam suas extremidades carregadas negativamente para o íon. Em lipídios ou até mesmo em proteínas, não existe acomodação eletrostática análoga à presença do íon (estas substâncias têm uma constante dielétrica relativamente baixa em comparação com a água). Em vez disso, as proteínas de canais de $\mathrm{K}^{+}$têm quatro características estruturais específicas que mantêm o íon quase totalmente estável como acontece na água. Primeiro, os canais usam a abundância de água para tornar o íon estável. Em vez de manter um poro estreito da dimensão de um átomo por toda a espessura da membrana, parte do caminho permeável é amplo e contém uma grande quantidade de água (Figura 7). Essa explicação foi proposta há muitos anos atrás, sobretudo, como uma explicação da grande condutância de certos canais de $\mathrm{K}^{+}$ativados por $\mathrm{Ca}^{2+}$ (Latorre \& Miller, 1983), e é confirmada pelo cristal das estruturas de dois poros de dois canais de $\mathrm{K}^{+}$diferentes presentes em bactérias, KcsA e MthK (Doyle et al., 1998; Jiang et al., 2002a; Morais Cabral et al., 1998; Zhou et al., 2001a). Ademais, os canais de $\mathrm{K}^{+}$, aparentemente, estabilizam os íons e alcançam seletividade catiônica por utilizarem a influência eletrostática dos dipolos das hélices. Cada a-hélice possui um momento dipolo e o vestíbulo intracelular dos canais de $\mathrm{K}^{+}$tem as extremidades negativas de quatro dipolos das hélices apontados para seu centro (Doyle et al., 1998). Doyle e colaboradores (1998) e Roux \& MacKinnon (1999) propuseram que esses dipolos das hélices produzem uma estabilização preferencial por cátions próximos à entrada do 
filtro seletivo. Esse conceito é baseado na arquitetura bastante diferente dos canais que conduzem a carga negativa dos íons clorídricos. Esses têm as extremidades positivas de múltiplas hélices apontadas para o local do íon central (Dutzler et al., 2002).

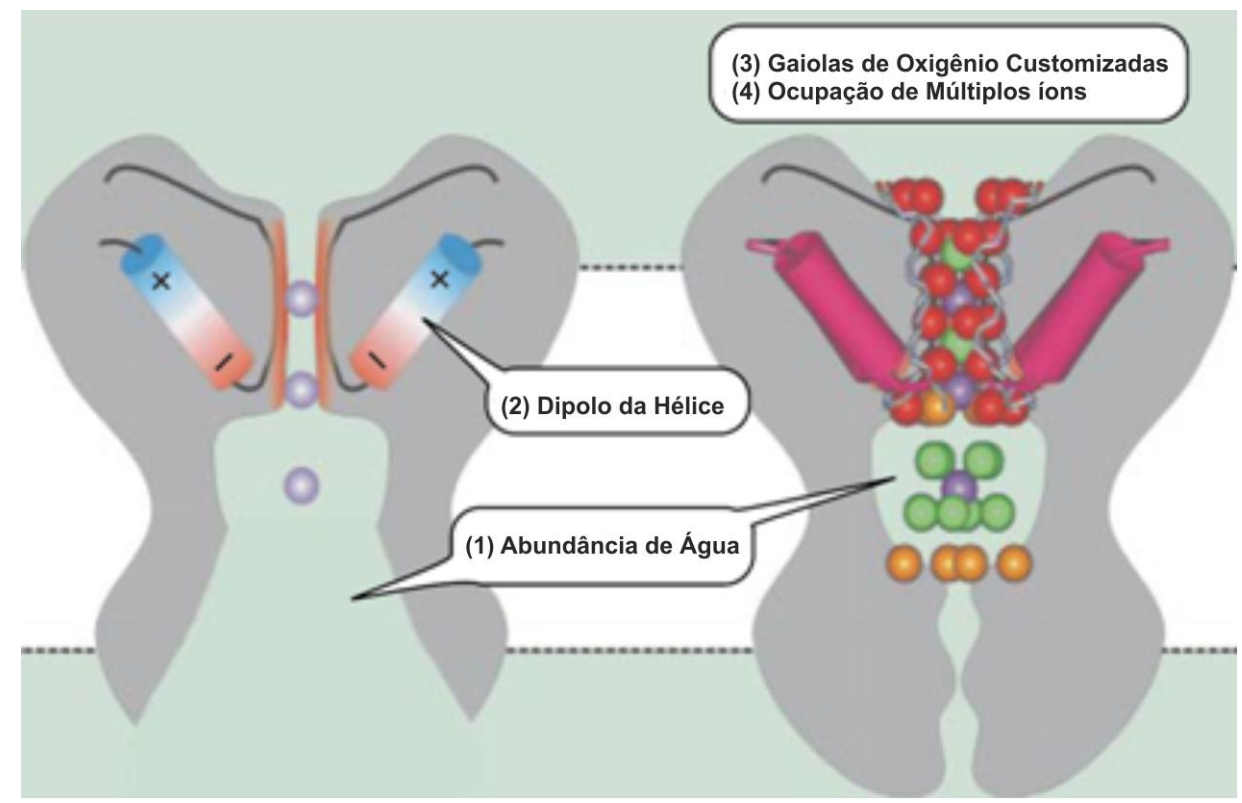

Figura 7 - Características arquitetônicas dos canais de $\mathrm{K}^{+}$importantes para a permeabilidade de íons. Aproximação de um corte transversal de um canal de $\mathrm{K}^{+}$aberto, baseado na estrutura do canal MthK (esquerda) (Jiang et al., 2002). $O$ vestíbulo intracelular aberto e os poros dos dipolos das hélices estão realçados. $O$ diagrama da direita é uma representação derivada da estrutura de alta resolução do canal KcsA (Zhou et al., 2001), mostrando um acesso estreito, provavelmente fechado, para a cavidade cheia de água no centro da proteína de membrana. Um íon $\mathrm{K}^{+}$ aprisionado (esfera roxa) e suas oito moléculas de água de hidratação (esferas verdes); os oxigênios de suporte do filtro seletivo (esferas vermelhas) fornecem uma boa correspondência para esse ambiente de hidratação para os íons potássio. A ocupação do poro por múltiplos íons $\mathrm{K}^{+}$ apresenta um papel importante na seletividade e em outras propriedades do canal (Morais-Cabral et al., 2001; Hodgkin \& Keynes, 1955; Hille \& Schwarz, 1978; Spassova \& Lu, 1998). Essa arquitetura básica também pode produzir canais catiônicos não seletivos (Heginbotham et al., 1992) ou canais seletivos para íons $\mathrm{Na}^{+}$ou $\mathrm{Ca}^{2+}$ (Ren et al., 2001). Esferas na cor laranja indicam cadeias laterais de átomos de oxigênio. Figura modificada de Doyle e colaboradores (1998).

Uma terceira característica quanto à abordagem sobre a permeabilidade e a seletividade a íons dos canais de $\mathrm{K}^{+}$é a formação de uma série de "gaiolas" apolares de oxigênio. Como íons $\mathrm{K}^{+}$difundem-se através da água, esses quase sempre estão cercados por uma gaiola de átomos polares de oxigênio das moléculas de água. A água é extremamente flexível e facilmente se adapta ao tamanho e configuração da gaiola para acomodar íons de diferentes tamanhos, como o $\mathrm{Na}^{+}$e $\mathrm{K}^{+}$. O filtro de seletividade do canal de $\mathrm{K}^{+}$é projetado para imitar a estrutura da água do entorno de um ín $\mathrm{K}^{+}$, mas também é designado para 
não adotar a estrutura do entorno do íon $\mathrm{Na}^{+}$, presumivelmente mais compacta (como originalmente proposto por Armstrong, 1974). Cada íon $\mathrm{K}^{+}$no filtro de seletividade é cercado por dois grupos de quatro átomos de oxigênio. Assim, como na água, esses átomos de oxigênio são mantidos no lugar por uma proteína e constituem, de fato, os oxigênios carboxílicos do suporte principal dos loops do filtro de seletividade das quatro subunidades.

Finalmente, uma característica bem conhecida dos canais de $\mathrm{K}^{+}$é que os íons $\mathrm{K}^{+}$passam em uma única fila, com ocupação de múltiplos íons simultaneamente (Hille \& Schwarz, 1978; Hodgkin \& Keynes, 1955; Keynes \& Kimura, 1978; Morais-Cabral et al., 2001; Spassova \& Lu, 1998). A mutua repulsão eletrostática entra os íons $\mathrm{K}^{+}$adjacentes (espaçados cerca $7 \AA$ entre si) causa desestabilização de íons no poro, permitindo uma outra interação favorável para produzir a seletividade de íons sem produzir uma forte ligação que poderia prejudicar a rápida permeabilidade.

As características estruturais dos canais de potássio são, portanto, perfeitamente adaptadas à sua função. O problema da estabilização eletrostática dos íons é resolvido utilizando água e os dipolos das hélices para neutralizar a dielétrica desfavorável do ambiente interno da membrana, sem torná-los muito mais estáveis do que estão na água. Além disso, o problema da estabilização do potássio em preferência ao sódio é resolvido por uma precisa combinação da configuração dos átomos de oxigênio ao redor de um íon potássio solvatado. Existem três mecanismos estabelecidos pelos quais canais $\mathrm{K}_{\mathrm{V}}$ podem se fechar. Dois deles envolvem uma constrição conformacional da via de permeação, e o terceiro envolve uma obstrução condicional dos poros por uma parte auto-inibidora da proteína de canal. A seguir, será discutido cada um desses mecanismos.

\subsubsection{Gating no segmento S6}

O canal pode ser fechado por compressão da entrada intracelular. Essa obstrução intracelular, ou gate S6, da entrada vai desde a superfície do citoplasma até a "cavidade" no centro do canal.

A região transmembrana S6 corresponde à "hélice interna" do canal de bactéria KcsA. A parte superior da região final (extracelular) das quatro hélices 
S6 forma um suporte para o filtro seletivo, enquanto que a base da região final converge para o "canal de passagem" do lado direito abaixo da cavidade. Esse canal de passagem corresponde ao local de fechamento, funcionalmente determinado, de pelo menos alguns canais $\mathrm{K}_{\mathrm{V}}$ (del Camino \& Yellen, 2001; Liu et al., 1997).

A região transmembrana S6 e sua extensão intracelular apresentam sequências altamente conservadas dentre as principais famílias de canais $\mathrm{K}_{\mathrm{v}}$, e no canal de passagem há uma sequência de prolina (PxP ou $P x G$ ) que não é encontrada em canais de $\mathrm{K}^{+}$de bactérias. Estudos dessa região indicam que provavelmente $\mathrm{S} 6$ dobre tanto em canais fechados quanto abertos (del Camino et al., 2000; del Camino \& Yellen, 2001; Holmgren et al., 1997). A provável natureza do movimento de abertura de $\mathrm{S} 6$, foi evidenciado através da determinação da estrutura de um canal de $\mathrm{K}^{+}$de bactéria, MthK6, (tetramérico 2TM) que pode abrir através de $\mathrm{Ca}^{2+}$ intracelular. Essa estrutura aparenta representar o canal MthK no estado aberto (Figura 8) e não apresenta canal de passagem. Em vez disso, os homólogos da hélice S6 são abertos sem constrição entre a solução intracelular e o filtro seletivo (Jiang et al., 2002b). Comparando essa com a estrutura de KcsA supostamente no estado fechado, temos uma figura plausível do movimento de gating (Figura 8, topo e centro): as hélices S6 abrem se balançando através de uma dobradiça localizada em um resíduo de glicina altamente conservado. O movimento implícito é muito maior do que previamente foi sugerido por ressonância paramagnética de elétron mensurada em KcsA (Perozo et al., 1999). Ainda não se sabe se os canais dependentes de voltagem podem usar a sequência PxP como uma segunda (ou alternativa) dobradiça, ou se a sequência PxP fornece uma curva fixa que permite ao gate $\mathrm{S} 6$ desses canais se conectarem com sensor de voltagem transmembrana (em vez dos sensores de cálcio intracelular usados pelo MthK).

Uma consequência importante do mecanismo de gating S6 é a interação com bloqueadores de canais. Pequenos bloqueadores orgânicos, incluindo moléculas do tipo anestésico locais, agem por meio de ligações em locais dentro da cavidade. Por causa do gate S6, esses bloqueadores só podem entrar no canal quando este se encontrar aberto (por voltagem ou outro estímulo), e alguns bloqueadores podem ser aprisionados na cavidade quando 
o gate S6 se fecha (Armstrong, 1971; Holmgren et al., 1997). A recente descoberta desses fenômenos por Armstrong inspirou a hipótese inicial de um gate intracelular (Armstrong, 1971 e 1974).

Bloqueadores de gating e aprisionamento também constituem um mecanismo primário para a ação estado-dependente e uso-dependente de bloqueadores de canais, uma característica que é muitas vezes crucial para o valor terapêutico para a ação de drogas de canais iônicos (por exemplo, anticonvulcivantes que devem inibir a atividade elétrica excessiva sem afetar os níveis basais para uma atividade normal).

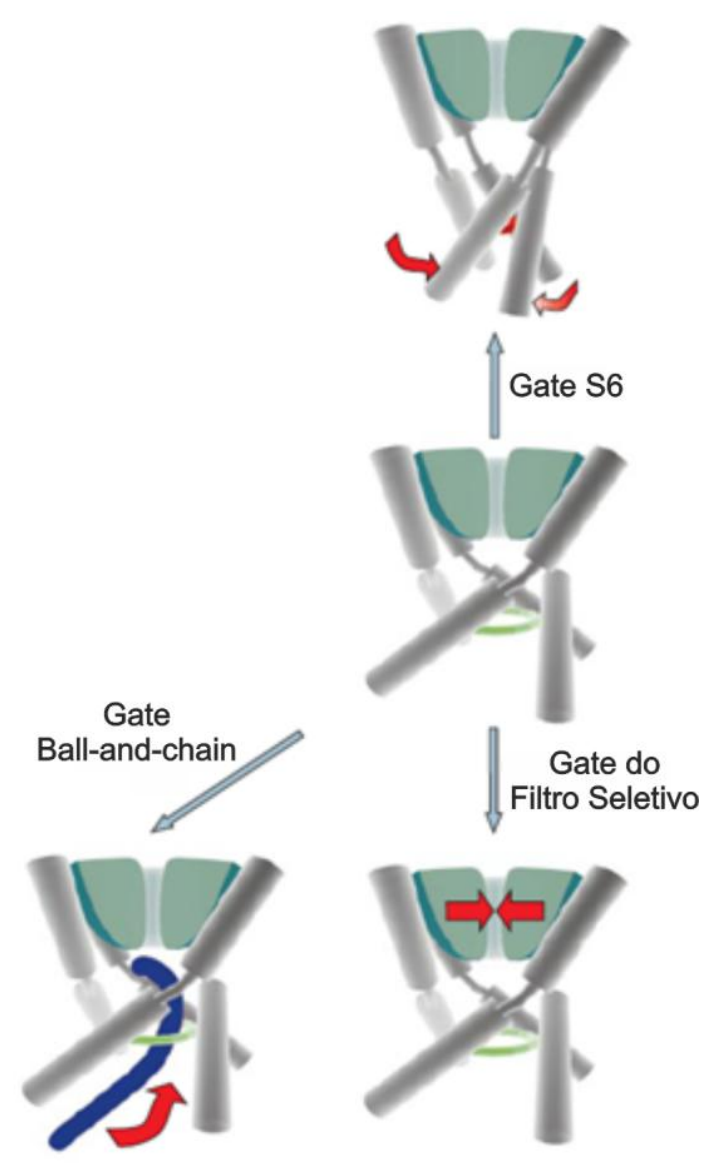

Figura 8 - Mudanças conformacionais que abrem e fecham o poro do canal de $\mathrm{K}^{+}$. $\mathrm{O}$ diagrama central mostra a estrutura do centro de um canal de $\mathrm{K}^{+}$aberto, com base na estrutura de MthK (Jiang et al, 2002b). O filtro seletivo (em verde) é representado com um corte para mostrar o poro estreito. As hélices externas não estão representadas para poder mostrar as hélices internas, correspondentes ao S6. No estado aberto os segmentos S6 estão espalhados para fora, como na estrutura de MthK, utilizando a dobradiça conservada de glicina próxima ao filtro seletivo. 0 diagrama superior mostra um canal de $\mathrm{K}^{+}$no estado fechado, com base na estrutura de KcsA (Doyle et al, 1998). Os quatro segmentos transmembrana S6 balançam em conjunto para produzir um fechamento do caminho de passagem (del Camino \& Yellen, 2001). Isso corta o fluxo de íons e pode prender bloqueadores orgânicos dos canais na cavidade fechada. $O$ anel em verde e 0 em vermelho ilustram o estado aberto e fechado, respectivamente, do gate $\mathbf{S 6}$. Alternativamente, o canal pode de ser fechado no filtro seletivo (diagrama da direita no canto inferior), ou por ligação de um peptídeo auto-inibitório (diagrama da esquerda no canto inferior) quando o sítio de ligação no poro é exposto pela abertura do gate S6. Figura modificada de Jiang e colaboradores (2002). 


\subsubsection{Inativação N-type (Gate "Ball-and-chain")}

Um segundo mecanismo para o fechamento do poro é o uso do gate $\mathrm{S} 6$ para regular a ligação de um peptídeo auto-inibitório que faz parte da proteína do canal (Figura 8, parte inferior no lado direito). Similar aos pequenos bloqueadores orgânicos estudados por Armstrong (Armstrong, 1971 e 1974), o $\mathrm{N}$-terminal dos canais de $\mathrm{K}^{+}$Shaker pode atuar como bloqueador do canal, provavelmente por ligação direta com a cavidade. Pelo fato de tal interação ocorrer somente após a abertura do gate $\mathrm{S} 6$, alguns canais $\mathrm{K}_{\mathrm{V}}$ conduzem apenas de maneira transitória, durante um pequeno período após a abertura do gate $\mathrm{S} 6$ e antes dos peptídeos $\mathrm{N}$-terminal bloquearem os canais. Os eletrofisiologistas chamam isso de "inativação N-type".

A inativação $\mathrm{N}$-type (também chamada de mecanismo "ball-and-chain", porque envolve um bloqueador "amarrado", inicialmente imaginou-se ser uma bola), ocorre em diversos canais $\mathrm{K}_{v} \mathrm{~s}$ conhecidos, e pode envolver tanto o $\mathrm{N}$ terminal da subunidade principal do canal (subunidade- $\alpha$ ) (Hoshi et al., 1990) como o N-terminal de uma subunidade- $\beta$ associada (Rettig et al., 1994). Esse mecanismo de inativação pode ser interrompido por remoção enzimática ou genética da sequência do N-terminal (Hoshi et al., 1990), e recuperado por adição de um peptídeo solúvel com a mesma sequência na solução de banho intracelular (Zagotta et al., 1990). Há uma pequena conservação na sequência entre os vários $\mathrm{N}$-terminais capazes de produzirem essa forma de inativação, apesar de que tanto cargas positivas quanto o caráter hidrofóbico serem importantes para a interação com o canal aberto (Murrell-Lagnado \& Aldrich, 1993; Zagotta et al., 1990). O peptídeo parece inativar o canal por um simples mecanismo de bloqueio: compete com bloqueadores de canais aplicados intracelularmente (Choi et al., 1991); é expelido pelo fluxo de potássio do lado oposto da membrana (Demo \& Yellen, 1991); e é especificamente afetado pela mutação de resíduos no interior da cavidade (Zhou et al., 2001a).

\subsubsection{Gating no filtro seletivo}

Um terceiro mecanismo de fechamento do poro se dá pela compressão do próprio filtro seletivo - um filtro seletivo ou gate do poro (Figura 8, parte 
superior, no lado direito). Esse mecanismo foi reconhecido pela primeira vez na forma de "inativação C-type", uma alternativa para a inativação N-type e para produzir uma condutância transiente de $\mathrm{K}^{+}$por fechamento dos canais, apesar da existência de um estímulo constante. Inativação C-type persiste em canais Shaker, quando a inativação Ball-and-chain é deletada (Hoshi et al., 1991), e é bastante sensível à concentração de $\mathrm{K}^{+}$extracelular e a mutações na entrada extracelular do poro (Lopez-Barneo et al., 1993). O fechamento deste gate pode ser prevenido pela ligação do íon extracelular tetraetilamônio (TEA) no poro (Choi et al., 1991). Uma vez fechado, esse gate de inativação pode ser travado por um íon metálico que introduz pontes dissulfeto em cada uma das quatro subunidades na região do poro da porção extracelular (Liu et al., 1996; Yellen et al., 1994). Esse processo de inativação (normalmente mais lento do que a inativação $\mathrm{N}$-type), provavelmente, tem uma função de regular atividades elétricas repetitivas; sua sensibilidade à concentração de $\mathrm{K}^{+}$pode determinar uma resposta fisiológica para o acumulo extracelular de $\mathrm{K}^{+}$(Baukrowitz \& Yellen, 1995; Pardo et al., 1992).

Detalhes estruturais da inativação C-type provavelmente se assemelham com deformações do filtro seletivo de KcsA, que é observado quando esses canais são cristalizados com baixa concentração de $\mathrm{K}^{+}$(Zhou et al., 2001b): o filtro seletivo contém menos íons $\mathrm{K}^{+}$e, em vez de apontar para o eixo central, os oxigênios carbonil do filtro projetam-se obliquamente, com um colapso parcial do filtro. $\mathrm{Em}$ alguns canais $\mathrm{K}_{\mathrm{v}}$, o filtro seletivo inativado pode continuar a conduzir íons $\mathrm{Na}^{+}$quando todo $\circ \mathrm{K}^{+}$é removido, sugerindo uma forma de colapso ligeiramente diferente onde oxigênios carbonil possam, agora, acomodar "confortavelmente" um íon $\mathrm{Na}^{+}$(Kiss et al., 1999).

Medições de um único canal $K_{V}$ (Chapman et al., 1997; Zheng \& Sigworth, 1997) têm sugerido que, mesmo durante o processo normal de ativação (que, pelo menos em Shaker, envolve o gate S6), pode haver movimentos do filtro seletivo. Embora o gating no filtro seletivo possa ter um papel ainda mais proeminente em outros canais $\mathrm{K}_{\mathrm{V}}$ da mesma família, em canais CNG (Flynn \& Zagotta, 2001) (mas não em canais HCN, segundo Rothberg e colaboradores, 2002) o filtro seletivo, aparentemente, atua como um gate principal do canal. Há, praticamente, livre acesso a partir da solução intracelular até a região $\mathrm{S} 6$, mesmo no estado fechado do canal, embora haja 
alguma mudança na restrição no tamanho do acesso com o gating (Flynn \& Zagotta, 2001), e há claras mudanças conformacionais no S6 (Johnson \& Zagotta, 2001).

Em geral, parece provável que o funcionamento básico do gate S6 e do gate do filtro seletivo são conservados nos diferentes canais: o gate S6 se movimenta em resposta a um sensor de voltagem transmembrana ou ao domínio sensor intracelular, e o filtro seletivo pode reagir à mudança em S6, abrindo ou fechando. A glicina conservada que atua como uma dobradiça no gating em canal MthK, provavelmente auxilia a dissociar esses dois movimentos, mas não completamente. Dependendo dos detalhes estruturais, 0 gate S6 pode se fechar completamente (como em canais Shaker e HCN), ou pode permanecer entreaberto, ainda que no estado "fechado" (como em canais de $\mathrm{K}^{+}$ativados por $\mathrm{Ca}^{2+}$, CNG e pequenas condutâncias). Além disso, dependendo dos detalhes, o gate do filtro seletivo pode permanecer sempre aberto, pode responder ao movimento de S6 por abertura ou fechamento, ou pode responder diretamente aos movimentos do sensor de voltagem.

\subsubsection{Sensor de voltagem}

O sensor de voltagem é, obviamente, fundamental para o funcionamento dos canais $\mathrm{K}_{\mathrm{V}}$, mas sua estrutura tridimensional ainda não é bem conhecida. Há, no entanto, uma grande quantidade de informações funcionais sobre o sensor de voltagem. A voltagem transmembrana deve ser sentida por uma estrutura de carga que se move, pelo menos parcialmente, através da membrana. A energia do gating de voltagem, junto com medições elétricas diretas do movimento de carga do gating, mostra que mais de quatro cargas por subunidade do canal são efetivamente translocadas através da membrana enquanto o canal alterna entre o estado aberto e fechado (Sigworth, 1994).

A expectativa de que as cargas transmembrana seriam responsáveis pelo sensor de voltagem tornou relativamente fácil reconhecer o provável sensor de voltagem nos primeiros canais e sequências clonadas (Noda et al., 1984). O único motivo conservado na sequência de todos os canais iônicos voltagem-dependentes $\left(\mathrm{Na}^{+}, \mathrm{Ca}^{2+}, \mathrm{K}^{+}\right)$é na quarta região transmembrana (S4), 
que a cada terceira posição, tem um resíduo de carga positiva arginina ou lisina.

De um modo geral, presume-se que os quatro segmentos S1-S4 formem o domínio sensor de voltagem. Com base no padrão de conservação da sequência, acessibilidade à cisteína e tolerância à substituição, todos são, provavelmente, essencialmente a-hélices (Durell et al., 1998; Hong \& Miller, 2000; Li-Smerin et al., 2000; Monks et al., 1999). O padrão dos resíduos com carga a cada terceira posição levou à proposta inicial de um movimento de "parafuso helicoidal" (helical screw) (Catterall, 1986; Guy \& Seetharamulu, 1986): o S4 avançaria como um parafuso para movimentar cada carga para a posição da próxima carga e assim por diante, mantendo, desta forma, a distribuição de carga no centro, enquanto produz um conjunto de translocação de carga em toda a membrana.

Muitas medições físicas foram feitas com sondas de fluorescência anexadas a cisteínas colocadas dentro ou perto do S4, em uma tentativa de inferir o movimento do sensor de voltagem. O padrão de fluorescência e alterações no padrão das distâncias estimadas a partir de transferência de energia de ressonância está de acordo com a ideia de uma rotação (Cha et al., 1999; Glauner et al., 1999). No entanto, todas as medidas de alteração na distância (em especial a partir das medições com maior grau de precisão) são muito pequenas (cerca de $1 \AA$ ) e aparentam ser inconsistentes com a proposta mais aceita que é a de uma rotação substancial. Existem outras maneiras pelas quais a translocação efetiva de carga poderia ser efetuada, como o movimento lateral relativo de hélices cruzadas ou um movimento oscilante na interface entre dois domínios. Ainda falta conhecimento da estrutura tridimensional para resolver tal enigma em particular.

\subsubsection{Subfamílias de canais $\mathrm{K}_{\mathrm{V}}$}

Canais de potássio constituem o maior e mais diverso grupo de canais iônicos, representados por cerca de 70 loci conhecidos no genoma de mamíferos. O primeiro gene clonado de canal de potássio foi o canal voltagemdependente Shaker de Drosophila. Foram identificados em seguida outros genes de canais de potássio voltagem- e ligante-dependentes em moscas, 
mamíferos, e muito outros organismos. Canais $\mathrm{K}_{\mathrm{v}}$, por sua vez, formam a maior família com cerca de 40 genes dentro do grupo de canais de potássio de humanos, que também incluem as famílias dos canais $\mathrm{K}_{\mathrm{V}}$ ativados por $\mathrm{Ca}^{2+}$ (KCa), KIR, K2P (dois poros).

Canais $\mathrm{K}_{\mathrm{V}}$ formam um grupo extremamente diversificado, muito mais do que se poderia prever simplesmente com base no número de genes distintos que os codificam. Essa diversidade resulta de alguns fatores, como:

1) Heteromultimerização - Cada gene de $K_{V}$ codifica uma subunidade, quatro das quais são necessárias para formar um canal funcional. Canais $\mathrm{K}_{\mathrm{V}}$ podem ser homotetraméricos, mas também podem ser heterotetraméricos, sendo formados por diferentes subunidades dentro da mesma família (no caso das famílias $\mathrm{K}_{\mathrm{V}} 1, \mathrm{~K}_{\mathrm{V}} 7$ e $\mathrm{K}_{\mathrm{v}} 10$ ), e estes diversos heterotetrâmeros expressam propriedades que podem ser consideradas diferentes daquelas de qualquer um dos homotetrâmeros.

2) Subunidades "modificadoras" - Quatro famílias de $K_{v}\left(K_{v} 5, K_{v} 6\right.$, Kv8 e Kv9) traduzem subunidades que atuam como modificadoras. Embora estas não produzam canais funcionais por si só, elas formam heterotretâmeros com subunidades da família $\mathrm{K}_{\mathrm{v}} 2$, aumentando a diversidade funcional dentro dessa família.

3) Proteínas acessórias - Uma variedade de outros peptídeos tem mostrado a capacidade de se associarem com tetrâmeros $\mathrm{K}_{\mathrm{V}}$ e modificar suas propriedades, incluindo diversas subunidades $\beta$ (que se associam com canais $\mathrm{K}_{\mathrm{v}} 1$ e $\mathrm{K}_{\mathrm{v}}$ ), KCHIP1 (Kv4), calmodulinas ( $\left.\mathrm{K}_{\mathrm{v}} 10\right)$, e mink ( $\left.\mathrm{K}_{\mathrm{v}} 11\right)$.

4) Splicing alternativo do mRNA - Alguns genes de canal $K_{V}$ são conhecidos por conterem regiões com deleção de íntrons, incluindo todos os genes da família $K_{v} 1$ (com somente exceção dos $K_{V}$ 1.7) e $K_{V}$ 9.3. Embora splicing alternativo de exons não codificantes possam ser importantes para a regulação da expressão desses canais, um gene pode produzir somente um único tipo de subunidade. Porém, diversos membros das famílias de genes $\mathrm{K}_{\mathrm{v}} 3, \mathrm{~K}_{\mathrm{v}} 4, \mathrm{~K}_{\mathrm{v}} 6, \mathrm{~K}_{\mathrm{v}} 7, \mathrm{~K}_{\mathrm{v}}$ 9, $\mathrm{K}_{\mathrm{v}} 10$ e $\mathrm{K}_{\mathrm{v}} 11$ possuem regiões codificantes formadas por alguns exons que são alternadamente processados, proporcionando outra fonte significativa de uma diversidade funcional de canal $\mathrm{K}_{\mathrm{V}}$. 
5) Modificação pós-traducional - Muitos canais $K_{V}$ podem ser modificados pós-tradução, como por exemplo, por fosforilação (Jerng et al., 2004) e ubiquitina, modificando a função do canal.

Uma de suas subfamílias mais bem estuda é a subfamília $K_{V} 1$, também conhecida como Shaker. Esta subfamília é codificada por 8 diferentes genes, cada um codificando uma isoforma do canal para potássio ( $\left.\mathrm{K}_{\mathrm{v}} 1.1-\mathrm{K}_{\mathrm{v}} 1.8\right)$. Estas isoformas são amplamente distribuídas pelos organismos e são frequentemente encontradas no cérebro ( $\mathrm{K}_{\mathrm{v}} 1.1$ a $\mathrm{K}_{\mathrm{v}} 1.4 ; \mathrm{K}_{\mathrm{v}} 1.6$ e $\left.\mathrm{K}_{\mathrm{v}} 1.8\right)$, no sistema nervoso periférico ( $\mathrm{K}_{\mathrm{v}} 1.1$ e $\left.\mathrm{K}_{\mathrm{v}} 1.2\right)$, no coração $\left(\mathrm{K}_{\mathrm{V}} 1.1, \mathrm{~K}_{\mathrm{V}} 1.2 ; \mathrm{K}_{\mathrm{V}} 1.4 \mathrm{a}\right.$ $\left.\mathrm{K}_{\mathrm{v}} 1.8\right)$, no músculo liso ( $\mathrm{K}_{\mathrm{v}} 1.2$ e $\left.\mathrm{K}_{\mathrm{v}} 1.5\right)$, no pâncreas $\left(\mathrm{K}_{\mathrm{v}} 1.1\right.$ a $\left.\mathrm{K}_{\mathrm{v}} 1.3\right)$, no pulmão ( $\mathrm{K}_{v} 1.3$ a $\left.\mathrm{K}_{v} 1.7\right)$, nos rins ( $\mathrm{K}_{v} 1.5$ a $\left.\mathrm{K}_{v} 1.8\right)$, na retina ( $\mathrm{K}_{v} 1.1$ e $\left.\mathrm{K}_{v} 1.2\right)$ e, também, em células hematopoiéticas, linfócitos e osteoclastos ( $\left.K_{v} 1.3\right)$ (Mouhat et al., 2008). As isoformas $\mathrm{K}_{\mathrm{V}} 1.1$ a $\mathrm{K}_{\mathrm{V}} 1.3$ têm chamado a atenção de toxinologistas por serem os principais alvos de toxinas. As isoformas $\mathrm{K}_{\mathrm{v}} 1.4 \mathrm{e}$ $\mathrm{K}_{\mathrm{v}} 1.5$, por outro lado, são consideradas atualmente, alvos órfãos de peptídeos, já que não possuem toxinas ligantes específicas (Mouhat et al., 2008).

A subfamília Kv2 também conhecida como Shab, compreende apenas duas isoformas (Kv2.1 e $\left.K_{v} 2.2\right)$ e são encontrados principalmente nos neurônios, cérebro, coração, rins, músculo esquelético, pulmão, retina e pâncreas.

A subfamília Shaw ou $K_{v} 3$, codificada por 4 genes $\left(K_{v} 3.1-4\right)$ é encontrada principalmente no cérebro e, somente, para as isoformas Kv3.2 e Kv3.4 foram descritos toxinas seletivas, isoladas de anêmonas do mar. A subfamília Shal, ou $\mathrm{K}_{\mathrm{v}} 4$, é representada por apenas 3 isoformas $\left(\mathrm{K}_{\mathrm{V}} 4.1\right.$ a $\left.K_{v} 4.3\right)$ localizados essencialmente no cérebro, coração e musculatura lisa. Toxinas de aranhas e de escorpiões foram relatadas como bloqueadores específicos para as 3 isoformas. Para a família KQT $\left(K_{v} 7\right)$, codificada por 5 genes, não foi encontrado nenhum ligante natural (Mouhat et al., 2008).

As últimas 3 subfamílias funcionais ( $\mathrm{K}_{\mathrm{V}} 10$ ou ether-a-go-go; $\mathrm{K}_{\mathrm{v}} 11$ ou Eag-related-gene e $\mathrm{K}_{\mathrm{V}} 12$, ou eag-like) são conhecidas simplesmente como subfamília Eag, com isoformas encontradas principalmente no sistema nervoso central. Tais isoformas são poucos elucidadas, com exceção da isoforma $\mathrm{K}_{\mathrm{V}} 10.1$ ou EAG1, tendo sido relacionadas com processos oncogenéticos. 
As subfamílias $\mathrm{K}_{\mathrm{v}} 5, \mathrm{~K}_{\mathrm{v}} 6, \mathrm{~K}_{\mathrm{v}} 8$ e $\mathrm{K}_{\mathrm{v}} 9$ não formam canais para potássio funcionais por si só, mas podem formar canais heteromultiméricos com subunidades alfa da subfamília $\mathrm{K}_{\mathrm{v}} 2$.

$\mathrm{Na}$ Tabela 1, encontram-se listados os nomes atribuídos pela International Union of Pharmacology (IUPHAR) para as famílias de canais $\mathrm{K}_{\mathrm{V}}$ (Gutman et al., 2003), bem como os nomes dos genes estabelecidos pela HUGO Gene Nomenclature Committee (HGNC).

\begin{tabular}{|c|c|c|c|c|c|}
\hline IUPHAR & $\mathrm{HGNC}$ & Other & IUPHAR & $\mathrm{HGNC}$ & Other \\
\hline$K_{\mathrm{v}} 1.1$ & KCNA1 & Shaker-related family & $K_{v} 7.1$ & KCNQ1 & $K \backsim Q T$ \\
\hline$K_{v} 1.2$ & KCNA2 & & $K_{v} 7.2$ & $K C N Q 2$ & KQT2 \\
\hline$K_{v} 1.3$ & KCNA3 & & $K_{v} 7.3$ & KCNQ3 & \\
\hline$K_{\mathrm{v}} 1.4$ & KCNA4 & & $\kappa_{v} 7.4$ & KCNQ4 & \\
\hline$K_{v} 1.5$ & KCNAS & & $K_{v} 7.5$ & $K C N Q 5$ & \\
\hline$K_{V} 1.6$ & KCNAG & & $K_{1} 8.1$ & $K C N V 1$ & Modifiers \\
\hline$K_{v} 1.7$ & KCNAT & & $K_{\imath} 8.2$ & $K C N V / 2$ & \\
\hline$K_{v} 1.8$ & KCNA1O & & $K_{v} 9.1$ & KCNS1 & Modifiers \\
\hline$K_{1} 2.1$ & $K C N B 1$ & Shab-related family & $K_{v} 9.2$ & KCNS2 & \\
\hline$K_{\mathrm{v}} 2.2$ & KCNB2 & & $K_{v} 9.3$ & KCNS3 & \\
\hline$K_{4} 3.1$ & KCNC1 & Shaw-related family & $K_{v} 10.1$ & $K C N H 1$ & eag 1 \\
\hline$K_{4} 3.2$ & KCNC2 & & $K_{v} 10.2$ & KCNH5 & $\operatorname{eag} 2$ \\
\hline$K_{4} 3.3$ & KCNC3 & & $K_{v} 11.1$ & $K C N H 2$ & erg1 \\
\hline$K_{\mathrm{v}} 3.4$ & KCNC4 & & $K_{v} 11.2$ & KCNH6 & erg2 \\
\hline$K_{V} 4.1$ & $K C N D 1$ & Shal-related family & $\kappa_{v} 11.3$ & KCNH7 & erg3 \\
\hline$K_{V} 4.2$ & KCND2 & & $K_{v} 12.1$ & KCNH8 & elk1, elk3 \\
\hline$K_{V} 4.3$ & KCND3 & & $K_{v} 12.2$ & KCNH3 & elk2 \\
\hline$K_{4} 5.1$ & KCNF1 & Modifier & $K_{v} 12.3$ & KCNH4 & elk1 \\
\hline
\end{tabular}


As Figura 9 e Figura 10 mostram duas árvores filogenéticas, uma para as famílias $K_{V} 1-9$ e outra para as famílias $K_{V} 10-12$, com base em alinhamentos das sequências de aminoácidos similares de todo o centro hidrofóbico das proteínas.

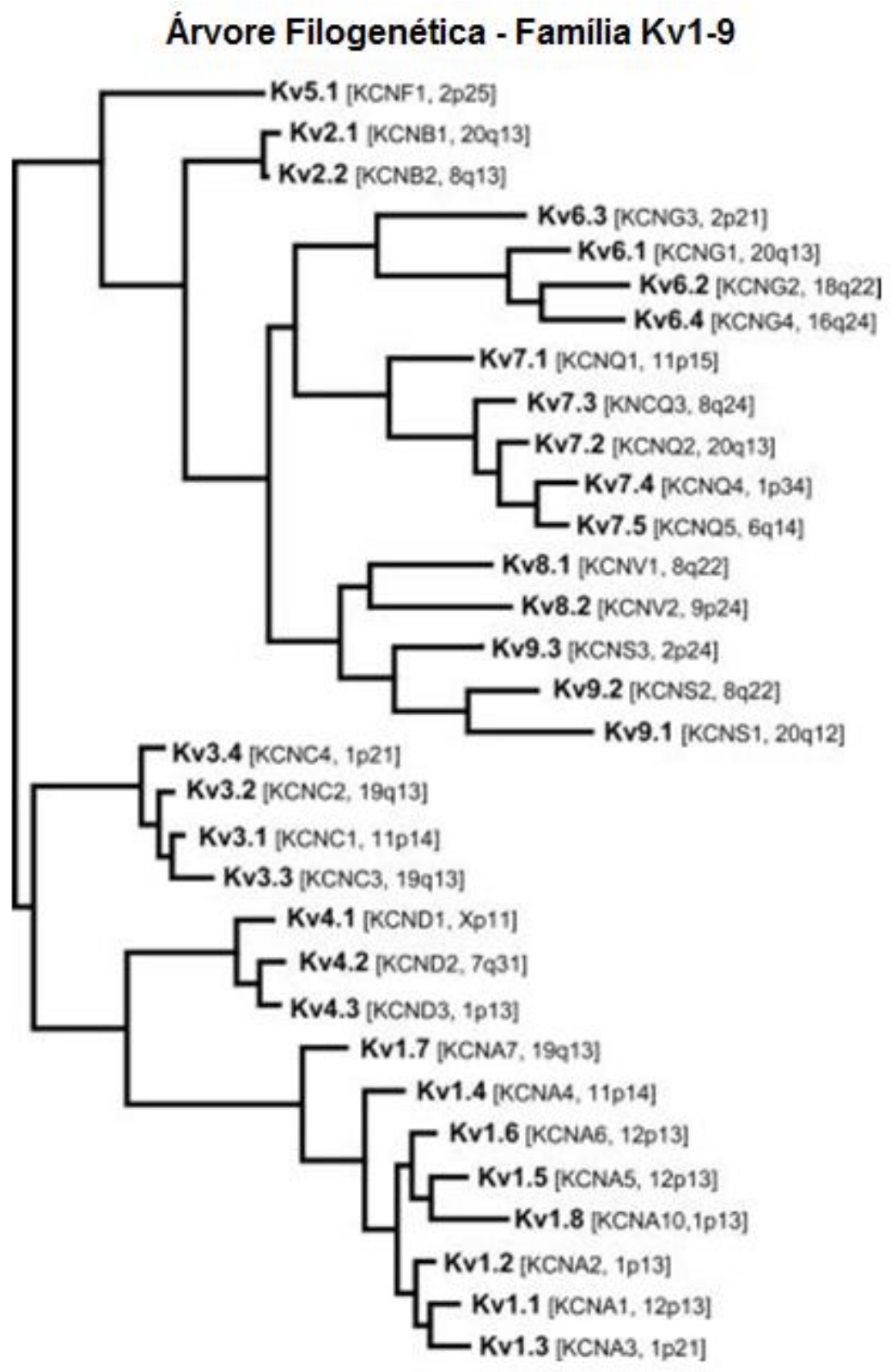

Figura 9 - Árvore filogenética para as famílias $K_{\mathrm{V}}$ 1-9: alinhamentos das sequências de aminoácidos das proteínas de canais $K_{v}$ de humano foram criados por meio da utilização da ferramenta CLUSTALW e da análise por máxima parcimônia, utilizando PAUP. Como resultado, foi criada uma árvore sem raiz compreendendo as famílias $K_{v} 1-K_{v} 6$ e $K_{v} 8-K_{v} 9$ que apareceram anteriormente. As sequências de $K_{v}$ 7.1-7.5, $K_{v} 6.4$ e $K_{v} 8.2$ foram adicionadas ao alinhamento existente, e essas novas sequências foram incorporadas na topologia da árvore já existente utilizando uma combinação de máxima parcimônia e análise neighbor-joining. Somente os núcleos hidrofóbicos (S1-S6) foram utilizados para análise. Os nomes dados pela IUPHAR e pela HGNC estão mostrados junto com a localização do gene no cromossomo e outros nomes comumente utilizados. Figura modificada de Gutman e colaboradores (2003). 
Árvore Filogenética - Familia Kv10-12

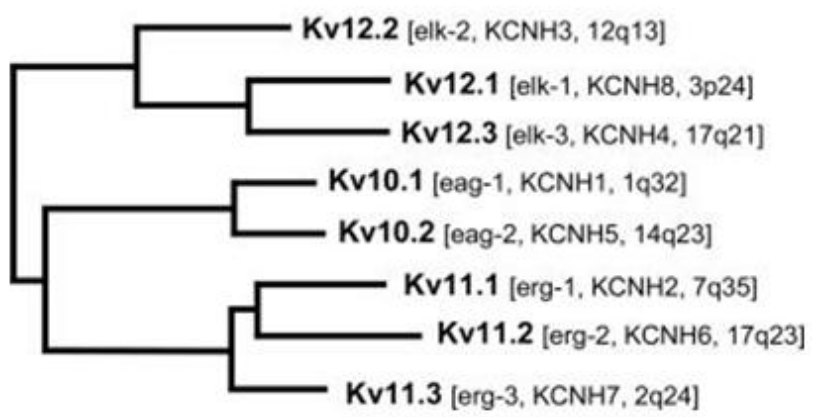

Figura 10 - Árvore filogenética para as famílias $\mathrm{K}_{\mathrm{v}} 10-12$ : Esta árvore sem raiz foi criada como descrito na Figura 9. Os nomes dados pela IUPHAR e pela HGNC estão mostrados junto com a localização do gene no cromossomo e outros nomes comumente utilizados. Figura modificada de Gutman e colaboradores (2003).

\subsection{Toxinas de anêmonas do mar e canais para sódio sensíveis à voltagem}

Os canais para sódio são alvos moleculares para vários grupos de toxinas que atuam alterando significativamente a função do canal. Essa ação acontece através da ligação específica em sítios receptores do canal. Foram identificados 5 tipos principais de sítios receptores (Figura 11) nos canais para sódio sensíveis à voltagem (Cestele \& Catterall, 2000).

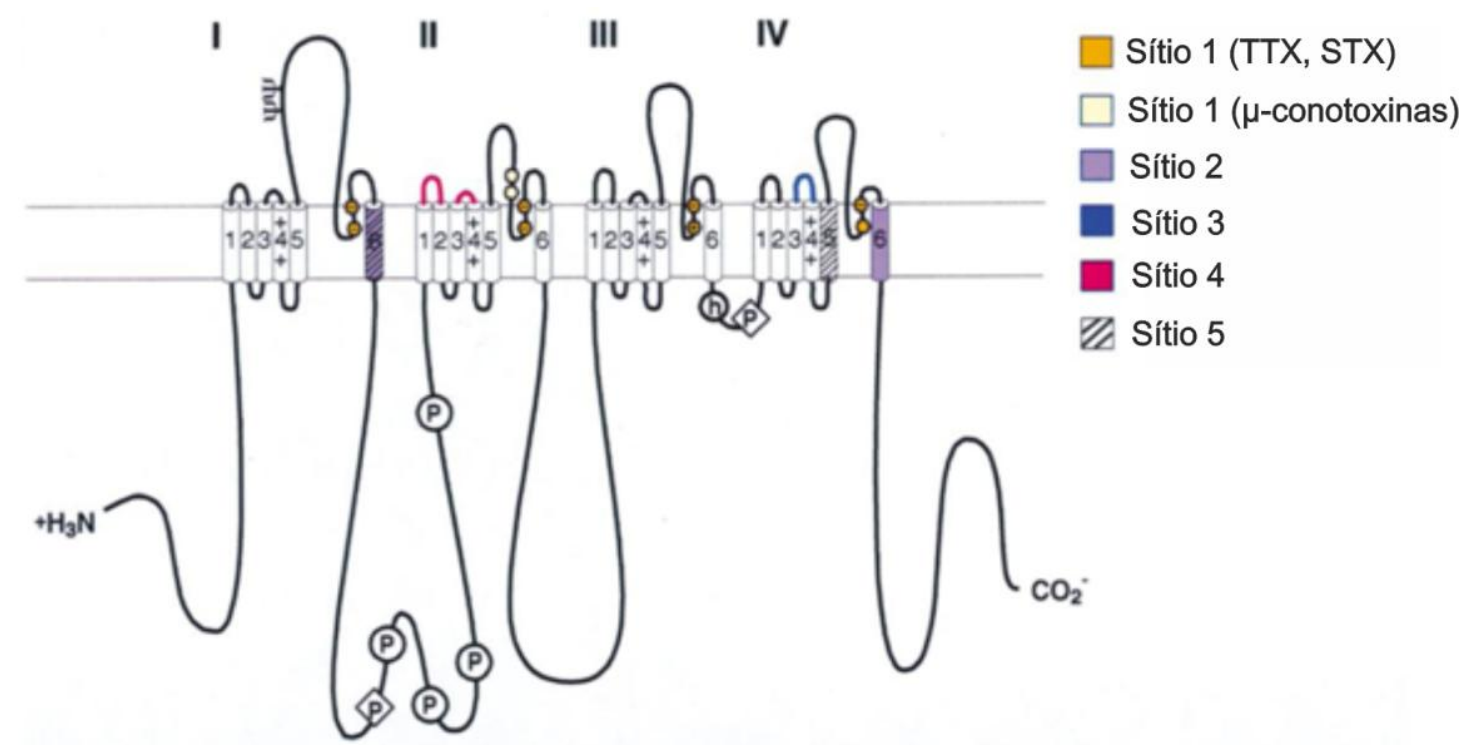

Figura 11 - Arranjo transmembrana da subunidade $\alpha$ dos canais para sódio evidenciando os principais sítios de interação com toxinas. Fonte: Cestele \& Catterall, 2000. 
O maior grupo de neurotoxinas de anêmonas do mar interage com os canais Nav. Estes peptídeos, em sua maioria básicos, atuam como moduladores, retardando a fase de inativação. Este mecanismo mantém o canal no estado aberto e consequentemente a célula mantém-se despolarizada e excitada por mais tempo (Oliveira et al., 2004; Rogers et al., 1996). Os efeitos biológicos causados por este mecanismo são neurotoxicidade (Beress \& Beress, 1975; Bruhn et al., 2001; Turlapaty et al., 1973) e cardiotoxicidade (Beress \& Beress, 1975; Norton et al., 1976) podendo causar a paralisia e, geralmente, a morte da presa.

A ligação do peptídeo aos canais se faz através de ligações eletrostáticas, ligações de hidrogênio e ligações do tipo Van de Waals entre os aminoácidos positivos presentes na toxina e alguns resíduos negativos presentes no segmento transmembranas S3-S4, no domínio IV do canal Nav (Cestele \& Catterall, 2000). Outros resíduos presentes nos segmentos S5-S6 do domínio I e segmentos S5-S6 do domínio IV também podem estar envolvidos (Oliveira et al., 2004).

Atualmente, as toxinas de anêmonas do mar que interagem com os canais $\mathrm{Nav}$ são classificadas de acordo com sua estrutura primária. Desde a primeira classificação proposta por Norton (1991), o número de toxinas aumentou e estas foram agrupadas em três principais grupos (tipo 1, 2 e 3), consolidados na literatura. Posteriormente, um quarto grupo (tipo 4) surgiu e este é composto pelas neurotoxinas Calitoxinas I e II (CLX-1 e CLX-II) (Honma \& Shiomi, 2006).

\subsubsection{Toxinas de canal de sódio tipo 1.}

Trinta e cinco peptídeos de 13 espécies da família Actiniidae e de duas espécies da família Stichodactylidae representam as neurotoxinas do tipo 1 que são compostas por 46-49 aminoácidos, exceto por Ae-I (Actinia equina) que contém 54 aminoácidos (Lin et al., 1996). Estes peptídeos são estabilizados pela ligação de 6 resíduos de cisteínas, formando 3 pontes dissulfeto, ligadas da seguinte maneira: C1-C5, C2-C4 e C3-C6.

As toxinas de canal de sódio do tipo 1 representam o tipo mais estudado de neurotoxinas de anêmonas do mar e algumas são empregadas como 
importantes ferramentas farmacológicas como, por exemplo, a ATX-II (Av2) de Anemonia sulcata $(A$. viridis). Estas toxinas se ligam à maioria dos canais presentes em humanos ( $\mathrm{Nav}_{v} 1.1-\mathrm{Na}$ 1.6), retardando a fase de inativação. Suas potências são maiores em canais do subtipo Nav1.1 e Nav1.2. As toxinas AFTII e Bclll, de Anthopleura fuscoviridis e Bunodosoma caissarum, respectivamente, também atuam em canais $\mathrm{Nav}$ de humanos, porém com menor potência (Oliveira et al., 2004).

Muitos estudos têm sido realizados a fim de elucidar o funcionamento dos canais $\mathrm{Na}_{\mathrm{v}}$. Com isso, alguns aminoácidos foram caracterizados como essenciais para atividade das neurotoxinas. Como exemplo, tem-se a flexibilidade da região conhecida como "Arg-Loop" nas posições 12-21 da toxina AP-B da Anthopleura xanthogrammica. Acredita-se que esta região seja essencial para a sua ligação aos canais Nav. A contribuição da (Arginina) R16 e R18 dentro do loop; e (Leucina) L22 e (Serina) S23 próximas a região $\mathrm{NH}_{2}{ }^{-}$ terminal podem contribuir muito para a afinidade da toxina.

Moran e colaboradores (2006), em seu estudo de mutagênese sítiodirigida e expressão recombinante de ATX-II (Av2) demonstraram a importância do envolvimento de alguns resíduos de aminoácidos aromáticos da ATX-II na potência e afinidade de sua ligação aos diferentes Nav, expressados em ovócitos de Xenopus laevis.

Deve-se notar que Oliveira e colaboradores (2004) também demonstraram a importância que alguns aminoácidos da ATX-II, AFT-II e Bclll têm no processo de ligação aos diferentes clones de $\mathrm{Nav}$ humanos e consequentemente nas diferenças de potência.

No entanto estas toxinas nativas foram testadas em canais $\mathrm{Na}_{v}$ clonados, expressados em células HEK 293, enquanto que Moran e colaboradores (2006), utilizaram toxinas recombinantes em canais transfectados em ovócitos de Xenopus laevis, o que pode gerar alguns resultados distintos devido aos diferentes sistemas de expressão. Desse modo, fica claro que discretas diferenças na sequência das toxinas podem levar a maiores ou menores afinidades a determinado canal (Honma \& Shiomi, 2006).

A partir de observações das sequências dessa família de toxinas, podese constatar uma Asparagina $(\mathrm{N})$ muito conservada na posição 16 das toxinas do Tipo 1 de canais de sódio, com exceção da Bglll de Bunodosoma 
granulifera e Cangitoxinas-II e III (CGTX-II e CGTX-III) de B. cangicum que possuem um ácido aspártico (N16D). Esta substituição é responsável por uma significativa perda na atividade da BgIII $\left(\mathrm{IC}_{50}=1,3 \mu \mathrm{M}\right)$ em canais de sódio de inseto do tipo para/tipE, quando comparada à $\mathrm{Bgll}\left(\mathrm{IC}_{50}=5,5 \mathrm{nM}\right)$ que possui a Asparagina nesta posição (Bosmans et al., 2002).

Apesar dessas diferenças, ambas toxinas possuem a mais alta eficácia em canais para/tipE de insetos quando comparados aos canais de mamíferos. Curiosamente, CGTX-II e CGTX-III também têm essa substituição N16D, mas esta posição crítica observada em Bgll e BgllI não é crucial para CGTX-II e III, sendo sua potência semelhante à Bclll de B. caissarum (Zaharenko et al., 2008b).

Oliveira e colaboradores (2006) verificaram que a toxina BcIV de $B$. caissarum, bem como Bgll e Bglll, exercem um claro efeito sobre o potencial de ação em preparações de nervos sensoriais amielínicos de apêndices locomotores de crustáceos, mas nenhuma ação na corrente de canais de células de mamíferos. Tal resultado possibilita inferir que estas toxinas foram selecionadas para atuar em pequenos crustáceos e, dada a estreita relação evolutiva entre crustáceos e insetos (subfilo Crustacea é parafilético em relação aos insetos), não é de se estranhar que toxinas de anêmonas do mar também possam afetar canais de sódio de insetos, constituindo, dessa maneira, importantes ferramentas para o desenvolvimento de novos inseticidas (Bosmans \& Tytgat, 2007).

\subsubsection{Toxinas de canal de sódio tipo 2 .}

Toxinas do tipo 2 são peptídeos que apresentam entre 47 e 49 aminoácidos, entre os quais, 6 resíduos são cisteínas. A estabilização da toxina é feita através de três pontes dissulfeto que se ligam da mesma forma que as toxinas do tipo 1. Convém notar que as massas moleculares destas toxinas variam entre 3 e $5 \mathrm{kDa}$, assim como as do tipo 1 e suas atividades biológicas em canais $\mathrm{Nav}$ são similares às do tipo 1. Este grupo é composto por 10 peptídeos pertencentes à família Stychodactilidae: Heteractis crispa $(\mathrm{Hm}-\mathrm{I}$ a $\mathrm{Hm}-\mathrm{V})$, Radianthus paumotensis (Rp-II, Rp-III), Stichodactyla gigantea (Gigantoxin-III), S. haddoni (SHTX-4) e S. helianthus (ShP-I). 


\subsubsection{Toxinas de canal de sódio tipo 3.}

Esta terceira família é composta por quatro peptídeos (Da-I e Da-II, da anêmona do mar Dofleina armata; Er-I da Entacmaea ramsayi; e PA-TX Entacmae actinostoloides), os quais possuem entre 30 e 32 aminoácidos, estabilizados por 8 resíduos de cisteína, que formam quatro pontes dissulfeto. Honma \& Shiomi (2006), sugerem excluir desta família, a toxina ATX-III devido à sua baixa homologia aos outros membros.

\subsubsection{Toxinas de canal de sódio tipo 4.}

Esta quarta família é formada pelas toxinas Calitoxinas 1 e 2 (CLX-1 e 2), obtidas da peçonha da anêmona do mar Calliactis parasitica. CLX-1 e CLX2 são peptídeos de 46 aminoácidos com seis resíduos de cisteína, diferindo pela substituição E6K. Entretanto, seus resíduos de aminoácidos são muito diferentes se comparados aos peptídeos das outras três famílias. Suas atividades biológicas em $\mathrm{Na}_{v}$ são, supostamente, similares às outras três famílias descritas acima (Spagnuolo et al., 1994).

\subsubsection{Superfície bioativa de toxinas de anêmonas do mar que} atuam em canal de sódio sensível à voltagem.

A primeira tentativa de se descobrir os resíduos com um papel funcional em uma toxina de anêmona do mar foi através de modificações químicas da Av2 (Barhanin et al., 1981). Esse estudo levantou o papel, na bioatividade, da Asp7, Asp9, Arg14 His32, His37, Lys35, Lys36, Lys-6 e do C-terminal. No entanto, uma vez que: (i) somente resíduos com carga foram modificados; (ii) em muitos casos, resíduos foram modificados simultaneamente; e (iii) o folding pode ter sido alterado, a significância desses resultados é questionável. Entretanto, mutagêneses da Av2 e outras toxinas do Tipo 1 forneceram um cenário diferente (Blumenthal \& Seibert, 2003; Moran et al., 2006).

A toxina do Tipo 1 de anêmonas do mar mais extensivamente estudada na última década foi a ApB (Gallagher \& Blumenthal, 1992). Com o advento da produção de recombinantes utilizando um sistema de expressão com 
Escherichia coli, Blumenthal e seu grupo puderam modificar resíduo por resíduo e avaliar o efeito dessas substituições na bioatividade. Todos os mutantes de ApB foram testados em canais cardíacos $\mathrm{rNav} 1.5$ e de cérebro rNav1.2a expressados em células HEK, ou linhagens de células de mamíferos que expressam constitutivamente esses canais dentre uma minoria de outros subtipos. Esses estudos sugeriram um papel na bioatividade para $\operatorname{Arg} 12$, Asn16, Leu18, Ser19, Trp33, Lys37 e Lys49. Desses resíduos, o de maior relevância para a bioatividade estava associado com o loop da Arg14 e com a substituição da Leu18, tendo um forte efeito na atividade da ApB (Blumenthal \& Seibert, 2003; Dias-Kadambi et al., 1996a; Dias-Kadambi et al., 1996b; Kelso et al., 1996; Khera \& Blumenthal, 1996; Seibert et al., 2004) (Figura 12).

Em contraste com esses resultados obtidos através de modificações químicas da Av2 (Barhanin et al., 1981), a análise mutagênica indicou que a Arg14, His34 e His39 não apresentam papel na bioatividade (Khera \& Blumenthal, 1994; Khera \& Blumenthal, 1996). A expressão de uma nova neurotoxina transcrita de uma Anthopleura (espécie desconhecida), cuja atividade foi testada através da força contrátil do átrio isolado de rato, sugere que os resíduos da posição 14, 22 e 25 podem ter papel na bioatividade (Wang et al., 2004). Porém, esses resultados aguardam futuras validações utilizandose ensaios eletrofisiológicos, de binding e toxicidade, que são mais comuns em análises de toxinas (Blumenthal \& Seibert, 2003; Moran et al., 2006; Moran \& Gurevitz, 2006).

A expressão funcional da toxina Av2 possibilitou um minucioso scaning de alanina e elucidação de sua superfície bioativa para insetos (Moran et al., 2006). A análise de todos os mutantes através de toxicidade em larva de mosca varejeira e ensaios de binding em membranas neuronais de barata indicaram o papel funcional para a Val2, Leu5, Asn16, Leu18 e lle41 (Figura 12). Além disso, análises eletrofisiológicas desses mutantes contra hNav1.5, indicam que a superfície bioativa para canais de mamíferos é similar a de canais de insetos com exceção da Ser19, cuja substituição afetou somente a atividade em um único canal cardíaco.

As toxinas Av2 e ApB são 79\% idênticas quanto aos seus aminoácidos e, excluindo a Arg12 e Lys49, todos os outros resíduos que demonstram serem importantes em Av2 estão presentes em ApB. Porém, uma maior variação 
entre essas toxinas é o papel funcional proposto para o Trp33 e Lys37 em ApB, considerando que a substituição de seus Trp31 e Lys35 equivalentes em Av2 não teve efeito na atividade inseticida, mas afetou ligeiramente a atividade em Nav1.5 (Moran et al., 2006). Além disso, dos quatros resíduos alifáticos funcionais na superfície da Av2, somente a Leu-18 foi atribuída à superfície bioativa antimamífero da ApB (Dias-Kadambi et al., 1996b).

Estas diferenças sugerem que, apesar de alguns pontos comuns na superfície bioativa da Av2 e ApB, as duas toxinas devem interagir de forma diferente com o receptor do sítio-3 em Navs de insetos e mamíferos. Essa suposição é corroborada por achados de Benzinger e colaboradores (1997), que sugeriram diferenças no sítio de ligação da $A p A$ e $A p B$ em músculo esquelético de rato e Navs cardíacos.

Mutagênese dos resíduos de glicina abrangendo o loop flexível da Arg14 alterou severamente a capacidade da ApB e Av2 de afetar Navs (Moran et al., 2006; Seibert et al., 2003). Com base nesses resultados e com o fato de a glicina normalmente ser encontrada em sequências de proteínas em posições em que possa aumentar a flexibilidade estrutural, foi proposto que a flexibilidade do loop da Arg14 é uma característica importante para a interação da toxina com o sítio receptor do canal. Outro resíduo cuja substituição por alanina afeta a ação da toxina é a conservada Asp9 (Khera \& Blumenthal, 1996; Moran et al., 2006). Como a substituição D9N teve somente um pequeno efeito sobre a toxicidade, o grupo carboxil da Asp9 não é crítico para a atividade da Av2 e ApB. Como foi inferido a partir da estrutura determinada por RMN (Ressonância Magnética Nuclear) da ApA e ApB, existe uma ligação de hidrogênio entre o grupo carboxil na cadeia lateral da Asp9 e amina da Cys6 (Monks et al., 1995; Pallaghy et al., 1995). Teoricamente essa ponte pode ser mantida quando o aspartato é substituído por asparagina.

Khera \& Blumenthal (1996), reportaram que a Asp9 é crítica para proporcionar o folding do recombinante ApB com base no relevante declínio na produção quando mutado nessa posição. Contudo, o mesmo fenômeno não foi observado em mutantes Asp9 de Av2 (Moran et al., 2006), sugerindo que o papel da ligação de hidrogênio formada pela carbonila da Asp9 com a Cys6 é limitar a livre inclinação do loop da Arg14. Na hipótese de que a ligação de toxinas de anêmonas do mar ao receptor do sítio-3 inclua uma etapa de ajuste 
induzido (Koshland, 1958), a qual envolve o loop da Arg14, é possível que sua flexibilidade permita a adoção de uma conformação necessária para a ligação. No entanto, não se pode excluir que a carbonila do Asp9 simplesmente interage com o sítio receptor de Nav.

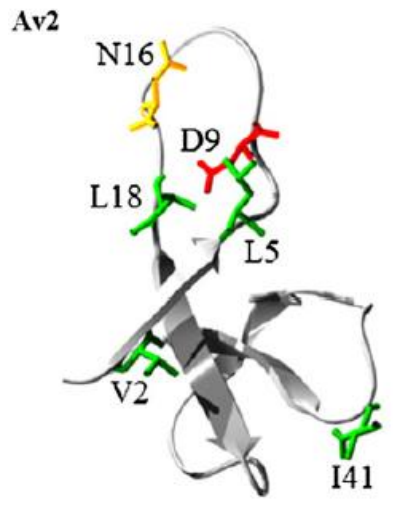

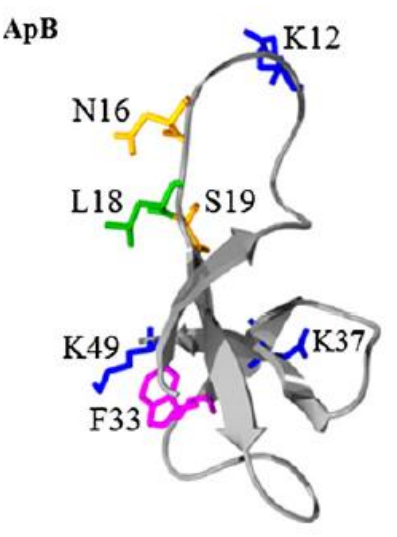

$10 \AA$

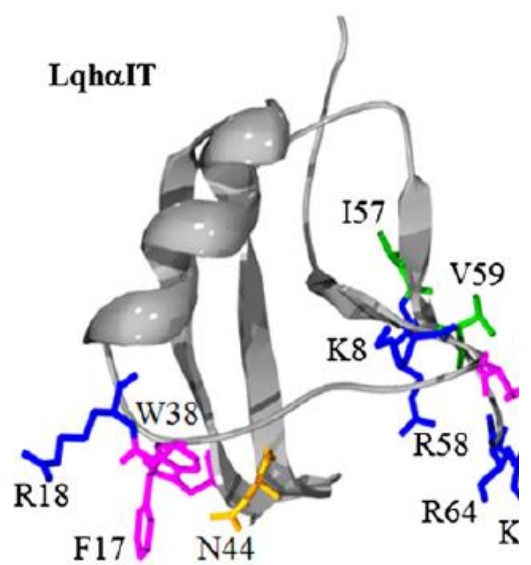

F17 N44

Figura 12 - Comparação da superfície bioativa de toxinas que ligam ao sítio 3. Os resíduos que constituem a superfície "inseticida" de escorpião $\alpha$-toxina LqhalT (Karbat et al, 2004), a toxina de anêmona do mar do tipo 1 Av2 (Moran et al, 2006), assim como os que compõem a superfície bioativa para $\mathrm{Na}_{\mathrm{v}} \mathrm{s}$ cardíacos da toxina de anêmona do mar do tipo 1 ApB (Blumenthal \& Seibert, 2003; Seibert et al, 2004) estão representadas por sticks das cadeias laterais e por ribbon da estrutura do $\mathrm{C} \alpha$. As entradas para do PDB para as estruturas da LqhalT e ApB são, respectivamente, 1LQI e 1APF. Aminoácidos aromáticos estão representados em rosa; os alifáticos em verde; polares em laranja; positivos em azul e negativos em vermelho. Figura modificada de Moran e colaboradores (2009).

\subsection{Canais para sódio sensíveis a voltagem}

A permeabilidade dos canais voltagem-dependentes de sódio a íons sódio é um evento que depende da voltagem e do tempo. Após a despolarização da membrana, o canal $\mathrm{Na}_{v}$ é ativado e passa do estado fechado (repouso) para o estado aberto. Poucos milissegundos após a ativação, a permeabilidade aos íons $\mathrm{Na}^{+}$retorna espontaneamente ao nível de repouso, pois o canal passa para o estado inativado (funcionalmente fechado) (Figura 13). Quando, subsequentemente, a membrana repolariza, o canal retorna ao estado fechado. Um canal inativado é refratário a despolarização, o que significa que ele deve retornar para o estado fechado por repolarização ("recuperação" da inativação) antes de se tornar suscetível a uma nova ativação (Hille, 2001). Em alguns neurônios, no entanto, canais de sódio transitam abertos durante a recuperação da inativação, dando origem a 
"correntes ressurgentes" após a membrana ser repolarizada (Raman \& Bean, 2001).

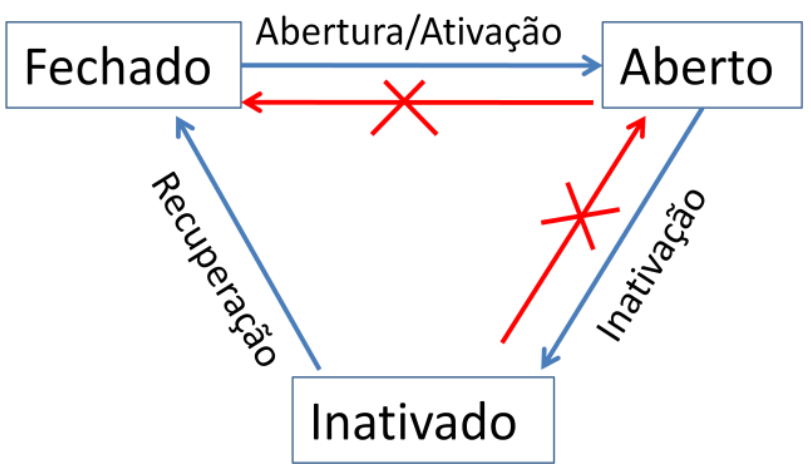

Figura 13 - Representação dos estados de um canal voltagem-dependente de sódio. As setas representam a transição de um estado para outro. As setas em vermelho indicam que não ocorre a passagem de um estado para o outro.

O canal Nav é uma glicoproteina complexa, constituída de uma subunidade- $\alpha$ de 220-260 kDa e associada com uma ou duas subunidades- $\beta$ $(\beta 1-\beta 4)$ de $30-40 \mathrm{kDa}$ (Yu \& Catterall, 2003) (ver Figura 14). Somente a expressão da subunidade- $\alpha$ formadora de poro é suficiente para construir um canal $\mathrm{Na}_{v}$ funcional, considerando que a co-expressão com subunidades- $\beta$ modula a cinética e dependência de voltagem do gating do canal (ou seja, abertura e fechamento do canal), e influencia na localização do canal e adesão celular (Goldin et al., 1986; Isom et al., 1992; Noda et al., 1986; Patton et al., 1994; Schreibmayer et al., 1994). As subunidades- $\beta$ são compostas de um único segmento transmembrana com um pequeno C-terminal intracelular e um extenso domínio N-terminal extracelular, que é homólogo, quanto a sua estrutura, com diversos fold de cadeias de imunoglobulinas.

A subunidade- $\alpha$ é composta por quatro domínios homólogos (DI-IV), mas não idênticos, conectados por loops citoplasmáticos. Os quatro domínios se estruturam juntos em sentido horário, onde DI e DIV estão posicionados próximos, delimitando o caminho que conduz o íon (Li et al., 2001). Cada domínio consiste de seis segmentos transmembrana (S1-S6).

O quarto segmento (S4) de cada domínio compreende o sensor de voltagem. Este é constituído por aminoácidos com carga positiva (lisina, arginina e histidina) em toda terceira posição do segmento S4 (Stuhmer et al., 1989). No estado de repouso, o campo elétrico negativo interno transmembrânico exerce uma forte força junto aos resíduos positivos, puxando 
o sensor de voltagem S4 para uma posição "engatilhada". Os modelos "helical screw" ou "sliding helix" têm como base o fato de que os resíduos de aminoácidos carregados no sensor de voltagem são estabilizados no campo transmembrana, devido à formação de pares iônicos com resíduos negativamente carregados em segmentos transmembrana adjacentes (Guy \& Seetharamulu, 1986). A despolarização da membrana libera o sensor de voltagem a se movimentar para fora ao longo de um caminho em espiral, mudando a conformação do canal e, assim abrindo o caminho condutor do íon (Armstrong, 1981; Hirschberg et al., 1995; Kontis et al., 1997; Yang et al., 1996). Até agora, o exato mecanismo molecular do processo de ativação não é totalmente conhecido (Elinder et al., 2007).

Os segmentos transmembrana S5 e S6 de todos os quatro domínios (DI-DIV) circundam o poro do canal, enquanto que o loop extracelular entre S5 e S6 (chamado de "loop P") "mergulha" de volta para a região transmembrana da proteína para formar uma "boca" estreita externa ao poro (Catterall, 2000). Estes loops $\mathrm{P}$ reentrantes na membrana contêm aminoácidos altamente conservados em posições análogas em todos os quatro domínios, espacialmente arranjados em um anel interno "DEKA" (formado por resíduos Asp, Glu, Lys e Ala dos domínios DI, DII, DIII e DIV, respectivamente) e um anel externo "EEDD” (formado por resíduos Glu, Glu, Asp e Asp dos domínios DI, DII, DIII e DIV, respectivamente) (ver Figura 14). Esses resíduos constituem a chamada "sequência de assinatura", localizada na parte mais estreita do poro, formando o filtro seletivo, responsável pela alta seletividade do canal para íons $\mathrm{Na}^{+}$(Heinemann et al., 1992). 


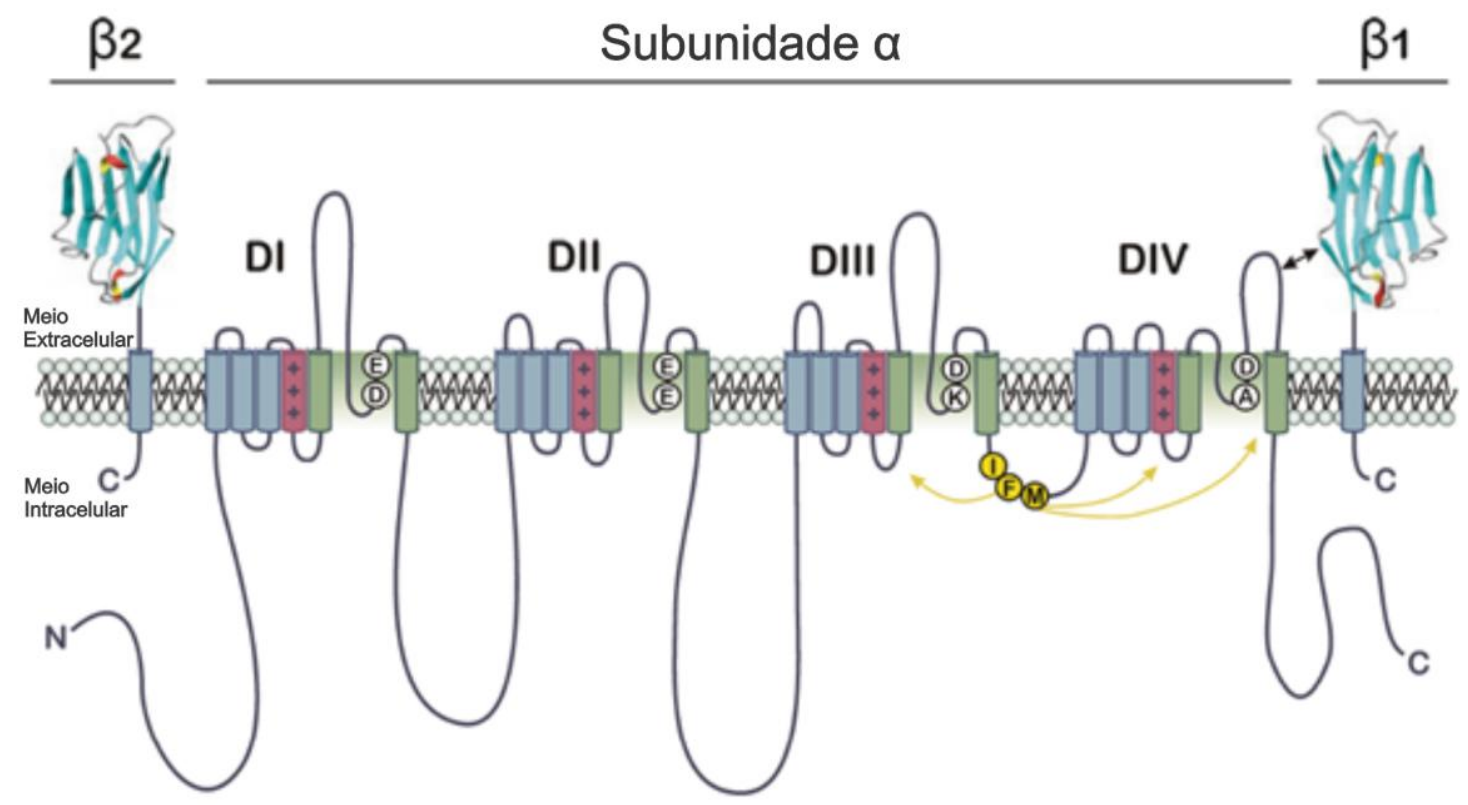

Figura 14 - Representação esquemática da topologia da membrana de canais $\mathrm{Na}_{\mathrm{v}}$. A subunidade- $\alpha$ (DI-IV) formadora de poro está representada no centro, flanqueada por duas subunidades- $\beta$ ( $\beta_{1}$ e $\beta_{2}$ ) auxiliares. Os segmentos S1-S3 estão coloridos em vermelho; S5 e S6 estão coloridos em verde. Os resíduos DEKA e EEDD no linker S5-S6, que formam os anéis interno e externo do filtro seletivo, estão representados por círculos brancos. Os resíduos IFM no gate de inativação estão representados por círculos amarelos; os possíveis locais que formam o receptor do gate de inativação estão indicados por setas amarelas. Adaptado de King e colaboradores (2008a) e Yu \& Catterall (2003).

Outra característica importante dos canais $\mathrm{Na}_{\mathrm{v}}$, além da ativação voltagem-dependente e uma alta seletividade por íons $\mathrm{Na}^{+}$, é a rápida e espontânea inativação após a ativação. Essa é uma característica essencial para o funcionamento do canal $\mathrm{Nav}$, por que uma abertura persistente do canal pode despolarizar células excitáveis, levando a potenciais de ação prolongados e, caso ocorrera influxo de $\mathrm{Na}^{+}$suficiente, tal pode resultar em uma prolongada inexcitabilidade, uma vez que uma despolarização persistente pode levar ao estado estacionário inativado dos canais Nav (Bezanilla \& Armstrong, 1977). Pelo menos dois modelos de inativação de canais $\mathrm{Na}_{v}$ vêm sendo descritos: um de inativação rápida (em uma escala de tempo de milissegundos) e outro de inativação lenta (em uma escala de tempo de segundos até minutos) (Denac et al., 2000).

O loop intracelular que conecta DIII e DIV contém uma tríade hidrofóbica conservada composta pelos resíduos lle, Phe e Met (chamado "motivo IFM"), e acredita-se que esse funcione como gate para inativação, mediando à inativação rápida (Smith \& Goldin, 1997; West et al., 1992). Os resíduos Gly e Pro vizinhos ao motivo IFM podem servir como "dobradiças" para permitir o 
fechamento do gate de inativação como uma tampa articulada ocluindo a região do poro do canal na porção intracelular (Figura 15) (Kellenberger et al., 1997). O receptor para esse gate de inativação é formado por múltiplos resíduos hidrofóbicos localizados próximo ao poro, localizados no loop intracelular S4-5 dos domínios DIII e DIV, e no final da porção intracelular do DIVS6 (ver Figura 14) (Catterall, 2000). Além disso, dados recentes indicam um papel significativo para a região do C-terminal do canal $\mathrm{Na}_{\vee}$ na inativação rápida, provavelmente através de uma interação carga-dependente com o gate de inativação (Nguyen \& Goldin, 2010).

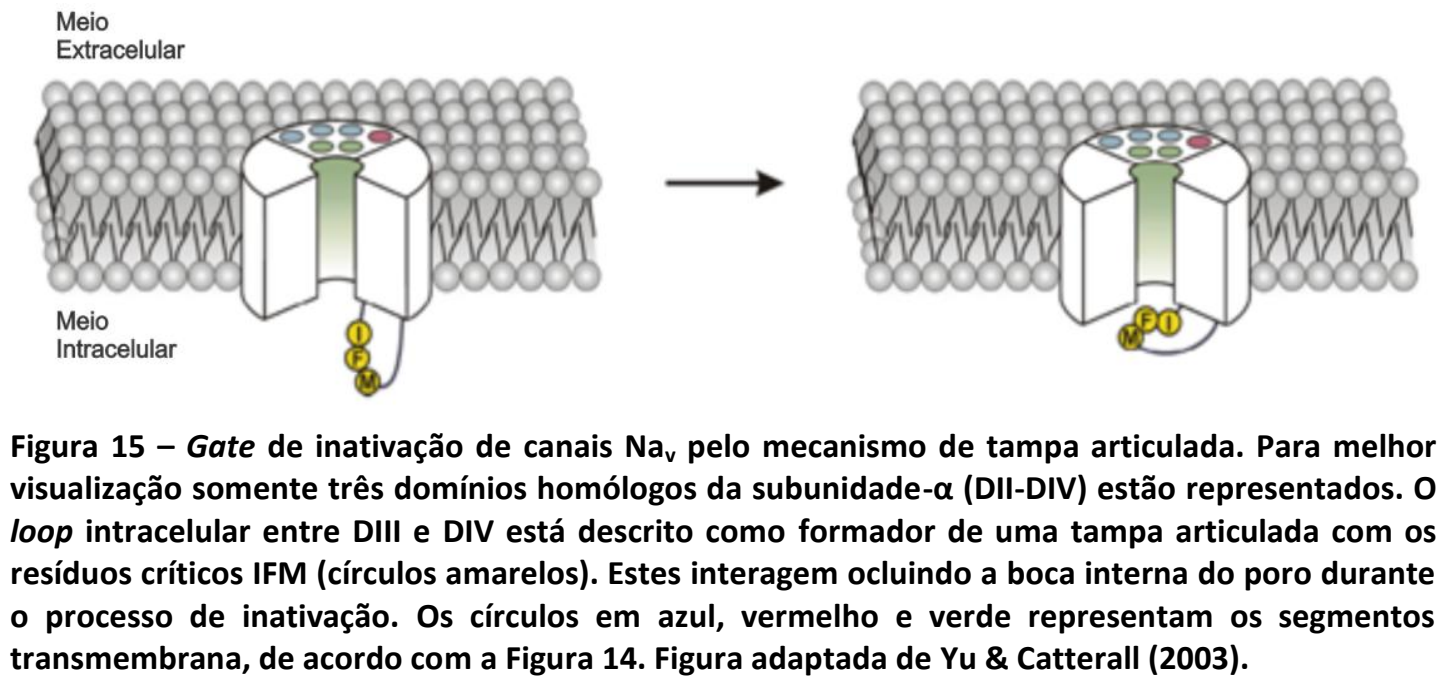

A inativação rápida do canal $\mathrm{Na}_{\mathrm{v}}$ resulta de sua dependência de voltagem do acoplamento para o processo de ativação (Armstrong, 1981; Catterall, 2000). Acredita-se que o movimento para fora do segmento DIVS4 durante a ativação inicie a inativação rápida por fechamento do gate de inativação (Kuhn \& Greeff, 1999). No entanto, o exato mecanismo molecular de acoplamento do movimento do S4 no DIV para a oclusão do gate de inativação continua sob investigação.

\subsubsection{Canais $\mathrm{Na}_{v}$ de mamíferos}

Durante as últimas décadas uma variedade de subunidades e subtipos de Navs de mamíferos foram identificados e caracterizados por meio de clonagem molecular, purificação bioquímica e registros eletrofisiológicos. Até o momento, nove diferentes genes de mamíferos que codificam nove diferentes 
subtipos de canais $\mathrm{Na}_{v}$ funcionais $\left(\mathrm{Na}_{v} 1.1-9\right)$ foram clonados e caracterizados do ponto de vista funcional (Figura 16) (os subtipos Nav1.1-8 foram expressados com sucesso em sistema heterólogo) (Catterall et al., 2005; Yu \& Catterall, 2003).

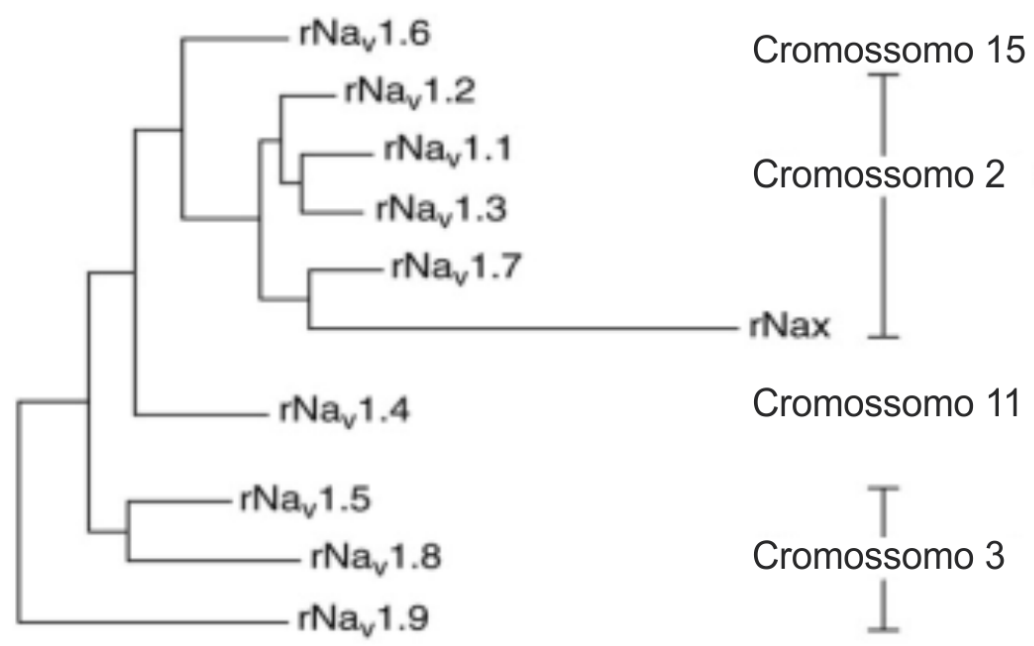

Figura 16 - Árvore filogenética da subunidade- $\alpha$ de canal $\mathrm{Na}_{v}$ de mamífero. As sequências de aminoácidos para $\mathrm{Na}_{v}$ de ratos foram alinhadas utilizando ClustalW e a árvore foi construída utilizando PAUP. Os cromossomos humanos, nos quais o ortólogo humano correspondente de cada gene de rato é encontrado estão representados no lado direito. Figura modificada de Catterall e colaborradores (2005).

Esses subtipos de $\mathrm{Na}_{v}$ de mamíferos compartilham uma homologia considerável (49-87\% de identidade dos aminoácidos entre os subtipos de $\mathrm{Na}_{\mathrm{v}}$ de humanos). Apesar de sua significativa similaridade de sequência, subtipos de canais $\mathrm{Nav}$ podem diferir muito em suas propriedades biofísicas, incluindo cinética e dependência de voltagem do gating. Além disso, os subtipos de canais $\mathrm{Na}_{v}$ são distribuídos diferencialmente, ainda que não exclusivamente, por todo o corpo em vários tecidos eletricamente excitáveis (Tabela 2). 
Tabela 2- Subtipos de canais $\mathrm{Na}_{\mathrm{v}} 1$ de mamífero. S, sensível em concentração na faixa de nanomolar de tetrodotoxina (TTX); R, resistente acima de concentrações na faixa de micromolar de TTX; CNS, sistema nervoso central; PNS, sistema nervoso periférico. Figura modificada de Goldin, 2001.

\begin{tabular}{|c|c|c|c|c|}
\hline $\begin{array}{l}\text { Nome } \\
\text { Sistemático }\end{array}$ & $\begin{array}{l}\text { Nome } \\
\text { Trivial }\end{array}$ & Gene & TTX-S/-R & Localização \\
\hline $\mathrm{Na}_{\vee} 1.1$ & Type 1 & SCN1A & $\mathrm{S}$ & CNS, PNS \\
\hline $\mathrm{Na}_{\mathrm{v}} 1.2$ & Type 2 & SCN2A1 & S & CNS, níveis baixos no PNS \\
\hline $\mathrm{Na}_{\vee} 1.3$ & Type 3 & SCN3A & S & CNS embrionário, DRG lesionado \\
\hline $\mathrm{Na}_{\mathrm{v}} 1.4$ & Skm1, $\mu 1$ & SCN4A & S & $\begin{array}{l}\text { Musculatura esquelética de adultos, } \\
\text { níveis baixos em musculatura esquelética } \\
\text { embrionária }\end{array}$ \\
\hline $\mathrm{Na}_{\vee} 1.5$ & $\mathrm{H} 1, \mathrm{Skm} 2$ & SCN5A & $\mathrm{R}$ & $\begin{array}{l}\text { Musculatura esquelética cardíaca e embrionária, } \\
\text { CNS embrionária }\end{array}$ \\
\hline $\mathrm{Na}_{\vee} 1.6$ & Pn4, Cerlll & SCN8A & S & CNS, níveis baixos em PNS \\
\hline $\mathrm{Na}_{\mathrm{v}} 1.7$ & $\begin{array}{l}\text { Pn1, hNe, } \\
\text { NaS }\end{array}$ & SCN9A & S & PNS, níveis baixos em CNS \\
\hline $\mathrm{Na}_{\mathrm{v}} 1.8$ & PN3,SNS & SCN10A & $\mathrm{R}$ & PNS \\
\hline $\mathrm{Na}_{\vee} 1.9$ & $\begin{array}{l}\text { PN5, NaN, } \\
\text { SNS-2 }\end{array}$ & SCN11A & $\mathrm{R}$ & PNS, níveis baixos em CNS \\
\hline
\end{tabular}

Os subtipos $\mathrm{Na}_{v} 1.1, \mathrm{Na}_{v} 1.2, \mathrm{Na}_{v} 1.3$ e $\mathrm{Na}_{v} 1.6$ são principalmente expressados em neurônios do sistema nervoso central (SNC) (Goldin, 1999). Curiosamente, diferentes níveis de expressão de subtipos são observados durante o desenvolvimento: o nível de expressão do Nav1.3 em roedores é altos durante a vida embrionária e diminuem após o nascimento, enquanto que Nav1.1, Nav1.2 e Nav1.6 apresentam maior abundância no SNC (Beckh et al., 1989).

Os subtipos $\mathrm{Na}_{v} 1.7, \mathrm{Na}_{\vee} 1.8$ e $\mathrm{Na}_{v} 1.9$ são subtipos predominantes no sistema nervoso periférico (SNP), com Nav1.8 e Nav1.9 expressados exclusivamente em neurônios sensoriais. Nav1.1 e Nav1.6 também podem ser encontrados no SNP, embora em níveis mais baixos. Dois subtipos estão presentes em tecido muscular: Nav1.4 em músculo esquelético (e níveis baixos em músculo esquelético embrionário) e Nav1.5 em musculatura cardíaca e embrionária (Goldin, 2001). Embora Nav1.5 tenha sido considerado por muito tempo um subtipo específico de tecido muscular, foi também encontrado em SNC (Hartmann et al., 1999; Wu et al., 2002). Evidentemente, a expressão diferencial dos subtipos de $\mathrm{Na}_{v}$ desempenha um papel importante na 
plasticidade do sistema nervoso e a diversidade das propriedades elétricas de tecidos excitáveis.

Além dos subtipos de Nav1, proteínas relacionadas a canais de sódiolike ( $\mathrm{Nax}$ ) ( 50\% de similaridade com a sequência da família de $\mathrm{Nav} 1$ ) foram clonadas de camundongos, ratos e humanos (Catterall et al., 2005). Acreditouse, originalmente, que esses canais representavam uma nova subfamília de canais $\mathrm{Nav}_{v}$ (George et al., 1992), mas esses nunca foram expressados em sistema heterólogo. A sequência de aminoácidos na região crítica para o funcionamento do $\mathrm{Nav}$, como o sensor de voltagem, o gate e a inativação são poucos conservados em canais $\mathrm{Nax}_{\mathrm{x}}$, o que leva a acreditar que esses canais não são voltagem-dependetes. Watanabe e colaboradores (2000) sugerem que $\mathrm{Nax}$ representa um canal de $\mathrm{Na}^{+}$dependente de concentração que regula a absorção de sal no SNC.

Por fim, canais epiteliais de sódio $(\mathrm{ENaC})$ são canais de sódio não dependentes de voltagem e, estruturalmente não se relacionam aos canais Nav1 (Yu \& Catterall, 2003). Esses canais foram identificados como um determinante crítico para o transporte de íons $\mathrm{Na}^{+}$e água em vários tecidos, incluindo os epitélios renal e pulmonar (Gaillard et al., 2010; Hamm et al., 2010).

\subsubsection{Canais $\mathrm{Na}_{v}$ de insetos versus mamíferos}

$\mathrm{Na}$ década de 1980, o primeiro gene putativo de inseto que codifica a subunidade- $\alpha$ de um canal $\mathrm{Na}_{\mathrm{v}}$ foi identificada em mosca Drosophila melanogaster (Loughney et al., 1989). O gene (designado para) foi isolado utilizando paralisia sensível à temperatura, fenótipo exibido por alelos mutantes no cromossomo X de Drosophila. Quase uma década depois, a expressão em sistema heterólogo da proteína codificada de para (DmNav1) em ovócito de Xenopus confirmou que para codifica um canal $\mathrm{Na}_{v}$ funcional (Feng et al., 1995; Warmke et al., 1997). Além do para, outro gene putativo de canal de Nav de inseto $(D S C 1)$ e seus ortólogos (BSC1) foram identificados em $D$. melanogaster e na barata alemã Blatella germanica (Liu et al., 2001; Salkoff et al., 1987a; Salkoff et al., 1987b). 
No entanto, depois de duas décadas de especulação, recentemente foi descoberto que BSC1 codifica um novo canal seletivo de cálcio (Zhou et al., 2004). De acordo com esta constatação, a sequência assinatura de BSC1 e DSC1 (DEEA) foge da sequência assinatura DEKA, encontrada em todos os canais $\mathrm{Na}_{\mathrm{v}}$, incluindo para, e se assemelha à sequência assinatura de canais Cav1 (EEEE) (Figura 17). Canais BSC1 ou DSC1-type com essa substituição K-E são, portanto, prováveis canais seletivos de cálcio em vez de canais $\mathrm{Na}_{\mathrm{v}}$ (King et al., 2008a). Exceto pela modesta homologia com DSC1, para não compartilha similaridade com outros genes no genoma de $D$. melanogaster ou de outra espécie de insetos. Por isso, atualmente parece que para é o único gene que codifica um canal Nav em insetos (King et al., 2008a).

DI

\begin{tabular}{|c|c|c|}
\hline & DI & DII \\
\hline$n \mathrm{Na}_{\mathrm{v}} 1$ & EDLYQ & MV \\
\hline & YQ & F \\
\hline $\mathrm{MdNa}_{\mathrm{v}} 1$ & YQ & \\
\hline $\mathrm{rNa}_{\mathrm{v}} 1.1$ & YQ & $1 \mathrm{Ih}$ \\
\hline $\mathrm{Na}_{\mathrm{v}} 1.2$ & $Y Q$ & WW \\
\hline $\mathrm{rNa}_{\mathrm{v}} 1.3$ & IODYW. & R \\
\hline $\mathrm{rNa}_{\mathrm{v}} 1.4$ & $\mathrm{FQ}$ & \\
\hline $\mathrm{rNa}$ & $2 \mathrm{HDCW}$ & $1 \mathrm{WW}$ \\
\hline $\mathrm{rNa}_{\mathrm{v}} 1.6$ & MTODYWE & AW \\
\hline 1.7 & TODYW & IW \\
\hline $\mathrm{rNa}$ & $\mathrm{YQ}$ & VI \\
\hline $\mathrm{rNa}_{v} 1.9$ & MTODSWERLYR & WIENMW \\
\hline $\mathrm{rNa}_{\mathrm{x}}$ & RLMTODYPELLYH & WIENLW \\
\hline & QLITLDYWENVYN & WTEPLW \\
\hline DSc1 & ZWENVYN & IEPLW \\
\hline
\end{tabular}

DIII

\begin{tabular}{|c|c|}
\hline 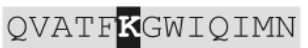 & QMs \\
\hline & VL \\
\hline JIQIMN & Q \\
\hline VMD IMY & $\angle L A$ \\
\hline & 0. \\
\hline MY & LLA \\
\hline MY & uL \\
\hline $1 Y$ & $\mathrm{LS}$ \\
\hline [MY & DGLLL \\
\hline FKGWMD IMY & WDGLTIA \\
\hline 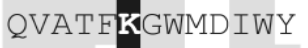 & LLS \\
\hline YKGWLEIMN & AGGDTLLN \\
\hline YNGWIS IMN & WDTMLD \\
\hline & GWNDVLG \\
\hline & \\
\hline
\end{tabular}

Figura 17 - Alinhamento das sequências da região do poro de canais de sódio de insetos e mamíferos e canais de cálcio de inseto BSC1/DSC1. O alinhamento mostra a sequência de aminoácidos do loop $\mathrm{P}$ dos quatro domínios (DI-IV) de $\mathrm{Na}_{\mathrm{v}}$ de canais $\mathrm{Na}_{\mathrm{v}}$ para-type de mosca de fruta, barata alemã e mosca caseira (topo), canais $\mathrm{Na}_{\mathrm{v}} 1$ de rato (meio) e canais BSC1/DSC1 de mosca da fruta e barata alemã (inferior). Resíduos de aminoácidos idênticos com aqueles de $\mathrm{DmNa}_{v} 1$ estão representados com o fundo cinza claro. Resíduos da sequência assinatura (DEKA em canais $\mathrm{Na}_{\mathrm{v}}$ ) estão representados com o fundo preto. Resíduos Glu do DIII de canais BSC1/DSC1tyoe estão representados com o fundo cinza escuro. Resíduos importantes para resistência a TTX (Cys e Ser) estão em negrito. Figura retirada de King e colaboradores (2008a).

Em canais $\mathrm{Na}_{v}$ de insetos, acredita-se que se tenha alcançado uma diversidade funcional principalmente por splicing alternativo e edição do RNA do gene para, considerando que no caso de seus homólogos de mamíferos, nove diferentes genes codificam diferentes subtipos funcionais de canais $\mathrm{Na}_{v}$ (Song et al., 2004; Tan et al., 2002a). No total, até hoje, nove locais de splicing alternativo bem conservados foram identificados em genes para, o que poderia levar a mais de cem diferentes canais $\mathrm{Na}_{v}$ funcionais (Lin et al., 2009). Os canais $\mathrm{Na}_{v}$ para-type são extremamente conservados em diferentes espécies 
de insetos (87-98\% identity), em relação aos canais Nav de mamíferos (King et al., 2008a). De um modo geral, a estrutura de canais $\mathrm{Na}_{v}$ de insetos é muito semelhante à de mamíferos na maioria das regiões importantes, do ponto de vista funcional, como a sequência assinatura, sensor de voltagem e região do poro são extremamente conservadas (Figura 17). Entretanto, ocorrem algumas diferenças na estrutura primária, por exemplo, no motivo IFM localizado no gate de inativação, que é alterado para MFM em canais $\mathrm{Na}_{v}$ de insetos (Davies et al., 2007). É importante ressaltar que, canais $\mathrm{Na}_{v}$ de mamíferos e insetos podem ser distinguidos farmacologicamente utilizando-se agentes inseticidas empregados na agricultura, como dichlorodiphenyltrichloroethano (DDT) ou piretróides e um diverso arsenal de toxinas inseto-seletivas provenientes de animais peçonhentos como aranhas, anêmonas do mar e escorpiões (Dong, 2007; King et al., 2008a). O canal de inseto DmNav1 é 1000 vezes mais sensível para piretróides deltametrina do que o canal rNav1.2 de mamíferos (Vais et al., 2000). Um único resíduo de aminoácido parece ser, pelo menos em parte, responsável por essa alta seletividade para inseto. A substituição da Ile874 no loop intracelular IIS4-S5 do canal rNav1.2 por um resíduo Met resulta em um aumento de 100 vezes na sensibilidade para piretróide (Peng et al., 2009; Vais et al., 2000). Não é, portanto, nenhuma conhecidência que o resíduo correspondente em canais $\mathrm{Na}_{v}$ de insetos, Met918, demonstra ter um papel importante na resistência a piretróides em insetos (Williamson et al., 1996).

Atualmente, três canais $\mathrm{Na}_{v}$ para-type de insetos foram expressados em sistema heterólogo e caracterizados em ovócitos de Xenopus: DmNav1 de mosca da fruta (Warmke et al., 1997), MdNav1 de mosca caseira ( $M$. domestica) (Smith et al., 1997) e BgNav1 de barata alemã (Tan et al., 2002b).

Homólogos das subunidades- $\beta$ de mamíferos aparentam estar ausentes em insetos, e nos leva a especular que estas subunidades auxiliares possam ter surgido na evolução, após a divergência dos deuterostômios (culminando com os vertebrados) e protostômios (culminando com os artrópodes, incluindo insetos) (Littleton \& Ganetzky, 2000). Porém, a proteína tipE (temperatureinduced paralytic E), produto do locus Drosophila, foi identificada por desempenhar um papel funcionalmente similar ao das subunidades $\beta$ de mamíferos. Essa proteína de $65 \mathrm{kDa}$ com dois segmentos transmembrana 
(tipE) modula a cinética do DmNav1 e aumenta o tráfico do canal desde o retículo endoplasmático até a membrana (Feng et al., 1995; Moore et al., 2001; Tseng et al., 2007). TipE também aumenta os níveis de expressão de BgNav1 em ovócitos de Xenopus (Tan et al., 2002b). Além disso, quatro tipE homólogos (TEH1-4) foram encontrados em $D$. melanogaster. Os três primeiros (TEH1-3) têm efeitos similares aos de canais para-type nos níveis de expressão e cinética (Derst et al., 2006). Finalmente, uma proteína ortóloga com propriedades similares às da tipE foi isolada e caracterizada a partir de mosca doméstica (Lee et al., 2000).

\subsection{Novas classes de toxinas de anêmonas do mar}

Muitas toxinas foram isoladas, mas suas caracterizações biológicas são restritas. Os ensaios mais comumente realizados são injeções in vivo em caranguejos, como nos casos das toxinas Acrorhagin-I e II, Gigantoxin-I, AETXII e III e também a Am-I. No caso da SHTX-1 e 2, também foi observado um efeito bloqueador de canais de potássio em sinaptosomas de cérebro de ratos (Honma et al., 2008). A toxina Acrorhagina-I não possui homologia com nenhum peptídeo a partir de pesquisas em bancos de dados. Já a Acrorhagin-II e lla possuem similaridade parcial com bloqueadores de canal de cálcio de aranhas e moluscos do gênero Conus (Honma et al., 2005b). As SHTX-1 e 2 apresentam efeitos quando injetadas em caranguejos, mas experimentos demonstraram que esses peptídeos podem competir com ${ }^{125} \mathrm{I}$-dendrotoxin, provavelmente atuando como um bloqueador de canal de potássio. Essas toxinas apresentam similaridade parcial com a toxina Am-I e acredita-se que essas pertençam a um novo grupo de peptídeos de canal de potássio.

Um novo grupo de toxinas é representado pela Gigantoxin-I e SHTX-5. Ambas são muito similares a fatores de crescimento da epiderme de mamíferos (EGFs). Foi demonstrado que a Gigantoxin-I se liga a receptores EGF de humanos e induz paralisia quando injetada em caranguejos, mas não apresentou efeito em camundongos, sugerindo que essa toxina seja seletiva a invertebrados (Shiomi et al., 2003). Já a SHTX-5 foi apenas identificada através de clones de CDNA, mas sua atividade biológica ainda não foi determinada (Honma et al., 2008). 
Outro grupo de novas toxinas é representado pelos peptídeos APETx2 e BclV, isolados da Anthopleura elegantissima e Bunodosoma caissarum, respectivamente. A APETx2, como mencionado anteriormente, é um bloqueador específico de canais ASIC 3 (Diochot et al., 2004). A BcIV induz um efeito paralisante quando injetada in vivo em caranguejos e, quando aplicada na preparação de nervo de apêndice locomotor de caranguejo, aparentemente atua retardando a inativação de canais de $\mathrm{Na}^{+}$. De outro lado, a BcIV é inativa em canais de $\mathrm{Na}^{+}$de mamíferos (Oliveira et al., 2006). Ambos os peptídeos são muitos similares à APETx1, um modulador de canal de potássio $h E R G$. Esses resultados sugerem que o grupo dos peptídeos APETx- e BcIV-símile podem pertencer a uma nova família de toxinas de anêmonas do mar, que podem eventualmente possuir alvos muito divergentes.

Zaharenko e colaboradores (2008a) isolaram e caracterizaram a fração neurotóxica (FrlII) da peçonha da anêmona do mar Bunodosoma cangicum. As massas moleculares dos principais compostos purificados foram checadas e identificou-se 81 componentes com massas entre aproximadamente 250 até $6000 \mathrm{Da}$. Foram descobertos nove novos peptídeos. Destes, três são peptídeos de aproximadamente $4500 \mathrm{Da}$, pertencentes à classe de toxinas como BcIV, BDS-I, BDS-II, APETx1, APETx2 e Am-II. Outros três representam um novo grupo de toxinas ( $3200 \mathrm{Da})$ e as três moléculas restantes pertencem ao grupo de neurotoxinas de canal de sódio do tipo 1. Quando o potencial de ação foi testado em nervo de crustáceo, um dos peptídeos similares a BcIV e APETx exibiu uma ação similar às toxinas de canal de sódio do tipo 1 , sugerindo um mesmo alvo.Porém, um outro novo peptídeo de 3176 Da mostrou atividade similar com bloqueadores de canal de potássio.

Em geral, os estudos de neurotoxinas de anêmonas do mar têm sido realizados com o intuito de elucidar (1) os aspectos evolutivos das sinapses, diferenciação tecidual e desenvolvimento (Dunn et al., 2006; Grimmelikhuijzen et al., 1989; Holland, 2004; Miller et al., 2005; Mohrlen et al., 2006); (2) comunicação e simbiose química (Ayre, 1982; Fautin \& Lowenstein, 1992; Mebs, 1994); (3) importância médica, tendo em vista que algumas espécies são nocivas aos seres humanos durante o envenenamento (Freudenthal \& Barbagallo, 2002; Garcia et al., 1994; Maretic \& Russell, 1983; Nagai et al., 2002; Sanchez-Rodriguez et al., 2001); (4) importância farmacológica e 
fisiológica exercidas pelos efeitos biológicos dos diferentes compostos neuroativos encontrados em seu corpo e peçonha (Beress et al., 1982; Macek, 1992; Mahnir et al., 1993; Malpezzi \& Freitas, 1990; Oshiro et al., 2004); e (5) potencial terapêutico desses compostos (Chandy et al., 2001; Kem et al., 1999; Lewis \& Garcia, 2003).

\subsection{Considerações finais}

Muitos organismos peçonhentos, desde escorpiões e aranhas a serpentes e moluscos do gênero Conus, têm sido amplamente investigados e novas moléculas bioativas têm sido identificadas e caracterizadas, resultando na publicação anual de dezenas de artigos científicos, contendo descrições de novos peptídeos que atuam sobre os mais variados alvos fisiológicos (Armishaw \& Alewood, 2005; Buczek et al., 2005; Escoubas, 2006a; Escoubas, 2006b; Fox et al., 2006; Livett et al., 2004; Nascimento et al., 2006; Norton \& Olivera, 2006; Olivera, 2006; Salles et al., 2006; Sanz et al., 2006; Shevchenko et al., 2005). Isso nos mostra o potencial que existe na abordagem proteômica para o estudo de peçonhas e, principalmente, na caracterização de peçonhas de anêmonas do mar, já que estas são pouco investigadas.

Por causa do papel central na eletroexitabilidade, os canais voltagemdependentes são alvos de interesse farmacológico. Toxinas provenientes de peçonhas têm permitido a discriminação de subtipos de canais voltagemdependentes estritamente relacionados, tornando-as poderosas ferramentas para se estudar o funcionamento e estrutura desses canais. Assim, o presente estudo apresenta a purificação, caracterização estrutural e funcional de neurotoxinas da peçonha da anêmona do mar Anthopleura cascaia. 
2. Objetivos 


\subsection{Objetivo geral}

Avaliar os aspectos fisiológicos e toxinológicos dos compostos mais abundantes na fração neurotóxica da anêmona do mar Anthopleura cascaia.

\subsection{Objetivos específios}

a) Estabelecer um modelo experimental de purificação de toxina(s) ativa(s) sobre canais iônicos, presente(s) na peçonha da anêmona do mar Anthopleura cascaia;

b) Caracterizar do ponto de vista químico as toxinas purificadas de interesse quanto à:

- Massa molecular

- Estrutura primária

c) Caracterizar do ponto devista funcional as toxinas de interesse presentes na peçonha por meio de técnicas eletrofisiológicas de Voltage-clamp com dois microeletrodos (experimentos realizados na Katholieke Universiteit Leuven, Bélgica, sob supervisão do professor doutor Jan Tytgat);

d) Estudar a possível similaridade das moléculas obtidas com outras toxinas, cujas sequências estão depositadas em banco de dados, para verificação do possível mecanismo de ação;

e) Avaliar a formação do complexo toxina-canal por meio de experimentos in silico. 


\section{Material e Métodos}




\subsection{Reagentes}

Todos os reagentes utilizados neste trabalho foram de qualidade analítica, das marcas Merck, Sigma, Aldrich, Biorad, e Vetec. As soluções utilizadas nas cromatografias foram preparadas em água purificada em sistema milli-Q e os reagentes utilizados foram de grau HPLC procedentes das marcas JT Baker, Tedia e Fluka.

\subsection{Captura e manutenção das anêmonas do mar}

Indivíduos adultos, com diâmetro pedal maior que $1,2 \mathrm{~cm}$, de Anthopleura cascaia (Corrêa, 1964) foram coletados em costões rochosos do litoral de Bertioga e São Sebastião, litoral norte de São Paulo, no mesolitoral inferior e na franja do infralitoral, durante períodos de maré-baixa, quando são facilmente encontradas. Os animais foram transportados vivos e mantidos em aquário com água marinha, suprimento adequado de oxigênio e alimentados diariamente com artêmias.

\subsection{Obtenção da peçonha de Anthopleura cascaia}

Os animais foram mantidos por $48 \mathrm{~h}$ sem alimentação, para a eliminação de eventuais partículas alimentares presentes na cavidade gastrovascular. A extração da peçonha dos animais foi realizada por estimulação elétrica in vivo de 10 exemplares de cada vez, de acordo com Malpezzi e colaboradores (1993). Cada grupo de animais foi colocado em um béquer com cerca de 20 $\mathrm{mL}$ de água do mar artificial e estimulado eletricamente, por meio de um estimulador Grass Instruments, modelo SD-9, com intensidade de saída do aparelho de $100 \mathrm{~V}$ (a voltagem medida na água do mar com o animal imerso chega a ser de apenas de 1 a $3 \mathrm{~V}$, devido à corrente de curto-circuito). $\mathrm{A}$ duração de cada pulso de estímulo foi de $10 \mathrm{~ms}$ por aproximadamente $60 \mathrm{~s}$, através de 2 eletrodos de carbono, um colocado próximo da cavidade gastrovascular do animal e outro na água circundante, encostado na coluna e nos tentáculos, fechando o circuito. Essa sequência foi repetida de 6 a 7 vezes com cada grupo de 10 anêmonas. O líquido obtido foi centrifugado a $10000 \mathrm{~g}$ 
por 15 minutos, para a remoção de possíveis partículas contaminantes do sobrenadante. Este foi liofilizado e conservado sob congelamento $\left(-20^{\circ} \mathrm{C}\right)$.

\subsection{Determinação do conteúdo protéico}

O conteúdo protéico da peçonha e das frações obtidas no processo de purificação foi determinado pelo método do ácido bicinconínico (BCA; 4,4'dicarboxi-2,2'-biquinolina) por meio de "kit", no qual a albumina de soro bovino (BSA, Sigma) foi utilizada como padrão, seguindo as instruções preconizadas pelo fabricante (BioAgency).

\subsection{Purificação da peçonha de Anthopleura cascaia}

\subsubsection{Purificação por gel-filtração em gel de Sephadex G-50}

O fracionamento da peçonha liofilizada de $A$. cascaia foi realizado através de uma coluna $(1,9 \mathrm{~cm} \times 131 \mathrm{~cm})$ empacotada com gel Sephadex G-50 (Amersham Biosciences, Uppsala, Suécia). A peçonha previamente centrifugada e liofilizada (cerca de 1-2 g de material seco; contendo cerca de $70 \mathrm{mg}$ de proteína) foi dissolvida em $10-20 \mathrm{~mL}$ de tampão acetato de amônio 0,1M, pH 7,0 e aplicada ao topo da coluna, equilibrada e eluída por gravidade com o mesmo tampão. As frações foram coletadas, agrupadas e liofilizadas.

A absorbância de cada fração, uma medida relativa da quantidade de proteína contida em cada uma, foi registrada diretamente na saída da coluna, através da passagem do efluente por um detector de UV (Spectra / ChromTM Flow Thru UV Monitor com unidade óptica de 280 nm e UV Monitor Controller, Spectrum, Áustria) antes de entrar no coletor de frações. A informação, captada pelo detector, foi integrada e registrada permanentemente em papel (Spectra / Chrom TM 1 Channel Recorder, Spectrum, Áustria). O registro direto na saída da coluna permitiu o acompanhamento constante do processo de filtração em gel, facilitando desta maneira o processo de coleta.

3.5.2 Purificação por cromatografia de fase reversa (RP-HPLC) da fração neurotóxica da peçonha

O conjunto da fração neurotóxica obtida de cromatografias por filtração em gel foi ressuspendido em água Milli-Q (Millipore Inc.) e injetado em um 
sistema de purificação Shimadzu de HPLC constituído por um detector UV-VIS SPD-10A VP, bombas LC-10AD VP e um sistema controlador SCL-10A VP (Shimadzu Corp., Japão). A amostra foi cromatografada em uma coluna semipreparativa C-18 de fase reversa $(10 \times 250 \mathrm{~mm}, 5 \mu \mathrm{m}$; Capcell PAK Shiseido ${ }^{\mathrm{TM}}$ ) através de um gradiente linear de 10 a $60 \%$ (em $40 \mathrm{~min}$ ) do solvente "B", composto de acetonitrila $+0,1 \%$ de ácido trifluoroacético $\left(\mathrm{CH}_{3} \mathrm{CN} /\right.$ $0,1 \%$ TFA), com fluxo de $2,5 \mathrm{~mL} / \mathrm{min}$ durante 40 minutos, através de monitoramento em UV $214 \mathrm{~nm}$. O solvente "A", composto de 0,1\% de TFA em água Milli-Q. Todos os picos obtidos foram coletados e liofilizados.

\subsection{Determinação dos espectros de massa}

As massas moleculares das frações obtidas na segunda etapa de fracionamento foram determinadas por espectrometria de massas (MS) MALDITOF. Foi utilizado um aparelho Ultraflex III (Bruker Daltonics, Alemanha), controlado pelo programa FlexControl 3.0 (Bruker Daltonics, Alemanha).

Soluções de amostras foram misturadas com solução saturada de matriz (ácido alfa-ciano-4-hidroxicinâmico ou Super-DHB, uma mistura de ácido dihidroxibenzóico e ácido 2-hidroxi-5-metoxibenzóico) em uma relação 1:1 e foram gotejadas (spotted) $(2 \mu \mathrm{L}$ ) em uma placa de amostras (MTP AnchorChip 400/384). Os espectros de massa foram obtidos em modo positivo/refletido, com a frequência de laser ajustada em $50 \mathrm{~Hz}$. O aparelho foi calibrado com padrões externos (Protein Calibration Standard II e III, Bruker Daltonics, Alemanha). Os dados foram analisados através do programa FlexAnalysis 3.0 (Bruker Daltonics, Alemanha).

\subsection{Determinação da sequência N-terminal}

A sequência de aminoácidos $\mathrm{N}$-terminal foi determinada por método automático pelo programa padrão de sequenciamento por degradação de Edman (Edman, 1950), utilizando-se sequenciador de proteínas e peptídeos (modelo PPSQ-21, Shimadzu).

Cerca de $30 \mu \mathrm{g}$ da amostra (toxina nativa) solubilizada em $50 \mu \mathrm{L}$ de solução TFA: $\mathrm{H}_{2} \mathrm{O}: \mathrm{ACN}(0,1: 0,5: 0,5)$ foram aplicadas sobre um disco de fibra de 
vidro previamente tratado com o polímero SEQUA-BRENE (Sigma), de acordo com os procedimentos padrões do equipamento. A derivatação foi seguida da etapa de conversão do intermediário tiazolina em PTH-aminoácido, por uma solução aquosa de ácido trifluoracético a $25 \%$. A separação dos aminoácidosPTH ocorreu em uma coluna de fase reversa (WAKOSIL-PTH $250 \times 4,6 \mathrm{~mm}$, Wako, Japão) com a eluição conduzida em condição isocrática por uma solução de composição desconhecida, denominada PTH-AA mobile phase (Wako, Japão) fornecida pelo fabricante. Os aminoácidos-PTH foram identificados pelos tempos de retenção, por comparação com os padrões.

\subsection{Pesquisa de homologia dos peptídeos neurotóxicos}

As sequências obtidas foram analisadas, quanto às suas homologias com outras sequências conhecidas, utilizando-se as plataformas on-line BLAST-NCBI (Altschul \& Lipman, 1990), BLITZ EMBL (Collins \& Coulson, 1990), a ferramenta Fasta 33 (http://www.ebi.ac.uk/fasta33/), o banco de dados UniProtKB/Swiss-Prot, o banco de dados de toxinas de aranhas ArachnoServer (Herzig et al., 2011) e a plataforma para toxinas de conus ConoServer (Kaas et al., 2012). Alinhamentos de sequências primárias foram realizados utilizandose a ferramenta aling do UniProt (http://www.uniprot.org/) e o programa ClustalW2 (http://www.ebi.ac.uk/Tools/clustalw2/index.html). Sequências similares foram agrupadas em famílias, de acordo com suas identidades, homologias e alvos biológicos.

\subsection{Análise estatística}

Os resultados de todos os ensaios biológicos foram analisados através do (1) teste de Dunnett, o qual compara os resultados dos grupos positivos com o grupo controle, (2) tabelas ANOVA para análises de variância e (3) teste-t. O programa utilizado foi o Microcal Origin (Microsoft, Inc). 
3.10 Medidas eletrofisiológicas em oócitos de Xenopus laevisTécnica de voltage clamp com dois microeletrodos

Os ensaios eletrofisiológicos utlizando a técnica voltage clamp com dois microeletrodos foram realizados no Laboratório de Toxicologia da Universidade Católica de Leuven, Bélgica, coordenado pelo professor Dr. Jan Tytgat.

\subsubsection{Isolamento e preparação dos oócitos}

Oócitos de Xenopus laevis foram isolados através de ovariotectomia parcial (Figura 18 A e B). Os animais foram anestesiados com tricaína $1 \mathrm{~g} / \mathrm{L} \mathrm{e}$ gelo. Os animais anestesiados foram mantidos em gelo durante toda a cirurgia. Após a retirada dos oócitos, os mesmos foram defoliculados por tratamento com solução de colagenase $2,5 \mathrm{mg} / \mathrm{mL}$ em solução ND96 livre de cálcio em pH 7,5 por 1 hora e meia, $15-16^{\circ} \mathrm{C}$. Após o período de tratamento, os oócitos dos estágios $\mathrm{V}$ e I da maturação foram selecionados para posterior injeção do cRNA (Figura $18 \mathrm{C}$ e D). Os cRNAs transcritos foram sintetizados a partir dos plasmídeos linearizados utilizando kit de transcrição (T7 ou SP6 mMESSAGE m MACHINE, Ambion, USA). Os oócitos traduzem o cRNA injetado nas suas respectivas proteínas, que são expressas na membrana celular dos mesmos, podendo, então, ser utilizados para os ensaios eletrofisiológicos. Foram utilizados os cRNAs dos seguintes subtipos de canais: $\mathrm{K}_{\mathrm{v}} 1.1-6$, shaker IR, $\mathrm{K}_{\mathrm{v}} 2.1, \mathrm{~K}_{\mathrm{v}} 3.1, \mathrm{~K}_{\mathrm{v}} 4.2-3$, hERG, Nav1.2-8 e DmNav1. 

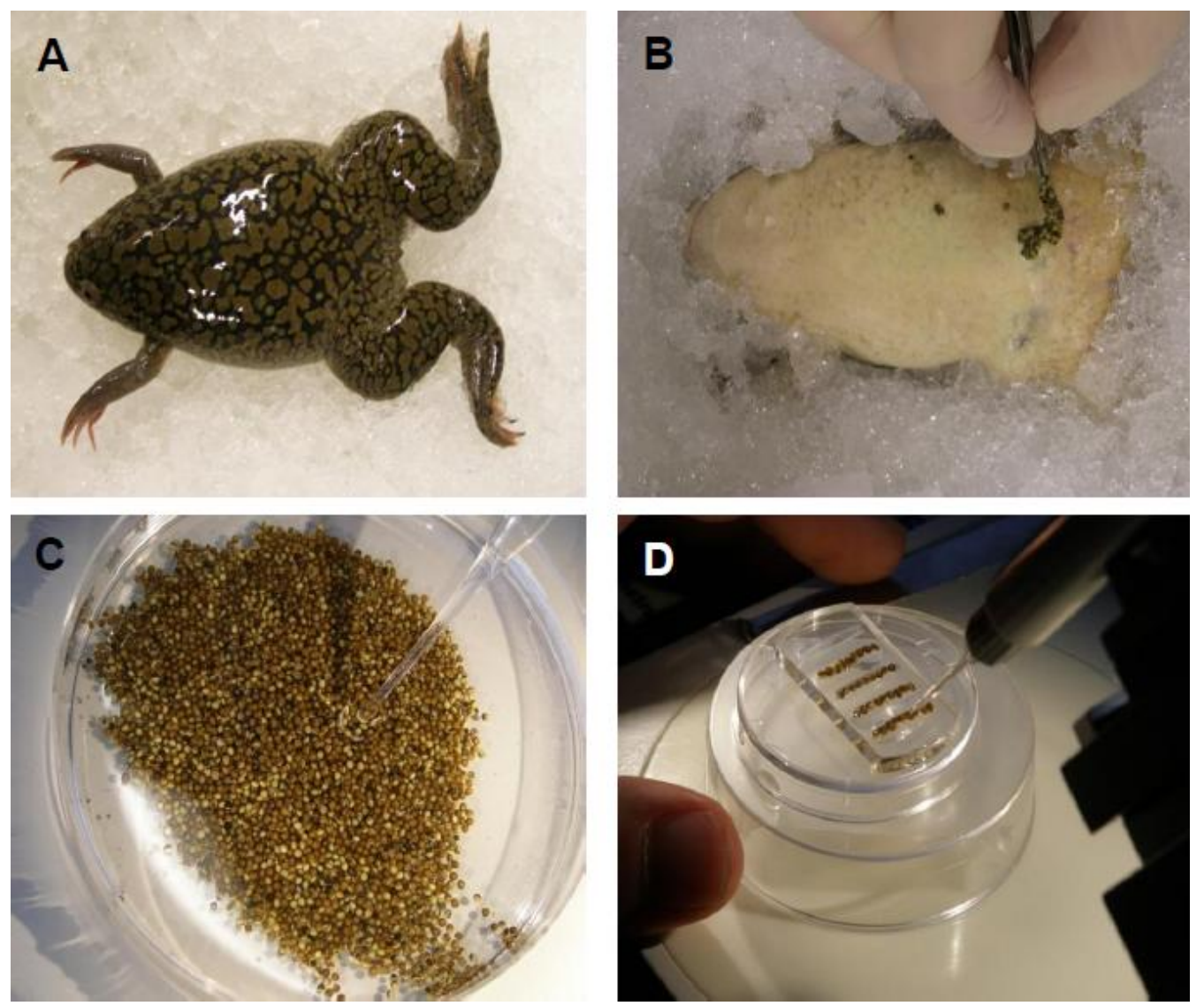

Figura 18 - Isolamento e preparação dos oócitos de Xenopus laevis. (A) Exemplar do Xenopus laevis. (B) Ovariotectomia parcial para a retirada dos oócitos. (C) Seleção dos oócitos. (D) Injeção do cRNA dos canais de interesse nos oócitos. Fotos cedidas por Eva Cuypers, do Laboratório de Toxicologia da Universidade Católica de Leuven, Bélgica.

\subsubsection{Eletrofisiologia}

Para as medidas eletrofisiológicas, utilizou-se a técnica twomicroelectrode voltage clamp. Os registros foram realizados à temperatura ambiente $\left(18-22{ }^{\circ} \mathrm{C}\right.$ ) utilizando um amplificador Gene Clamp 500 (Axon Instruments, EUA) controlados por um sistema de aquisição de dados Clampex9 (Axon Instruments, EUA). As micropipetas foram confeccionadas a partir de capilares de vidro (borosilicato WPI 1B120-6) estiradas, utilizando um estirador manual WPI. A resistência foi de 0,6 a $1,0 \mathrm{M} \Omega$ para os dois eletrodos. As correntes dos oócitos foram registradas 1-2 dias após a injeção do cRNA, para os canais para potássio, e 3-5 dias após a injeção do cRNA, para os canais para sódio.

As toxinas purificadas foram testadas em uma ampla variedade de subtipos de canais tanto de potássio (subfamília Shaker: $\mathrm{K}_{\mathrm{v}} 1.1, \mathrm{~K}_{\mathrm{v}} 1.2, \mathrm{~K}_{\mathrm{v}} 1.3$, $\mathrm{K}_{\mathrm{v}} 1.4, \mathrm{~K}_{\mathrm{v}} 1.5$, $\mathrm{K}_{\mathrm{v}} 1.6$ e shaker; Subfamília Shab: K 2.1 ; Subfamília Shaw: $\mathrm{K}_{\mathrm{v}} 3.1$; 
Subfamília Shal: $\mathrm{K}_{\mathrm{v}} 4.2$ e $\mathrm{K}_{\mathrm{v}} 4.3$; e Subfamília EAG: $\mathrm{hERG)} \mathrm{quanto} \mathrm{de} \mathrm{sódio}$ (Nav1.2, Nav1.3, Nav1.4, Nav1.5, Nav1.6, Nav1.7, Nav1.8 e DmNav1), na concentração inicial de $5 \mu \mathrm{M}$.

\subsubsection{Soluções}

A solução de banho e perfusão, ND96, consistiu em mM: $\mathrm{NaCl} 96 ; \mathrm{KCl}$;; $\mathrm{Mgl}_{2}$ 2; HEPES 5; $\mathrm{CaCl}_{2}$ 1,8, pH 7,4 corrigido com NaOH. A solução de banho HK consistiu em mM: $\mathrm{NaCl}, 2$; $\mathrm{KCl}, 96 ; \mathrm{CaCl}_{2}, 1,8 ; \mathrm{MgCl}_{2}$, 2 e HEPES, 5 (pH 7,4). As micropipetas foram preenchidas com $\mathrm{KCl} 3 \mathrm{M}$. Os oócitos foram mantidos após injeção do cRNA em solução ND96 enriquecida com $50 \mathrm{mg} / \mathrm{L}$ de sulfato de gentamicina.

\subsubsection{Protocolo}

Os protocolos utilizados estão representados na Figura 19. Para os subtipos $\mathrm{K}_{\mathrm{v}} 1.1, \mathrm{~K}_{\mathrm{v}} 1.2, \mathrm{~K}_{\mathrm{v}} 1.3, \mathrm{~K}_{\mathrm{v}} 1.4, \mathrm{~K}_{\mathrm{v}} 1.5, \mathrm{~K}_{\mathrm{v}} 1.6$ e $\mathrm{K}_{\mathrm{v}} 2.1$, os ovócitos foram mantidos em um potencial de $-90 \mathrm{mV}$ (holding potential) e foram rapidamente despolarizados para $0 \mathrm{mV}$, seguindo uma repolarização para $-50 \mathrm{mV}$ e depois para $-90 \mathrm{mV}$. O tempo total do protocolo foi de 1 segundo. Para a isoforma $\mathrm{hERG}$ foi utilizado um protocolo em que os ovócitos eram mantidos a $-90 \mathrm{mV}$, em seguida eram despolarizados a $+40 \mathrm{mV}$, por 2 segundos, seguido de um potencial de $-120 \mathrm{mV}$ por mais 2 segundos. O tempo total do protocolo foi de 4 segundos. Para os subtipos Kv 4.2 e 4.3, os ovócitos foram mantidos a -90 mV e então despolarizados a $+20 \mathrm{mV}$, em um pulso de 500 milissegundos.

No protocolo utilizado para as isoformas Nav1.2-8 e DmNav1, os ovócitos foram mantidos em um potencial de $-90 \mathrm{mV}$ (holding potential), em seguida foram despolarizados para $0 \mathrm{mV}$, seguindo-se de uma repolarização para $-90 \mathrm{mV}$. O tempo total do protocolo foi de 100 milissegundos.

A dependência da indução da toxina para remover a inativação dos canais $\mathrm{Na}_{v}$ foi medida pela plotagem da corrente tardia normalizada em função da concentração da toxina, segundo a equação de Hill: $I_{30 \mathrm{~ms}} / / /_{\text {pico }}=100 /[1+$ $\left(\mathrm{IC}_{50} /[\text { toxina] })^{h}\right]$, onde $\mathrm{IC}_{50}$ é a concentração de toxina que induz metade da inibição máxima da inativação rápida, [toxina] é a concentração da toxina e $h$ é o coeficiente de Hill. Para verificar a dependência da concentração da toxina para induzir um efeito inibitório em canais $\mathrm{K}_{\mathrm{v}}$, foi construída uma curva dose- 
resposta, onde a porcentagem de inibição da corrente foi plotada em função da concentração da toxina. Os dados foram ajustados com a equação de Hill: $y=$ $100 /\left[1+\left(\mathrm{IC}_{50} /[\text { toxin }]\right)^{h}\right]$, onde y é a amplitude do efeito induzido pela toxina $\mathrm{IC}_{50}$ é a concentração da toxina na metade do máxima eficácia, [toxina] é a concentração da toxina e $h$ é o coeficiente de Hill.

Para verificar o mecanismo de ação da toxina sobre o canal $\mathrm{K}_{\mathrm{V}}$ (bloqueadora ou moduladora), foi investigada a relação entre corrente e voltagem. Para tal experimento, a corrente foi aumentada em intervalos de 10 $\mathrm{mV}$, iniciando-se em -90 mV e chegando-se até $+90 \mathrm{mV}$. Este experimento foi realizado em duas condições: na ausência e na presença da toxina em uma concentração próxima à sua $\mathrm{IC}_{50}$. Os valores de $\mathrm{I}_{\mathrm{K}}$ (corrente dos íons potássio) foram plotadas utilizando a equação de Boltzmann: $I_{K} / I_{\max }=\left[1+(\exp (V g-V) / k]^{-}\right.$ 1 , onde $I_{\max }$ representa a $I_{K}$ máxima, $V g$ é a voltagem correspondente à metade da corrente máxima, e $k$ é o fator de inclinação. A corrente obtida para 0 controle e em presença da toxina foram normalizadas com a corrente máxima obtida no controle. Sendo assim, espera-se que a corrente em presença da toxina, utilizando a concentração por volta de seu $\mathrm{IC}_{50}$, seja de $50 \%$ da corrente obtida no controle.

A comparação entre duas amostras foi feita por um teste t Student ( $p<$ 0.05). Todos os dados representam pelo menos 3 experimentos independentes $(n \geq 3)$ e são apresentados como a média \pm o erro padrão. 


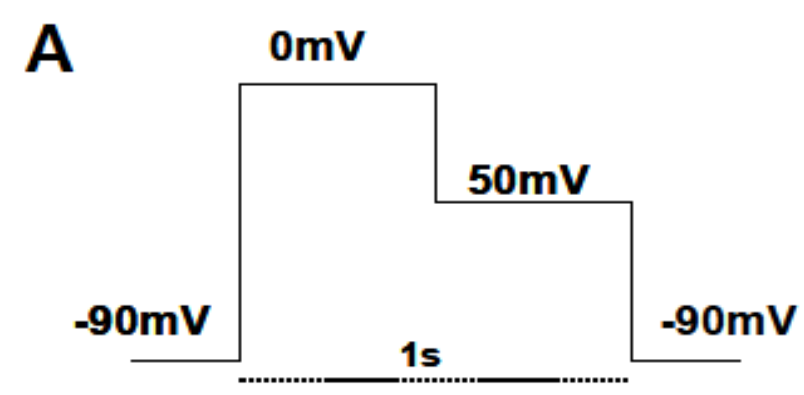

B
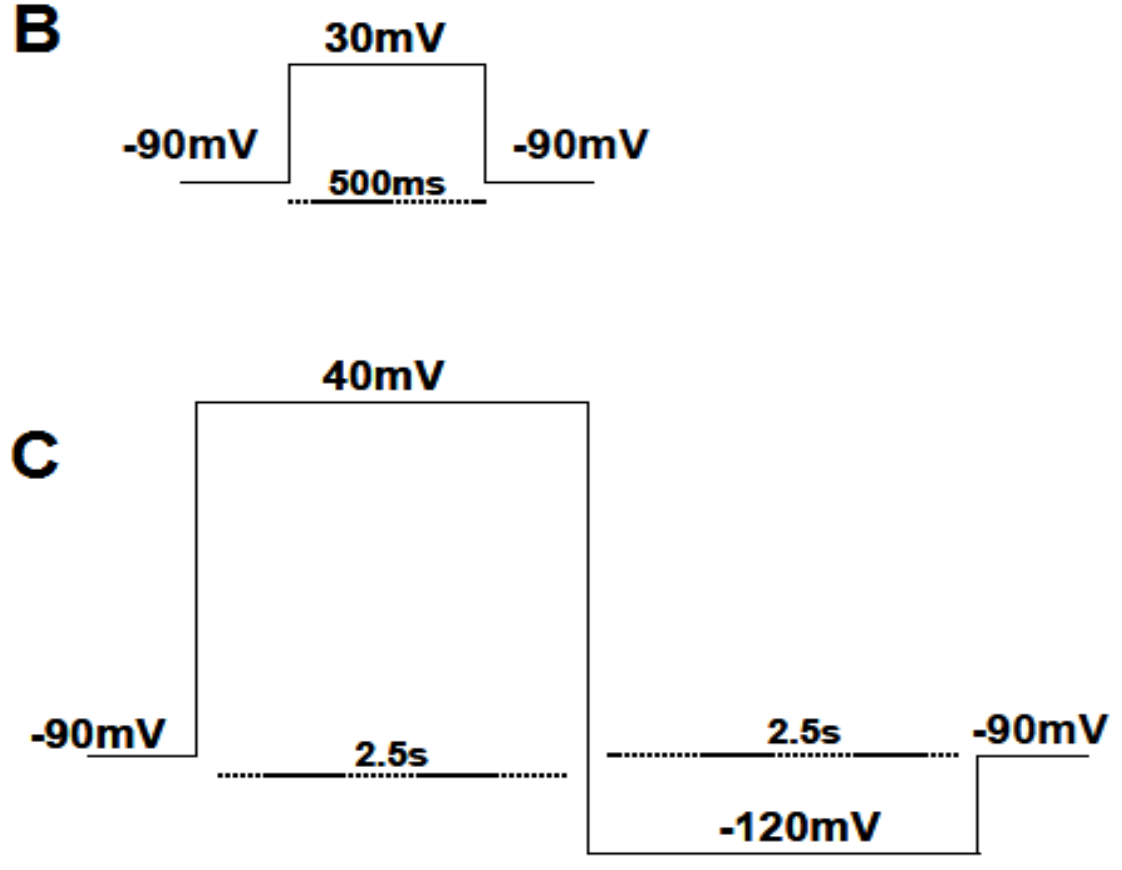

D

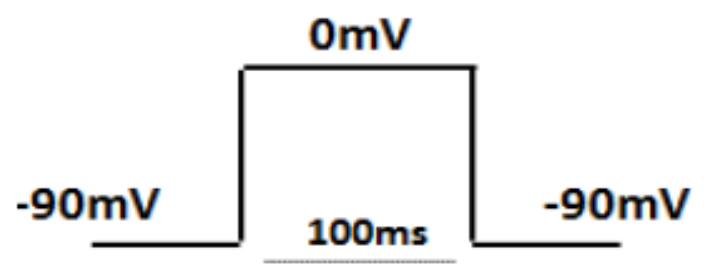

Figura 19 - Protocolo de pulsos de voltagem utilizado para os registros das correntes de potássio e de sódio em oócitos de $X$. laevis. (A) Protocolo utilizado para isoformas $K_{v}$ 1.1-6. O potencial de membrana dos oócitos foi mantido em $-90 \mathrm{mV}$ e rapidamente despolarizados para $0 \mathrm{mV}$, seguido de uma repolarização para $-50 \mathrm{mV}$. 0 tempo total do protocolo foi de 1 segundo. (B) Protocolo utilizado para isoforma $\mathrm{K}_{\mathrm{v}}$ 3.1. Oócitos foram mantidos a um potencial de $-90 \mathrm{mV}$, despolarizados

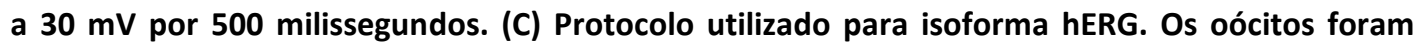
mantidos a um potencial de $\mathbf{- 9 0} \mathrm{mV}$, despolarizados a $\mathbf{4 0} \mathrm{mV}$ por $\mathbf{2 , 5}$ segundos, seguido de um potencial de $-120 \mathrm{mV}$ por mais 2,5 segundos. 0 tempo total do protocolo foi de 5 segundos. (D) Protocolo utilizado para isoformas $\mathrm{Na}_{v}$ 1.2-8 e DmNav1. Os oócitos foram mantidos a um potencial de $-90 \mathrm{mV}$ e despolarizados a $0 \mathrm{mV}$ por $100 \mathrm{~ms}$. 


\subsection{Análises in silico}

3.11.1 Dendograma funcional

O dendograma funcional para análise da toxina Acalll1425 foi construído utilizando o método Maximum Likelihood baseado no modelo de Whelan \& Goldman (2001). Atualmente, o método Maximum Likelihood é considerado um dos estados da arte nas técnicas filogenéticas, permitindo testes estatísticos de hipóteses evolutivas (Whelan \& Goldman, 2001).

O dendograma consensual foi inferido de 1000 replicatas bootstrap (Felsenstein, 1985). Os ramos correspondentes a partições reproduzidas em menos de $50 \%$ das replicatas bootstrap foram colapsados. O dendograma foi construído em escala, com o tamanho dos ramos mensurados no número de substituições por local. A análise envolveu 76 sequências de aminoácidos, que foram alinhadas utilizando a ferramenta align do UniProt e refinadas manualmente. As toxinas foram selecionadas por apresentarem o mesmo padrão de cisteínas. Os respectivos códigos de acesso do UniProt, os nomes das toxinas e espécie de onde a peçonha foi extraída encontram-se na Tabela 8. Todas as posições com menos de $95 \%$ de cobertura foram eliminadas. Ou seja, menos do que 5\% das lacunas do alinhamento foram permitidas em qualquer posição. Houve um total de 12 posições no conjunto de dados final. As análises foram reanalisadas, utilizando o programa MEGA 5.0 (Tamura et al., 2011).

\subsubsection{Modelagem molecular}

O software MODELLER 9v10 (Sali \& Blundell, 1993) foi utilizado para construir modelos tridimensionais. Este programa contempla a modelagem comparativa, satisfazendo restrições espaciais. Os procedimentos para modelagem se inicia com o alinhamento da sequência de aminoácidos (alvo) e com uma ou várias sequências primarias de proteínas, com estruturas tridimensionais conhecidas (moldes ou templates). Este alinhamento é utilizado como informação de entrada (input) para o programa. O arquivo de saída (output) é um modelo tridimensional da sequência alvo contendo todos os átomos da cadeia principal e das cadeias laterais, com exceção dos átomos de hidrogênio. Um total de 1000 modelos foram gerados para cada peptídeo pelo 
programa MODELLER9v10. O modelo final foi selecionado baseando-se na sua qualidade estereoquímica.

Foi utilizado como template para o subtipo de canal $\mathrm{rK}_{\mathrm{v}} 1.6$, a estrutura do canal mKV1.2 (código no PDB, 3LUT) que apresenta uma resolução de 2,9 A. Para a Acalll1425 foram utilizados múltiplos templates, sendo estes as toxinas MVIIC (código no PDB, 1CNN) e MVIIA (código no PDB, 1TTK) de Conus magus, PVIIA (código no PDB, 1KCP) de Conus purpurascens e GVIA (código no PDB, 2CCO) de Conus geographus. Todas as toxinas utilizadas para a modelagem da Acall11425 apresentam o motivo estrutural ICK.

O programa Chimera versão 1.6 (Pettersen et al., 2004) foi utilizado para a visualização, análise e preparo das figuras dos modelos gerados.

Para avaliar a qualidade estereoquímica dos modelos gerados foi usado o programa Procheck (Laskowski et al., 1993), que analisa a geometria global da estrutura ou de cada resíduo individualmente, utilizando para isso parâmetros estereoquímicos derivados de estruturas de alta resolução ou bem refinadas (Morris et al., 1992), as quais constituem sua base de dados. Os parâmetros estereoquímicos checados pelo Procheck são: ligações covalentes, planaridade de grupos planares (aromáticos, ligações peptídicas, etc.), ângulos diédricos, quiralidade, interações não covalentes, ligações de hidrogênio da cadeia principal e pontes dissulfeto.

O Procheck requer, como entrada, um arquivo das coordenadas atômicas da estrutura da proteína a ser avaliada no formato "PDB", produzindo representações em PostScript que descrevem a estrutura da proteína e compara com duas estruturas de proteínas relacionadas. Em conjunto, o programa fornece uma lista detalhada de cada resíduo, o que permite a avaliação da qualidade total da estrutura, em comparação às estruturas bem refinadas de mesma definição, além de destacar as regiões que podem necessitar uma investigação mais detalhada.

Dentre as várias análises fornecidas pelo Procheck, utilizou-se 0 Diagrama de Ramachandran e o G-factor.

\subsubsection{Diagrama de Ramachandran}

Ramachandran (1963) descreveu as conformações possíveis para os aminoácidos em uma cadeia polipeptídica. A conformação da cadeia peptídica 
é descrita pelos valores dos ângulos diedros na estrutura principal da proteína (ângulo descrito pelo nitrogênio e carbono alfa, $\mathrm{N}-\mathrm{C}_{\alpha}$, e o ângulo descrito pelo carbono alfa e carbono, $\mathrm{C}_{\alpha}-\mathrm{C}$ ) (Figura 20). Esses ângulos são denominados ângulos de torção $\Psi$ e $\Phi$, respectivamente. Em principio, $\Psi$ e $\Phi$ podem ter qualquer valor entre $-180^{\circ}$ e $+180^{\circ}$, porém muitos valores de $\Psi$ e $\Phi$ são proibidos pelas interferências estéricas entre átomos pertencentes ao mesmo esqueleto polipeptídico e pelas cadeias laterais dos resíduos de aminoácidos.

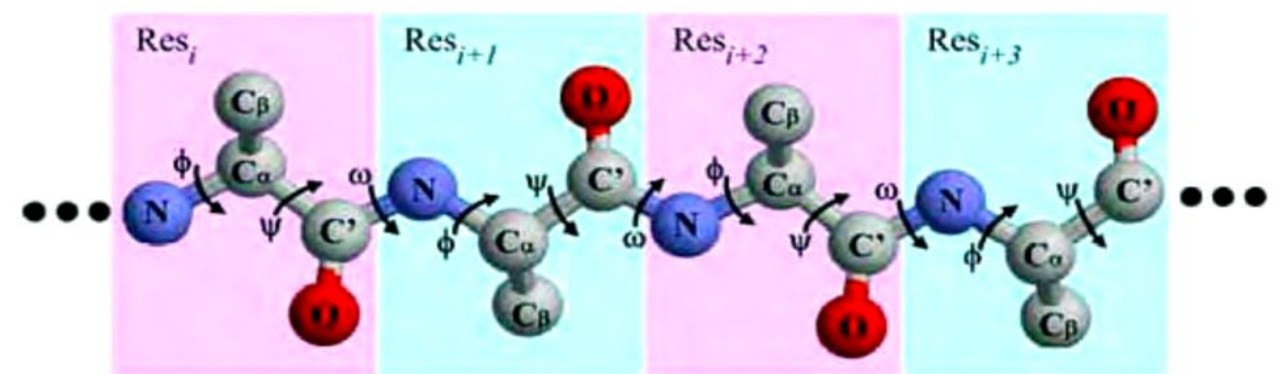

Figura 20 - Representação de uma parte de uma cadeia polipeptídica com os graus de torção dos ângulos diedros $\Psi$ e $\Phi$. Figura retirada de Laskowski et al. (1993).

O esqueleto principal não é livre para girar ao redor do terceiro tipo de ligação na estrutura da proteína, a ligação peptídica, por ser uma ligação parcialmente dupla e, portanto, quimicamente restrita a ser planar; sendo assim, os valores de $\Psi$ e $\Phi$ para cada aminoácido fornecem uma descrição completa da estrutura da cadeia principal da proteína. Consequentemente, os ângulos de torção $\Psi$ e $\Phi$, que fazem com que as esferas colidam, correspondem à conformação estéricamente não permitida (região não permitida) para a cadeia principal de um polipeptídio.

O diagrama de Ramachandran (Ramachandran, 1963; Ramakrishnan \& Ramachandran, 1965) indica a distribuição dos ângulos $\Psi$ e $\Phi$ dos resíduos pertencentes a uma determinada estrutura. Uma estrutura de boa qualidade deve ter $90 \%$ ou mais de seus resíduos nas regiões mais favoráveis (Figura 21). Na Figura 21, as áreas em bege correspondem às regiões onde existem os choques estereoquímicos na proteína. Estas regiões não permitidas valem para todos os aminoácidos, com exceção da glicina (Gly), que é o único aminoácido que não possui cadeia lateral, podendo adotar os ângulos de torção $\Psi$ e $\Phi$ em todos os quadrantes do diagrama de Ramachandran. As regiões em vermelho correspondem à conformação onde não há nenhum 
choque estereoquímico, ou seja, são as regiões permitidas e onde se encontram as $\alpha$-hélices e fitas- $\beta$. As áreas em marrom mostram as regiões limites onde um raio ligeiramente mais curto de van der Waals é usado no cálculo. Isto faz com que se tenha uma região adicional que corresponda às hélices esquerda e direita.

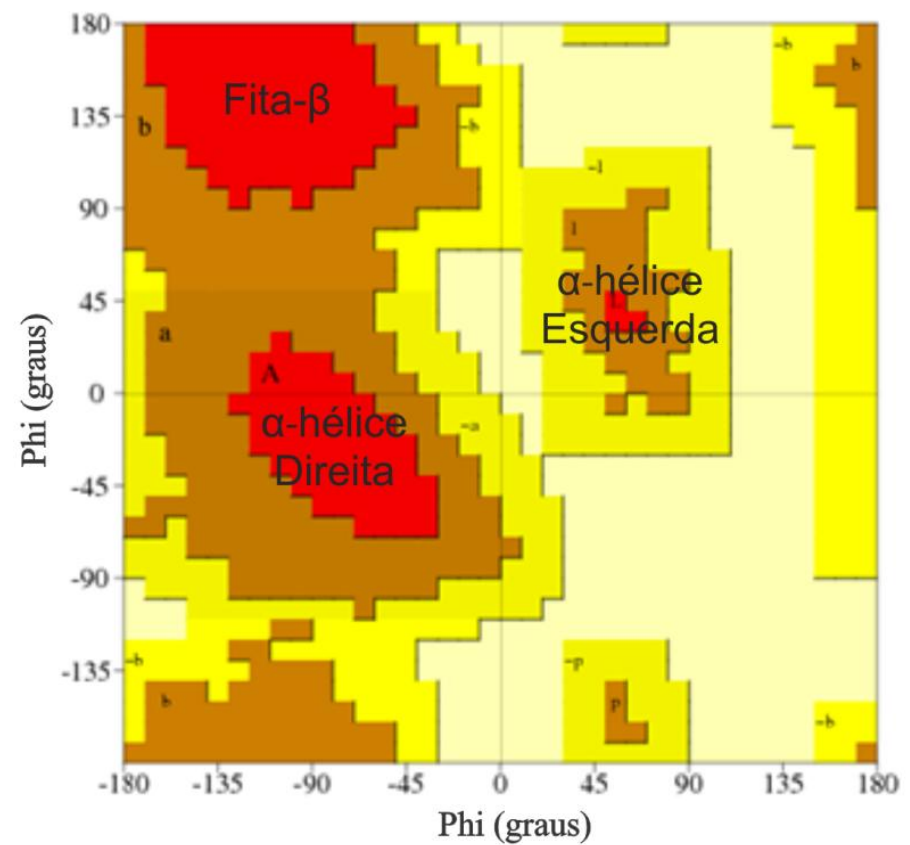

Figura 21 - Diagrama de Ramachandran. A região colorida em vermelho representa a região "permitida", em marrom a região "adicionalmente permitida" e em amarelo a região "não permitida". Figura adaptada de Ramachandran (1963).

\subsubsection{G-factor}

O G-factor fornece uma medida do desvio de uma dada propriedade estereoquímica (ângulos de torção e geometria covalente), baseado nas distribuições observadas nos parâmetros estereoquímicos em sua base de dados e uma medida da normalidade da estrutura como um todo.

O cálculo do G-factor envolve a média dos diversos G-factors dos ângulos de torção (Phi-psi; Chi1-chi2; Chi1; Chi3-chi4 e Omega), juntamente com a geometria covalente, fornecendo em um único número o G-factor para toda a estrutura.

O G-factor global é a melhor medida da qualidade estereoquímica total de uma molécula. Por exemplo, os resíduos que caem nas regiões não permitidas do diagrama de Ramachandran terão um G-factor baixo. Se uma proteína ou peptídeo tiver muitos resíduos com G-factor baixo, sugere-se que 
algo possa estar errado com a geometria total da proteína avaliada e, consequentemente, o modelo gerado não será bom. Assim, o ideal é o G-factor estar acima de -0,5. Portanto, os modelos que apresentarem G-factor entre -1,0 e $-0,5$ devem ser investigados.

\subsubsection{Potencial eletrostático}

As representações do potencial eletrostático na superfície do canal rKv1.6 e da toxina Acalll1425 foram gerados utilizando o programa APBS (Adaptive Poisson-Boltzmann Solver) (Baker et al., 2001). Para gerar os mapas de potencial foi utilizado o programa PDB2PQR (Dolinsky et al., 2007). Para visualização e preparo das figuras foi utilizado o programa VMD (Humphrey et al., 1996).

3.11.4 Predição da interação entre canal e toxina - "Docking Molecular"

A predição da interação, ou docking, entre o canal e a toxina foi realizada automaticamente através do programa AutoDockVina (Trott \& Olson, 2010). Para determinação da área de busca por interação foi utilizado o programa AutoDockTools versão 1.5.6 (Sanner, 1999). A área (grid) de busca foi criada na porção do canal que fica na região extracelular. Para o canal Kv1.6 foi criado um grid de $80 \AA$ x $80 \AA$ x $50 \AA$, utilizando um espaçamento de 1 Å. Foram obtidos, inicialmente, 1 milhão de modelos de interação. Destes, foram selecionados os 20 melhores modelos, utilizando como critério a energia potencial. Com base no RMSD (desvio médio quadrado, do inglês root mean square deviation), que é a medida da distância média entre os átomos (geralmente os átomos do backbone) de proteínas sobrepostas, foi selecionada uma conformação representativa. No estudo conformacional de proteínas globulares, normalmente se mede a semelhança da estrutura tridimensional pelo RMSD das coordenadas atômicas do Ca após sobreposição com a estrutura rígida ideal.

Para a análise da interação do complexo receptor-ligante, o programa LigPlot $^{+}$v1.3 (Wallace et al., 1995) foi utilizado para checar as ligações de hidrogênio e as interações hidrofóbicas entre os átomos do receptor com os do ligante em uma distância de até $5 \AA$. Também foram utilizados os programas 
Pymol v1.5 (Schrodinger, 2010) e o Chimera v1.6.1 (Pettersen et al., 2004), para visualizar as interações e preparar as Figura 40, Figura 41 e Figura 45.

Para uma melhor análise da interação entre a toxina e o canal, o modelo do complexo gerado foi colorido de acordo com o seu grau de hidrofobicidade, segundo a escala de hidrofobicidade padronizada por Hessa e colaboradores (2005), na qual valores mais negativos refletem maior hidrofobicidade (Figura 41). 
Para melhor organização dos dados, os Resultados e a Discussão foram separados em "Resultados Gerais", "AcallI2970 e Acalll3090" e "Acalll1425".

\subsection{Resultados gerais}

\subsubsection{Obtenção da peçonha}

Por meio da estimulação elétrica obtivemos cerca de $1 \mathrm{mg}$ de peçonha por exemplar.

\subsubsection{Fracionamento da peçonha}

A Figura 22 mostra o perfil obtido do fracionamento de $10 \mathrm{mg}$ de proteína da peçonha bruta por cromatografia em Sephadex G-50, a qual é adequada para a separação de proteínas globulares de 1500 a 30000 Da. Essa etapa cromatográfica separou a peçonha em 4 grupos principais denominados Acal, Acall, Acalll e AcalV, Aca se refere à Anthopleura cascai, seguido por numeração em algarismo romano de acordo com a ordem de eluição. Podemos observar que a AcalV foi a de maior abundância e a Acall de menor abundância. A Acalll foi utilizada para dar continuidade aos experimentos, pois de acordo com Lagos e colaboradores (2001) essa é a fração com a faixa de massa molecular referente às neurotoxinas de anêmonas do mar.

\subsubsection{Purificação da fração neurotóxica (Acalll)}

$\mathrm{Na}$ Figura 23, observa-se o perfil obtido de cerca de $1 \mathrm{mg}$ da fração Acalll na cromatografia de fase reversa, utilizando-se uma coluna semipreparativa ( $10 \times 250 \mathrm{~mm}, 5 \mu \mathrm{m}$; Capcell PAK Shiseido $\left.{ }^{\mathrm{TM}}\right)$. Cada uma das frações foram numeradas segundo sua ordem de eluição. Foram obtidos 4 frações majoritários. Os compostos presentes em menor concentração foram coletados e agrupados em frações $(\mathrm{Fr}$ ) para análises posteriores. Observa-se que as frações de maior abundância, 3 e 4, são compostos hidrofóbicos, ou seja, eluem no final do cromatograma, devido a maior concentração de acetonitrila. 


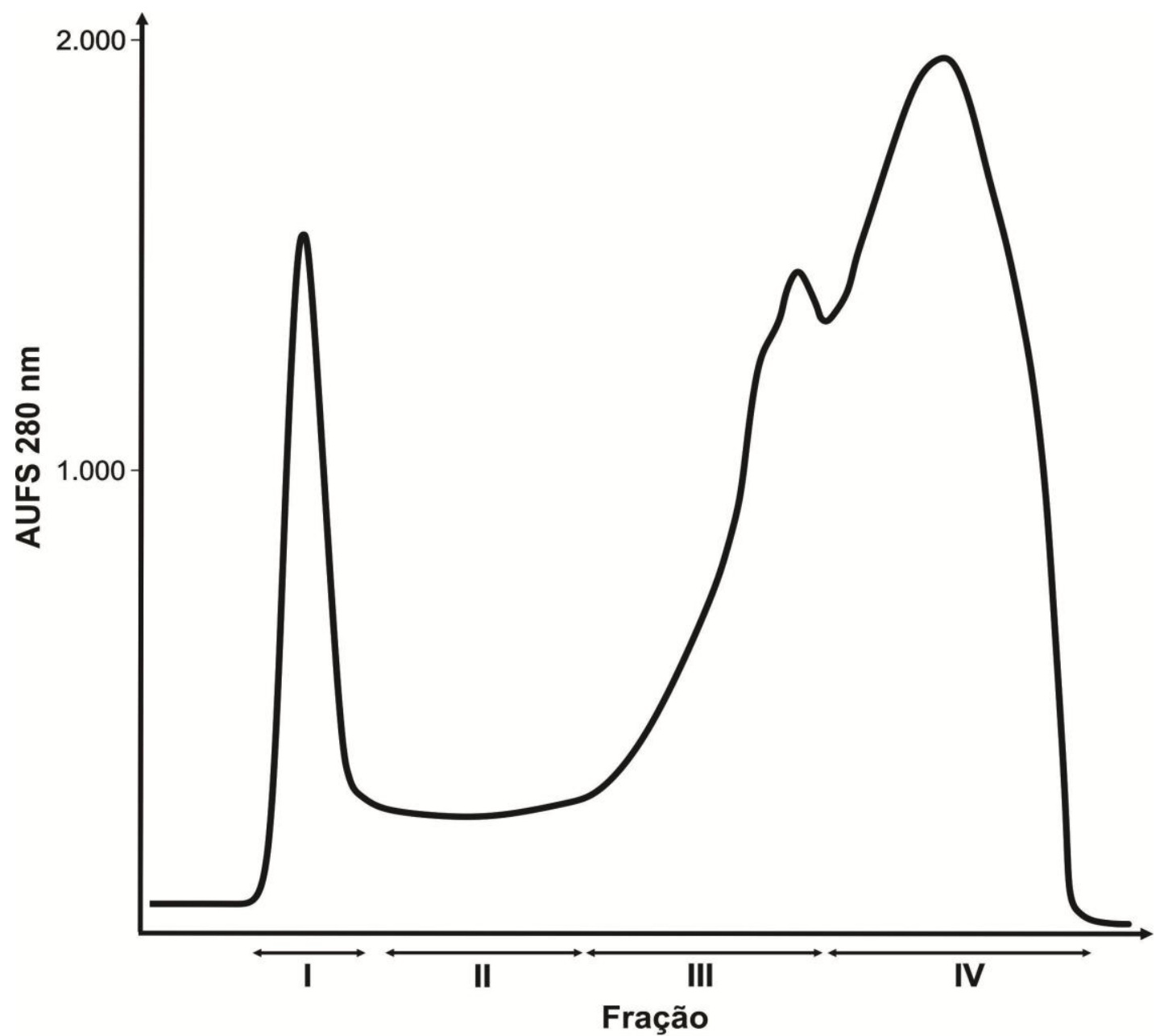

Figura 22 - Cromatograma da peçonha da anêmona do mar $A$. cascaia obtido através de uma coluna empacotada com Sephadex G-50. A cromatografia foi monitorada à $280 \mathrm{~nm}$. O perfil obtido resultou em 4 frações, sendo suas atividades biológicas conhecidas como: fosfolipásica (Acal), hemolítica (Acall), neurotóxica (AcallI) e compostos de baixa massa molecular (AcalV). 


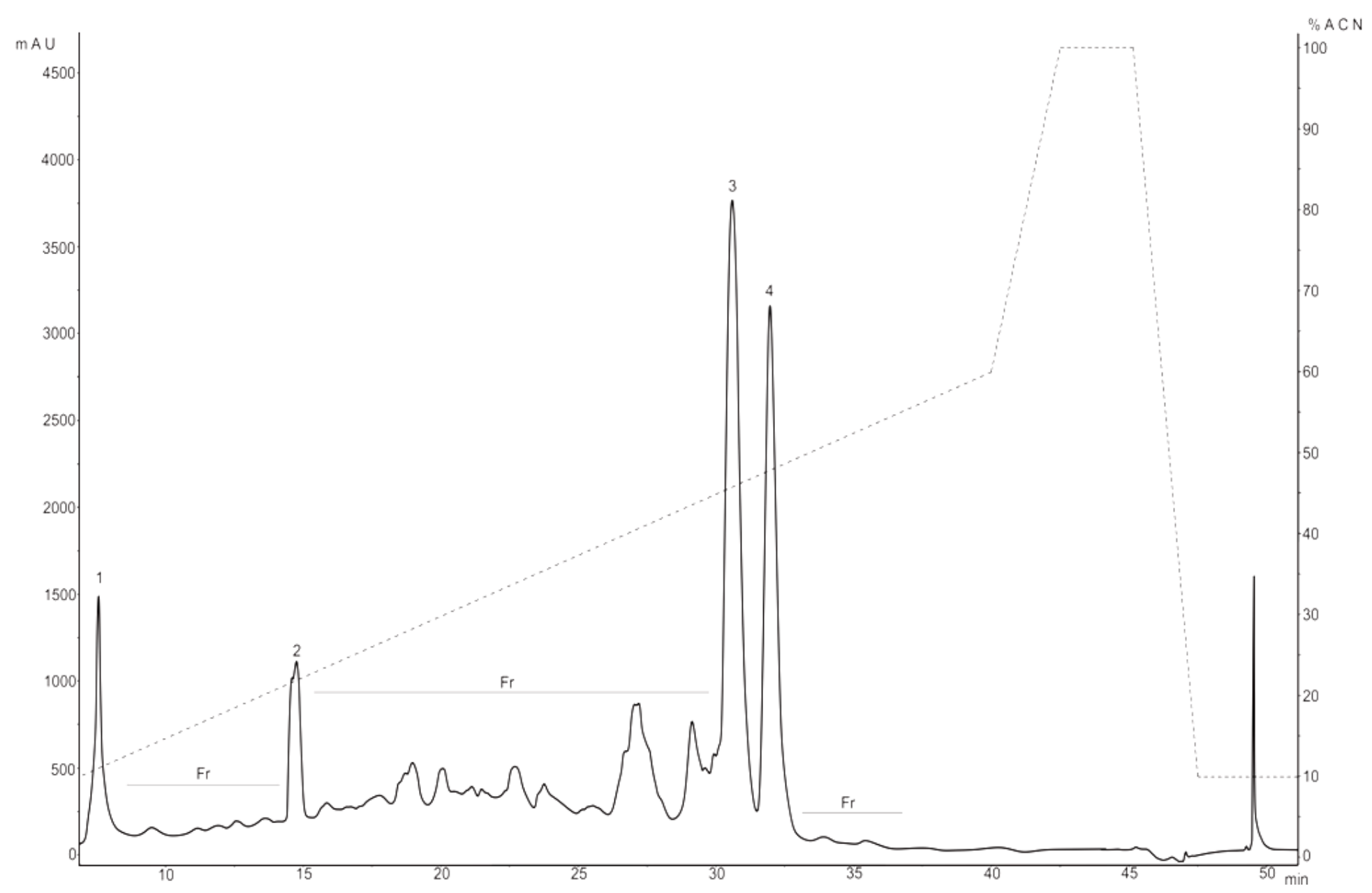

Figura 23 - Cromatograma representativo da Acalll $(500 \mu \mathrm{g})$. Os números acima dos picos foram dados conforme os tempos de eluição. As escalas das ordenadas mostram as unidades arbitrárias de absorbância à $214 \mathrm{~nm}$ (esquerda) e o percentual de solvente $\mathrm{B}\left(\mathrm{CH}_{3} \mathrm{CN} / 0,1 \%\right.$ TFA) empregado na purificação. A linha tracejada mostra a variação do gradiente empregado na purificação. $O$ gradiente foi de 10 a $60 \%$ de tampão $B$ em um fluxo de $2,5 \mathrm{~mL} /$ min por 40 minutos. 


\subsubsection{Espectometria de massas}

As frações eluídas das cromatografias de fase reversa foram submetidas à análise por espectrometria de massas com o intuito de identificar toxinas que possivelmente atuem sobre canais iônicos, bem como acessar a diversidade de massas moleculares protéicas presentes na fração Acalll.

$O$ resultado da análise por espectrometria de massas, utilizando-se a interface MALDI-TOF, encontra-se na Tabela 3. Observa-se a presença de massas moleculares entre 1109,0 Da até $5658 \mathrm{Da}$. Foram encontrados cerca de 144 sinais de massa/carga diferentes. 
Tabela 3 - Lista de massas moleculares das subfrações eluídas da cromatografia de fase reversa da fração Acallı.

\begin{tabular}{|c|c|c|c|c|c|c|c|c|c|c|c|c|c|}
\hline$\% A C N$ & MW & $\% A C N$ & MW & $\% A C N$ & MW & $\% A C N$ & MW & $\% A C N$ & MW & $\% A C N$ & MW & $\% A C N$ & MW \\
\hline 13,5 & 1158,6 & 32,87 & 1175,1 & 36,5 & 5489,6 & 38,8 & 2722,1 & 41 & 5023,8 & 45 & 4510,2 & 46 & 2462,6 \\
\hline 13,5 & 1732,8 & 33 & 2650,6 & 37 & 2426,7 & 39 & 2929,9 & 41 & 5024 & 45 & 4746,6 & 47 & 3251 \\
\hline 14,1 & 1842 & 33 & 4582,1 & 37 & 3059 & 39 & 3245,1 & 41 & 3763,6 & 45 & 5022,5 & 47 & 3395,3 \\
\hline 25,25 & 3337,4 & 33,19 & 3761,5 & 37 & 3143 & 39 & 4802,7 & 41 & 3276,4 & 45 & 5100,9 & 48 & 4231,5 \\
\hline 23,5 & 1802,5 & 33,19 & 4462,4 & 37,5 & 3584,6 & 39 & 5024,2 & 41 & 2877 & 45 & 2993,8 & 48 & 4442,3 \\
\hline 24,1 & 2794,9 & 33,19 & 4463,3 & 37,5 & 4171 & 39 & 3347,4 & 42 & 4881,7 & 45 & 4342 & 48 & 4483,2 \\
\hline 25,82 & 2975,6 & 33,6 & 1231,7 & 37,5 & 4600,5 & 39 & 5363,3 & 42,14 & 5086 & 45 & 4386,2 & 48 & 4563,9 \\
\hline 28,76 & 5486,2 & 33,6 & 1387,7 & 37,5 & 5487,9 & 39 & 2755,2 & 43 & 1188,6 & 45,5 & 4441,4 & 48 & 4782,8 \\
\hline 28,76 & 3369,5 & 34,09 & 1611,8 & 37,5 & 1174,9 & 39,33 & 2891,8 & 43 & 3176,7 & 45,5 & 4724,7 & 48 & 4920 \\
\hline 29,56 & 4083,5 & 34,5 & 1725,9 & 37,5 & 1222,9 & 39,33 & 3151,9 & 43 & 4519,5 & 45,5 & 4783,2 & 48 & 4953,5 \\
\hline 29,56 & 3769,3 & 34,5 & 4518,6 & 37,5 & 1280 & 40,1 & 3180,9 & 44 & 5115,7 & 45,5 & 5081,9 & 48 & 5349,5 \\
\hline 30,54 & 4082,8 & 34,5 & 1429,6 & 38 & 2425 & 40,1 & 4801,8 & 44 & 4880,5 & 45,5 & 5138,3 & 48 & 5365,7 \\
\hline 30,54 & 1888,7 & 34,5 & 1251,7 & 38 & 2716,5 & 40,1 & 3304,8 & 44 & 5027,4 & 45,5 & 3926,9 & 48 & 5646,9 \\
\hline 30,92 & 2538,9 & 35,31 & 1504,5 & 38 & 3770,8 & 40,1 & 4781,3 & 44 & 5658,4 & 45,5 & 4339 & 48 & 3164,4 \\
\hline 30,92 & 3307,5 & 35,5 & 2889,8 & 38 & 4084,4 & 40,1 & 1174,6 & 44,3 & 1109,9 & 45,5 & 4499,5 & 48 & 3250,4 \\
\hline 31 & 4480,7 & 36 & 2610,9 & 38 & 1146,7 & 40,65 & 1743,6 & 44,5 & 2612,7 & 46 & 4530,3 & 48 & 3365,1 \\
\hline 32,13 & 2378,1 & 36 & 5093,8 & 38 & 1202,7 & 40,65 & 2650,3 & 44,5 & 2995,9 & 46 & 4712 & 48,5 & 1786,7 \\
\hline 32,13 & 4583 & 36 & 1308,8 & 38 & 2311,2 & 41 & 2721,3 & 45 & 3232,1 & 46 & 4730,5 & 48,5 & 4419,8 \\
\hline 32,13 & 5019,9 & 36,14 & 1826,8 & 38,8 & 2844,6 & 41 & 3076,7 & 45 & 3253,1 & 46 & 4784,8 & 48,5 & 4490,5 \\
\hline 32,87 & 1702,9 & 36,14 & 1390,3 & 38,8 & 1502,7 & 41 & 3777,4 & 45 & 3842,5 & 46 & 3349,5 & & \\
\hline 32,87 & 1913,1 & 36,5 & 3914,4 & 38,8 & 2580,5 & 41 & 4465,8 & 45 & 4265,9 & 46 & 4564,5 & & \\
\hline
\end{tabular}




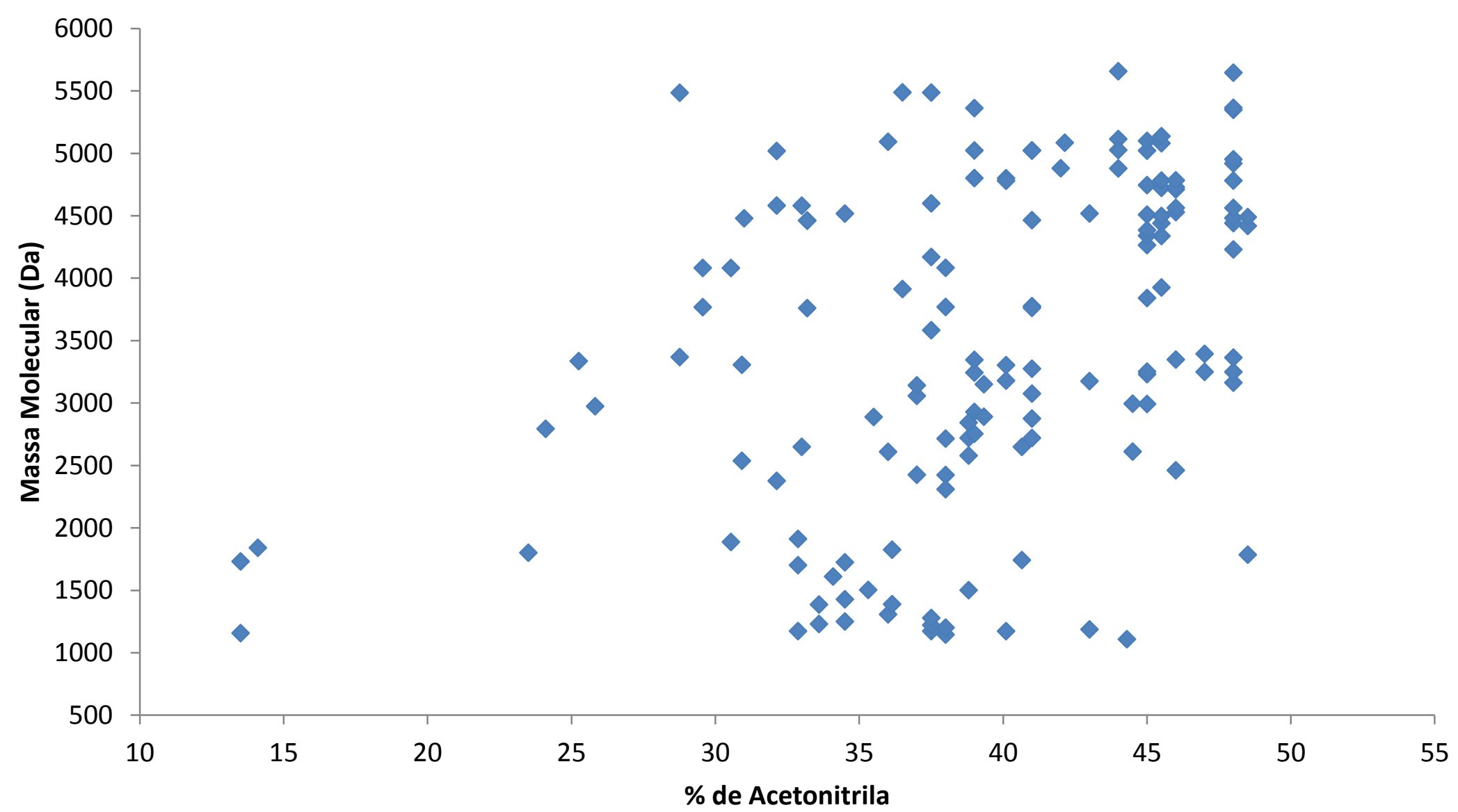

Figura 24 - Gráfico de massas moleculares versus \%ACN necessária para eluição dos componentes da fração AcallI. 
4.1.5 Determinação da sequência N-terminal

Foram determinadas a estrutura primária por meio da degradação de Edman de 3 compostos. As sequências obtidas estão descritas na Tabela 4:

Tabela 4 - Sequências $\mathbf{N}$-terminais obtidas.

\begin{tabular}{ll}
\hline Composto & \multicolumn{1}{c}{ Sequência } \\
\hline \hline Acall11425 & CGGAGAKCSTKSDCCSGLWCSGTGSCYHRRYT \\
Acalll2970 & GVPCLCESGG... \\
Acalll3090 & GVPCLCESDGPSVHGNTLSGTIWVFGCPEGWHDCK... \\
\hline
\end{tabular}

\subsection{Resultados: Acalll2970 e Acall/3090}

\subsubsection{Terceira etapa de fracionamento}

As frações Acalll2970 e Acalll3090 (respectivamente número 3 e 4 no cromatograma da Figura 23) foram utilizadas para dar continuidade ao processo de purificação. A cromatografia de fase reversa (RP-HPLC) de ambas resultou em um pico majoritário (Figura 25 e Figura 26). A pureza desses foi confirmada por espectrometria de massa. Os picos mantiveram sua nomenclatura Acalll2970 e Acalll3090, por serem os picos majoritários e em quantidade suficiente para serem utilizados nos ensaios eletrofisiológico, determinação de sua massa molecular e estrutura primária. 


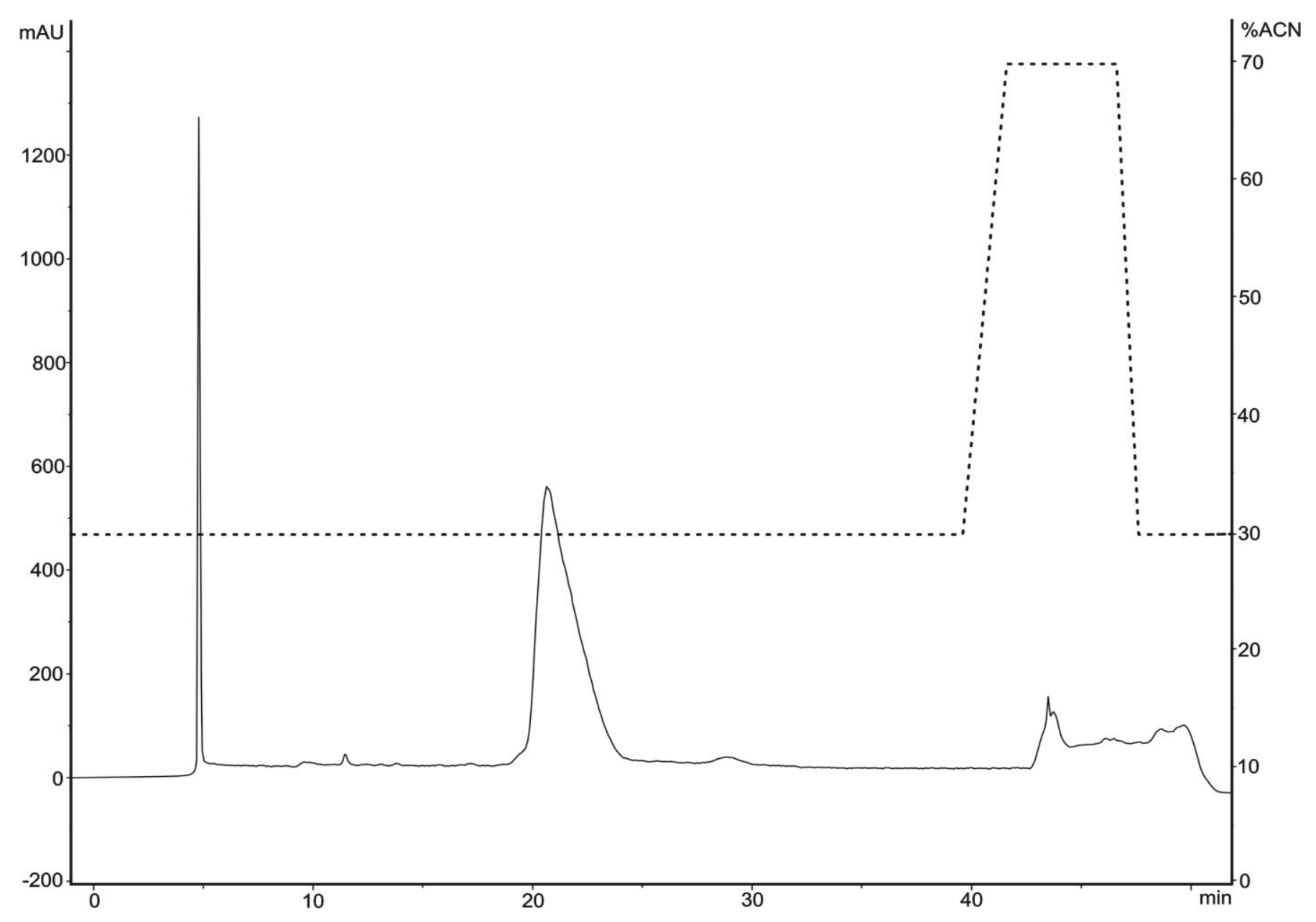

Figura 25 - Perfil cromatográfico da fase reversa (RP-HPLC) da fração Acalll2970. Coluna: CAPCELL PAK C-18 (4,6 X $250 \mathrm{~mm}$ ) equilibrada com eluente A (água). A Acalll2970 foi eluída no modo isocrático do eluente B (30\% de acetonitrila). Amostra: $200 \mu \mathrm{g}$ de proteínas. Fluxo: 1,0 mL/min. A eluição foi monitorada pela absorbância a $214 \mathrm{~nm}$. 


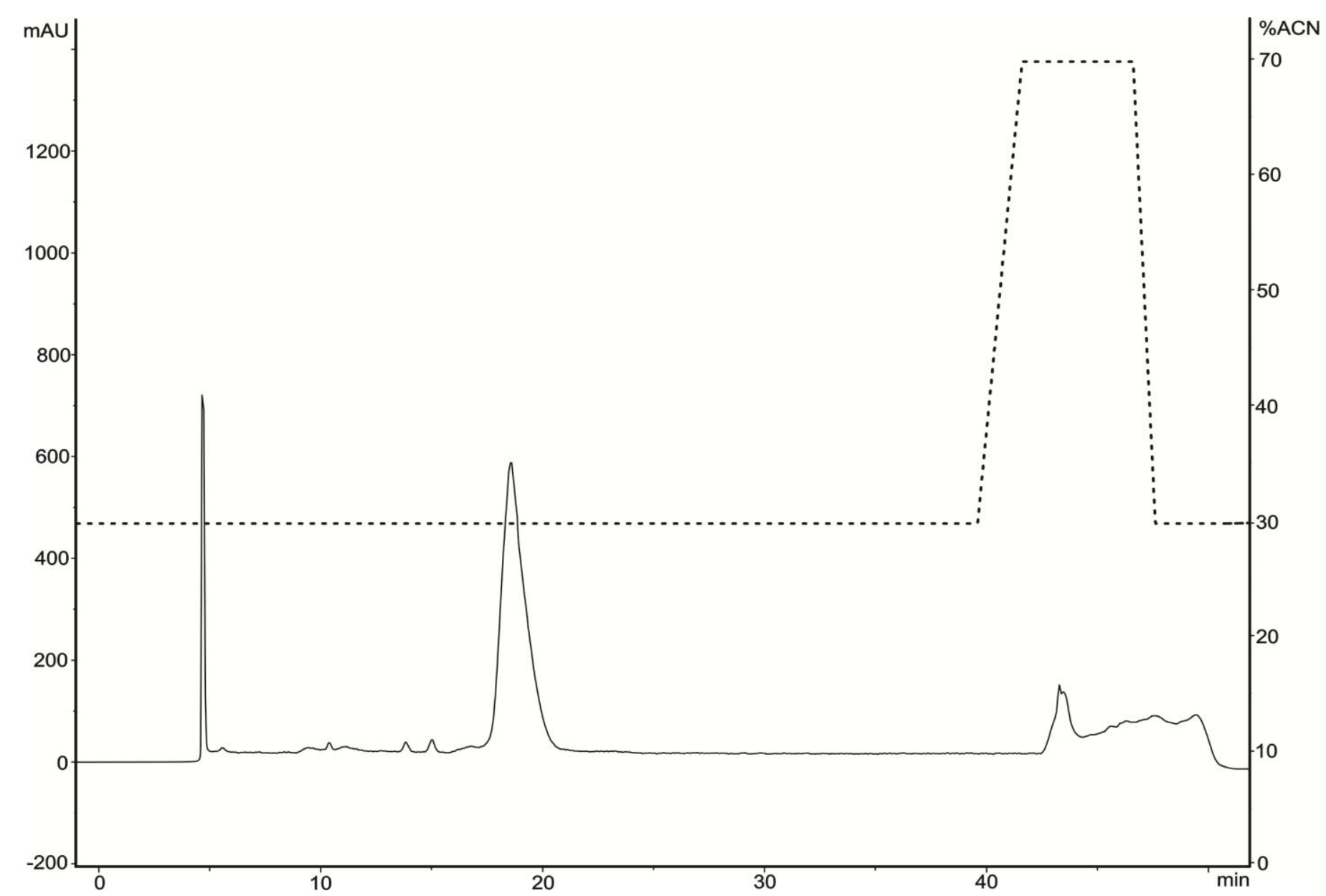

Figura 26 - Perfil cromatográfico da fase reversa (RP-HPLC) da fração Acalll3090. Coluna: CAPCELL PAK C-18 (4,6 X $250 \mathrm{~mm}$ ) equilibrada com eluente A (água). A Acalll3090 foi eluída no modo isocrático do eluente B (30\% de acetonitrila). Amostra: $200 \mu \mathrm{g}$ de proteínas. Fluxo: 1,0 mL/min. A eluição foi monitorada pela absorbância a $214 \mathrm{~nm}$. 


\subsubsection{Ensaio eletrofisiológico}

Na Figura 27, observa-se o screening da Acalll2970 (4881,7 Da) e Acalll3090 (4880,5 Da) em canais Navs em uma concentracão de $5 \mu \mathrm{M}$. Tanto a Acalll2970 quanto a Acalll3090 causaram um retardo na inativação nos canais Nav1.2, Nav1.3, Nav1.5, Nav1.6 e DmNav1, sendo mais potente nos canais Nav1.3, Nav1.6 e DmNav1. Desta forma, foi determinada a dependência da indução da toxina para remover a inativação desses subtipos de canais $\mathrm{Nav}$, medindo a plotagem da corrente tardia normalizada em função da concentração da toxina $\left(1_{30 \mathrm{~ms}} / \mathrm{l}_{\text {pico }}\right)$ (Figura 28$)$. Ambas as toxinas apresentaram a maior potência em canais do subtipo $\mathrm{DmNa}_{v} 1$. Quando comparadas, podemos observar que a Acalll3090 demonstrou uma maior eficiência do que a Acalll2970.

A Figura 28 dependência da concentração no retardo da inativação induzida pelas toxinas Acall12970 e Acalll3090 nos canais em que apresentaram maior eficiência. Os $\mathrm{IC}_{50}$ (Tabela 5) foram obtidos após a plotagem dos dados em uma curva sigmoidal. Para a Acalll2970, os seguintes valores de IC $\mathrm{I}_{50}$ foram obtidos: $\mathrm{DmNav}_{1}=162,19 \pm 11,22 \mathrm{nM}$, Nav1.6 $=645,92$ $\pm 18,52 \mathrm{nM}$, Nav1.3 $=572,56 \pm 44,96 \mathrm{nM}$. Para a Acalll3090, os seguintes valores de IC ${ }_{50}$ foram obtidos: $\mathrm{DmNav}_{1}=99,03 \pm 9,25 \mathrm{nM}, \mathrm{Nav} 1.6=158,30 \pm$ $33,86 \mathrm{nM}, \mathrm{Na} v 1.3=371,60 \pm 6,48 \mathrm{nM}$. Assim, se ranquearmos de acordo com potência da Acalll2970 teremos: DmNav1 >>Nav1.3>Nav1.6; para Acalll3090: DmNav1>Nav1.6>>Nav1.3. 


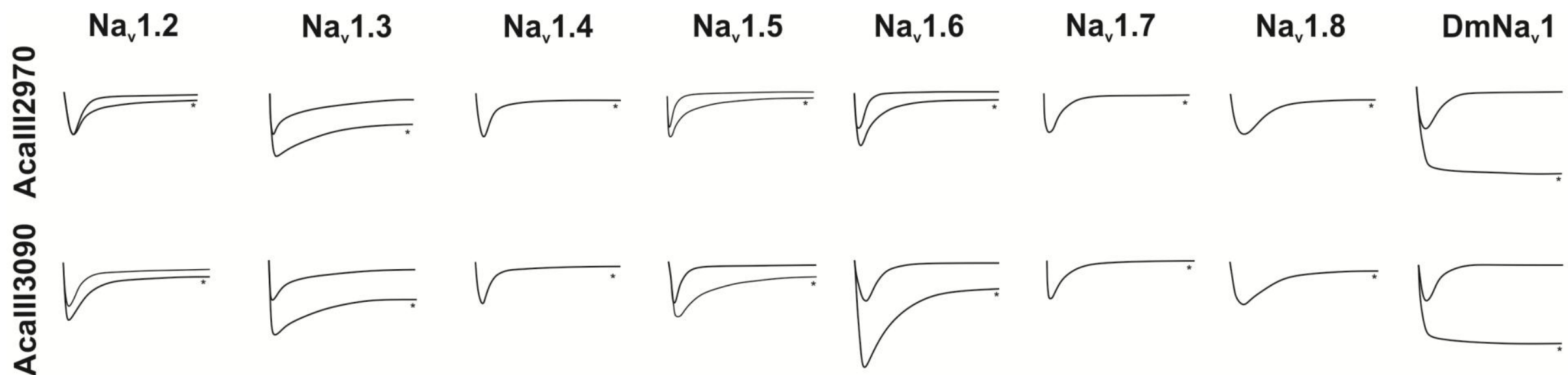

Figura 27 - Efeito das toxinas Acalll2970 e Acalll3090 nos diferentes subtipos de $\mathrm{Na}_{\mathrm{v}}$. Os perfis representam a situação controle e quando aplicados $5 \mu \mathrm{M}$ da toxina ( marcado com *). Cada subtipo foi testado em quadruplicata $(n=4)$. 

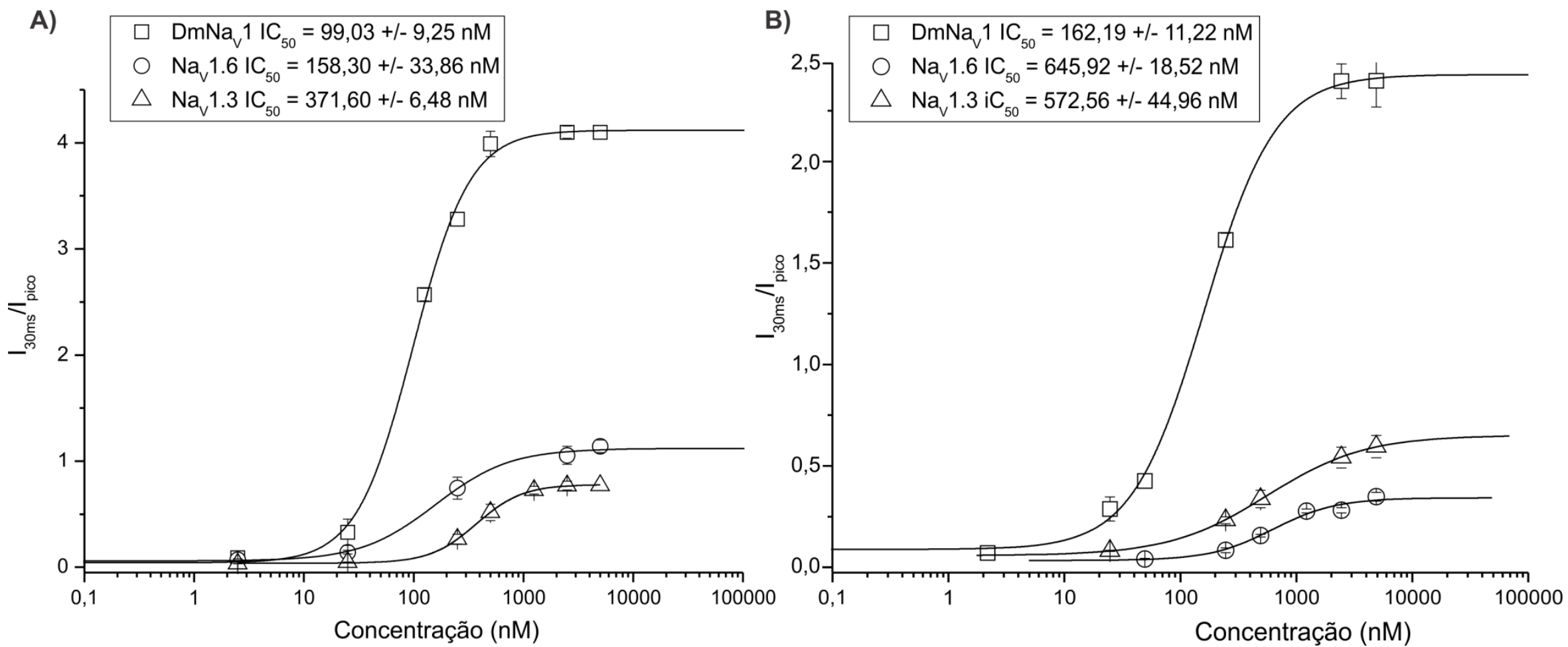

Figura 28 - A: Curva dose-resposta da toxina Acall12970 nos subtipos $\mathrm{DmNa}_{v}, \mathrm{Na}_{\mathrm{v}} 1.3$ e $\mathrm{Na}_{\mathrm{v}} 1.6$. Essa toxina apresentou uma maior afinidade para o subtipo $\mathrm{DmNa}$ do que para os subtipos $\mathrm{Na}_{v} 1.3$ e Nav1.6. B: Curva dose-resposta da toxina Acalll3090 nos subtipos DmNav, Nav1.3 e $\mathrm{Na}_{v} 1.6$. Como a Acallı2970, a Acalll3090 também apresentou uma maior afinidade para o subtipo $\mathrm{DmNa}_{\mathrm{v}}$ do que para os subtipos $\mathrm{Na}_{\mathrm{v}} 1.3 \mathrm{e} \mathrm{Na}_{\mathrm{v}} 1.6$.

Tabela 5 - Sumário dos valores de IC 50 obtidos da Acalll2970 e Acalll3090 em canais voltagem dependentes de sódio.

$\mathrm{IC}_{50}$ AcallI2970 IC $\quad \mathrm{C}_{50}$ Acalll3090

\begin{tabular}{ccc}
\hline $\mathrm{DmNa}_{\mathrm{v}} 1$ & $162,19 \pm 11,22 \mathrm{nM}$ & $99,03 \pm 9,25 \mathrm{nM}$ \\
$\mathrm{Na}_{\mathrm{v}} 1.3$ & $572,56 \pm 44,96 \mathrm{nM}$ & $371,60 \pm 6,48 \mathrm{nM}$ \\
$\mathrm{Na}_{\mathrm{v}} 1.6$ & $645,92 \pm 18,52 \mathrm{nM}$ & $158,30 \pm 33,86 \mathrm{nM}$
\end{tabular}


4.2.3 Determinação da sequência N-terminal e busca por similaridades

Até a presente data, foi determinada somente a sequência parcial dos aminoácidos da Acall12970 e Acalll3090. As sequências obtidas estão descritas na Tabela 6.

Tabela 6 - Sequências N-terminais

\begin{tabular}{ll}
\hline Composto & \multicolumn{1}{c}{ Sequência } \\
\hline AcallI2970 & GVPCLCESGG... \\
AcallI3090 & GVPCLCESDGPSVHGNTLSGTIWVFGCPEGWHDCK... \\
\hline
\end{tabular}

A sequência $\mathrm{N}$-terminal das toxinas Acalll2970 (4881,7 Da) e Acalll3090 (4880,5 Da) apresentaram similaridade com outras toxinas de anêmonas do mar, as quais, por sua vez, apresentam atividade em canais Navs, classificadas como toxinas de anêmonas do mar do tipo 1 de canais de sódio (Figura 29). 


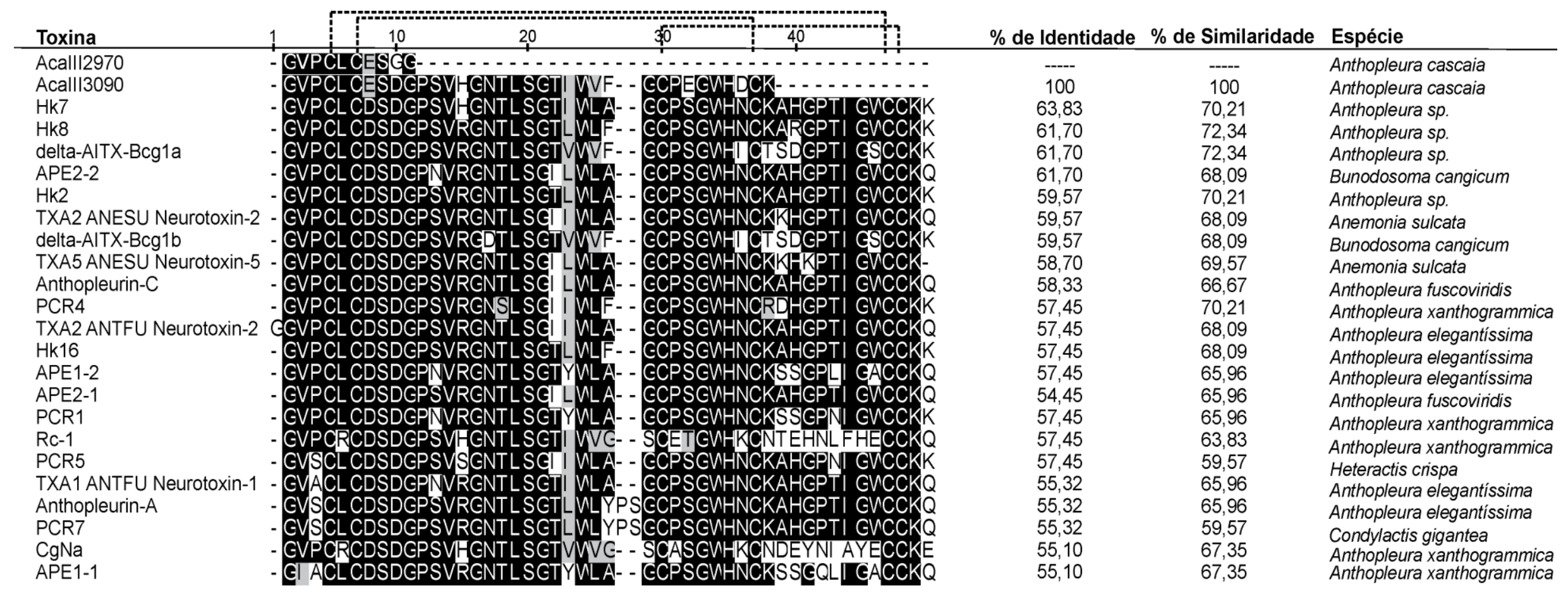

Figura 29 - Alinhamento das toxinas AcallI2970 e Acallı3090. Estas apresentaram homologia com outras toxinas de anêmonas do mar como: Neurotoxin-5 (P01529) e Neurotoxin-2 (P01528) de Anemonia sulcata; Hk2 (P0C5F4), Hk7 (P0C5F5), Hk8 (P0C5F6) e Hk16 (P0C5F7) de Anthopleura sp. (strain 'Zhanjiang'); APE1-1 (P0C1F0), APE12 (P0C1F1), APE2-1 (P0C1F2), APE2-2 (P0C1F3) e Anthopleurin-C (P01532) de Anthopleura elegantíssima; CgNa (P0C280) de Condylactis gigantea; Neurotoxin-1 (P10453) e Neurotoxin-2 (P10454) de Anthopleura fuscoviridis; Rc-1 (P0C5G5) de Heteractis crispa; delta-AITX-Bcg1a (P86459) e delta-AITX-Bcg1b (P86460) de Bunodosoma cangicum; PCR1 (P0C5F8), PCR4 (P0C5G1), PCR5 (P0C5G2), PCR7 (P0C5G4) e Anthopleurin-A (P01530) de Anthopleura xanthogrammica. As linhas pontilhadas acima do alinhamento representa o padrão de pontes dissulfeto para toxinas de anêmona do mar do tipo 1 de canal de sódio. 


\subsection{Resultados: Acall/1425}

\subsubsection{Terceira etapa de fracionamento}

A fração Acalll1425 (respectiva ao número 2 no cromatograma da Figura 23) foi utilizada para dar continuidade ao processo de purificação. A cromatografia de fase reversa (RP-HPLC) resultou em um pico majoritário (Figura 30). A pureza desse pico foi confirmada por espectrometria de massas. O pico foi denominado Acalll1425, por ser o majoritário e único em quantidade suficiente para ser utilizado em ensaios eletrofisiológico, na determinação de sua massa por meio de espectrometria e na determinação da estrutura primaria (Tabela 4). 


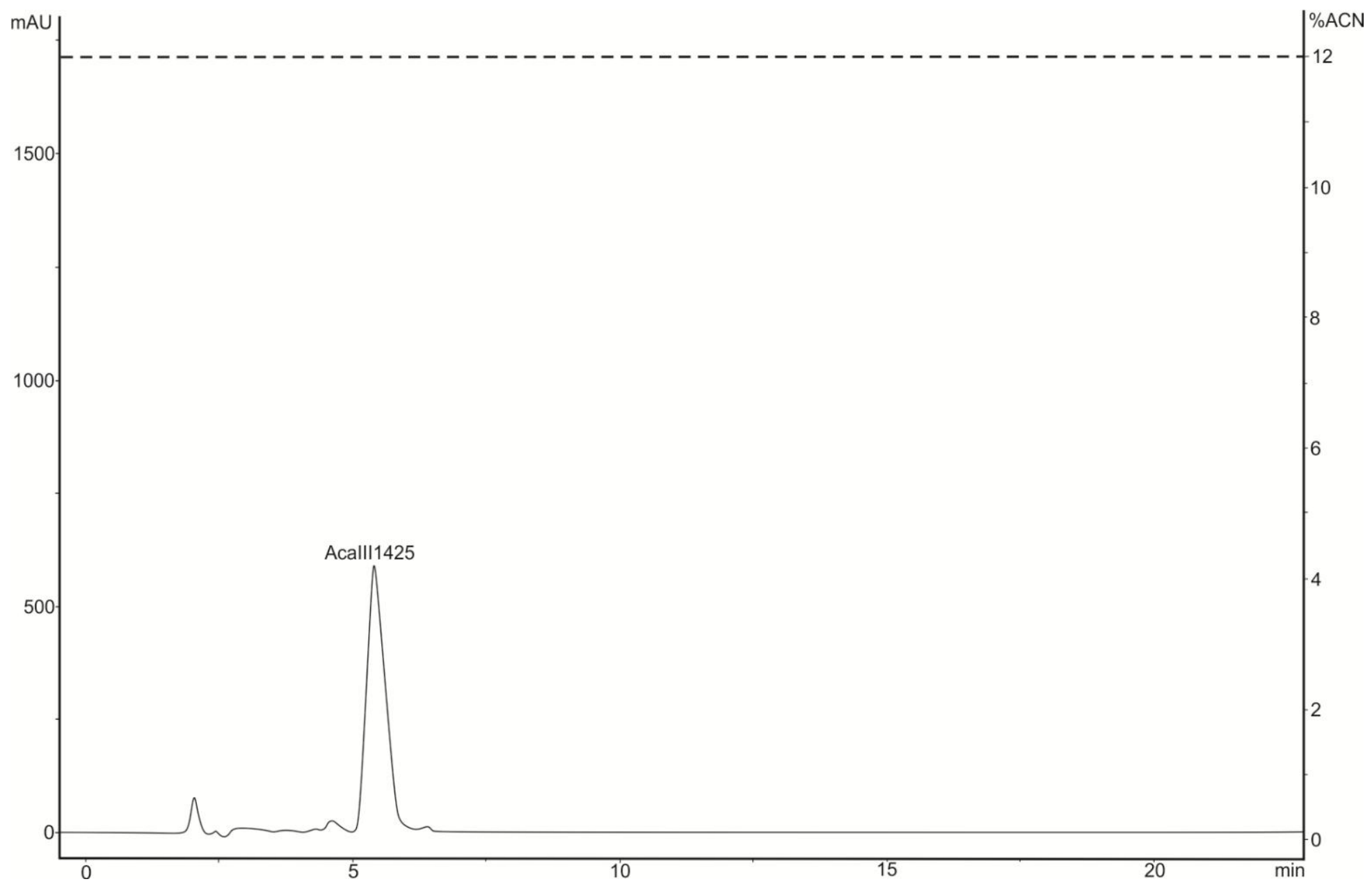

Figura 30 - Perfil cromatográfico da fase reversa (HPLC) da fração Acalll1425. Coluna: CAPCELL PAK C-18 (4,6 X $250 \mathrm{~mm})$ equilibrada com eluente A (água). A Acalll1425 foi eluída no modo isocrático do eluente B (12\% de acetonitrila). Amostra: $200 \mu \mathrm{g}$ de proteínas. Fluxo: 1,0 mL/min. A eluição foi monitorada pela absorbância a $214 \mathrm{~nm}$. 


\subsubsection{Ensaio eletrofisiológico}

O screening da toxina Acalll1425 (3887,4 Da) foi realizado em uma concentração de $5 \mu \mathrm{M}$ nos subtipos de canais de potássio voltagemdependentes das Subfamílias: Shaker: $\mathrm{K}_{\mathrm{v}} 1.1$, $\mathrm{K}_{\mathrm{v}} 1.2$, $\mathrm{K}_{\mathrm{v}} 1.3, \mathrm{~K}_{\mathrm{v}} 1.4, \mathrm{~K}_{\mathrm{v}} 1.5, \mathrm{~K}_{\mathrm{v}} 1.6$ e Shaker IR (Drosophila melanogaster); Subfamília Shab: $K_{\mathrm{v}} 2.1$; Subfamília Shaw: $K_{\mathrm{v}} 3.1$; Subfamília Shal: $\mathrm{K}_{\mathrm{v}} 4.2$ e $\mathrm{K}_{\mathrm{v}} 4.3$ e Subfamília EAG: hERG (human ether-a-go-go-related gene) (Figura 31); nos subtipos de canais de sódio voltagem-dependentes $\mathrm{Na}_{v} 1.2, \mathrm{Na}_{v} 1.4, \mathrm{Na}_{v} 1.6$ e DmNav1 (Figura 32). Como resultado, obtivemos um bloqueio da corrente nos subtipos $\mathrm{K}_{\mathrm{v}} 1.1$ e $\mathrm{K}_{\mathrm{v}} 1.6$, da subfamília Shaker e Kv4.3, da subfamília Shal. A porcentagem de bloqueio da corrente dos subtipos $\mathrm{K}_{\mathrm{v}} 1.1$, $\mathrm{K}_{\mathrm{v}} 1.6$ e $\mathrm{K}_{\mathrm{v}} 4.3$ foi de aproximadamente $40 \%, 100 \%$ e $5 \%$, respectivamente. Os subtipos $\mathrm{K}_{\mathrm{v}} 1.2, \mathrm{~K}_{\mathrm{v}} 1.3, \mathrm{~K}_{\mathrm{v}} 1.4, \mathrm{~K}_{\mathrm{v}} 1.5, \mathrm{~K}_{\mathrm{v}} 2.1, \mathrm{~K}_{\mathrm{v}} 3.1$, $K_{v} 4.2$, e hERG das subfamílias Shab, Shaw, Shal e EAG não sofreram alteração na corrente (Figura 31). 


\section{Acalll1425}
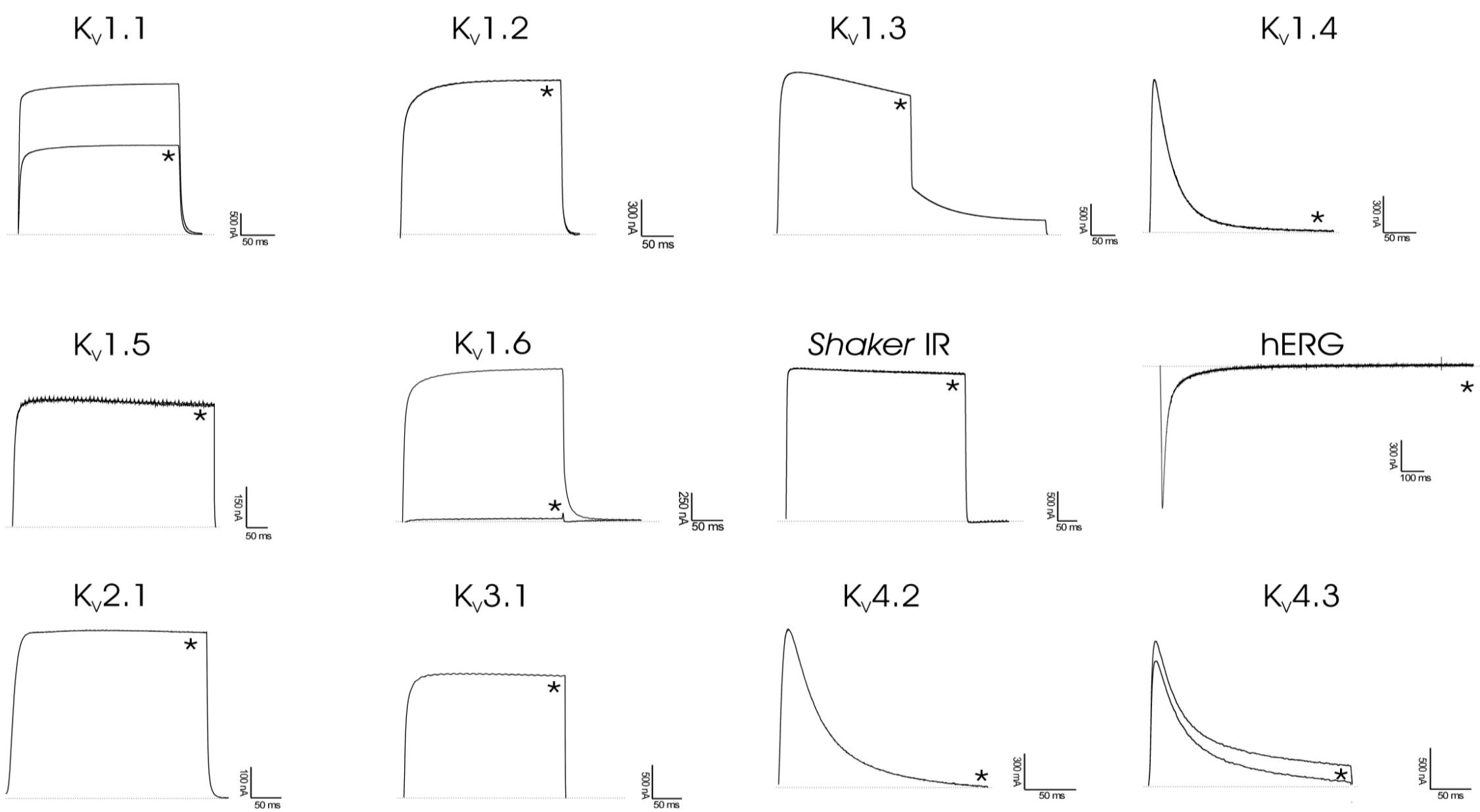

Figura 31 - Screening da Acall11425 em canais $K_{v}$ s. Os perfis representam a situação controle e quando aplicados $5 \mu \mathrm{M}$ da toxina (marcado com *). Cada subtipo foi testado em quadruplicata $(n=4)$. Essa toxina apresentou seletividade para os canais do subtipo $K_{v} 1.1$ e $K_{v} 1.6$. 
$\mathrm{Na}_{\vee} 1.2$

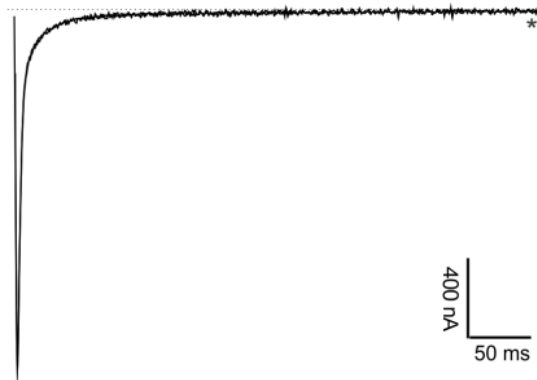

$\mathrm{Na}_{\mathrm{v}} 1.6$

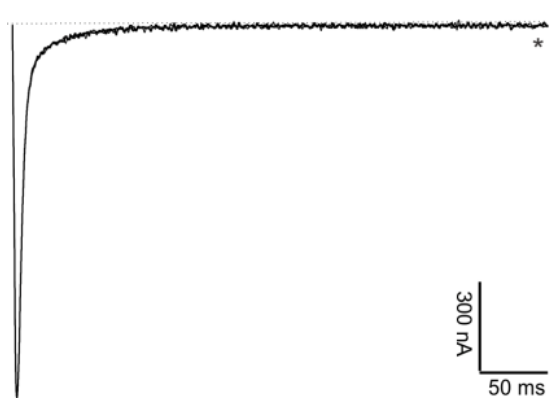

$\mathrm{Na}_{\mathrm{v}} 1.4$

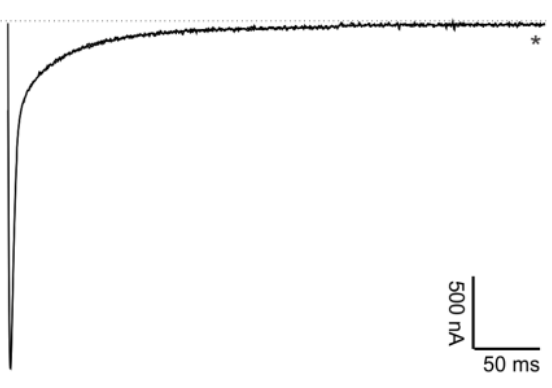

Figura 32 - Efeito da toxina Acalll1425 nos diferentes subtipos de $\mathrm{Na}_{\mathrm{V}}$. Os perfis representam a situação controle e quando aplicados 5 $\mu \mathrm{M}$ da toxina (marcado com *). Cada subtipo foi testado em quadruplicata $(n=4)$. Essa toxina não apresentou atividade nos subtipos de $\mathrm{Na}_{\mathrm{v}} s$ testados.

$\mathrm{DmNa}_{\mathrm{v}} 1$

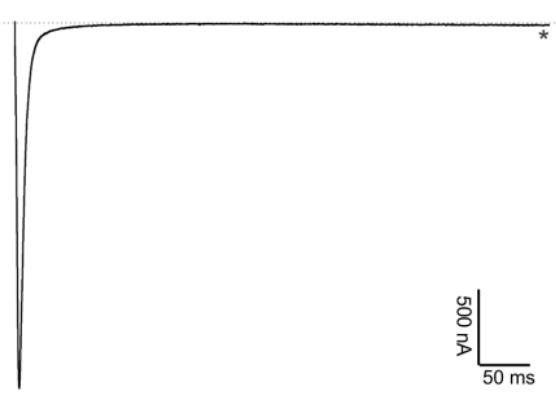


Devido a maior especificidade da toxina Acalll1425 pelos subtipos $\mathrm{K}_{\mathrm{v}} 1.1$ e $K_{V} 1.6$, foram realizados ensaios de bloqueio da corrente do canal em função da concentração da toxina (curva dose-resposta). Os valores de $\mathrm{IC}_{50}$ para os

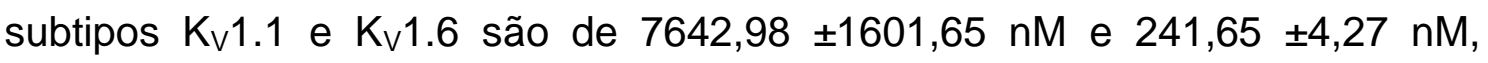
respectivamente (Figura 33). Assim, se ranquearmos de acordo com potência da Acall1425 teremos: $K_{V} 1.6 \gg>K_{V} 1.1$. A Acalll1425 é cerca de 32 vezes mais potente em canais do subtipo $\mathrm{K}_{\mathrm{V}} 1.6$ do que em relação aos canais do subtipo $\mathrm{K}_{\mathrm{V}} 1.1$.

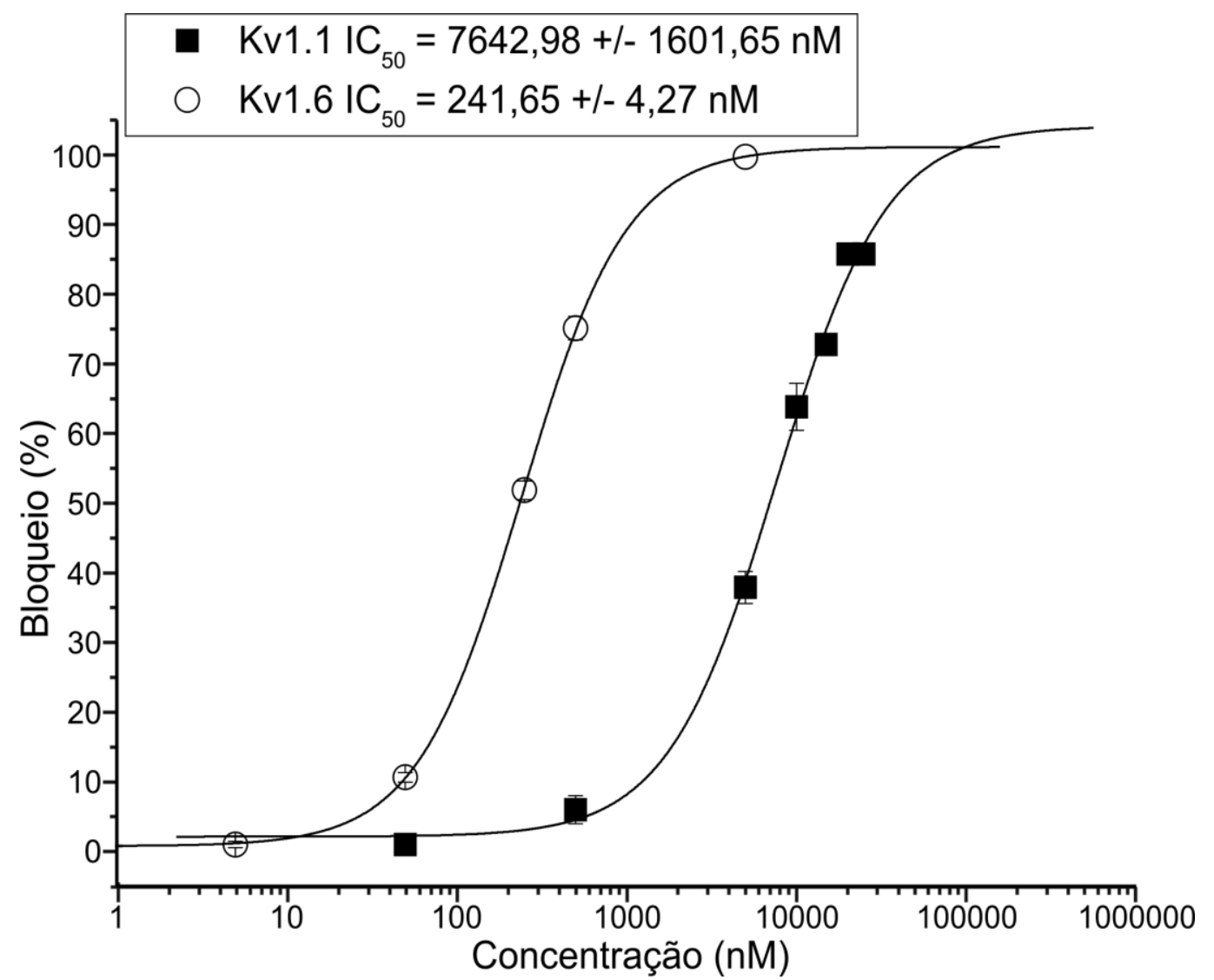

Figura 33 - Curva dose-resposta da toxina Acalll1425. Essa toxina apresentou uma maior afinidade para o subtipo $\mathrm{K}_{\mathrm{v}} 1.6$ do que para o subtipo $\mathrm{K}_{\mathrm{v}} 1.1$.

Uma vez que a toxina Acall11425 apresentou maior afinidade pelo canal rK 1.6 , essa isoforma foi utilizada para uma caracterização mais detalhada da inibição dos canais.

Com a finalidade de investigarmos se a inibição da corrente observada quando a toxina se liga ao canal $\mathrm{rK}_{\mathrm{v}} 1.6$ é devido a um bloqueio do poro ou por uma alteração do gating do canal, as curvas IV (corrente Vs voltagem) em solução ND96 e HK foram construídas (Figura 34). A aplicação de 250 nM de 
toxina Acalll1425 causou uma inibição de $55.36 \pm 4.32 \%$ e $63.14 \pm 3.44 \%$ na corrente de potássio em ND96 e HK, respectivamente $(n=4)$. Em ND96, a curva IV no controle e na presença de $250 \mathrm{nM}$ de toxina Acalll1425 foi caracterizada por um valor de $\mathrm{V}_{1 / 2}$ de $-13,5 \pm 1,1 \mathrm{mV}$ e $-12,8 \pm 1,1 \mathrm{mV} \quad(\mathrm{n}=5)$, respectivamente. A Acalll1425 não influencia significativamente o potencial reverso $E_{K}$, como pode ser visto na relação IV em solução $H K(P>0.05 ; n=5)$. Os valores de $E_{K}$ obtidos foram -7,24 \pm 1,54 $\mathrm{mV}$ para o controle e -7,46 $\pm 2,36$ $\mathrm{mV}$ após a aplicação da toxina. Desta forma, esses experimentos indicam que a inibição da corrente devido a ligação da toxina Acalll1425 não resulta de uma alteração na dependência de voltagem do gating do canal. 

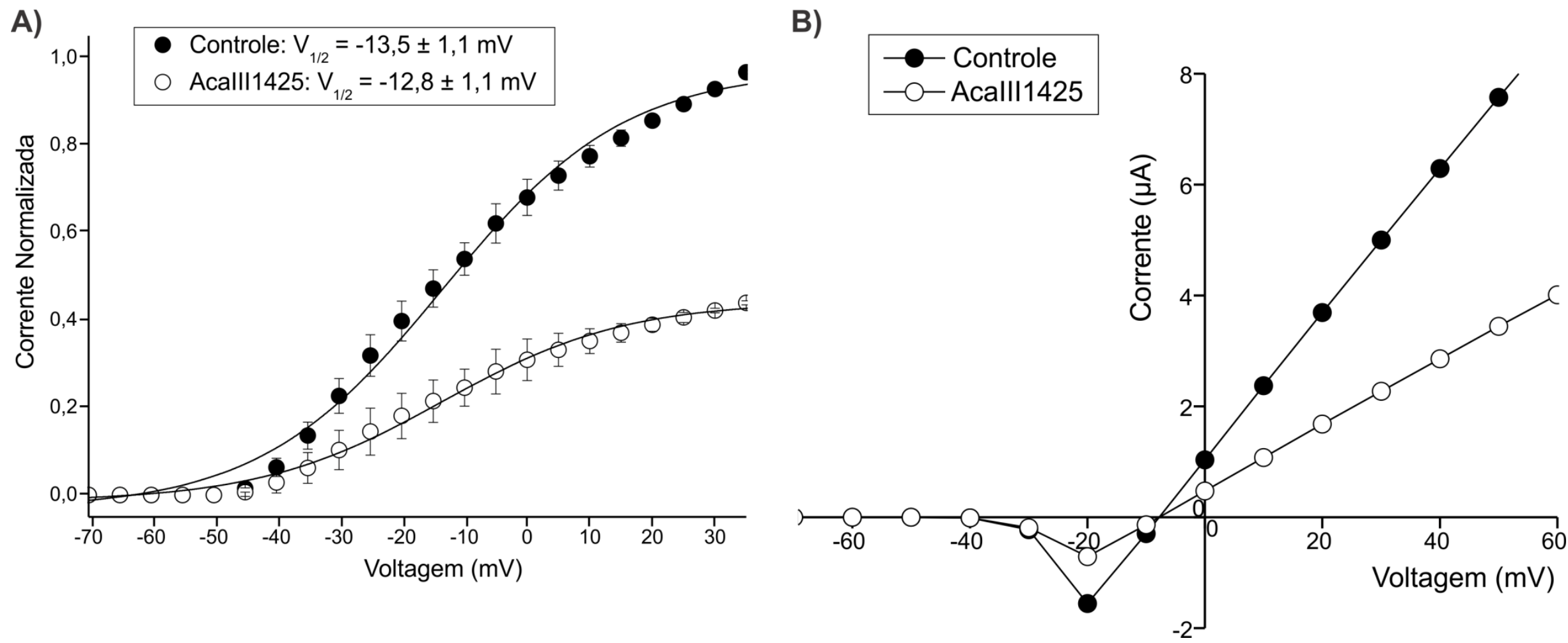

Figura 34 - Curvas da relação entre corrente e voltagem (IV). Os círculos fechados representam o controle e os círculos abertos na presença de $250 \mathrm{nM}$ de toxina Acalll1425. Em " $A$ ", curva IV em solução ND96. A curva IV, no controle e na presença de $250 \mathrm{nM}$ de toxina Acalll1425, foi caracterizada por um valor de $\mathrm{V}_{1 / 2}$ de $-13,5 \pm$ $1,1 \mathrm{mV}$ e $-12,8 \pm 1,1 \mathrm{mV}(\mathrm{n}=5)$, respectivamente; $\mathrm{Em}$ " $\mathrm{B}$ ", IV em solução HK, onde os círculos fechados representam o controle e o os círculos abertos na presença de 250 nM de toxina Acalll1425. Não foram observados deslocamentos significativos. 


\subsubsection{Determinação da sequência N-terminal e busca por similaridades}

A sequência de aminoácidos da Acalll 1425 está representada na Tabela 7. As análises de similaridade estrutural com outras toxinas estão apresentadas na Figura 35. Para facilitar as análises foi construído um dendograma funcional, que será apresenta a seguir.

Tabela 7 - Sequência de aminoácidos da toxina Acalll1425.

\begin{tabular}{ccc}
\hline Composto & Sequência & $\mathbf{n}^{\circ}$ de Aminoácidos \\
\hline \hline AcallI1425 & CGGAGAKCSTKSDCCSGLWCSGSGHCYHRRYT & 32 \\
\hline
\end{tabular}

\subsubsection{Dendograma funcional}

O dendograma funcional foi construído utilizando o método Maximum Likelihood para análise da toxina Acalll1425, e está representado na Figura 36. Esse foi construído a partir do alinhamento da Figura 35. Os códigos de acesso no UniProt, o nome da toxina e de que espécie foi extraída encontram-se na Tabela 8.

Podemos observar que o dendograma funcional resultou em dois ramos principais, separando as toxinas provenientes de peçonhas de aranhas e das toxinas provenientes de moluscos do gênero Conus e da Acalll1425 (seta pontilhada na Figura 36). Dentro dos ramos menores as toxinas foram agrupadas de acordo com sua atividade. A Acalll1425 encontra-se na base do grupo das conotoxinas. Esse grupo divide-se em toxinas ativas em canais $\mathrm{Cav}$ e toxinas ativas em $\mathrm{Nav}_{\mathrm{v}}$, sendo que a Acalll1425 foi agrupada com as conotoxinas que apresentam atividade em canais $\mathrm{Cav}$. 


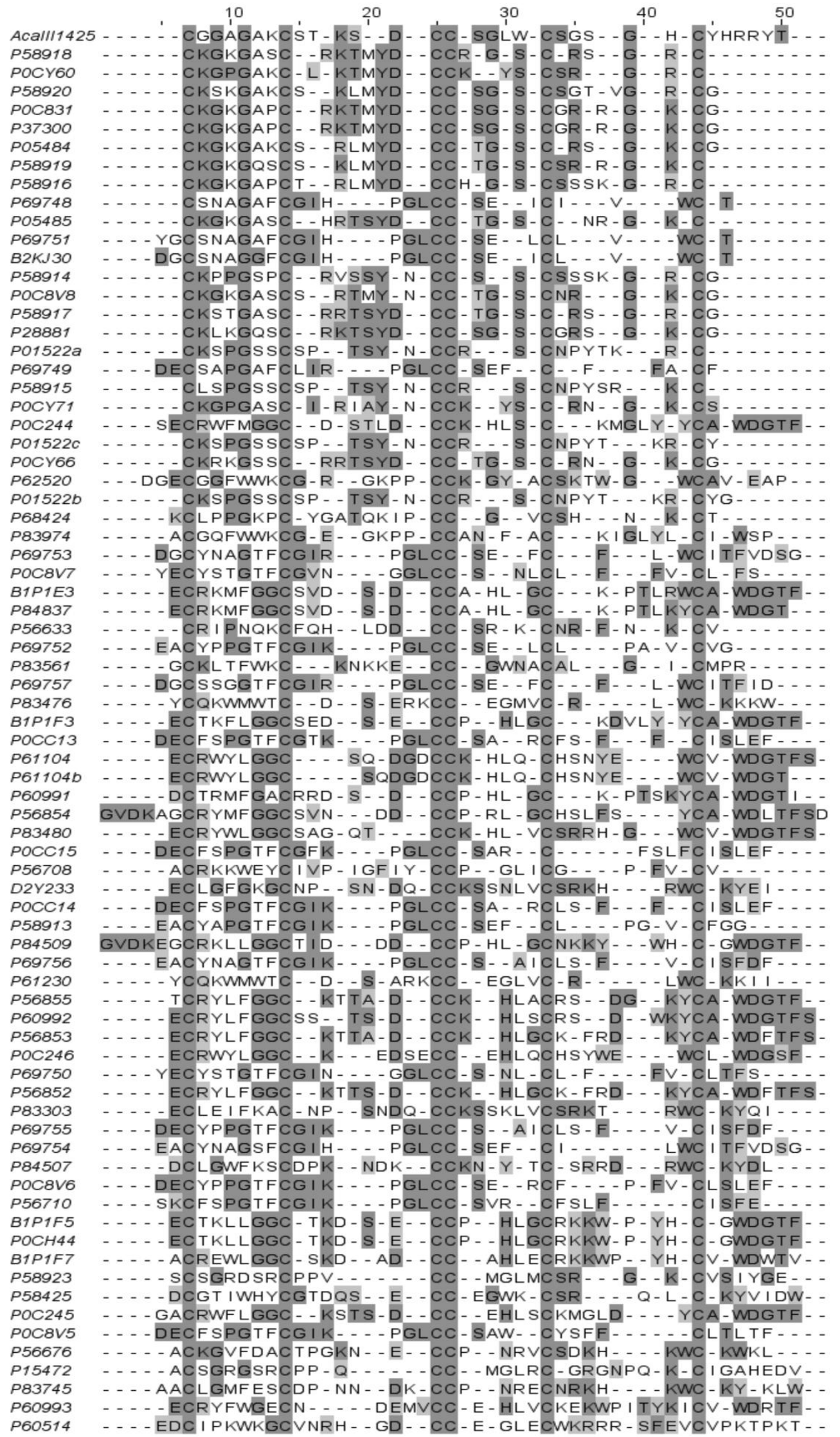

Figura 35 - Alinhamento construído utilizando a ferramenta align do UniProt e refinado manualmente. Todas as toxinas utilizadas apresentam o mesmo padrão de pontes dissulfeto. Os respectivos códigos de acesso do UniProt, o nome da toxina e a espécie da qual foi extraída a peçonha encontram-se na Tabela 8. 
Tabela 8 - Código de acesso, nome das toxinas e espécie da qual foram extraídas, referente às toxinas utilizadas no alinhamento e no dendograma funcional.

\begin{tabular}{|c|c|c|}
\hline Código UniProt & Toxina & Espécie \\
\hline P58918 & Omega-conotoxin CVIB & Conus catus \\
\hline P0CY60 & Omega-conotoxin-like Bu1 & Conus bullatus \\
\hline P58920 & Omega-conotoxin CVID & Conus catus \\
\hline P0C831 & Omega-conotoxin-like S6.6 & Conus striatus \\
\hline P37300 & Omega-conotoxin MVIIC & Conus magus \\
\hline P05484 & Omega-conotoxin MVIIA & Conus magus \\
\hline P58919 & Omega-conotoxin CVIC & Conus catus \\
\hline P58916 & Omega-conotoxin CnVIIA & Conus consors \\
\hline P69748 & Delta-conotoxin-like AVIA & Conus aurisiacus \\
\hline P05485 & Omega-conotoxin MVIIB & Conus magus \\
\hline P69751 & Delta-conotoxin-like CVIE & Conus catus \\
\hline $\mathrm{B} 2 \mathrm{KJ} 30$ & Delta-conotoxin-like S6.8 & Conus striatus \\
\hline P58914 & Omega-conotoxin RVIA & Conus radiatus \\
\hline P0C8V8 & Omega-conotoxin-like Ac6.4 & Conus achatinus \\
\hline P58917 & Omega-conotoxin CVIA & Conus catus \\
\hline P28881 & Omega-conotoxin SVIB & Conus striatus \\
\hline P01522a & Omega-conotoxin GVIA & Conus geographus \\
\hline P69749 & Delta-conotoxin-like BVIA & Conus bullatus \\
\hline P58915 & Omega-conotoxin TVIA & Conus tulipa \\
\hline POCY71 & Conotoxin Bu13 & Conus bullatus \\
\hline P0C244 & Tau/kappa-theraphotoxin-Pc1a & Psalmopoeus cambridgei \\
\hline P01522c & Omega-conotoxin GVIC & Conus geographus \\
\hline P0CY66 & Omega-conotoxin-like Bu8 & Conus bullatus \\
\hline P62520 & Beta-theraphotoxin-Cj1a & Chilobrachys jingzhao \\
\hline P01522b & Omega-conotoxin GVIB & Conus geographus \\
\hline P68424 & Omega-theraphotoxin-Hh1a & Haplopelma schmidti \\
\hline P83974 & Delta-theraphotoxin-Cj1a & Chilobrachys jingzhao \\
\hline P69753 & Delta-conotoxin-like MVIA & Conus magus \\
\hline P0C8V7 & Delta-conotoxin-like Ac6.3 & Conus achatinus \\
\hline B1P1E3 & Kappa-theraphotoxin-Cj1a & Chilobrachys jingzhao \\
\hline P84837 & Kappa-theraphotoxin-Pg2a & Chilobrachys jingzhao \\
\hline P56633 & Kappa-conotoxin PVIIA & Conus purpurascens \\
\hline P69752 & Delta-conotoxin-like EVIB & Conus ermineus \\
\hline P83561 & Beta-hexatoxin-Mg1a & Macrothele gigas \\
\hline P69757 & Delta-conotoxin-like SmVIA & Conus stercusmuscarum \\
\hline P83476 & Beta/omega-theraphotoxin-Tp2a & Thrixopelma pruriens \\
\hline B1P1F3 & U17-theraphotoxin-Cj1a & Chilobrachys jingzhao \\
\hline P0CC13 & Delta-conotoxin-like CnVIB & Conus consors \\
\hline
\end{tabular}




\begin{tabular}{|c|c|c|}
\hline P61104 & Omega-theraphotoxin-Hh2a & Haplopelma schmidti \\
\hline P61104b & Omega-theraphotoxin-Hh2b & Haplopelma schmidti \\
\hline P60991 & Kappa-theraphotoxin-Sc1a & Stromatopelma calceatum \\
\hline P56854 & Omega-theraphotoxin- $\mathrm{Hg} 1 \mathrm{a}$ & Hysterocrates gigas \\
\hline P83480 & Beta-theraphotoxin-Tp1a & Thrixopelma pruriens \\
\hline P0CC15 & Delta-conotoxin-like CnVID & Conus consors \\
\hline P56708 & Mu-conotoxin MrVIA & Conus marmoreus \\
\hline D2Y233 & Mu-theraphotoxin-Hhn1b & Haplopelma hainanum \\
\hline P0CC14 & Delta-conotoxin-like CnVIC & Conus consors \\
\hline P58913 & Delta-conotoxin PVIA & Conus purpurascens \\
\hline P84509 & Beta-theraphotoxin- $\mathrm{Cm} 2 \mathrm{a}$ & Ceratogyrus marshalli \\
\hline P69756 & Delta-conotoxin-like MVID & Conus magus \\
\hline P61230 & Kappa-theraphotoxin-Ps1a & Paraphysa scrofa \\
\hline P56855 & Kappa-theraphotoxin-Scg1a & Stromatopelma calceatum griseipes \\
\hline P60992 & Kappa-theraphotoxin-Hm1a & Heteroscodra maculata \\
\hline P56853 & Kappa-theraphotoxin-Gr1b & Grammostola rosea \\
\hline P0C246 & Tau-theraphotoxin-Pc1c & Psalmopoeus cambridgei \\
\hline P69750 & Delta-conotoxin-like CnVIA & Conus consors \\
\hline P56852 & Kappa-theraphotoxin-Gr1a & Grammostola rosea \\
\hline P83303 & Mu-theraphotoxin-Hh2a & Haplopelma schmidti \\
\hline P69755 & Delta-conotoxin-like MVIC & Conus magus \\
\hline P69754 & Delta-conotoxin-like MVIB & Conus magus \\
\hline P84507 & Beta-theraphotoxin-Cm1a & Ceratogyrus marshalli \\
\hline P0C8V6 & Delta-conotoxin-like Ac6.2 & Conus achatinus \\
\hline P56710 & Delta-conotoxin NgVIA & Conus nigropunctatus \\
\hline B1P1F7 & Mu-theraphotoxin-Cj1a & Chilobrachys jingzhao \\
\hline P58923 & Conotoxin TVIIA & Conus tulipa \\
\hline P58425 & Kappa-sparatoxin-Hv1a & Heteropoda venatoria \\
\hline P0C245 & Tau-theraphotoxin-Pc1b & Psalmopoeus cambridgei \\
\hline P0C8V5 & Delta-conotoxin-like Ac6.1 & Conus achatinus \\
\hline P56676 & Mu/omega-theraphotoxin-Hh1a & Haplopelma schmidti \\
\hline P15472 & Mu-conotoxin GS & Conus geographus \\
\hline P83745 & Kappa-theraphotoxin-Tb1a & Theraphosa blondi \\
\hline P60993 & Kappa-theraphotoxin-Hm2a & Heteroscodra maculata \\
\hline P60514 & Pi-theraphotoxin-Pc1a & Psalmopoeus cambridgei \\
\hline
\end{tabular}




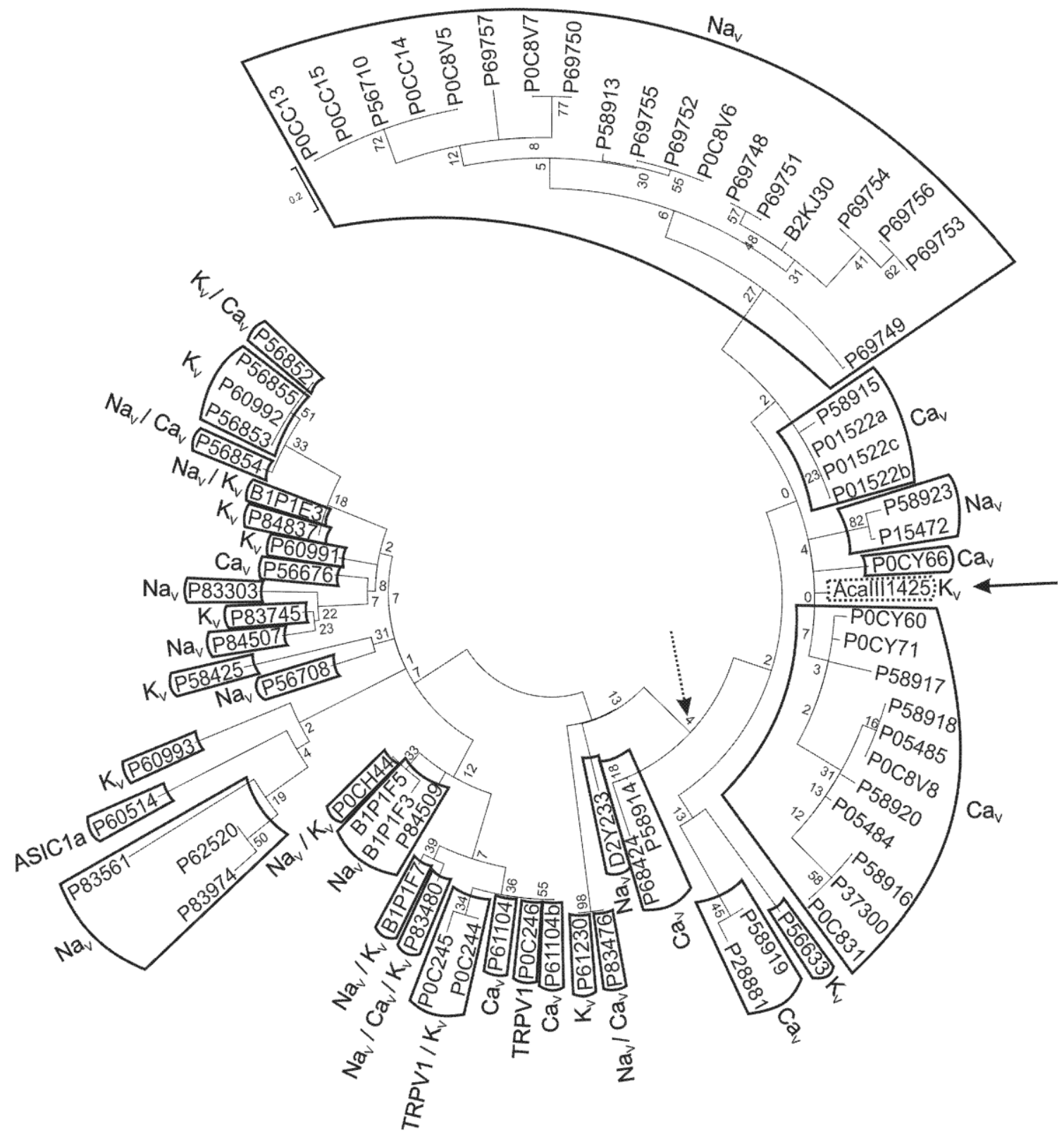

Figura 36 - Dendograma funcional construído a partir do alinhamento da Figura 35. A seta indica a posição da toxina Acallı1425, extraída da anêmona do mar Anthopleura cascaia. A seta tracejada indica a divisão em dois ramos principais, um compreendendo as toxinas provenientes de peçonhas de aranhas e outro representado por toxinas de molusco do gênero Conus e a Acalli1425. Os respectivos alvos das toxinas estão escritos ao lado destas. Quando toxinas de um mesmo ramo apresentam o mesmo alvo, estas foram agrupadas em uma caixa.

\subsubsection{Modelagem molecular}

A modelagem molecular da toxina Acalll1425 foi realizada através do programa MODELLER (Sali \& Blundell, 1993), utilizando a técnica de modelagem comparativa. Para a validação dos modelos gerados foi utilizado o programa Procheck (Laskowski et al., 1993). O modelo final foi 
selecionado conforme a qualidade estereoquímica observada no diagrama de Ramachandran e nos valores do G-factor.

A análise do diagrama de Ramachandran para o modelo da Acalll1425 (Figura 37 ) indica que $87,5 \%$ dos resíduos estão localizados nas regiões mais favoráveis (Tabela 9), com 10 resíduos localizados na região de a-hélice de mão direita (9 na região $A$ e 1 na região a) e 17 resíduos localizados na região de fita- $\beta$ (15 na região $B$ e 2 na b). Os resíduos aminoterminais e carboxiterminais não foram considerados, porque podem se localizar em qualquer região do diagrama.

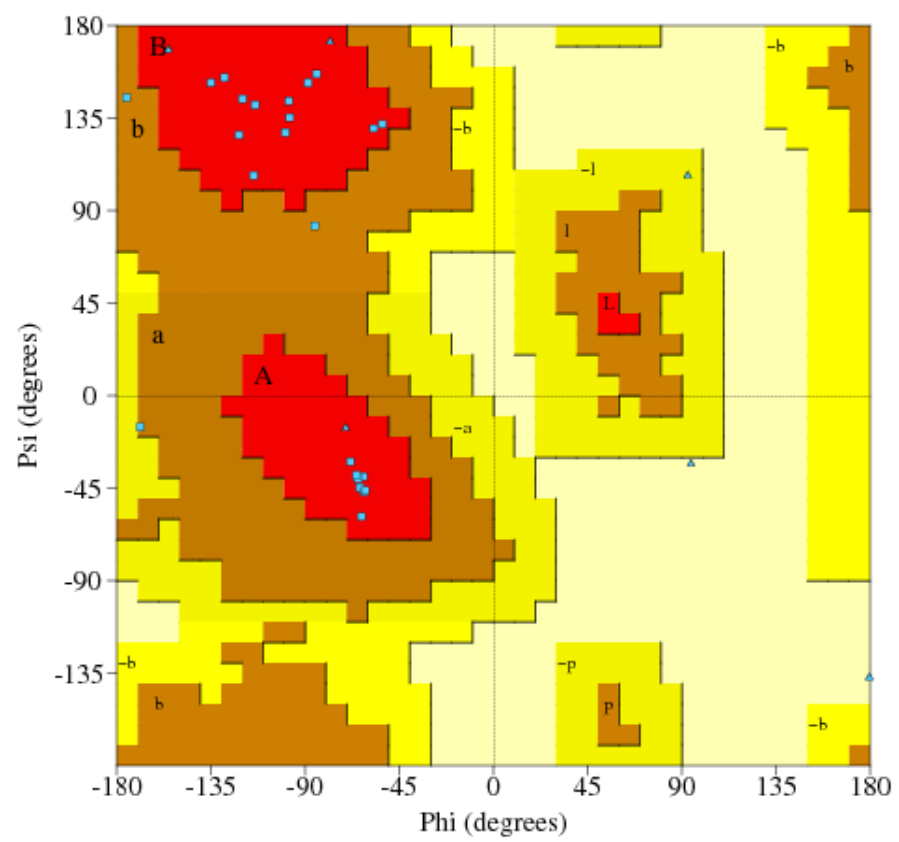

Figura 37 - Diagrama de Ramachandran gerado pelo Procheck para o modelo da toxina AcallI1425.

Como mostra a Tabela 9, a média dos valores de G-factor foi de - 0,29 para o modelo da Acalll1425.

Tabela 9 - Análise da qualidade estereoquímica para o modelo da toxina Acalll1425.

\begin{tabular}{|c|c|c|c|c|c|c|c|}
\hline \multirow[b]{2}{*}{ Peptídeo } & \multicolumn{4}{|c|}{ Região do Diagrama de Ramachandran } & \multicolumn{3}{|c|}{ G-Factor } \\
\hline & $\begin{array}{c}\text { Mais } \\
\text { Favorável } \\
(\%)\end{array}$ & $\begin{array}{c}\text { Adicionalmente } \\
\text { permitida (\%) }\end{array}$ & $\begin{array}{c}\text { Favoravelmente } \\
\text { permitida (\%) }\end{array}$ & $\begin{array}{c}\text { Não } \\
\text { permitida } \\
(\%)\end{array}$ & $\begin{array}{c}\text { Ângulo } \\
\text { de } \\
\text { Torção }\end{array}$ & $\begin{array}{l}\text { Geometria } \\
\text { covalente }\end{array}$ & $\begin{array}{c}\text { Média } \\
\text { Total }\end{array}$ \\
\hline Acalll1425 & 87,5 & 12,5 & 0 & 0 & $-0,15$ & $-0,53$ & $-0,29$ \\
\hline
\end{tabular}

A Figura 38 mostra uma representação das estruturas da toxina Acalll1425. Em "A" temos uma representação da estrutura primária e esquema da estrutura secundária. Formam-se três fitas- $\beta$, sendo que a primeira $(\beta 1)$ 
compreende os resíduos A4, G5, A6 e K7; a segunda ( $\beta 2)$ compreende G17, L18, W19 e C20; e a terceira (B3) a S23, G24, H25, C26, Y27 e H28. Em "B" temos uma representação tridimensional, em ribbon da estrutura secundária. Podemos observar a disposição das três fitas- $\beta$ antiparalelas que foram preditas. As linhas amarelas representam as pontes dissulfeto, que seguem 0 padrão C1-C4, C2-C5 e C3-C6. Esse padrão concede à estrutura tridimensional uma forma globular e o motivo estrutural ICK. Em "C" e "D" temos uma representação da superfície do modelo gerado para a estrutura tridimensional da toxina Acalll1425, com o intuito de facilitar a visualização da distribuição dos aminoácidos da toxina. Os resíduos básicos foram coloridos em azul, s ácidos em vermelho, os apolares e hidrofóbicos em verde, os polares sem carga em cinza e os aromáticos em laranja. Observa-se uma predominância de resíduos aromáticos e positivos na "face" representada em “D”, e que os resíduos hidrofóbicos e apolares, assim como o único resíduo negativo (D13) encontram-se na face da toxina representada em "C". Os aminoácidos positivos encontram-se nas extremidades da estrutura. 


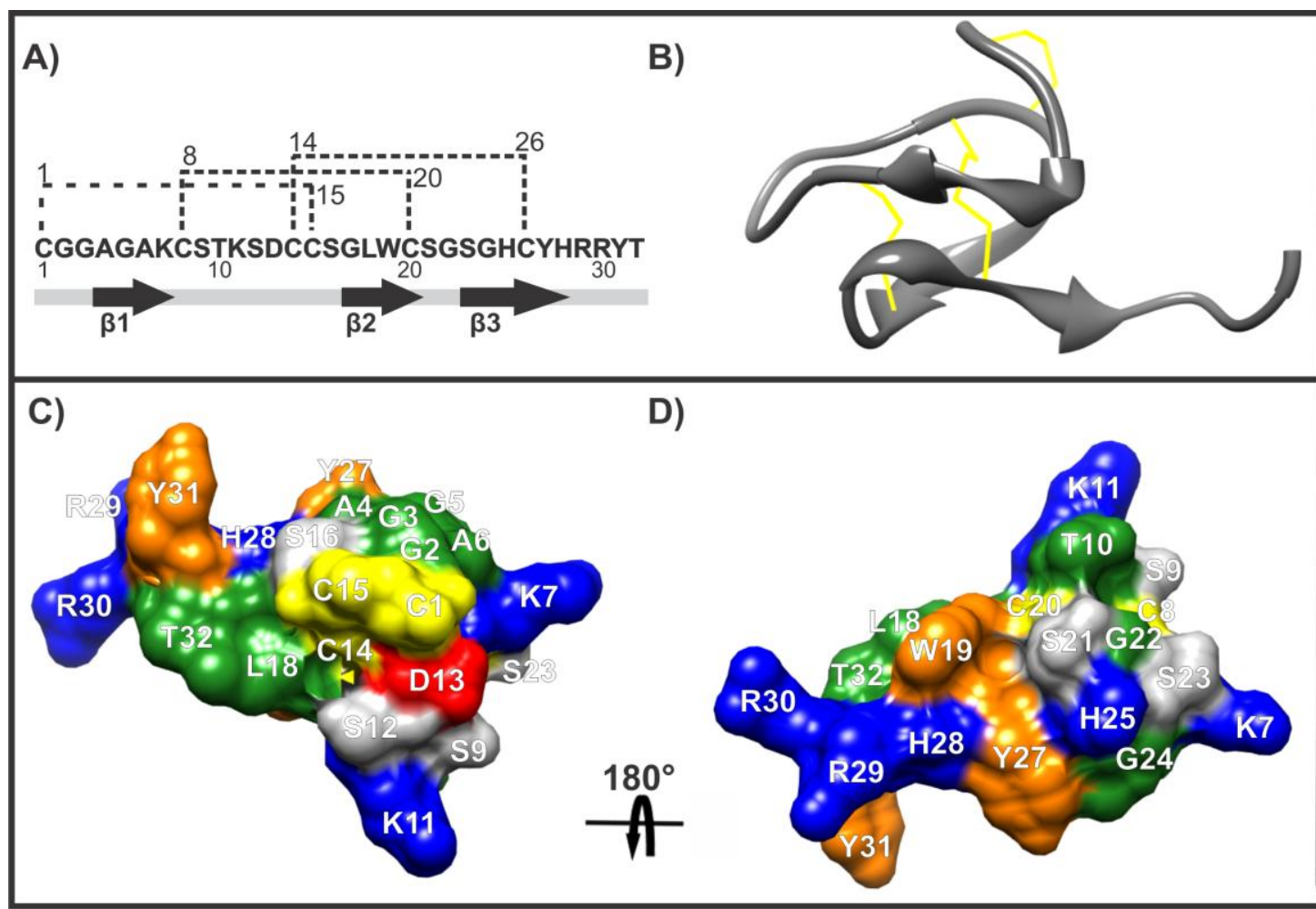

Figura 38 - Representação da estrutura da toxina AcallI1425. A) Estrutura primária da toxina Acalll1425. Linhas pontilhadas representam o possível padrão de pontes dissulfeto. Abaixo da estrutura primária encontra-se uma representação da estrutura secundária, onde as setas representam as fitas- $\beta$. B) Esquema em ribbon da estrutura secundária da toxina Acalli1425. As linhas em amarelo representam as pontes dissulfeto. C) e D) Representação da superfície da toxina Acalll1425 gerado a partir do modelo construído. Os resíduos básicos foram coloridos em azul, os ácidos em vermelho, os apolares e hidrofóbicos em verde, os polares sem carga em cinza e os aromáticos em laranja. A representação do lado direito da figura (D) é decorrente de uma rotação de $180^{\circ}$ da representação do lado esquerdo (C).

\subsubsection{Potencial eletrostático}

A aparência do potencial eletrostático na superfície da toxina Acalll1425 e canal $\mathrm{rK}_{\mathrm{v}} 1.6$ estão representados na Figura 39. Podemos observar que a superfície da toxina Acalll1425 apresenta um potencial eletrostático predominantemente positivo, formado principalmente pelas cadeias laterais dos resíduos positivamente carregados, como lisina e arginina. Diferentemente, o poro do canal $\mathrm{rK}_{\mathrm{v}} 1.6$, que se encontra fora da membrana celular, carrega um grande potencial eletrostático negativo (pontilhado vermelho) que é centrossimétrico em volta do eixo central do canal.

A resultante do momento dipolo (representado por uma seta verde na Figura 39) do canal $\mathrm{rK}_{\mathrm{V}} 1.6$ é orientada ao longo do eixo simétrico que vai do meio extracelular ao intracelular. A resultante do momento dipolo da neurotoxina Acall11425 aponta para a face representada na Figura $38 \mathrm{C}$. 
A carga líquida do canal $\mathrm{rK}_{\mathrm{v}} 1.6$ é de $-17,7$ e da toxina Acalll1425 é de 3,1. A Acalll1425 apresenta apenas um resíduo de aminoácido negativo (D13) e seis resíduos de aminoácidos positivos (K7, K11, H25, R26, R27).
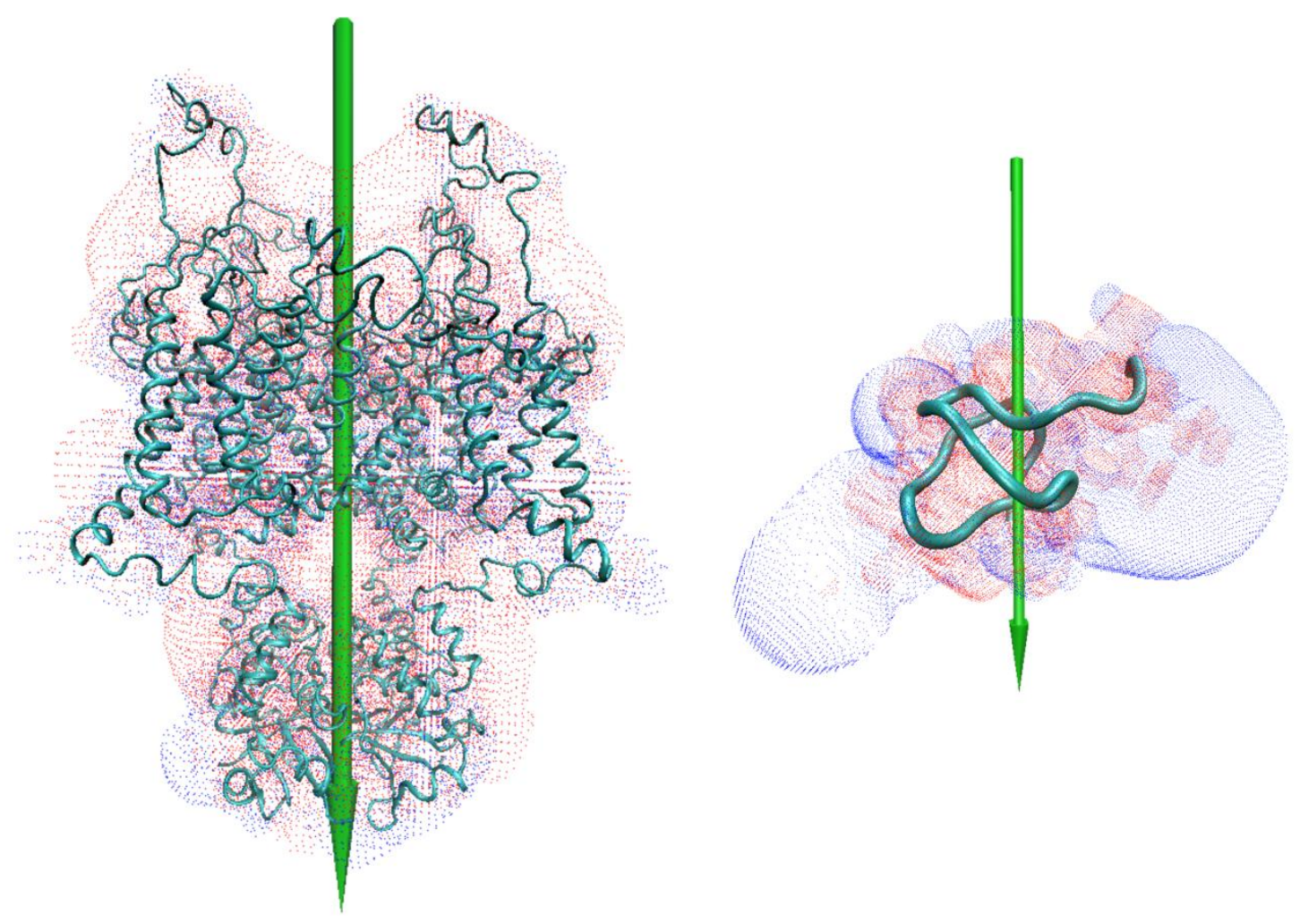

Figura 39 - Mapa do contorno do potencial eletrostático para o canal rKV1.6 e a toxina da anêmona do mar Anthopleura cascaia Acalll1425 em uma força iônica de 0,15 M. O pontilhado vermelho representa a energia de potencial eletrostático igual a $1 \mathrm{kT}$; o pontilhado azul representa a energia de potencial eletrostático igual a $1 \mathrm{kT}$. A seta em verde indica a direção do dipolo.

\subsubsection{Predição da interação entre canal e toxina - Docking}

Para obtermos um modelo representativo da interação entre a toxina Acalll1425 e o canal $\mathrm{rK}_{\mathrm{v}} 1.6$ foram gerados 1 milhão de candidatos. Os 20 melhores modelos foram analisados quanto a sua afinidade $(\mathrm{kcal} / \mathrm{mol})$, distância do RMSD no limite inferior (RMSD I.b., do inglês lower bound) e a distância do RMSD no limite superior (RMSD u.b., do inglês upper bound). Os valores estão representados na Tabela 10. Desses, foi selecionado o modelo número 1 para representar o complexo toxina-canal utilizando-se como critério de seleção a afinidade e a distância do RMSD I.b. e u.b.. A afinidade entre a toxina Acalll1425 e o canal $\mathrm{rK}_{v} 1.6$ dentre os 20 melhores modelos oscilou dentro de $0,8 \mathrm{kcal} / \mathrm{mol}$ (de $-6,0$ até $-6,8 \mathrm{kcal} / \mathrm{mol})$. 
Tabela 10 - Afinidade e distância do RMSD I.b. e u.b. dos 20 melhores modelos da interação entre a toxina da anêmona do mar Anthopleura cascaia e o canal $\mathrm{rK}_{\mathrm{v}}$ 1.6. Desses 20 modelos foi escolhido o número 1 para representar o complexo toxina-canal.

\begin{tabular}{cccc}
\hline Modelo & $\begin{array}{c}\text { Afinidade } \\
\text { (kcal/mol) }\end{array}$ & $\begin{array}{c}\text { Distância do } \\
\text { RMSD I.b. }\end{array}$ & $\begin{array}{c}\text { Distância do } \\
\text { RMSD u.b. }\end{array}$ \\
\hline \hline 1 & $-6,7$ & 0,000 & 0,000 \\
2 & $-6,8$ & 18,754 & 30,961 \\
3 & $-6,8$ & 1,284 & 2,822 \\
4 & $-6,7$ & 22,069 & 30,305 \\
5 & $-6,6$ & 19,647 & 31,312 \\
6 & $-6,5$ & 28,606 & 36,865 \\
7 & $-6,3$ & 3,802 & 8,354 \\
8 & $-6,3$ & 22,525 & 30,670 \\
9 & $-6,3$ & 10,801 & 17,820 \\
10 & $-6,3$ & 11,431 & 18,717 \\
11 & $-6,3$ & 28,212 & 36,518 \\
12 & $-6,2$ & 4,913 & 13,462 \\
13 & $-6,2$ & 2,994 & 5,775 \\
14 & $-6,2$ & 18,675 & 30,759 \\
15 & $-6,2$ & 3,628 & 11,290 \\
16 & $-6,2$ & 3,589 & 11,262 \\
17 & $-6,1$ & 4,079 & 13,529 \\
18 & $-6,1$ & 1,816 & 3,665 \\
19 & $-6,0$ & 22,251 & 29,404 \\
20 & $-6,0$ & 3,879 & 14,326 \\
\hline \hline
\end{tabular}

A Figura 40 é uma representação gráfica da vista lateral do modelo do canal rKv1.6 (Figura 40, A), da superfície do canal com as subunidades coloridas (Figura 40, B), da superfície do complexo canal-toxina do modelo 1 obtido no docking (Figura 40, C) e da face de contato da toxina com o canal (Figura 40, D). Podemos observar que a toxina Acall11425 ocluí fisicamente 0 poro do canal rKv1.6 impossibilitando a passagem de íons potássio (Figura 40, C). A face de contato (Figura 40, D - figura de maior tamanho) apresenta uma maior concentração de resíduos positivos e aromáticos, que seguem uma disposição resíduos positivos-aromáticos-positivos. Já a face oposta (Figura 40, D - figura de menor tamanho) apresenta o único aminoácido negativo (D13) e resíduos hidrofóbicos e apolares. 


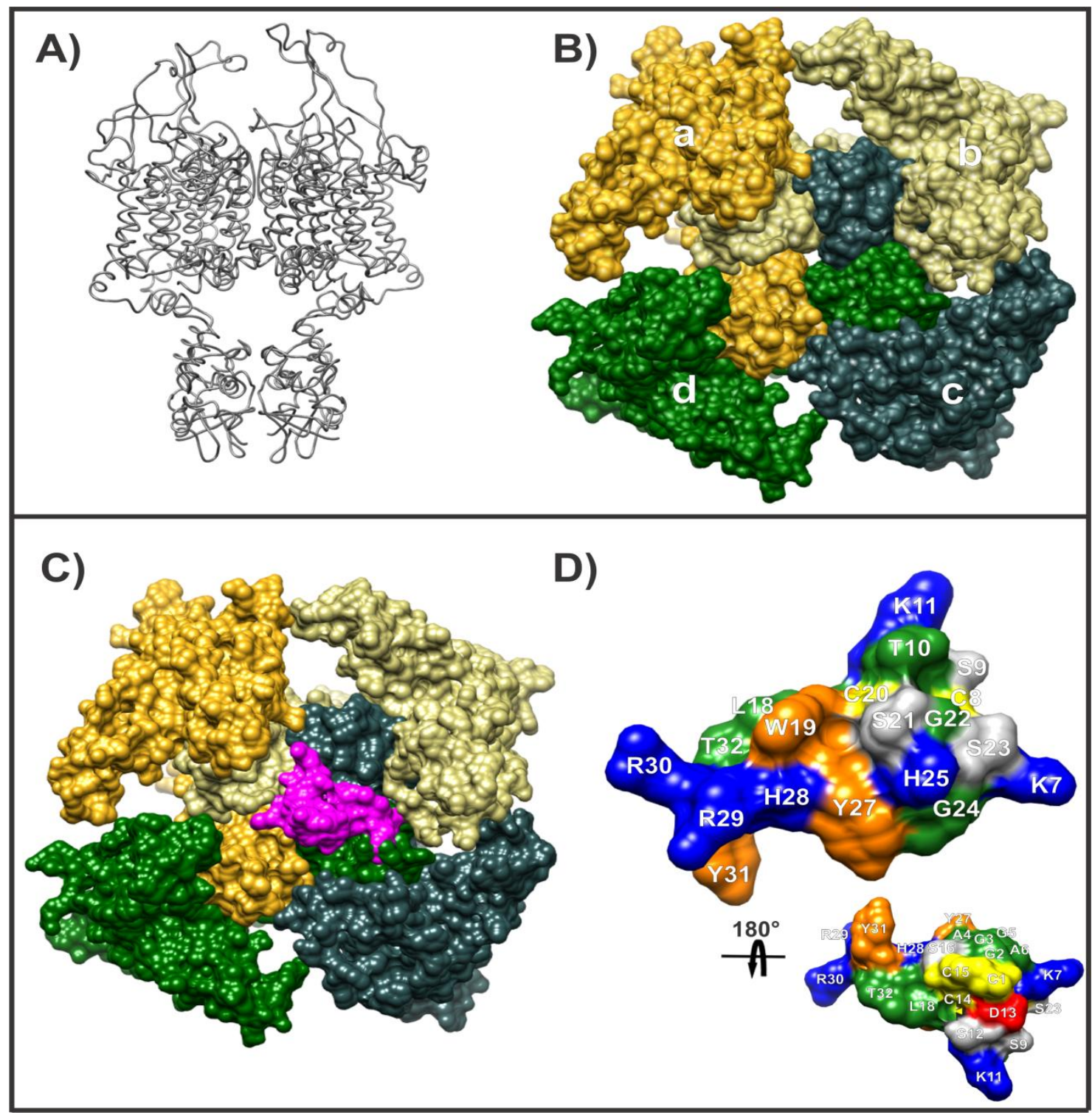

Figura 40 - A) Representação da vista lateral da parte extracelular do modelo do canal rK 1.6 ; B) Representação da superfície do canal $\mathrm{rK}_{\mathrm{v}} 1.6$ visto de cima. $\mathrm{a}, \mathrm{b}, \mathrm{c}$ e d representam um dos quatro domínios que formam o canal $\mathrm{rK}_{\mathrm{v}}$ 1.6. Esses domínios foram coloridos cada um de uma cor, para melhor visualização. C) Figura representativa da superfície do complexo toxina-canal do modelo 1 gerado no docking. A superfície da toxina Acalll1425 está representada em rosa. D) Em maior tamanho está representada a face de contato da toxina Acallı1425 com a superfície do canal rK 1.6 . A figura menor é a face oposta, que é vista de cima quando observamos a figura C).

A análise do grau de hidrofobicidade da superfície do complexo toxinacanal encontra-se na Figura 41. Podemos observar que a região do poro do canal $\mathrm{rK}_{\mathrm{v}} 1.6$ é levemente hidrofóbica com alguns pontos hidrofílicos. Esses pontos foram circulados e numerados (Figura 41, B). Os pontos de contato da toxina Acalll1425 com esses pontos do canal também foram circulados (Figura 41, C e D). Essas regiões circuladas na toxina também são hidrofílicas e 0 centro de sua estrutura tridimensional é levemente hidrofóbica, semelhante à região do poro do canal. 


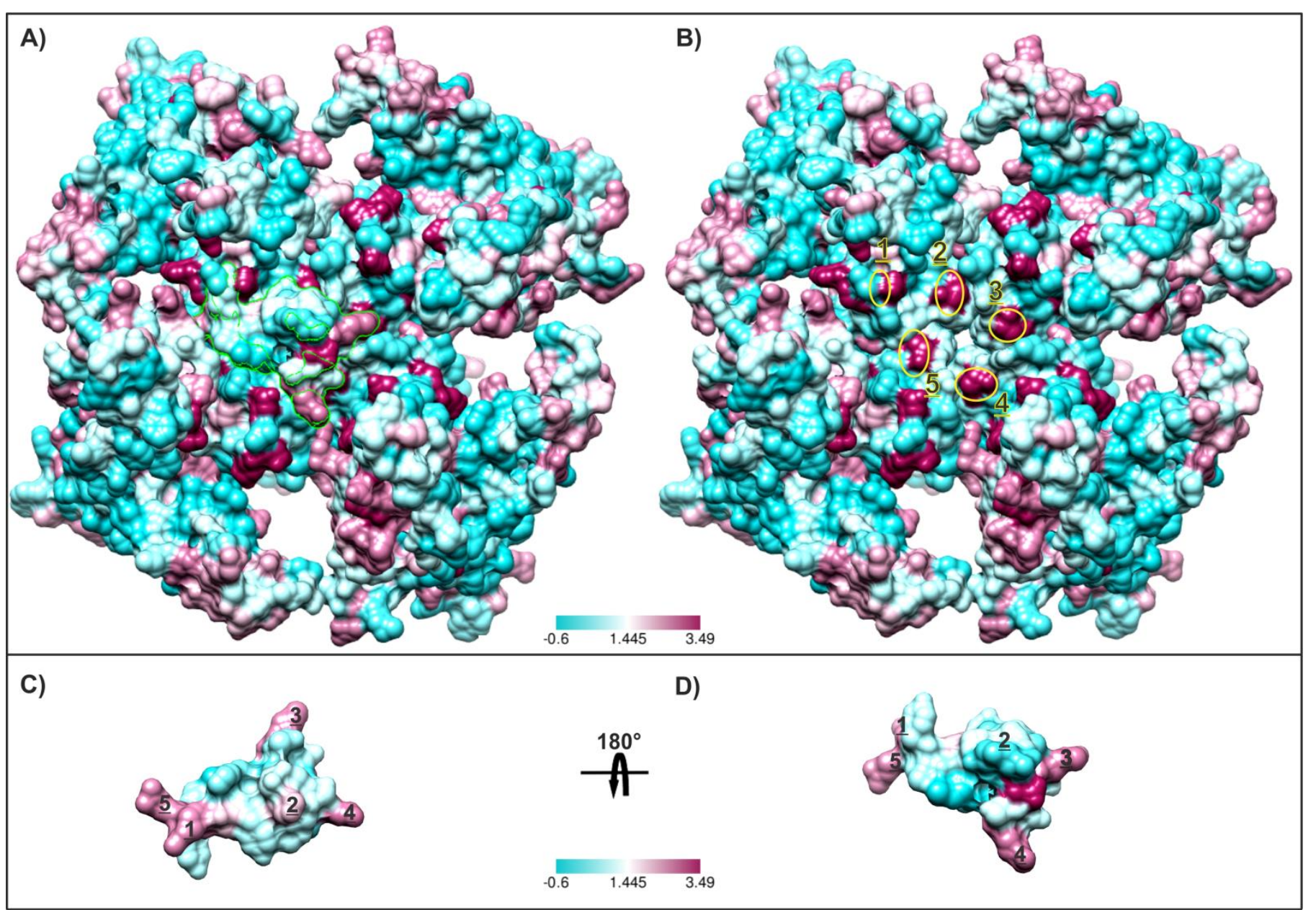

Figura 41 - Superfície da toxina Acalll1425 e do canal $\mathrm{rK}_{\mathrm{v}} 1.6$ representadas segundo a escala de hidrofobicidade padronizada por Hessa e colaboradores (2005), onde valores mais negativos refletem maior hidrofobicidade. Em A): Superfície do complexo toxinacanal do modelo 1 gerado no docking. A toxina Acalll1425 está contornada em verde para podermos identificá-la; B) Canal r $\mathrm{K}_{\mathrm{v}} 1.6$. Os pontos circulados e numerados de 1 a 5 , marcam regiões mais hidrofílicas do canal que fazem contatos com regiões da toxina Acalll1425, também hidrofílicas; C) Face de contato da toxina Acalll1425 com a superfície do canal rKV1.6. Os pontos que foram marcados em "B", também foram marcados na toxina. Essas regiões também são hidrofílicas e o centro da toxina é levemente hidrofóbico, como a região do poro do canal; D) Face oposta ao contato da toxina com o canal. 
O modelo selecionado foi analisado no programa LigPlot ${ }^{+}$para verificar os possíveis aminoácidos responsáveis por essa interação. Os pares de aminoácidos que possivelmente fazem ligações de hidrogênio no complexo toxina-canal e a distância entre eles encontram-se na Tabela 11.

Tabela 11 - Possíveis ligações de hidrogênio formadas entre a toxina Acalll1425 da anêmona do mar Anthopleura cascaia e o canal $\mathrm{rK}_{\mathrm{v}} 1.6$ no complexo toxina-canal. Os pares de interações foram organizados de acordo com a localização no canal $\mathrm{rK}_{\mathrm{v}} 1.6$.

\begin{tabular}{|c|c|c|c|c|c|}
\hline & \multicolumn{2}{|c|}{ Acalll1425 } & \multicolumn{2}{|c|}{$\mathrm{rK}_{\mathrm{v}} 1.6$} & \multirow[b]{2}{*}{ Distância $(\AA ̊$} \\
\hline & Resíduo & Átomo & Resíduo & Átomo & \\
\hline \multirow{6}{*}{ 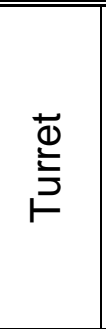 } & Arq29 & $\mathrm{N}^{\varepsilon}$ & "Glu399 (A) & $\overline{\mathrm{O}^{\varepsilon 2}}$ & 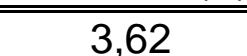 \\
\hline & & $\mathrm{NH}_{1}$ & & $\mathrm{O}^{\varepsilon 1}$ & 2,45 \\
\hline & & $\mathrm{NH}_{1}$ & & 0 & 3,27 \\
\hline & & $\mathrm{NH}_{2}$ & & $\mathrm{O}$ & 3,94 \\
\hline & & $\mathrm{NH}_{1}$ & Asp402 (A) & $\mathrm{O}^{\delta 1}$ & 3,47 \\
\hline & Tyr31 & $\mathrm{OH}$ & Asp404 (A) & $\mathrm{O}^{\delta 1}$ & 3,07 \\
\hline \multirow{8}{*}{ 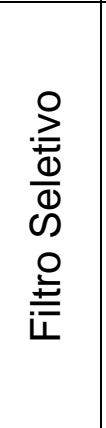 } & His25 & $\mathrm{N}^{\varepsilon 2}$ & Tyr426 (A) & $\mathrm{O}$ & 2,36 \\
\hline & His25 & $\mathrm{N}^{\varepsilon 2}$ & Tyr426 (D) & 0 & 3,64 \\
\hline & His25 & $N^{\delta 1}$ & Tyr426 (B) & $\mathrm{O}$ & 4,12 \\
\hline & Ser21 & $\mathrm{O}^{r}$ & Tyr426 (B) & $\mathrm{O}$ & 3,75 \\
\hline & Ser23 & $\mathrm{N}$ & Gly427 (B) & 0 & 3,81 \\
\hline & Tyr27 & $\mathrm{OH}$ & Asp428 (A) & 0 & 3,44 \\
\hline & Lys7 & $\mathrm{N}^{3}$ & Asp428 (C) & 0 & 3,74 \\
\hline & His28 & $\mathrm{N}$ & Asp428 (D) & $\mathrm{O}$ & 3,35 \\
\hline \multirow{4}{*}{ 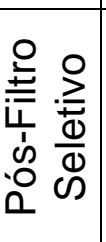 } & Lys7 & $\mathrm{N}$ & Tyr430 (C) & $\mathrm{OH}$ & 3,29 \\
\hline & Ser23 & $\mathrm{O}^{r}$ & Tyr430 (B) & $\mathrm{OH}$ & 2,29 \\
\hline & His28 & $\mathrm{N}$ & Tyr430 (A) & 0 & 3,91 \\
\hline & Thr32 & $N$ & $\operatorname{Met} 432(A)$ & $S^{\delta}$ & 2,52 \\
\hline
\end{tabular}




\subsection{Obtenção da peçonha de Anthopleura cascaia}

A utilização da metodologia descrita por Malpezzi e colaboradores (1993) permitiu que obtivéssemos amostras provenientes da peçonha da anêmona do mar Anthopleura cascaia. A maior parte dos trabalhos publicados com neurotoxinas de anêmonas do mar caracteriza-se basicamente em purificações guiadas por bioensaio, a partir de extratos corpóreos totais de anêmonas do mar (Beress \& Beress, 1975; Bosmans et al., 2002; Diochot et al., 2004; Diochot et al., 2003; Goudet et al., 2001; Honma et al., 2005a; Schweitz et al., 1981; Vincent et al., 1980). Tal abordagem não permite afirmar se as moléculas isoladas são produzidas pelos animais como toxinas, envolvidas na predação, competição e/ou defesa, ou se são simplesmente peptídeos provenientes de tecidos corpóreos, com outras funções nos animais. Desse modo, o emprego de uma técnica que permita a extração de moléculas provenientes dos nematocistos nos possibilita afirmar que as substâncias isoladas e caracterizadas são componentes secretados pelas anêmonas do mar durante o disparo dos nematocistos. Além disso, por não ocasionar morte dos animais, essa metodologia nos permite a realização de diversas etapas de extração, resultando na obtenção de uma maior quantidade de peçonha por indivíduo.

\subsection{Fracionamento da peçonha}

O fracionamento da peçonha por cromatografia em Sephadex G-50 (Figura 22) foi similar a perfis já descritos. Pela faixa de massas moleculares sabemos que os primeiros compostos do perfil (Acal) apresentam, possivelmente, atividade fosfolipásica, a segunda fração (Acall) atividade hemolítica, a terceira (AcallI) neurotóxica (FrIII) e a quarta e última (AcalV) são compostos purínicos de baixa massa.

\subsection{Purificação da fração neurotóxica (AcallI)}

Por meio do método utilizado na purificação conseguimos distribuir os compostos ao longo do perfil, o que proporcionou maior pureza dos compostos 
e diminui a quantidade de etapas necessárias para se obter os compostos puros.

Os picos de maior abundância foram o 3 (Acalll2970) e 4 (Acalll3090). Estes são compostos hidrofóbicos por eluirem no final do cromatograma (Figura 23), momento em que a concentração de acetonitríla é alta.

\subsection{Espectometria de massas}

A partir dos dados obtidos por meio de espectrometria de massas, utilizando a interface MALDI-TOF (Tabela 3), e sabendo que as neurotoxinas que atuam em canais de potássio apresentam massas entre 3,5 - 5,5 kDa (Castaneda et al., 1995; Gendeh et al., 1997; Schweitz et al., 1995; Yeung et al., 2005) e as de canais de sódio 3 - 5 kDa (Beress \& Beress, 1975; Honma \& Shiomi, 2006; Rathmayer, 1979), podemos observar a presença de sinais de massa na fração AcallI, os quais correspondem com a massa molecular de neurotoxinas.

Observou-se a presença de massas moleculares entre 1109,0 Da até $5658 \mathrm{Da}$ e foram encontrados mais de 144 sinais de massa diferentes. Ou seja, a fração Acalll possui cerca de 144 compostos diferentes. Tal dado mostra a riqueza de compostos presentes na peçonha de anêmonas do mar e a potencial fonte de novas moléculas.

\subsection{Determinação da sequência N-terminal e busca por similaridades}

A sequência parcial da Acall12970 e Acalll3090 e a busca por similaridade mostrou que essas toxinas pertencem ao grupo de toxinas de anêmonas do tipo 1 que atuam em canais de sódio (Figura 29). Esse grupo de neurotoxinas de anêmonas do mar é um dos que foram mais bem caracterizados e tem o maior número de representantes na literatura.

A Acalll1425 apresenta um padrão de cisteínas que nunca foi descrito em peçonhas de anêmonas do mar. Sendo assim, sugere-se que esta seja uma nova classe de toxinas de anêmonas do mar que atuam em canais $\mathrm{K}_{\mathrm{V}}$. Seus resíduos de aminoácido possuem similaridade com toxinas de aranhas e do molusco do gênero Conus, as quais, além de apresentarem atividade em 
canais de potássio, também apresentam atividade em canais de sódio, cálcio, TRPV e ASIC (Figura 35Figura 36).

Até o presente, 94 sequências peptídicas completas de anêmonas foram obtidas por purificação das toxinas a partir da peçonha ou por estudos de genes codificantes das mesmas. Estas sequências estão depositadas em banco de dados. Assim, futuramente contribuiremos com mais sequências o que permitirá definirmos melhor os grupos de toxinas de anêmonas. Teremos à disposição, também, um maior número de moléculas para entendermos a biologia desses organismos e a forma de atuação de suas peçonhas. Além disso, mudanças sutis entre essas toxinas, possibilitam uma melhor compreensão da conformação e comportamento de canais iônicos.

\subsection{Acalll2970 e Acall/3090}

A fim de caracterizarmos os principais mecanismos neurotóxicos da peçonha da anêmona do mar Anthopleura cascaia, foram selecionados os compostos mais abundantes desta, dentre eles estão as toxinas Acalll2970 e Acalll3090. Estas são as neurotoxinas mais abundantes na peçonha da anêmona do mar A. cascai, sendo a Acalll2970 a neurotoxina mais abundante seguida pela Acalll3090 (Figura 23).

Para garantirmos a pureza da Acalll2970 e Acalll3090 foi realizada uma terceira etapa de purificação, por meio de cromatografia líquida de fase-reversa em HPLC. A partir dessa terceira etapa, obtivemos os peptídeos Acalll2970 e Acalll3090 (Figura 25 e Figura 26) isolados. A pureza desses compostos foi checada por espectrometria de massas (MALDI-TOF), por meio do qual obtivemos uma relação massa carga $(\mathrm{m} / \mathrm{z})$ de $4881,7 \mathrm{Da}$ e $4880,5 \mathrm{Da}$, respectivamente, e, também, pelo sequenciamento por degradação automatizada de Edman.

Por seu papel relevante na eletroexcitabilidade, os canais $\mathrm{Na}_{v}$ são um dos principais e mais importantes alvos de peçonhas animais. A maioria das toxinas de anêmonas do mar conhecidas atualmente modulam 0 funcionamento de canais $\mathrm{Na}_{v}$, retardando ou inibindo o processo de inativação dos canais. Essas toxinas são capazes de discriminar entre subtipos de canais $\mathrm{Nav}$ estreitamente correlacionados. Entretanto, para a maioria das toxinas de 
anêmona do mar conhecidas, o padrão exato dos subtipos de $\mathrm{Na}_{v}$ que elas atuam é desconhecido ou os dados são incompletos. Dessa forma, para caracterizar os subtipos de canais $\mathrm{Nav}$, junto aos quais a Acalll2970 e Acalll3090 atuam, foram utilizadas técnicas eletrofisiológicas de voltage-clamp com dois microeletrodos. Tanto a Acalll2970 quanto a Acalll3090 atuaram em uma concentração de $5 \mu \mathrm{M}$ nos canais Nav1.2, Nav1.3, Nav1.5, Nav1.6 e DmNav1 (Figura 27). Os outros subtipos testados mostraram ser resistentes aos peptídeos Acalll2970 e Acalll3090 nesta mesma concentração. A concentração de $5 \mu \mathrm{M}$ utilizada para o screening foi determinada através das $\mathrm{IC}_{50}$ já descritas para toxinas de anêmonas do mar, onde essas toxinas atuam na ordem de nM. Sendo assim, $5 \mu \mathrm{M}$ seria uma concentração de toxina suficiente para conseguirmos observar modificações na permeabilidade de íons em canais voltagem dependentes.

A alteração ocasionada nos canais $\mathrm{Nav}$ pelas toxinas Acalll2970 e Acalll3090 indica um retardo no processo de inativação. As toxinas retardaram a inativação rápida de subtipos específicos de canais $\mathrm{Nav}$, resultando num aumento da amplitude do pico da corrente e uma inativação incompleta ou uma corrente persistente no final do teste de despolarização. Esses efeitos são observados devido ao aumento do pico de ativação, quando mais canais se encontram no estado aberto, durante o início do estímulo, e pela presença de uma corrente persistente, quando menos canais se encontram no estado inativado.

A potência com que a Acalll2970 atua, indica uma maior afinidade para o subtipo DmNav1, uma vez que o valor de $I_{50}$ é de 162,19 $\pm 11,22 \mathrm{nM}$, enquanto que para o subtipo Nav1.3 é de 572,56 $\pm 44,96 \mathrm{nM}$ e para o subtipo Nav1.6 é de 645,92 \pm 18,52 nM. Para a Acalll3090 também foi observado uma maior afinidade para o subtipo DmNav1, uma vez que o valor de $I_{50}$ é de $99,03 \pm 9,25 \mathrm{nM}$, enquanto que para o subtipo Nav1.3 é de $371,60 \pm 6,48 \mathrm{nM}$ e para o subtipo Nav1.6 é de 158,30 $\pm 33,86 \mathrm{nM}$. Quando compararmos a potência das duas toxinas observamos que a Acalll3090 é mais potente do que a Acalll2970 para os 3 subtipos de canais Navs. Uma diferença é que enquanto a Acalll2970 é mais potente no subtipo Nav1.3 do que no Nav1.6, a Acalll3090 é mais potente no subtipo $\mathrm{Na}_{v} 1.6$ do que no Nav1.3. 
Em contraste com o claro efeito, mas modesta potência, das toxinas Acalll2970 e Acalll3090 em subtipos específicos de canais $\mathrm{Na}_{v}$ de mamíferos, essas afetam mais pronunciadamente a inativação do clone de canal de sódio de inseto DmNav1, presente em Drosophila melanogaster.

O fato da atividade da Acalll2970 e da Acalll3090 serem mais pronunciadas em canal DmNav1, é intrigante se considerarmos o fato de que anêmonas e insetos são organismos que vivem em ambientes muito distintos. Então, por que anêmonas do mar possuem toxinas que atuam em canais de insetos? Para respondermos a esta pergunta precisamos analisar algumas características ecológicas e evolutivas.

O predador natural de anêmonas do mar são grandes crustáceos. Pequenos crustáceos são fonte de alimento para as anêmonas do mar. Podese supor que anêmonas do mar possuem toxinas que atuam diretamente sobre pequenos crustáceos. Se levarmos em consideração que insetos e crustáceos são artrópodes, podemos sugerir que seus canais iônicos sejam similares. Esta hipótese é corroborada no nível de bioinformática, sobretudo quando a sequência codificante para $\mathrm{Na}_{\mathrm{v}}$, derivada do projeto inicial do genoma do crustáceo Daphnia pulex (projeto genoma disponível em: http://genome.jgipsf.org/Dappu1/Dappu1.home.html) é comparada com o gene para DmNav1 (acesso ao GenBank P35500).

Além disso, embora a maioria dos insetos seja terrestre, algumas formas larvais podem conviver com anêmonas, como por exemplo, em poças de marés. De fato, foi reportado que Nematostella vectensis alimenta-se de larvas de insetos (Frank \& Bleakney, 1978).

Até o momento, obtivemos apenas a sequência parcial das toxinas, e experimentos para determinação do padrão de cisteínas ainda não foram realizados. Consequentemente, decidiu-se buscar toxinas já descritas na literatura, que também apresentam sua sequência primária similar à sequência da Acalll2970 e Acalll3090 (Figura 29), para enriquecer a discussão. Ambas as toxinas são similares às toxinas do tipo 1 de anêmonas do mar que atuam em canais $\mathrm{Nav}$. Esse grupo de toxinas é o que apresenta mais toxinas identificadas até o presente, com aproximadamente 35 toxinas já descritas, mas poucas tiveram sua atividade testada em subtipos de canais de Nav (Billen et al., 2010). 
Até o momento, nenhuma toxina do Tipo 1 de anêmona do mar que é verdadeiramente seletiva para invertebrados foi reportada (Moran et al., 2008), porém, uma grande diferença na seletividade é observada. Como exemplo, temos o efeito da $\mathrm{Bg} 2$, uma toxina da Bunodosoma granulifera. Sua atividade foi avaliada em canais Navs de insetos versus de mamíferos, ambos expressados em oócito de Xenopus (Bosmans et al., 2002). A Bg2 apresentou atividade em DmNav1 em uma concentração da ordem de $5 \mathrm{nM}$, enquanto em Navs de mamíferos a concentração necessária foi cerca de 50 vezes maior.

Como as toxinas a-escorpiônicas e toxinas de anêmonas do mar induzem um efeito eletrofisiológico semelhante em canais $\mathrm{Na}_{\mathrm{v}}$, elas foram utilizadas para ensaios de ligação competitiva, a partir dos quais se concluiu que essas toxinas compartilham um sítio de ligação em canais $\mathrm{Nav}_{v}$ (Catterall \& Beress, 1978). Descobriu-se, depois, que o sítio de ligação dessas toxinas se sobrepõe, mas o sítio de ligação não é idêntico. Este foi, mais tarde identificado como sítio 3 de ligação (Catterall, 1979; Catterall, 2000) (Figura 11).

Diversos estudos de mutagênese indicaram que o loop extracelular entre S3 e S4 do Domínio IV representa uma parte substancial do sítio 3 de ligação (Benzinger et al., 1998; Rogers et al., 1996; Sheets et al., 1999; Thomsen \& Catterall, 1989; Ulbricht, 2005). Além disso, um estudo, no qual se utilizou quimeras de canais, indicou que toxinas escorpiônicas e de aranha, que retardam o processo de inativação de canais $\mathrm{Nav}$, atuam exclusivamente no sensor de voltagem (S3-S4) do DIV (Bosmans et al., 2008).

Acredita-se que, após se ligarem à parte extracelular do loop IVS3-S4, as toxinas que atuam no sítio 3 evitam o movimento normal do sensor de voltagem do DIV, afetando os processos de ativação, inativação e das mudanças conformacionais associadas com a rápida inativação do canal (Rogers et al., 1996). No entanto, no presente trabalho não foram realizados ensaios de ligação competitiva para corroborar a idéia de que as toxinas Acalll2970 e Acalll3090 se ligam de fato ao sítio 3.

Diversos estudos de mutagênese identificaram cada um dos resíduos de aminoácidos no IVS3-S4 que são determinantes para a ligação das toxinas com o sítio 3. Mais especificamente, o resíduo carregado negativamente, localizado na porção mais extracelular do segmento IVS3 foi apontado como sendo o hot spot (Benzinger et al., 1998; Rogers et al., 1996). É intrigante notar 
que essa carga negativa é conservada entre canais $\mathrm{Na} v$ de mamíferos e insetos. A neutralização ou reversão dessa carga em rNav1.5 (D1612R ou D1612N) causa um forte decaimento na afinidade da toxina de anêmona do mar ApB (Benzinger et al., 1998). Em contraste, a afinidade de ligação da toxina ATXII aumentou significativamente quando o resíduo correspondente Glu1613, em Nav1.2, sofreu mutação por um Asp (Rogers et al., 1996). Por outro lado, a substituição do Glu1616 por um resíduo Gln resulta em um forte decaimento na afinidade da ATXII para o subtipo rNav1.2 (Rogers et al., 1996).

Ao observarmos as sequências do IVS3-S4 do rNav1.2 e do rNav1.3, verificamos que estas são idênticas. No entanto, as toxinas Acalll2970 e Acalll3090 são mais potentes em rNav1.3. Esse achado corrobora a ideia previamente sugerida de que as toxinas de anêmona do mar interagem com um sítio que é descontínuo, onde regiões fora do loop IVS3-S4 contribuiriam com a heterogeneidade da seletividade dessas toxinas com subtipos de $\mathrm{Nav}$ (Moran et al., 2009; Oliveira et al., 2004; Rogers et al., 1996).

Recentemente, Payandeh e colaboradores (2011) determinaram a estrutura do canal voltagem dependente de sódio por meio de cristalografia. Estudos posteriores, conciliando os resultados obtidos com a Acalli2970 e Acalll3090, juntamente com a estrutura do canal $\mathrm{Nav}$ e ferramentas de bioinformática, poderão dar indícios de quais seriam as outras regiões/aminoácidos dos subtipos de canais $\mathrm{Nav}_{v}$ que estariam envolvidas na ligação e seletividade dessas toxinas de anêmona do mar. 


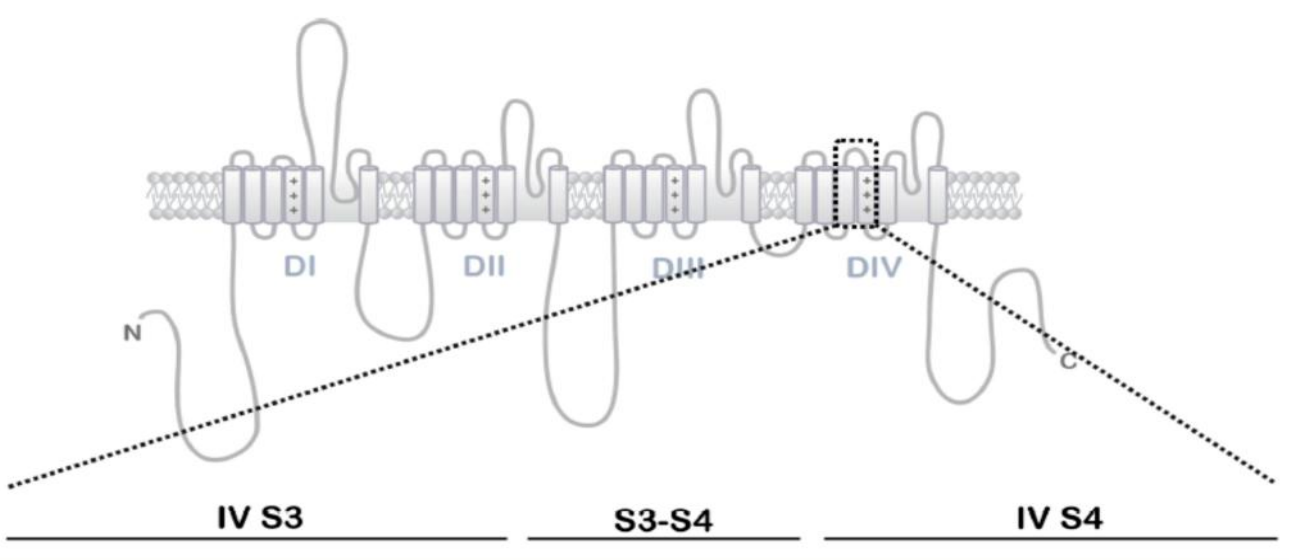

\begin{tabular}{|c|c|c|c|}
\hline & I & --- & RVVRVAKVGRVLRLVKGAKGIR \\
\hline & FDVVVVILSILGLVLSDI I & $---\mathbf{E K Y F V S P T L I}$ & ( \\
\hline $\mathrm{rNa}_{\mathrm{v}} 1.1$ & IGWN I FDFVVVILS IVGMFLAELI & ---EKYFVSPTLF & RVI \\
\hline $\mathrm{rNa}$ & EDFVVVILSIVGMFLAELI & ---EKYFVSPTLF & IIR \\
\hline $\mathrm{rNa}_{\mathrm{v}} 1.3$ & I GWN I FDFVVV I LS IVGMFLAEL I & $---\mathbf{E K Y F V S P T L F}$ & RVI \\
\hline $\mathrm{rNa}$ & I GWN I FDFVVVI LS IVGLALSDL I & $---Q K Y$ & RVI \\
\hline $\mathrm{hNe}$ & NSWNI FDFVVVILSIVGTVLSDI I & $---\mathrm{QK}$ & RV \\
\hline $\mathrm{mN}$ & FDFVVVILSTVC & $---\mathbf{E}$ & IR \\
\hline & EDFVVVILSIVGMFLAEMI & $---\mathbf{E K}$ & RVI \\
\hline & AIL & KSLEN & GIR \\
\hline & NGWNLFDCVVVVLSI ISTLVSRLE & DSDIS-F-PPTLF & ZVVRIARTGRIIRIUVRAARGIR \\
\hline
\end{tabular}

Figura 42 - Alinhamento da sequência IVS3-S4 de subtipos de $\mathrm{Na}_{\mathrm{V}}$ de insetos e mamíferos. $\mathrm{O}$ alinhamento dos aminoácidos dos segmentos transmembrana S3 e S4 dos DIV homólogos estão conectados pelo loop extracelular. As duas sequências no topo são de canais de insetos (MdNaV1 e DmNaV1; Md, mosca doméstica; Dm, mosca de fruta). As outras sequências são de subtipos de canais de mamíferos (NaV1.1-NaV1.9; $r$, rato; $m$, camundongo; $h$, humano). Os subtipos de canais $\mathrm{Na}_{v}$ afetados pela AcallI2970 e AcallI3090 estão representados com o fundo cinza. Os resíduos que diferem das sequências dos $\mathrm{Na}_{\mathrm{v}}$ 1.1-3 estão coloridos em vermelho. Os códigos de acesso dos resíduos dos subtipos são: MdNaV1, 1668 (Uniprot: Q94615); DmNaV1, 1680 (P35500); rNaV1.1, 1602 (P04774); rNaV1.2, 1592 (P04775); rNaV1.3, 1538 (P08104); rNaV1.4, 1407 (P15390); hNaV1.5, 1589 (Q14524); mNaV1.6, 1581 (Q9WTU3); rNaV1.7, 1574 (O08562); rNaV1.8, 1538 (Q62968); rNaV1.9, 1407 (088457).

\subsection{Acall/1425}

A fim de caracterizarmos os principais mecanismos neurotóxicos da peçonha da anêmona do mar Anthopleura cascaia, selecionamos os compostos mais abundantes desta, dentre eles a toxina Acalll1425.

Para garantirmos a pureza da Acalll1425, foi realizada uma terceira etapa de purificação, por meio de cromatografia líquida de fase-reversa em HPLC. Através dessa terceira etapa, obtivemos o peptídeo Acalll1425 (Figura 30) isolado. A pureza desses compostos foi checada por espectrometria de massas (MALDI-TOF), a partir do qual obtivemos uma relação massa carga $(\mathrm{m} / \mathrm{z})$ de $3337,4 \mathrm{Da}$, e por sequenciamento por degradação automatizada de Edman. 
Através da degradação automática de Edman conseguimos obter a sequência completa de aminoácidos. Esta possui 32 aminoácidos, seguindo um padrão $\mathrm{CX}_{6} \mathrm{CX}_{5} \mathrm{CCX}_{4} \mathrm{CX}_{5} \mathrm{C}$, onde $\mathrm{C}$ são as cisteínas, $\mathrm{X}$ pode ser qualquer resíduo de aminoácido e o número subscrito indica o espaçamento entre as cisteínas. Quando a sequência de aminoácidos da Acalll1425 foi comparada com outras toxinas de anêmona do mar, nenhuma das sequências, até o momento descritas, apresentam esse consenso. Por esta razão, comparamos com toxinas provenientes de outros animais peçonhentos e, como resultado, obtivemos que a Acalll1425 apresenta um padrão de cisteínas similar ao de toxinas com um motivo estrutural conhecido como nó de cisteínas inibitório (ICK, do inglês Inhibitor Cystine Knot).

O motivo ICK é formado pela conectividade das cisteínas, onde as pontes dissulfeto são formadas entre C1-C4, C2-C5 e C3-C6, como representado na Figura 43. Esse motivo estrutural tem como característica ser muito estável, pois a ponte dissulfeto formada por C3-C6 passa por dentro do anel formado por $\mathrm{C} 1-\mathrm{C} 4$ e $\mathrm{C} 2-\mathrm{C} 5$, formando o nó. Esse tipo de fold é caracterizado pela ocorrência de fitas- $\beta$ antiparalelas e pelas pontes dissulfeto. Além disso, representa uma das conformações mais estáveis e globulares para proteínas e peptídeos. As cisteínas e as cadeias laterais de resíduos próximos formam um core globular hidrofóbico. A maioria dos resíduos ficam expostos e tal condição define a carga do peptídeo. Toxinas com esse motivo têm em comum diversas superfícies, as quais apresentam cargas positivas ou negativas, assim como uma área hidrofóbica. Áreas hidrofóbicas são mais propensas a estarem envolvidas na interação com o receptor.

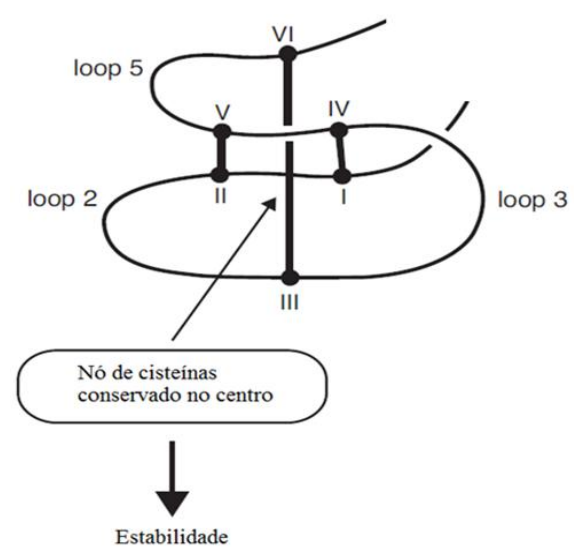

Figura 43 - Esquema representativo do motivo estrutural ICK. Os pontos ligados representam as cisteínas e seu respectivo padrão de pontes dissulfeto. Figura modifica de Pallaghy e colaboradores (1994). 
Canais de potássio constituem a classe mais diversa de canais iônicos, tanto do ponto de vista fisiológico como estrutural. Estes canais mantêm o equilíbrio do potencial da membrana de células excitáveis e contribuem para a repolarização da membrana durante o potencial de ação. Controlam, desse modo, a frequência e duração do sinal elétrico (Jan \& Jan, 1992; Pongs, 1992; Rudy et al., 1991). A multiplicidade dos subtipos de canais de potássio resulta em um aumento do nível de complexidade da corrente de potássio. Isso se deve à diversidade de tipos de canais encontrados em uma única célula, assim como a capacidade de formar estruturas heteromultiméricas, formando canais com uma variedade de propriedades eletrofisiológicas e farmacológicas. A descoberta de novas toxinas com uma grande especificidade para selecionar subtipos de canais é de grande importância para a elucidação do papel funcional de diferentes canais de potássio. Além disso, a ubiquidade e diversidade funcional dos canais de potássio fazem deles uma ferramenta com grande potencial para o desenvolvimento de novos agentes terapêuticos.

No presente estudo, nós reportamos o screening da Acalll1425 utilizando 4 canais Navs (Figura 32) e 12 canais Kvs (Figura 31). A Acalll1425 é capaz de bloquear os subtipos $\mathrm{K}_{\mathrm{v}} 1.1$, $\mathrm{K}_{\mathrm{v}} 1.6$ e $\mathrm{K}_{\mathrm{v}} 4.3$, mas com uma maior eficácia para $K_{V} 1.6$ (Figura 31 e Figura 33). A diferença significativa na afinidade e eficácia de bloqueio observada, não somente entre $K_{v} 1.1, K_{v} 1.6$ e $K_{v} 4.3$, mas entre todas as isoformas testadas, pode ser útil no estabelecimento de resíduos críticos para a interação entre canal/toxina e, desta forma, ajudar no desenvolvimento de ligantes altamente específicos para um subtipo particular de canal.

Até hoje, foram reportadas cerca de 14 toxinas de anêmonas do mar que atuam em Kvs, mas nenhuma delas apresenta o motivo estrutural ICK. Além disso, a baixa similaridade da estrutura primária da Acalll1425 com outras toxinas conhecidas de anêmona do mar, justifica a criação de uma nova família de toxinas de anêmona do mar que atuam em canais $\mathrm{K}_{\mathrm{v}}$, mostrando que ainda existem novas toxinas a serem descobertas, tornando relevante o estudo desse grupo.

Dado o ineditismo da toxina Acalll1425, um dendograma funcional foi construído como uma representação gráfica de um alinhamento de diversas toxinas que apresentam o mesmo padrão de cisteínas, com o intuito de prever 
possíveis atividades, além das já caracterizadas, o que poderá direcionar experimentos futuros.

No dendograma criado observamos dois ramos principais, um representado pelas toxinas provenientes de peçonhas de aranhas e outro com as toxinas de molusco do gênero Conus e a Acall11425 (seta pontilhada na Figura 36). Anêmonas do mar e Conus vivem no mesmo ambiente e podem ter sofrido pressões seletivas semelhantes (presas semelhantes, predadores, competição, etc.), propiciando a evolução de toxinas com características comuns, justificando tal agrupamento.

Além disso, a Acalll1425 foi agrupada com toxinas que são ativas em canais voltagem dependentes de cálcio. Sendo assim, sugere-se que além da atividade em canais $\mathrm{K}_{\mathrm{v}}$, a neurotoxina Acalll1425 pode apresentar atividade em canais Cav. Um indicativo dessa "promiscuidade" é a Acalll1425 estar próxima da base do dendograma funcional por não ter um grupo definido. É comum que toxinas encontradas em organismos mais basais apresentem atividade em mais de um alvo. King e colaboradores (2008a) descrevem toxinas que são seletiva para canais $\mathrm{Na}_{v}$ e Cav de insetos. Já Li-Smerin \& Swartz (1998) demonstraram que a Hanatoxina e a Grammotoxina (toxinas encontrada na peçonha da aranha Phrixotrichus spatulata) atuam tanto em $\mathrm{K}_{\mathrm{v}}$ quanto em $\mathrm{Cav}$ modificando o gating desses canais.

A atividade promíscua de algumas toxinas pode ocorrer devido a elementos estruturais compartilhados entre canais voltagem dependentes a diferentes íons. Como exemplo, temos toxinas que modulam canais voltagem dependentes. Essas toxinas reconhecem o domínio sensor de voltagem que é uma estrutura tridimensional altamente conservada entre os canais voltagem dependentes de $\mathrm{Na}^{+}, \mathrm{K}^{+}$e $\mathrm{Ca}^{2+}$. A conservação da sequência entre canais $\mathrm{K}_{\mathrm{V}}$, $\mathrm{Na} \mathrm{V}_{v}$ e $\mathrm{Ca}_{v}$ identificam estes canais como membros de uma superfamília. A promiscuidade de toxinas que modificam o gating destaca a conservação da estrutura tridimensional dos canais voltagem dependentes. É como se os canais voltagem dependentes seguissem uma arquitetura de multidomínios onde o domínio do poro seletivo aos íons divergiu para conferir seletividade para $\mathrm{K}^{+}, \mathrm{Na}^{+}$ou $\mathrm{Ca}^{2+}$, e para separar o domínio sensível à voltagem, que é conservado na sua estrutura e compartilhado por todos eles. 
Com base no que foi exposto, podemos chamar a atenção de que, possivelmente, muitas das toxinas já caracterizadas apresentam atividade em mais de um tipo de canal voltagem dependente. Uma das razões é que muitas vezes as técnicas aplicadas não abrangem todos os tipos de canais voltagem dependentes ou a concentração utilizada não é suficiente para obter uma alteração relevante na eletrofisiologia do canal.

Sendo assim, é possível que a Acalll1425 tenha como alvo canais voltagem dependentes a diferentes íons, apresentando atividade em canais $\mathrm{K}_{\mathrm{V}}$ e, possivelmente, em canais Cav. Realizaremos experimentos, no futuro, que poderão determinar se realmente a toxina Acalll1425 apresenta atividade em canais Cav.

O fold ICK é um motivo estrutural conservado, do ponto de vista evolutivo e compartilhado por um grande grupo de peptídeos com diversas sequências e atividade. Embora encontrado em diferentes filos, como Arachinida (aranhas e escorpiões) e Mollusca (molusco do gênero Conus), a origem evolutiva do motivo estrutural ICK ainda não é clara, uma vez que não se conhece proteínas corpóreas de invertebrados contendo esse motivo.

As anêmonas do mar constituem um dos grupos mais diversos e bem sucedidos, e se tem registro de que seu surgimento teria ocorrido por volta de 600 milhões de anos atrás (Whittington, 1985). Assim, no presente trabalho, reportamos o peptídeo, com motivo ICK, extraído do organismo "mais basal", se analisado do ponto de vista evolutivo.

Foi sugerido que ICKs com três pontes dissulfeto seriam uma forma elaborada de um simples ancestral com duas pontes dissulfeto, criado pelo motivo estrutural disulfide-directed $\beta$-hairpin (DDH) (Zhu et al., 2000). Foi descrito um peptídeo de peçonha de escorpião, denominado U1-LITX-Lw1a, que representa um exemplo único dessa estrutura proposta. Além disso, essa estrutura é um exemplo de um peptídeo natural que adota o fold DDH, considerado, previamente, como hipotético. Assim, Smith e colaboradores (2011) tentaram dar elementos que corroborassem a hipótese de que o fold DDH seria o precursor evolutivo do motivo ICK, onde o U1-LITX-Lw1a poderia ser um indicativo da origem evolutiva das ICKs de peçonhas. Nossos resultados vão contra essa hipótese uma vez que ainda não se conhece um peptídeo, como o U1-LITX-Lw1a, em peçonhas de anêmonas do mar. Além 
disso, Smith e colaboradores (2011) fizeram sua proposta com base no grupo Liochelidae, que não é um grupo basal na filogenia de escorpiões (Prendini, 2000), o que torna possível que o peptídeo U1-LITX-Lw1a não seja o precursor das ICKs, e sim um peptídeo derivado dessas.

Zhu e colaboradores (2003), com base na análise da organização do precursor e da estrutura gênica, combinada com a estrutura tridimensional e dados funcionais, destacaram uma origem evolutiva para peptídeos ICKs de animais. Ocorrendo uma pressão seletiva (restrições funcionais) na estrutura gênica (splicing eficiente) (Berget, 1995), na organização do precursor (processo pós-traducional eficiente, peptídeo maduro, e classificação) (Lewin, 1997) e na estrutura 3D (surgimento da função pela estrutura 3D) (Gething, 1992) durante o curso da evolução, a conservação desses três níveis entre duas proteínas ou peptídeos certamente proveem fortes evidências para uma origem evolutiva comum. Essas características comuns vêm sendo encontradas em toxinas ICKs de animais. Isso é um exemplo de divergência evolutiva entre toxinas de filos de animais peçonhentos distantemente relacionados, com diferentes hábitos alimentares e que vivem em diferentes habitats. Um achado interessante de Gething \& Sambrook (1992) é que diversos genomas de vírus também contém sequências ICKs. Comparado com genes de peptídeos ICKs derivados, eles perdem um propeptídeo e não contém introns. Dado o fato de que todas as viroses pertencem à família Baculoviridae, que afetam apenas invertebrados (Li, 2002; Kuzio, 1999), e que suas estruturas ICKs são mais relacionadas com peptídeos ICKs de animais, lançou-se a hipótese de que uma eventual transferência gênica poderia ter ocorrido entre um vírus ancestral e seu hospedeiro (Baldo \& Mcclure, 1999). Deste modo, os vírus teriam adquirido um gene de ICK de um genoma das células hospedeiras. Com os resultados aqui apresentados, propomos que as anêmonas do mar sejam possíveis candidatos a esse "hospedeiro infectado".

Quanto ao modelo da estrutura tridimensional gerado para análise da toxina Acalll1425, a média dos valores de $G$-factor obtidos foi de $-0,29$ para o modelo da Acalll1425, apresentando uma boa qualidade estereoquímica, como mostra a Tabela 9. A partir dos dados obtidos pela análise do Procheck (diagrama de Ramachandran e G-factor), pode-se inferir que o modelo é possível do ponto de vista esterioquímico. 
Podemos verificar na Figura 38 B que, possivelmente, a estrutura secundária da Acalll1425 será composta por três fitas- $\beta$ antiparalelas, o que é comum nas toxinas que possuem o motivo estrutural ICK. Os dez resíduos que caíram na região de $\alpha$-hélice, no diagrama de Ramachandran, não são vistos como $\alpha$-hélice no modelo gerado, o que é consistente com o que se tem descrito para toxinas com o motivo estrutural ICK (Craik et al., 2001). Essas são compostas por duas ou três fitas- $\beta$ antiparalelas.

A Figura 38 C e D é uma representação da superfície do modelo gerado para a estrutura tridimensional da toxina Acalll1425, com o intuito de facilitar a visualização da distribuição dos aminoácidos da toxina. Os resíduos básicos foram coloridos em azul, os ácidos em vermelho, os apolares e hidrofóbicos em verde, os polares sem carga em cinza e os aromáticos em laranja. Observa-se uma predominância de resíduos aromáticos e positivos na face representada na Figura 38 D, e que os resíduos hidrofóbicos e apolares e o único resíduo negativo (D13) encontram-se na face da toxina representada na Figura $38 \mathrm{C}$. Os resíduos de aminoácidos positivos estão dispostos nas extremidades da estrutura tridimensional. Essa distribuição pode ser importante no posicionamento da toxina com o canal. Tal mecanismo de interação será discutido mais adiante com auxílio do resultado obtido no docking.

Geralmente, a formação do complexo toxina-canal envolve uma combinação de interações eletrostáticas, hidrofóbicas e ligações de hidrogênio. Podemos observar na Figura 39 que a superfície da toxina Acalll1425 apresenta um potencial eletrostático predominantemente positivo enquanto que a porção extracelular do canal $\mathrm{rK}_{\mathrm{v}} 1.6$ e a região do poro carregam um potencial eletrostático negativo (pontilhado vermelho). Isso sugere que a toxina Acalll1425, carregada positivamente, é atraída pelo canal $\mathrm{rK}_{\mathrm{v}} 1.6$, carregado negativamente. Sendo assim, o potencial eletrostático da toxina pode ser um fator determinante para a interação da toxina com o canal, onde as cadeias laterais dos resíduos positivamente carregados da toxina se associariam com a entrada do canal $\mathrm{rK}_{\mathrm{v}} 1.6$, a qual apresenta um potencial eletrostático negativo. Tal concepção foi validada pela predição da interação entre a toxina e o canal, a qual será discutida mais adiante.

A resultante do momento dipolo (representado por uma seta verde na Figura 39) do canal $\mathrm{rK}_{\mathrm{v}} 1.6$ é orientada ao longo do eixo simétrico que vai do 
meio extracelular ao intracelular. Isso é determinante para a orientação dos compostos que irão interagir com o canal, pois o dipolo não será uma força oposta à aproximação da toxina. O momento dipolo da neurotoxina Acalll1425 aponta para a face representada na Figura $38 \mathrm{C}$. Esta é oposta à face de contato da toxina Acalll1425 com o canal, predita no docking. Sendo assim, acreditamos que o momento dipolo da toxina se torna irrelevante quando comparamos com outras forças que estão sendo exercidas, como, por exemplo, a hidrofobicidade e o potencial eletrostático.

O potencial eletrostático da toxina Acalll1425 e do canal $\mathrm{rK}_{\mathrm{v}} 1.6$, assim como o momento dipolo do canal mostram que a carga anisotrópica é, do ponto de vista de interações Coulômbicas, uma das forças que dirige a toxina para a associação com o canal $\mathrm{rK}_{\mathrm{v}} 1.6$.

Para obtermos indícios de quais resíduos de aminoácidos são importantes para a formação do complexo toxina-canal e de como seria um provável posicionamento da toxina Acalll1425 no canal $\mathrm{rK}_{\mathrm{v}} 1.6$, foi realizado um docking molecular.

O resultado do docking confirmou os experimentos eletrofisiológicos, onde a toxina Acalll1425 obstruiu fisicamente o poro do canal na porção extracelular, impedindo o fluxo de íon $\mathrm{K}^{+}$(Figura $40 \mathrm{C}$ ). Podemos verificar na Figura 41 que a hidrofobicidade da toxina e do canal favorecem a interação com região do poro. Na Figura $41 \mathrm{~B}$ e $\mathrm{C}$, observamos que há pontos (círculos em amarelo numerados de 1 a 5) hidrofílicos na toxina Acall1425, que são complementares aos pontos hidrofílicos do canal. Além disso, o poro e a porção central da face de contato da toxina são levemente hidrofóbicos, outro fator que favorece a interação com essa região.

Os pares de resíduos que, possivelmente fazem ligações de hidrogênio no complexo toxina-canal e a distância entre eles, encontram-se na Tabela 11. Podemos observar que todas as regiões da toxina (extremidades e porção central da estrutura tridimensional) estão ancoradas por ligações de hidrogênio. Além disso, alguns dos resíduos de aminoácidos da toxina Acalll1425 também fazem pontes salinas, tornando a ligação mais estável. São eles: a Arg29Glu399(A)/Asp402(A), Lys7-Asp428(C) e His28-Asp428(D), sendo que o primeiro aminoácido pertence à toxina, o segundo ao canal $\mathrm{rK}_{\mathrm{v}} 1.6$ e entre parênteses está a letra correspondente ao domínio do canal a que esse 
aminoácido pertence. Ao se analisar a toxina Acalll1425, observa-se que esses aminoácidos que formam pontes salinas encontram-se nas extremidades da estrutura tridimensional da toxina, o que possivelmente favorece a estabilização da toxina próxima ao poro. Já os resíduos de aminoácidos do canal se localizam espacialmente no turrent (Glu399 e Asp402) e na região do filtro seletivo (Asp428).

As ligações de hidrogênio entre His25-Tyr426(A, B e D), Tyr27-Asp428 (A), Ser21-Tyr426(B) e Ser23-Gly427(B), sendo que o primeiro aminoácido pertence à toxina, o segundo ao canal $\mathrm{rK}_{\mathrm{V}} 1.6$ e entre parênteses esta a letra correspondente ao domínio do canal que esse aminoácido pertence, estão localizadas espacialmente na região do filtro seletivo. Os resíduos da toxina interagem com o motivo "GYGD", que é conservado entre todos os subtipos aqui testados (Figura 44). As ligações de hidrogênio com essa região justifica a atividade biológica da toxina Acalll1425, que é bloquear canais $K_{V}$.

Os pares de resíduos Lys7-Tyr430(C), Ser23-Tyr430(B), His28Tyr430(A) e Thr32-Met4325(A) formam ligações de hidrogênio (Tabela 11). Esses aminoácidos do canal $\mathrm{rK}_{\mathrm{v}} 1.6$ estão localizados espacialmente entre 0 "filtro seletivo" e o "segmento 6" (Figura 44). Mais adiante, discutiremos a importância da interação dessa região para a seletividade da toxina.

A Figura 44 mostra um alinhamento da região em que a toxina Acalll1425 se ancora nos diferentes subtipos de canais $K_{v}$ testados nos ensaios de eletrofisiologia. Os aminoácidos do $\mathrm{rK}_{\mathrm{v}} 1.6$ que fazem ligações de hidrogênio com a toxina Acalll1425 estão destacados em vermelho.

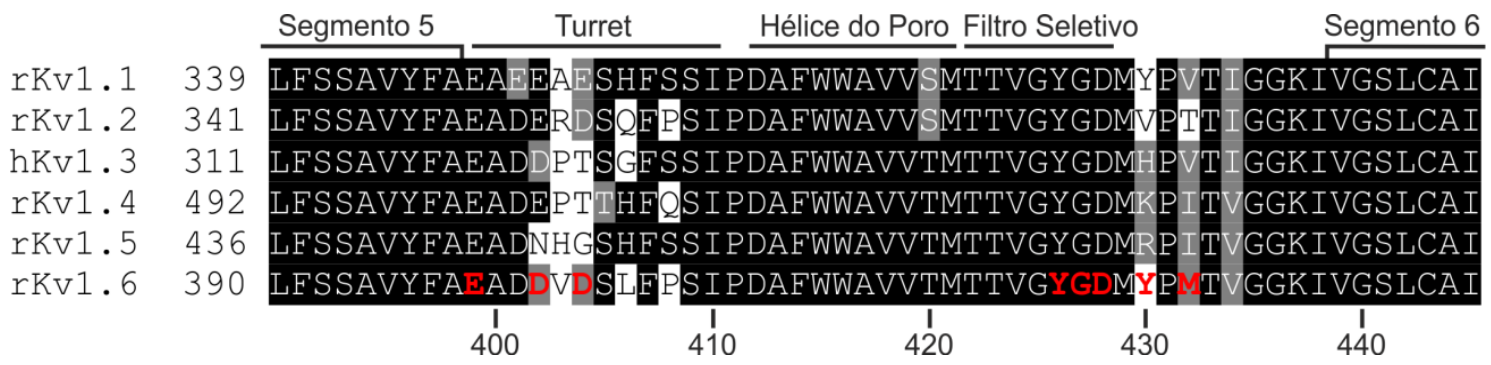

Figura 44 - Alinhamento da região do poro das isoformas de $K_{v} 1$. Posição e a sequência dos aminoácidos dos canais $K_{v}$ 1.1-6 (h: humano e $r$ : rato) nos segmentos 5 e 6. Os aminoácidos em vermelho no $\mathrm{rK}_{\mathrm{v}} 1.6$ estão envolvidos na interação da toxina Acalll1425. Aminoácidos idênticos estão com o fundo colorido de preto e aminoácidos similares em cinza. 
Existem características estruturais que são compartilhadas entre toxinas e algumas destas foram identificadas como sendo importantes para a atividade em canais $K_{v} 1$. Discutiremos a seguir o que se tem descrito na literatura, o que se aplica à toxina Acalll1425 e como se explicaria a seletividade da toxina para canais $\mathrm{K}_{\mathrm{v}} 1.1$ e $\mathrm{K}_{\mathrm{v}} 1.6$, e a maior potência em canais $\mathrm{K}_{\mathrm{v}} 1.6$ (cerca de 32 vezes mais potente do que em $\mathrm{K}_{\mathrm{v}} 1.1$ ).

Dauplais e colaboradores (1997) propuseram que as toxinas que atuam em $\mathrm{K}_{\mathrm{v}} 1$ compartilham uma díade funcional. De acordo com esses autores, esta é um par de resíduos de aminoácidos que estariam presentes em toxinas que apresentam atividade em $\mathrm{K}_{\mathrm{v}} 1$. A díade funcional é composta por um resíduo de aminoácido básico (normalmente uma lisina) associado com um resíduo hidrofóbico (aromático ou alifático, normalmente uma tirosina ou uma fenilalanina) em uma distância de 6,6 $\pm 1 \AA$, os quais estão expostos na superfície da toxina. Do ponto de vista funcional, acredita-se que a cadeia lateral do resíduo de aminoácido positivo se insira no poro do canal e o resíduo hidrofóbico (aromático ou alifático) interaja com um grupo de resíduos aromáticos do canal iônico. Sabe-se que a díade funcional das toxinas faz interações eletrostáticas com átomos de oxigênios carbonil do resíduo tirosina (motivo "GYGD"), no filtro seletivo do canal. Os resíduos que formam a díade funcional são tidos como responsáveis pela potência e afinidade com que as toxinas se ligam ao seu alvo biológico.

Com base no resultado obtido no docking molecular, podemos inferir que os resíduos His25 e Tyr27 da toxina Acalll1425 formam uma possível díade funcional, que faz ligações de hidrogênio com os resíduos Tyr426 (dos domínios A, B e D) e Asp428 (do domínio A), respectivamente (Tabela 11 e Figura 45). A histidina (His25) não é como uma lisina ou uma arginina que apresentam uma cadeia lateral longa, a qual, por sua vez, poderia se inserir profundamente no poro. Porém, a histidina pode formar um empilhamento do seu anel aromático com os anéis aromáticos das Tyr426 dos diferentes domínios. Esse tipo de interação é estável e forma um ponto de ancoramento semelhante à lisina e à arginina. Os resíduos Tyr426 e Asp428 pertencem ao motivo "GYGD" do canal rKv1.6 (Figura 44), localizado na região do poro, que é conservado nos diferentes subtipos de canais $\mathrm{K}_{\mathrm{v}} 1$. A interação da díade funcional explicaria o mecanismo de bloqueio da toxina junto ao canal, mas não 
explica a seletividade e diferença de potência da toxina Acalll1425 para canais $\mathrm{K}_{\mathrm{V}} 1$.

De fato, se a díade funcional fosse fundamental para o reconhecimento dos canais $\mathrm{K}_{\mathrm{v}} 1$, poderíamos esperar que todas as toxinas que apresentassem tal díade, com as características adequadas (natureza e posição relativa do par de resíduos chave), seriam capazes de reconhecer os vários tipos de canais $\mathrm{K}_{\mathrm{v}} 1$, pelo menos aqueles com uma baixa afinidade. Além disso, toxinas animais específicas (por exemplo: Tc32 (Batista et al., 2002), parabutoxin 1 (Huys et al., 2004), parabutoxin 3 (Huys \& Tytgat, 2003)) foram caracterizadas e estas não possuem uma díade funcional, mas, supostamente, continuam bloqueando a corrente de $\mathrm{K}^{+}$em alguns subtipos de canais $\mathrm{K}_{\mathrm{V}} 1$, embora com potências reduzidas. De modo geral, esses dados sugerem que a díade funcional não pode representar, por si só, um núcleo funcional mínimo que se liga a canais Kv1 (Dauplais et al., 1997; Gasparini et al., 1998; Gilquin et al., 2002; Menez, 1998; Savarin et al., 1998).

Mouhat e colaboradores (2004) verificaram a existência de um anel composto por resíduos básicos, na toxina $\mathrm{Pi1}$, do escorpião Pandinus imperator, os quais interagem com resíduos ácidos do turret do canal $\mathrm{K}_{\mathrm{v}} 1.2$ acima do vestíbulo externo do canal de $\mathrm{K}^{+}$, promovendo um bloqueio da corrente de íons $\mathrm{K}^{+}$, sem a presença de uma díade funcional. A toxina Acalll1425 possui resíduos positivos em seu entorno e alguns deles interagem com esses resíduos ácidos da região do turret. $O$ resíduo positivo que interage com resíduo ácido do turret é a Arg29, da toxina Acalll1425, com a Asp402, resíduo do canal $\mathrm{rK}_{\mathrm{V}} 1.6$. Sendo assim, a toxina interage com outras regiões do canal e essas são importantes para explicar os resultados eletrofisiológicos obtidos.

A proposta de Mouhat e claboradores (2004), além de sugerir que outros resíduos nas toxinas (um anel de resíduos básicos) estão envolvidos nos primeiros passos de reconhecimento do canal, também sugere que a díade funcional teria um papel mais secundário nesse processo. Dessa forma, Mouhat e colaboradores (2005) propuseram que as toxinas primeiramente reconhecem os vários subtipos de canais $\mathrm{K}_{\mathrm{v}} 1$ através de um conjunto de resíduos distintos da díade funcional. Essas interações provavelmente ocorreriam com os resíduos do turret dos canais (Jouirou et al., 2004; M'Barek 
et al., 2003; Mouhat et al., 2004). Esse conjunto de contatos moleculares definiriam a seletividade das toxinas para subtipos específicos de canais $\mathrm{K}_{\mathrm{v}}$, e seria suficiente por si só para prover um bloqueio consistente do efluxo de $\mathrm{K}^{+}$, embora com uma afinidade reduzida. A díade funcional, mesmo não sendo obrigatória, possivelmente tem duas finalidades. Primeiramente, ela fornece um ponto de ancoramento suplementar, profundo na estrutura do poro do canal, contribuindo assim para uma maior afinidade da toxina, mas sem alterar o perfil de seletividade ao canal iônico. Segundo, a posição crucial dos dois resíduos constitui uma primeira barreira física eficaz que é oposta ao efluxo de íons $\mathrm{K}^{+}$.

Com base no resultado obtido no docking molecular podemos inferir que a toxina Acall11425 interage com o canal $\mathrm{rK}_{\mathrm{v}} 1.6$ de forma similar ao modelo de interação proposto por Mouhat e colaboradores (2005). No docking, os resíduos His25 e Tyr27 da toxina Acalll1425 formam uma possível díade funcional, que faz ligações de hidrogênio com o resíduo Tyr426 (dos domínios A, B e D) e Asp428 (do domínio A), respectivamente (Tabela 11 e Figura 45). Os resíduos Tyr426 e Asp428 pertencem ao motivo "GYGD" (Figura 44), localizado na região do poro, que é conservado nos diferentes subtipos de canais $\mathrm{K}_{\mathrm{v}} 1$. Sendo assim, esse resultado corrobora com o mecanismo de formação do complexo toxina-canal $\mathrm{K}_{\mathrm{V}} 1$ proposto por Mouhat e colaboradores, onde a seletividade não é fornecida pela díade, mas essa teria função de fornecer um ponto de ancoramento suplementar para a toxina, contribuindo assim para uma maior afinidade da toxina, além de constituir uma primeira barreira física eficaz, que se opõe ao efluxo de íons $\mathrm{K}^{+}$. 

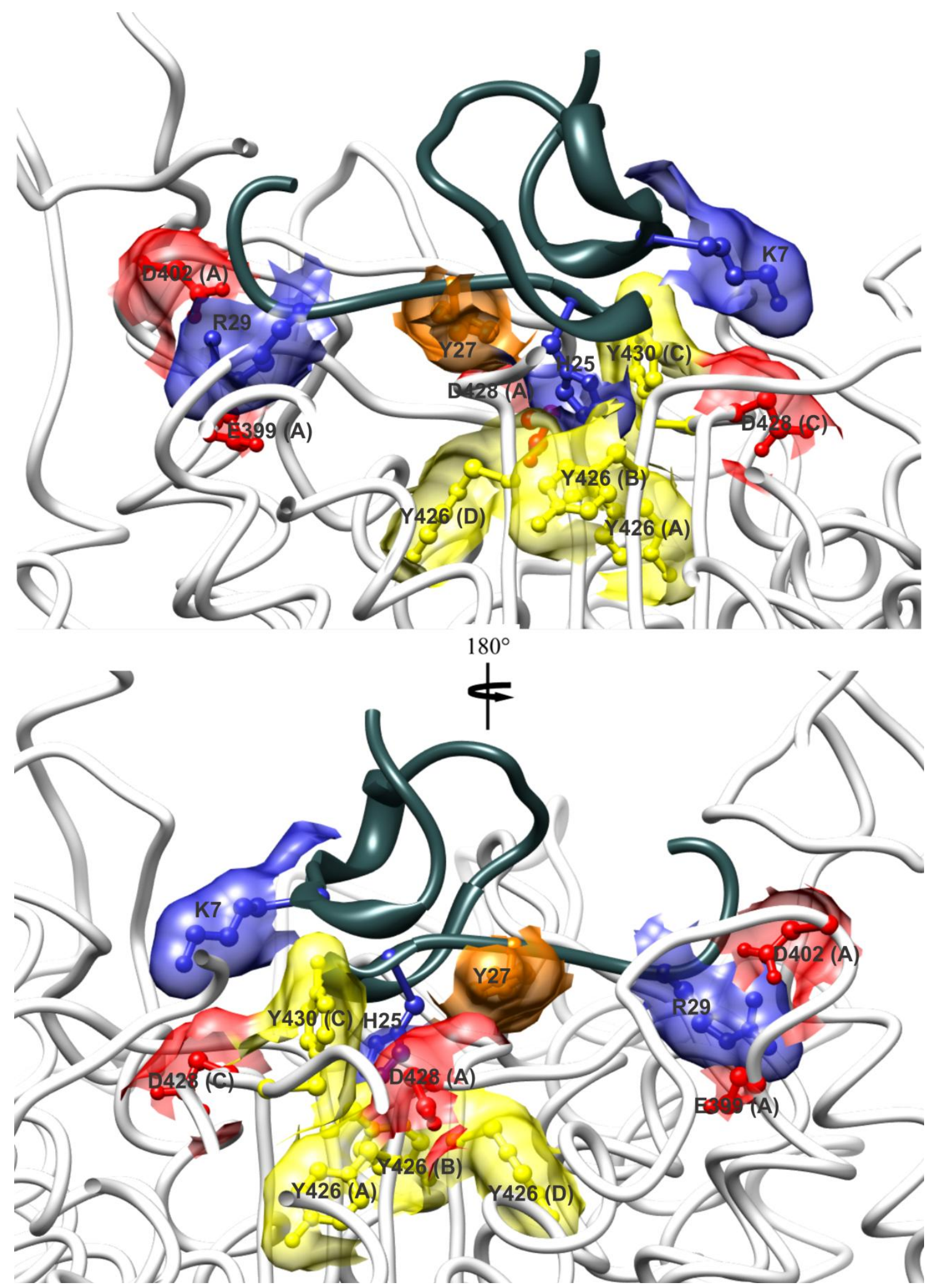

Figura 45 - Figura representativa do complexo toxina-canal. A toxina Acalll1425 e o canal rKV1.6 estão representados como ribbon. Os resíduos de aminoácidos tidos como importantes para a formação desse complexo foram destacados através da representação de sua cadeia lateral e superfície. Em vermelho, os resíduos ácidos do canal; em amarelo, os resíduos aromáticos do canal; em azul, os resíduos positivos da toxina; e em laranja, os resíduos aromáticos da toxina. Os resíduos candidatos à díade funcional são a H25, que se liga ao Y426 (A, B e D), e a Y27, que se liga ao D428 (D). A K7, que se liga ao D428 (C) e Y430 (C), e R29, que se liga ao E399 (A) e D402 (A), possivelmente são importantes para o ancoramento e seletividade da toxina. 
Quando analisamos os outros resíduos da toxina Acall1425, que supostamente formam ligação com o canal, nós conseguimos propor um possível mecanismo que levaria à seletividade da toxina Acalll1425 pelos subtipos rKV1.6 e, com menor potência, pelo rKv1.1 (dados experimentais de eletrofisiologia). O resíduo Arg29 da toxina Acalll1425, forma ligação de hidrogênio com Asp402 (do domínio A). A Tyr31 da toxina Acalll1425 faz ligação de hidrogênio com o Asp404 (do domínio A) (Tabela 11). Esses são resíduos pertencentes à região do turret do canal $\mathrm{rK}_{\mathrm{v}} 1$ 1.6. A Figura 44 mostra um alinhamento da região do segmento 5 ao segmento 6 dos diferentes subtipos de canais $K_{v} 1$ testados nos ensaios de eletrofisiologia. Podemos observar que apenas os subtipos $\mathrm{rK}_{\mathrm{v}} 1.1, \mathrm{rK}_{\mathrm{v}} 1.2$ e rK 1.6 apresentam nas duas posições resíduos de aminoácidos negativos. Este dado ainda não explicaria a ausência de atividade no subtipo $\mathrm{rK}_{\mathrm{v}} 1.2$. Sendo assim, a seletividade da toxina Acall1425, por diferentes subtipos de canais $K_{v} 1$, não seria somente ocasionada por ligações com os resíduos da região do turret dos canais, como proposto por Mouhat e colaboradores (2005).

Os resíduos Lys7, Ser23 e His28 da toxina Acalll1425 formam ligações com o resíduo Tyr430 dos domínios C, B e A do canal $\mathrm{rK}_{\mathrm{v}} 1.6$, respectivamente. A Tyr430 está localizada entre o filtro seletivo e o segmento 6 (Figura 44 e Tabela 11). Quando comparamos com os resíduos de mesma posição nos outros subtipos de canais $K_{v} 1$ testados (Figura 44), observamos que a Tyr430 também está presente no $\mathrm{rK}_{\mathrm{v}} 1.1$, mas, no $\mathrm{rK}_{\mathrm{v}} 1.2$, é substituído por uma Val. Este pode ser um fator para explicar a falta de atividade no subtipo $\mathrm{rK}_{\mathrm{v}} 1$.2. Já nos subtipos $\mathrm{rK}_{\mathrm{v}} 1.3-5$, essa posição é ocupada por resíduos positivos, o que constitui um fator impeditivo para a interação com os resíduos positivos Lys7 e His28 da toxina Acalll1425. Este é mais um fator para a falta de interação com os subtipos $\mathrm{rK}_{\mathrm{v}} 1.3-5$.

Outra interação importante para a seletividade e potência é a Thr32Met432 (A), resíduo também localizado entre o filtro seletivo e o segmento 6 (Figura 44 e Tabela 11). A posição da Met432 do rKv1.6 é substituída por uma Val, no $\mathrm{rK}_{\mathrm{v}} 1.1$, e por uma Thr, no $\mathrm{rK}_{\mathrm{v}} 1$.2. A variabilidade nessa posição pode ser um fator para a toxina Acalll1425 ser cerca de 32 vezes mais potente em canais $\mathrm{rK}_{\mathrm{v}} 1.6$ do que em canais $\mathrm{rK}_{\mathrm{v}} 1.1$ (resultados experimentais de eletrofisiologia). Desta forma, esses resíduos, entre o filtro seletivo e o 
segmento 6 (Tyr430 e Met432), poderiam ser determinantes para a seletividade e potência da toxina Acalll1425.

Com base nos nossos resultados in silico da interação entre a toxina Acalll1425 e o canal $\mathrm{rK}_{\mathrm{v}} 1.6$, e os resultados experimentais de eletrofisiologia, podemos inferir que a seletividade e potência da toxina Acalll1425 ocorrem devido à interação em diferentes pontos do canal $\mathrm{rK}_{\mathrm{v}} 1.6$. Acreditamos que a toxina Acalll1425 se aproxime do canal $K_{V}$ pela força do potencial eletrostático (toxina é positiva e a parte extracelular do canal é negativa; ver Figura 39) e pela hidrofobicidade (toxina e canal são mais hidrofóbicos e existem pontos de interação com a região do poro; ver Figura 41). Com base no modelo descrito por Mouhat e colaboradores (2005), a toxina se ancora ao canal com auxílio dos resíduos positivos Arg29 e Lys7, que estão nas extremidades da estrutura tridimensional da toxina, e pela sua díade funcional, formada através do par His25 e Tyr27, formando, desse modo, um ancoramento complementar, além de constituir uma primeira barreira física eficaz, a qual se opõe ao efluxo de íons $\mathrm{K}^{+}$(Figura 45). Os outros resíduos, já discutidos, complementam a formação do complexo toxina-canal. 


\section{Conclusões}


$\checkmark$ A peçonha da anêmona do mar, Anthopleura cascaia, é composta por quatro frações quando submetida a uma coluna de gel-filtração (SephadexG50);

$\checkmark$ A terceira fração eluída corresponde à fração neurotóxica (FrllI);

$\checkmark$ A Frlll apresentou 144 sinais de massa diferentes, o que reflete a diversidade de compostos presentes nessa fração. Foi observada a presença de massas moleculares entre 1109,0 Da até 5658 Da;

$\checkmark$ As toxinas Acall12970 e Acalll3090 são duas novas toxinas do tipo 1 de toxinas de anêmona do mar de canais $\mathrm{Na}_{\mathrm{v}}$;

$\checkmark$ A Acall12970 e Acalll3090 retardam, de maneira seletiva, a inativação rápida dos subtipos $\mathrm{rNa}_{v} 1.3, \mathrm{mNa}_{\mathrm{v}} 1.6, \mathrm{hNa}$ 1.5 e DmNav1, enquanto que as outras isoformas testadas permaneceram inalteradas;

$\checkmark$ As curvas da dependência da concentração no retardo da inativação induzida pelas toxinas Acall12970 e Acalll3090, mostraram uma "filoseletividade", onde observamos uma maior eficácia para o canal de inseto DmNav1;

$\checkmark$ A toxina Acall11425 atua bloqueando seletivamente os subtipos $\mathrm{rK}_{\mathrm{V}} 1.1$, $\mathrm{rK}_{\mathrm{v}} 1.6$ e $\mathrm{rK}_{\mathrm{v}} 4.3$, enquanto que as outras isoformas testadas permaneceram inalteradas;

$\checkmark$ Os ensaios de bloqueio da corrente do canal em função da concentração da toxina Acalll1425 revelaram que esta é cerca de 32 vezes mais potente em canais $\mathrm{rK}_{\mathrm{v}} 1.6$;

$\checkmark$ A sequência completa da Acall11425 não apresenta similaridade com outras toxinas de anêmonas do mar, mas é similar a toxinas de Conus e aranha que possuem um motivo estrutural conhecido como ICK. Sendo assim, propomos a criação de um novo tipo de toxinas de anêmonas do mar que atuam em canais $\mathrm{K}_{\mathrm{v}}$;

$\checkmark$ Através de um dendograma funcional, propomos que a toxina Acalll1425 possivelmente apresenta uma promiscuidade, atuando também em canais Cav. Experimentos serão realizados no futuro com o intuito de testar essa hipótese;

$\checkmark$ O docking molecular mostrou que a toxina Acall11425 interage com diferentes regiões do canal $\mathrm{rK}_{\mathrm{V}} 1.6$, sendo que estas regiões são essenciais para a seletividade e potência da toxina. 
Resumo 125

7. Resumo 
MADIO, B. Purificação e caracterização da fração neurotóxica da peçonha da anêmona do mar Anthopleura cascaia. 2012. 169 páginas. Dissertação (Mestrado). Instituto de Biociências da Universidade de São Paulo, Departamento de Fisiologia, São Paulo, 2012.

A peçonha de anêmonas do mar é uma fonte conhecida de compostos bioativos, incluindo peptídeos, que atuam em canais voltagem-dependentes. Foram descritos 4 tipos de neurotoxinas de anêmonas do mar, que atuam em canais $\mathrm{Na}_{v}$ e 4 tipos que atuam em canais $\mathrm{K}_{\mathrm{v}}$. Essas toxinas têm permitido discriminar subtipos de canais voltagem-dependentes, estreitamente relacionados, e constituem poderosas ferramentas para estudar 0 funcionamento e estrutura desses canais.

Neste estudo, foram isolados e caracterizados três peptídeos da fração neurotóxica da anêmona do mar Anthopleura cascaia. Esses peptídeos foram nomeados como Acalll1425, Acalll2970 e Acalll3090, onde Aca faz referência a espécie e os números seguem os resultados obtidos nas etapas de purificação.

A peçonha foi extraída por meio de estímulos elétricos e purificada por gelfiltração (Sephadex G-50) e fase reversa por HPLC (C-18). As massas moleculares foram obtidas por meio de MALDI-TOF, apresentando 3337,4 Da para a Acalll1425, 4881,7 Da para a Acalll2970 e 4880,5 Da para Acalll3090.

Através da técnica de voltage-clamp, esses peptídeos foram testados em diferentes subtipos de canais $\mathrm{Na}_{v}$ e $\mathrm{K}_{\mathrm{v}}$ expressados em ovócito de Xenopus. As toxinas Acalll2970 e Acalll3090 retardam, de maneira seletiva, a inativação rápida dos subtipos $\mathrm{rNa}_{v} 1.3, \mathrm{mNa}_{v} 1.6$ e $\mathrm{hNa}_{v} 1.5$, enquanto que as outras isoformas testadas permaneceram inalteradas. É importantemente salientar que, a Acalll2970 e Acalll3090 também foram examinadas no canal de inseto DmNav1, revelando uma clara "filo-seletividade" na eficácia da atividade das toxinas. A Acalll2970 e Acalll3090 inibem fortemente a inativação do canal $\mathrm{Nav}$ de inseto, resultando em um aumento na amplitude do pico da corrente e removendo completamente a inativação rápida. Para quantificarmos essa "filoseletividade", foram construídas curvas da dependência da concentração no retardo da inativação induzida pelas toxinas Acalll2970 e Acalll3090 nos canais em que apresentaram maior eficácia. Os $\mathrm{IC}_{50}$ foram obtidos após a plotagem dos dados em uma curva sigmoidal. Para a Acall12970, os seguintes 
valores de $\mathrm{IC}_{50}$ foram obtidos: $\mathrm{DmNa}_{\mathrm{v}} 1=162,19 \pm 11,22 \mathrm{nM}, \mathrm{mNa} 1.6=$ $645,92 \pm 18,52 \mathrm{nM}, \mathrm{rNa} 1.3=572,56 \pm 44,96 \mathrm{nM}$. Para a Acalll3090, os seguintes valores de $I_{50}$ foram obtidos: DmNav1 = 99,03 \pm 9,25 nM, mNav1.6 $=158,30 \pm 33,86 \mathrm{nM}, \mathrm{rNav1} .3=371,60 \pm 6,48 \mathrm{nM}$.

A Acall11425 atua, bloqueando, de modo seletivo os subtipos $\mathrm{rK}_{\mathrm{v}} 1.1, \mathrm{rK}_{\mathrm{v}} 1.6 \mathrm{e}$ $\mathrm{rK}_{\mathrm{v}} 4.3$, enquanto que as outras isoformas testadas permaneceram inalteradas. Devido à maior especificidade da toxina Acalll1425 pelos subtipos rK $1.1 \mathrm{e}$ $\mathrm{rK}_{\mathrm{V}} 1.6$, foram realizados ensaios de bloqueio da corrente do canal em função da concentração da toxina (curva dose-resposta). Os valores de $I_{50}$ para os subtipos rKv1.1 e rKv1.6 são de 7642,98 ₫1601,65 nM e 241,65 ₫4,27 nM, respectivamente. Desta forma, a Acalll1425 é cerca de 32 vezes mais potente em canais do subtipo $\mathrm{rK}_{\mathrm{V}} 1.6$ do que em relação aos canais do subtipo $\mathrm{rK}_{\mathrm{v}} 1.1$.

A estrutura primária das toxinas foram determinadas por degradação de Edman. A sequência parcial da Acalll2970 e Acalll3090 revelou que estas são similares a toxinas de canal de sódio do tipo1 de anêmonas do mar. A sequência completa da Acalll1425 não apresenta similaridade com toxinas de anêmonas do mar, mas é similar a toxinas de Conus e aranha que possuem um motivo estrutural conhecido como ICK. Dessa forma, propomos que a Acalll1425 seja um novo grupo de toxinas de anêmonas do mar que bloqueiam Kv.

Dado o ineditismo da toxina Acall11425, foram feitos experimentos in silico para obtermos um maior refinamento do mecanismo de interação entre a toxina e o canal $\mathrm{rK}_{\mathrm{v}}$ 1.6. Estes experimentos indicaram que diferentes regiões dos canais $K_{V}$ são importantes para a seletividade e potência da toxina, corroborando com as propostas que vem sendo descritas.

Palavras chave: Anêmonas do mar, peçonha, Anthopleura cascaia, neurotoxinas, canais iônicos voltagem-dependentes. 
MADIO, B. Purification and characterization of the neurotoxic fraction from the venom of the sea anemone Anthopleura cascaia. 2012. 169 pages. Thesis (Master). Instituto de Biociências da Universidade de São Paulo, Departamento de Fisiologia, São Paulo, 2012.

The venom of sea anemones is a known source of bioactive compounds, including peptides that act on voltage-gated ion channels. Four types of neurotoxins from sea anemones, acting on Nav channels, and four types acting on $\mathrm{K}_{\mathrm{V}}$ channels, have been reported. These toxins have developed the ability to discriminate closely related subtypes of voltage-gated channels, making them powerful tools to studying the function and structure of these channels.

In this study, we isolated and characterized three peptides of the neurotoxic fraction from the venom of the sea anemone Anthopleura cascaia. These peptides were named as Acalll1425, and Acall2970 Acalll3090, where Aca refers to the species and the following numbers refer to results obtained in the purification steps.

The venom was milked by electric shock and purified by molecular exclusion (Sephadex G-50) and reverse phase HPLC (C-18). Their molecular weights are 3337.4 Da to Acalll1425, 4881.7 Da to Acalll2970 and 4880.5 Da to Acalll3090, obtained through a MALDI-TOF.

Using the voltage-clamp technique, we have assayed the effects of these peptides on different subtypes of $\mathrm{Na}_{v}$ and $\mathrm{K}_{\mathrm{V}}$ channels expressed in Xenopus oocytes. Acall12970 and Acall13090 toxins selectively slow down the fast inactivation of $\mathrm{rNa} 1.3, \mathrm{mNa} 1.6$ and $\mathrm{hNav} 1.5$ subtypes, while the other mammalian isoforms remained unaffected. Importantly, Acalll2970 and Acalll3090 were also examined in insect DmNav1 channel, revealing a clear phyla-selectivity with regards to the efficacy of the toxin. Acall12970 and Acalll3090 strongly inhibit the inactivation of the insect $\mathrm{Na}_{v}$ channel, resulting in an increase in the amplitude of the peak current, and complete removal of the fast and steady-state inactivation. In order to quantify this "phyla-selectivity", curves of the concentration dependence of the delayed inactivation induced by AcallI2970 and Acalll3090 toxins channels with higher efficacy, were built. After plotting the data on a sigmoidal curve the $\mathrm{IC}_{50}$ values were obtained. For Acalll2970, the following $I_{50}$ values were obtained: $\mathrm{DmNa}_{\mathrm{v}} 1=162.19 \pm 11.22$ $\mathrm{nM}, \mathrm{mNa} 1.6=645.92 \pm 18.52 \mathrm{nM}$ and $\mathrm{rNa}_{\mathrm{v}} 1.3=572.56 \pm 44.96 \mathrm{nM}$. For 
Acalll3090, the following $\mathrm{IC}_{50}$ values were obtained: DmNav1 $=99.03 \pm 9.25$ $\mathrm{nM}, \mathrm{mNav} 1.6=158.30 \pm 33.86 \mathrm{nM}$ and $\mathrm{rNaV} 1.3=371.60 \pm 6.48 \mathrm{nM}$.

Acalll1425 acts, selectively, blocking $\mathrm{rK}_{\mathrm{v}} 1.1, \mathrm{rK}_{\mathrm{v}} 1.6$ and $\mathrm{rK}_{\mathrm{v}} 4.3$ subtypes, while the others isoforms tested remained unaltered. Due the higher specificity of Acalll1425 to $\mathrm{rK}_{\mathrm{v}} 1.1$ and $\mathrm{rK}_{\mathrm{v}} 1.6$ subtypes, assays were performed to evaluate the blocking channel current versus toxin concentration (dose-response curve). $I_{50}$ values for the subtypes $\mathrm{rK}_{\mathrm{v}} 1.6$ and $\mathrm{rK}_{\mathrm{v}} 1.1$ are $7642.98 \pm 1601.65 \mathrm{nM}$ and $241.65 \pm 4.27 \mathrm{nM}$, respectively. Thus, Acalll1425 is about 32 times more potent in the $\mathrm{rK}_{\mathrm{v}} 1.6$ than in the $\mathrm{rK}_{\mathrm{v}} 1.1$ channel.

The primary structure of the toxins was determined by the Edman degradation. The partial sequence of Acalll2970 and Acalll3090 revealed that these toxins are similar to the type 1 sodium channel sea anemones neurotoxins. The complete sequence of Acalll1425 has no similarity with other sea anemone toxins, but is similar to the Conus and spider neurotoxins which have a structural motif known as ICK. Thus, we propose that Acalll1425 comprises a new group of sea anemones toxins that block $\mathrm{K}_{\mathrm{v}}$ channels.

Given the unprecedented nature of the toxin Acalll1425, in silico assays were carried out in order to further refining the proposed mechanism underlying the interaction between the toxin and the $\mathrm{rK}_{\mathrm{v}} 1.6$ channel. The results indicate that, in agreement to what has been proposed elsewhere, different regions of the $K_{V}$ channels are important for the toxin selectivity and potency.

Keywords: Sea anemones, venom, Anthopleura cascaia, neurotoxins, voltagegated ion channels. 
Altschul SF, Lipman DJ (1990) Protein database searches for multiple alignments. Proc Natl Acad Sci U S A 87: 5509-5513

Anderluh G, Dalla Serra M, Viero G, Guella G, Macek P, Menestrina G (2003) Pore formation by equinatoxin II, a eukaryotic protein toxin, occurs by induction of nonlamellar lipid structures. J Biol Chem 278: 45216-45223

Anderson PAV, Bouchard C (2009) The regulation of cnidocyte discharge. Toxicon 54: 10461053

Armishaw CJ, Alewood PF (2005) Conotoxins as research tools and drug leads. Curr Protein Pept Sci 6: 221-240

Armstrong CM (1971) Interaction of tetraethylammonium ion derivatives with the potassium channels of giant axons. J Gen Physio/ 58: 413-437

Armstrong CM (1974) lonic pores, gates, and gating currents. Q Rev Biophys 7: 179-210

Armstrong CM (1981) Sodium channels and gating currents. Physiol Rev 61: 644-683

Ayre DJ (1982) Inter-Genotype Aggression in the Solitary Sea-Anemone Actinia-Tenebrosa. Mar Biol 68: 199-205

Baker NA, Sept D, Joseph S, Holst MJ, McCammon JA (2001) Electrostatics of nanosystems: Application to microtubules and the ribosome. Proceedings of the National Academy of Sciences of the United States of America 98: 10037-10041

Baldo AM, Mcclure MA (1999) Evolution and horizontal transfer of dUTPase- encoding genes in viruses and their hosts. Journal of Virology 73: 7710-7721

Ball EE, Hayward DC, Saint R, Miller DJ (2004) A simple plan--cnidarians and the origins of developmental mechanisms. Nat Rev Genet 5: 567-577

Barhanin J, Hugues M, Schweitz H, Vincent JP, Lazdunski M (1981) Structure-function relationships of sea anemone toxin II from Anemonia sulcata. J Biol Chem 256: 57645769

Batista CVF, Gomez-Lagunas F, de la Vega RCR, Hajdu P, Panyi G, Gaspar R, Possani LD (2002) Two novel toxins from the Amazonian scorpion Tityus cambridgei that block Kv1.3 and Shaker BK+-channels with distinctly different affinities. Bba-Proteins Proteom 1601: 123-131

Baukrowitz T, Yellen G (1995) Modulation of K+ current by frequency and external [K+]: a tale of two inactivation mechanisms. Neuron 15: 951-960

Beckh S, Noda M, Lubbert H, Numa S (1989) Differential regulation of three sodium channel messenger RNAs in the rat central nervous system during development. EMBO $\mathrm{J}$ 8: 3611-3616

Benzinger GR, Drum CL, Chen LQ, Kallen RG, Hanck DA, Hanck D (1997) Differences in the binding sites of two site-3 sodium channel toxins. Pflugers Arch 434: 742-749

Benzinger GR, Kyle JW, Blumenthal KM, Hanck DA (1998) A specific interaction between the cardiac sodium channel and site-3 toxin anthopleurin B. J Biol Chem 273: 80-84

Beress L, Beress R (1975) Purification of three polypeptides with neuro- and cardiotoxic activity from the sea anemone Anemonia sulcata. Toxicon 13: 359-367

Beress L, Ritter R, Ravens U (1982) The influence of the rate of electrical stimulation on the effects of the Anemonia sulcata Toxin ATX II in guinea pig papillary muscle. Eur J Pharmacol 79: 265-272 
Berget SM (1995) Exon recognition in vertebrate splicing. The Journal of Biological Chemistry 270: 2411-2414

Bezanilla F, Armstrong CM (1977) Inactivation of the sodium channel. I. Sodium current experiments. J Gen Physiol 70: 549-566

Billen B, Debaveye S, Beress L, Garateix A, Tytgat J (2010) Phyla- and Subtype-Selectivity of $\mathrm{CgNa}$, a $\mathrm{Na}$ Channel Toxin from the Venom of the Giant Caribbean Sea Anemone Condylactis Gigantea. Front Pharmacol 1: 133

Blumenthal KM, Seibert AL (2003) Voltage-gated sodium channel toxins: poisons, probes, and future promise. Cell Biochem Biophys 38: 215-238

Bontems F, Roumestand C, Boyot P, Gilquin B, Doljansky Y, Menez A, Toma F (1991) Threedimensional structure of natural charybdotoxin in aqueous solution by $1 \mathrm{H}-\mathrm{NMR}$. Charybdotoxin possesses a structural motif found in other scorpion toxins. Eur J Biochem 196: 19-28

Bosmans F, Aneiros A, Tytgat J (2002) The sea anemone Bunodosoma granulifera contains surprisingly efficacious and potent insect-selective toxins. FEBS Lett 532: 131-134

Bosmans F, Martin-Eauclaire MF, Swartz KJ (2008) Deconstructing voltage sensor function and pharmacology in sodium channels. Nature 456: 202-208

Bosmans F, Tytgat J (2007) Sea anemone venom as a source of insecticidal peptides acting on voltage-gated $\mathrm{Na}+$ channels. Toxicon 49: 550-560

Bruhn T, Schaller C, Schulze C, Sanchez-Rodriguez J, Dannmeier C, Ravens U, Heubach JF, Eckhardt K, Schmidtmayer J, Schmidt H, Aneiros A, Wachter E, Beress L (2001) Isolation and characterisation of five neurotoxic and cardiotoxic polypeptides from the sea anemone Anthopleura elegantissima. Toxicon 39: 693-702

Brusca RC, Brusca GJ (2003) Invertebrates, 2 Edition edn. Sounderland, Massachusetts: Sinauer Associates, Inc., Publishers.

Buczek O, Bulaj G, Olivera BM (2005) Conotoxins and the posttranslational modification of secreted gene products. Cell Mol Life Sci 62: 3067-3079

Cariello L, de Santis A, Fiore F, Piccoli R, Spagnuolo A, Zanetti L, Parente A (1989) Calitoxin, a neurotoxic peptide from the sea anemone Calliactis parasitica: amino acid sequence and electrophysiological properties. Biochemistry 28: 2484-2489

Castaneda O, Sotolongo V, Amor AM, Stocklin R, Anderson AJ, Harvey AL, Engstrom A, Wernstedt C, Karlsson E (1995) Characterization of a potassium channel toxin from the Caribbean Sea anemone Stichodactyla helianthus. Toxicon 33: 603-613

Catterall WA (1979) Neurotoxins as allosteric modifiers of voltage-sensitive sodium channels. Adv Cytopharmacol 3: 305-316

Catterall WA (1986) Voltage-Dependent Gating of Sodium-Channels - Correlating Structure and Function. Trends in Neurosciences 9: 7-10

Catterall WA (2000) From ionic currents to molecular mechanisms: the structure and function of voltage-gated sodium channels. Neuron 26: 13-25

Catterall WA, Beress L (1978) Sea anemone toxin and scorpion toxin share a common receptor site associated with the action potential sodium ionophore. I Biol Chem 253: 73937396 
Catterall WA, Goldin AL, Waxman SG (2005) International Union of Pharmacology. XLVII. Nomenclature and structure-function relationships of voltage-gated sodium channels. Pharmacol Rev 57: 397-409

Cestele S, Catterall WA (2000) Molecular mechanisms of neurotoxin action on voltage-gated sodium channels. Biochimie 82: 883-892

Cha A, Snyder GE, Selvin PR, Bezanilla F (1999) Atomic scale movement of the voltage-sensing region in a potassium channel measured via spectroscopy. Nature 402: 809-813

Chandy KG, Cahalan M, Pennington M, Norton RS, Wulff H, Gutman GA (2001) Potassium channels in T lymphocytes: toxins to therapeutic immunosuppressants. Toxicon 39: 1269-1276

Chapman ML, VanDongen HM, VanDongen AM (1997) Activation-dependent subconductance levels in the drk1 $\mathrm{K}$ channel suggest a subunit basis for ion permeation and gating. Biophys J 72: 708-719

Choi KL, Aldrich RW, Yellen G (1991) Tetraethylammonium blockade distinguishes two inactivation mechanisms in voltage-activated K+ channels. Proc Natl Acad Sci U S A 88: 5092-5095

Collins JF, Coulson AF (1990) Significance of protein sequence similarities. Methods Enzymol 183: $474-487$

Corrêa DD (1964) Corallimorpharia e Actiniaria do Atlântico Oeste Tropical. PhD Thesis, Departamento de Zoologia, Faculdade de Filosofia, Ciências e Letras, Universidade de São Paulo, São Paulo, Brazil

Craik DJ, Daly NL, Waine C (2001) The cystine knot motif in toxins and implications for drug design. Toxicon 39: 43-60

Dauplais M, Lecoq A, Song J, Cotton J, Jamin N, Gilquin B, Roumestand C, Vita C, de Medeiros CL, Rowan EG, Harvey AL, Menez A (1997) On the convergent evolution of animal toxins. Conservation of a diad of functional residues in potassium channel-blocking toxins with unrelated structures. J Biol Chem 272: 4302-4309

Davies TG, Field LM, Usherwood PN, Williamson MS (2007) A comparative study of voltagegated sodium channels in the Insecta: implications for pyrethroid resistance in Anopheline and other Neopteran species. Insect Mol Biol 16: 361-375

del Camino D, Holmgren M, Liu Y, Yellen G (2000) Blocker protection in the pore of a voltagegated K+ channel and its structural implications. Nature 403: 321-325

del Camino D, Yellen G (2001) Tight steric closure at the intracellular activation gate of a voltage-gated K+ channel. Neuron 32: 649-656

Demo SD, Yellen G (1991) The inactivation gate of the Shaker K+ channel behaves like an openchannel blocker. Neuron 7: 743-753

Denac H, Mevissen M, Scholtysik G (2000) Structure, function and pharmacology of voltagegated sodium channels. Naunyn Schmiedebergs Arch Pharmacol 362: 453-479

Derst C, Walther C, Veh RW, Wicher D, Heinemann SH (2006) Four novel sequences in Drosophila melanogaster homologous to the auxiliary Para sodium channel subunit TipE. Biochem Biophys Res Commun 339: 939-948

Dias-Kadambi BL, Combs KA, Drum CL, Hanck DA, Blumenthal KM (1996a) The role of exposed tryptophan residues in the activity of the cardiotonic polypeptide anthopleurin B. J Biol Chem 271: 23828-23835 
Dias-Kadambi BL, Drum CL, Hanck DA, Blumenthal KM (1996b) Leucine 18, a hydrophobic residue essential for high affinity binding of anthopleurin $B$ to the voltage-sensitive sodium channel. J Biol Chem 271: 9422-9428

Diochot S, Baron A, Rash LD, Deval E, Escoubas P, Scarzello S, Salinas M, Lazdunski M (2004) A new sea anemone peptide, APETX2, inhibits ASIC3, a major acid-sensitive channel in sensory neurons. EMBO J 23: 1516-1525

Diochot S, Loret E, Bruhn T, Beress L, Lazdunski M (2003) APETx1, a new toxin from the sea anemone Anthopleura elegantissima, blocks voltage-gated human ether-a-go-gorelated gene potassium channels. Mol Pharmacol 64: 59-69

Dolinsky TJ, Czodrowski P, Li H, Nielsen JE, Jensen JH, Klebe G, Baker NA (2007) PDB2PQR: expanding and upgrading automated preparation of biomolecular structures for molecular simulations. Nucleic Acids Res 35: W522-525

Dong K (2007) Insect sodium channels and insecticide resistance. Invert Neurosci 7: 17-30

Doyle DA, Lee A, Lewis J, Kim E, Sheng M, MacKinnon R (1996) Crystal structures of a complexed and peptide-free membrane protein-binding domain: molecular basis of peptide recognition by PDZ. Cell 85: 1067-1076

Doyle DA, Morais Cabral J, Pfuetzner RA, Kuo A, Gulbis JM, Cohen SL, Chait BT, MacKinnon R (1998) The structure of the potassium channel: molecular basis of $\mathrm{K}+$ conduction and selectivity. Science 280: 69-77

Dunn SR, Phillips WS, Spatafora JW, Green DR, Weis VM (2006) Highly conserved caspase and $\mathrm{Bcl}-2$ homologues from the sea anemone Aiptasia pallida: lower metazoans as models for the study of apoptosis evolution. J Mol Evol 63: 95-107

Durell SR, Hao Y, Guy HR (1998) Structural models of the transmembrane region of voltagegated and other $\mathrm{K}+$ channels in open, closed, and inactivated conformations. J Struct Biol 121: 263-284

Dutzler R, Campbell EB, Cadene M, Chait BT, MacKinnon R (2002) X-ray structure of a CIC chloride channel at 3.0 A reveals the molecular basis of anion selectivity. Nature 415: 287-294

Edman P (1950) Method for Determination of the Amino Acid Sequence in Peptides. Acta Chemica Scandinavica 4: 283-293

Elinder F, Nilsson J, Arhem P (2007) On the opening of voltage-gated ion channels. Physiol Behav 92: 1-7

Escoubas P (2006a) Mass spectrometry in toxinology: a 21st-century technology for the study of biopolymers from venoms. Toxicon 47: 609-613

Escoubas P (2006b) Molecular diversification in spider venoms: a web of combinatorial peptide libraries. Mol Divers 10: 545-554

Fautin DG (2009) Structural diversity, systematics, and evolution of cnidae. Toxicon 54: 10541064

Fautin DG, Lowenstein JM (1992) Scyphomedusae and their polyps are the same immunologically: implications for systematics. Comp Biochem Physiol B 102: 13-14

Felsenstein J (1985) Confidence-Limits on Phylogenies - an Approach Using the Bootstrap. Evolution 39: 783-791 
Feng G, Deak P, Chopra M, Hall LM (1995) Cloning and functional analysis of TipE, a novel membrane protein that enhances Drosophila para sodium channel function. Cell 82: 1001-1011

Flynn GE, Zagotta WN (2001) Conformational changes in S6 coupled to the opening of cyclic nucleotide-gated channels. Neuron 30: 689-698

Fox JW, Ma L, Nelson K, Sherman NE, Serrano SM (2006) Comparison of indirect and direct approaches using ion-trap and Fourier transform ion cyclotron resonance mass spectrometry for exploring viperid venom proteomes. Toxicon 47: 700-714

Frank PG, Bleakney JS (1978) Asexual Reproduction, Diet, and Anomalies of Anemone Nematostella-Vectensis in Nova-Scotia. Can Field Nat 92: 259-263

Freudenthal AR, Barbagallo JS (2002) Ghost anemone dermatitis. J Am Acad Dermatol 47: 722726

Gaillard EA, Kota P, Gentzsch M, Dokholyan NV, Stutts MJ, Tarran R (2010) Regulation of the epithelial $\mathrm{Na}+$ channel and airway surface liquid volume by serine proteases. Pflugers Arch 460: 1-17

Gallagher MJ, Blumenthal KM (1992) Cloning and expression of wild-type and mutant forms of the cardiotonic polypeptide anthopleurin B. J Biol Chem 267: 13958-13963

Garcia ML, Galvez A, Garciacalvo M, King VF, Vazquez J, Kaczorowski GJ (1991) Use of Toxins to Study Potassium Channels. Journal of Bioenergetics and Biomembranes 23: 615-646

Garcia PJ, Schein RM, Burnett JW (1994) Fulminant hepatic failure from a sea anemone sting. Ann Intern Med 120: 665-666

Gasparini S, Danse JM, Lecoq A, Pinkasfeld S, Zinn-Justin S, Young LC, de Medeiros CC, Rowan EG, Harvey AL, Menez A (1998) Delineation of the functional site of alpha-dendrotoxin. The functional topographies of dendrotoxins are different but share a conserved core with those of other Kv1 potassium channel-blocking toxins. J Biol Chem 273: 2539325403

Gendeh GS, Young LC, de Medeiros CL, Jeyaseelan K, Harvey AL, Chung MC (1997) A new potassium channel toxin from the sea anemone Heteractis magnifica: isolation, cDNA cloning, and functional expression. Biochemistry 36: 11461-11471

George AL, Jr., Knittle TJ, Tamkun MM (1992) Molecular cloning of an atypical voltage-gated sodium channel expressed in human heart and uterus: evidence for a distinct gene family. Proc Natl Acad Sci U S A 89: 4893-4897

Gething MJ, and Sambrook, J. (1992) Protein folding in the cell. Nature 355: 33-45

Gilquin B, Racape J, Wrisch A, Visan V, Lecoq A, Grissmer S, Menez A, Gasparini S (2002) Structure of the BgK-Kv1.1 complex based on distance restraints identified by double mutant cycles. Molecular basis for convergent evolution of Kv1 channel blockers. J Biol Chem 277: 37406-37413

Glauner KS, Mannuzzu LM, Gandhi CS, Isacoff EY (1999) Spectroscopic mapping of voltage sensor movement in the Shaker potassium channel. Nature 402: 813-817

Goldin AL (1999) Diversity of mammalian voltage-gated sodium channels. Ann $N$ Y Acad Sci 868: $38-50$

Goldin AL (2001) Resurgence of sodium channel research. Annu Rev Physiol 63: 871-894

Goldin AL, Snutch T, Lubbert H, Dowsett A, Marshall J, Auld V, Downey W, Fritz LC, Lester HA, Dunn R, et al.. (1986) Messenger RNA coding for only the alpha subunit of the rat brain 
$\mathrm{Na}$ channel is sufficient for expression of functional channels in Xenopus oocytes. Proc Natl Acad Sci U S A 83: 7503-7507

Goudet C, Ferrer T, Galan L, Artiles A, Batista CF, Possani LD, Alvarez J, Aneiros A, Tytgat J (2001) Characterization of two Bunodosoma granulifera toxins active on cardiac sodium channels. Br J Pharmacol 134: 1195-1206

Grimmelikhuijzen CJ, Graff D, McFarlane ID (1989) Neurones and neuropeptides in coelenterates. Arch Histol Cytol 52 Suppl: 265-278

Gulbis JM, Zhou M, Mann S, MacKinnon R (2000) Structure of the cytoplasmic beta subunit-T1 assembly of voltage-dependent K+ channels. Science 289: 123-127

Gutman GA, Chandy KG, Adelman JP, Aiyar J, Bayliss DA, Clapham DE, Covarriubias M, Desir GV, Furuichi K, Ganetzky B, Garcia ML, Grissmer S, Jan LY, Karschin A, Kim D, Kuperschmidt S, Kurachi Y, Lazdunski M, Lesage F, Lester HA, Mckinnon D, Nichols CG, O'Kelly I, Robbins J, Robertson GA, Rudy B, Sanguinetti M, Seino S, Stuehmer W, Tamkun MM, Vandenberg CA, Wei A, Wulff H, Wymore RS (2003) International Union of Pharmacology. XLI. Compendium of voltage-gated ion channels: Potassium channels. Pharmacological Reviews 55: 583-586

Guy HR, Seetharamulu P (1986) Molecular model of the action potential sodium channel. Proc Natl Acad Sci U S A 83: 508-512

Hamm LL, Feng Z, Hering-Smith KS (2010) Regulation of sodium transport by ENaC in the kidney. Curr Opin Nephrol Hypertens 19: 98-105

Hartmann HA, Colom LV, Sutherland ML, Noebels JL (1999) Selective localization of cardiac SCN5A sodium channels in limbic regions of rat brain. Nat Neurosci 2: 593-595

Heinemann SH, Terlau H, Stuhmer W, Imoto K, Numa S (1992) Calcium channel characteristics conferred on the sodium channel by single mutations. Nature 356: 441-443

Herzig V, Wood DL, Newell F, Chaumeil PA, Kaas Q, Binford GJ, Nicholson GM, Gorse D, King GF (2011) ArachnoServer 2.0, an updated online resource for spider toxin sequences and structures. Nucleic Acids Res 39: D653-657

Hessa T, Kim H, Bihlmaier K, Lundin C, Boekel J, Andersson H, Nilsson I, White SH, von Heijne G (2005) Recognition of transmembrane helices by the endoplasmic reticulum translocon. Nature 433: 377-381

Hille B (2001) Ion channels of excitable membranes, 3rd edn. Sunderland, Mass.: Sinauer.

Hille B, Schwarz W (1978) Potassium channels as multi-ion single-file pores. J Gen Physiol 72: 409-442

Hirschberg B, Rovner A, Lieberman M, Patlak J (1995) Transfer of twelve charges is needed to open skeletal muscle Na+ channels. J Gen Physiol 106: 1053-1068

Hodgkin AL, Keynes RD (1955) The potassium permeability of a giant nerve fibre. J Physiol 128: 61-88

Holland P (2004) Developmental biology. The ups and downs of a sea anemone. Science 304: $1255-1256$

Holmes TC, Fadool DA, Ren R, Levitan IB (1996) Association of Src tyrosine kinase with a human potassium channel mediated by SH3 domain. Science 274: 2089-2091

Holmgren M, Smith PL, Yellen G (1997) Trapping of organic blockers by closing of voltagedependent $\mathrm{K}+$ channels - Evidence for a trap door mechanism of activation gating. Journal of General Physiology 109: 527-535 
Holstein T, Tardent P (1984) An ultrahigh-speed analysis of exocytosis: nematocyst discharge. Science 223: 830-833

Hong KH, Miller C (2000) The lipid-protein interface of a Shaker K(+) channel. J Gen Physiol 115: 51-58

Honma T, Hasegawa Y, Ishida M, Nagai H, Nagashima Y, Shiomi K (2005a) Isolation and molecular cloning of novel peptide toxins from the sea anemone Antheopsis maculata. Toxicon 45: 33-41

Honma T, Kawahata S, Ishida M, Nagai H, Nagashima Y, Shiomi K (2008) Novel peptide toxins from the sea anemone Stichodactyla haddoni. Peptides 29: 536-544

Honma T, Minagawa S, Nagai H, Ishida M, Nagashima Y, Shiomi K (2005b) Novel peptide toxins from acrorhagi, aggressive organs of the sea anemone Actinia equina. Toxicon 46: 768774

Honma T, Shiomi K (2006) Peptide toxins in sea anemones: structural and functional aspects. Mar Biotechnol (NY) 8: 1-10

Hoshi T, Zagotta WN, Aldrich RW (1990) Biophysical and molecular mechanisms of Shaker potassium channel inactivation. Science 250: 533-538

Hoshi T, Zagotta WN, Aldrich RW (1991) Two types of inactivation in Shaker K+ channels: effects of alterations in the carboxy-terminal region. Neuron 7: 547-556

Humphrey W, Dalke A, Schulten K (1996) VMD: visual molecular dynamics. J Mol Graph 14: 33$38,27-38$

Huys I, Olamendi-Portugal T, Garcia-Gomez BI, Vandenberghe I, Van Beeumen J, Dyason K, Clynen E, Zhu SY, van der Walt J, Possani LD, Tytgat J (2004) A subfamily of acidic alpha-K+ toxins. Journal of Biological Chemistry 279: 2781-2789

Huys I, Tytgat J (2003) Evidence for a function-specific mutation in the neurotoxin, parabutoxin 3. European Journal of Neuroscience 17: 1786-1792

Isom LL, De Jongh KS, Patton DE, Reber BF, Offord J, Charbonneau H, Walsh K, Goldin AL, Catterall WA (1992) Primary structure and functional expression of the beta 1 subunit of the rat brain sodium channel. Science 256: 839-842

Jan LY, Jan YN (1992) Structural Elements Involved in Specific K+ Channel Functions. Annual Review of Physiology 54: 535-555

Jerng HH, Pfaffinger PJ, Covarrubias M (2004) Molecular physiology and modulation of somatodendritic A-type potassium channels. Mol Cell Neurosci 27: 343-369

Jiang XY, Yang WL, Chen HP, Tu HB, Wu WY, Wei JW, Wang J, Liu WH, Xu AL (2002a) Cloning and characterization of an acidic cytolysin cDNA from sea anemone Sagartia rosea. Toxicon 40: 1563-1569

Jiang Y, Lee A, Chen J, Cadene M, Chait BT, MacKinnon R (2002b) Crystal structure and mechanism of a calcium-gated potassium channel. Nature 417: 515-522

Johnson JP, Jr., Zagotta WN (2001) Rotational movement during cyclic nucleotide-gated channel opening. Nature 412: 917-921

Jouirou B, Mosbah A, Visan V, Grissmer S, M'Barek S, Fajloun Z, Van Rietschoten J, Devaux C, Rochat H, Lippens G, El Ayeb M, De Waard M, Mabrouk K, Sabatier JM (2004) Cobatoxin 1 from Centruroides noxius scorpion venom: chemical synthesis, threedimensional structure in solution, pharmacology and docking on $\mathrm{K}+$ channels. Biochem J 377: 37-49 
Kaas Q, Yu R, Jin AH, Dutertre S, Craik DJ (2012) ConoServer: updated content, knowledge, and discovery tools in the conopeptide database. Nucleic Acids Res 40: D325-330

Karbat I, Frolow F, Froy O, Gilles N, Cohen L, Turkov M, Gordon D, Gurevitz M (2004) Molecular basis of the high insecticidal potency of scorpion alpha-toxins. J Biol Chem 279: 3167931686

Kellenberger S, West JW, Catterall WA, Scheuer T (1997) Molecular analysis of potential hinge residues in the inactivation gate of brain type IIA Na+ channels. J Gen Physiol 109: 607617

Kelso GJ, Drum CL, Hanck DA, Blumenthal KM (1996) Role for Pro-13 in directing high-affinity binding of anthopleurin B to the voltage-sensitive sodium channel. Biochemistry 35: 14157-14164

Kem WR, Pennington MW, Norton RS (1999) Sea anemone toxins as templates for the design of immunosuppressant drugs. Perspect Drug Discov 16: 111-129

Keynes RD, Kimura JE (1978) Activation of the sodium channels in the squid giant axon [proceedings]. J Physiol 284: 140P

Khera PK, Blumenthal KM (1994) Role of the cationic residues arginine 14 and lysine 48 in the function of the cardiotonic polypeptide anthopleurin B. J Biol Chem 269: 921-925

Khera PK, Blumenthal KM (1996) Importance of highly conserved anionic residues and electrostatic interactions in the activity and structure of the cardiotonic polypeptide anthopleurin B. Biochemistry 35: 3503-3507

King GF, Escoubas P, Nicholson GM (2008a) Peptide toxins that selectively target insect $\mathrm{Na}_{v}$ and $\mathrm{Ca}_{v}$ channels. Channels 2: 100-116

Kiss L, LoTurco J, Korn SJ (1999) Contribution of the selectivity filter to inactivation in potassium channels. Biophys J 76: 253-263

Knaus HG, Eberhart A, Kaczorowski GJ, Garcia ML (1994) Covalent attachment of charybdotoxin to the beta-subunit of the high conductance $\mathrm{Ca}(2+)$-activated $\mathrm{K}+$ channel. Identification of the site of incorporation and implications for channel topology. J Biol Chem 269: 23336-23341

Kontis KJ, Rounaghi A, Goldin AL (1997) Sodium channel activation gating is affected by substitutions of voltage sensor positive charges in all four domains. J Gen Physiol 110: 391-401

Koshland DE (1958) Application of a Theory of Enzyme Specificity to Protein Synthesis. Proc Natl Acad Sci U S A 44: 98-104

Kreusch A, Pfaffinger PJ, Stevens CF, Choe S (1998) Crystal structure of the tetramerization domain of the Shaker potassium channel. Nature 392: 945-948

Kuhn FJP, Greeff NG (1999) Movement of voltage sensor S4 in domain 4 is tightly coupled to sodium channel fast inactivation and gating charge immobilization. Journal of General Physiology 114: 167-183

Kuzio JP, M. N.; Harwood, S. H.; Funk, C. J.; Evans, J. T.; Slavicek, J. M.; and Rohrmann, G. F. (1999) Sequence and analysis of the genome of a baculovirus pathogenic for Lymantria dispar. Virology 253: 17-34

Lagos P, Duran R, Cervenansky C, Freitas JC, Silveira R (2001) Identification of hemolytic and neuroactive fractions in the venom of the sea anemone Bunodosoma cangicum. Braz J Med Biol Res 34: 895-902 
Laskowski RA, Macarthur MW, Moss DS, Thornton JM (1993) Procheck - a Program to Check the Stereochemical Quality of Protein Structures. J Appl Crystallogr 26: 283-291

Latorre R, Miller C (1983) Conduction and selectivity in potassium channels. J Membr Biol 71: 11-30

Lee SH, Smith TJ, Ingles PJ, Soderlund DM (2000) Cloning and functional characterization of a putative sodium channel auxiliary subunit gene from the house fly (Musca domestica). Insect Biochem Mol Biol 30: 479-487

Lewin B (1997) Protein localization. In Genes VI, Lewin B (ed), pp 243-283. Oxford, England: Oxford University Press

Lewis RJ, Garcia ML (2003) Therapeutic potential of venom peptides. Nat Rev Drug Discov 2: 790-802

Li-Smerin Y, Hackos DH, Swartz KJ (2000) alpha-helical structural elements within the voltagesensing domains of a K(+) channel. J Gen Physiol 115: 33-50

Li-Smerin Y, Swartz KJ (1998) Gating modifier toxins reveal a conserved structural motif in voltage-gated Ca2+ and K+ channels. Proc Natl Acad Sci U S A 95: 8585-8589

Li LD, C.; Li, Q.; Willis, L. G.; Keddie, B. A.; Erlandson, M. A.; and Theilmann, D. A. (2002) Identification and Genomic Analysis of a Second Species of Nucleopolyhedrovirus Isolated from Mamestra configurata. Virology 297: 226-244

Li RA, Ennis IL, French RJ, Dudley SC, Jr., Tomaselli GF, Marban E (2001) Clockwise domain arrangement of the sodium channel revealed by (mu)-conotoxin (GIIIA) docking orientation. J Biol Chem 276: 11072-11077

Lin WH, Wright DE, Muraro NI, Baines RA (2009) Alternative splicing in the voltage-gated sodium channel DmNav regulates activation, inactivation, and persistent current. J Neurophysio/ 102: 1994-2006

Lin XY, Ishida M, Nagashima Y, Shiomi K (1996) A polypeptide toxin in the sea anemone Actinia equina homologous with other sea anemone sodium channel toxins: isolation and amino acid sequence. Toxicon 34: 57-65

Littleton JT, Ganetzky B (2000) Ion channels and synaptic organization: analysis of the Drosophila genome. Neuron 26: 35-43

Liu Y, Holmgren M, Jurman ME, Yellen G (1997) Gated access to the pore of a voltagedependent K+ channel. Neuron 19: 175-184

Liu Y, Jurman ME, Yellen G (1996) Dynamic rearrangement of the outer mouth of a K+ channel during gating. Neuron 16: 859-867

Liu Z, Chung I, Dong K (2001) Alternative splicing of the BSC1 gene generates tissue-specific isoforms in the German cockroach. Insect Biochem Mol Biol 31: 703-713

Livett BG, Gayler KR, Khalil Z (2004) Drugs from the sea: conopeptides as potential therapeutics. Curr Med Chem 11: 1715-1723

Lopez-Barneo J, Hoshi T, Heinemann SH, Aldrich RW (1993) Effects of external cations and mutations in the pore region on C-type inactivation of Shaker potassium channels. Receptors Channels 1: 61-71

Loughney K, Kreber R, Ganetzky B (1989) Molecular analysis of the para locus, a sodium channel gene in Drosophila. Cell 58: 1143-1154

M'Barek S, Mosbah A, Sandoz G, Fajloun Z, Olamendi-Portugal T, Rochat H, Sampieri F, Guijarro JI, Mansuelle P, Delepierre M, De Waard M, Sabatier JM (2003) Synthesis and 
characterization of $\mathrm{Pi} 4$, a scorpion toxin from Pandinus imperator that acts on $\mathrm{K}+$ channels. Eur J Biochem 270: 3583-3592

Macek P (1992) Polypeptide cytolytic toxins from sea anemones (Actiniaria). FEMS Microbiol Immunol 5: 121-129

Mahnir VM, Shumilov UN, Kovalevskaya AM, Romanenko LA, Grebelny SD (1993) Evidence for several types of biologically active substances in north Pacific sea anemones. Comp Biochem Physiol C 106: 661-665

Malpezzi EL, de Freitas JC, Muramoto K, Kamiya H (1993) Characterization of peptides in sea anemone venom collected by a novel procedure. Toxicon 31: 853-864

Malpezzi EL, Freitas JC (1990) Antimitotic effect of an extract of the sea anemone Bunodosoma caissarum on sea urchin egg development. Braz J Med Biol Res 23: 811-814

Maretic Z, Russell FE (1983) Stings by the sea anemone Anemonia sulcata in the Adriatic Sea. Am J Trop Med Hyg 32: 891-896

Mebs D (1994) Anemonefish symbiosis: vulnerability and resistance of fish to the toxin of the sea anemone. Toxicon 32: 1059-1068

Mendes EGDF, J. C. (1984) The responses of isolated preparations of Bunodosoma caissarum (Correa, 1964) (Cnidaria, Anthozoa) to drugs. Comparative Biochemistry Physiology C 79: $375-382$

Menez A (1998) Functional architectures of animal toxins: a clue to drug design? Toxicon 36: 1557-1572

Miller DJ, Ball EE, Technau U (2005) Cnidarians and ancestral genetic complexity in the animal kingdom. Trends Genet 21: 536-539

Mohrlen F, Maniura M, Plickert G, Frohme M, Frank U (2006) Evolution of astacin-like metalloproteases in animals and their function in development. Evol Dev 8: 223-231

Monks SA, Needleman DJ, Miller C (1999) Helical structure and packing orientation of the S2 segment in the Shaker K+ channel. J Gen Physiol 113: 415-423

Monks SA, Pallaghy PK, Scanlon MJ, Norton RS (1995) Solution structure of the cardiostimulant polypeptide anthopleurin-B and comparison with anthopleurin-A. Structure 3: 791-803

Moore RA, Ericsson C, Koshlukova SE, Hall LM (2001) The effect of the protein on Para sodium channel trafficking. Biophysical Journal 80: 233a-234a

Morais-Cabral JH, Zhou Y, MacKinnon R (2001) Energetic optimization of ion conduction rate by the K+ selectivity filter. Nature 414: 37-42

Morais Cabral JH, Lee A, Cohen SL, Chait BT, Li M, Mackinnon R (1998) Crystal structure and functional analysis of the HERG potassium channel $\mathrm{N}$ terminus: a eukaryotic PAS domain. Cell 95: 649-655

Moran Y, Cohen L, Kahn R, Karbat I, Gordon D, Gurevitz M (2006) Expression and mutagenesis of the sea anemone toxin Av2 reveals key amino acid residues important for activity on voltage-gated sodium channels. Biochemistry 45: 8864-8873

Moran Y, Gordon D, Gurevitz M (2009) Sea anemone toxins affecting voltage-gated sodium channels--molecular and evolutionary features. Toxicon 54: 1089-1101

Moran Y, Gurevitz M (2006) When positive selection of neurotoxin genes is missing. The riddle of the sea anemone Nematostella vectensis. FEBS J 273: 3886-3892 
Moran Y, Weinberger H, Reitzel AM, Sullivan JC, Kahn R, Gordon D, Finnerty JR, Gurevitz M (2008) Intron retention as a posttranscriptional regulatory mechanism of neurotoxin expression at early life stages of the starlet anemone Nematostella vectensis. $J$ Mol Biol 380: 437-443

Morris AL, MacArthur MW, Hutchinson EG, Thornton JM (1992) Stereochemical quality of protein structure coordinates. Proteins 12: 345-364

Mouhat S, Andreotti N, Jouirou B, Sabatier JM (2008) Animal toxins acting on voltage-gated potassium channels. Curr Pharm Des 14: 2503-2518

Mouhat S, De Waard M, Sabatier JM (2005) Contribution of the functional dyad of animal toxins acting on voltage-gated Kv1-type channels. J Pept Sci 11: 65-68

Mouhat S, Mosbah A, Visan V, Wulff H, Delepierre M, Darbon H, Grissmer S, De Waard M, Sabatier JM (2004) The 'functional' dyad of scorpion toxin Pi1 is not itself a prerequisite for toxin binding to the voltage-gated Kv1.2 potassium channels. Biochem J 377: 25-36

Murrell-Lagnado RD, Aldrich RW (1993) Energetics of Shaker K channels block by inactivation peptides. J Gen Physiol 102: 977-1003

Nagai H, Oshiro N, Takuwa-Kuroda K, Iwanaga S, Nozaki M, Nakajima T (2002) Novel proteinaceous toxins from the nematocyst venom of the Okinawan sea anemone Phyllodiscus semoni Kwietniewski. Biochem Biophys Res Commun 294: 760-763

Nascimento DG, Rates B, Santos DM, Verano-Braga T, Barbosa-Silva A, Dutra AA, Biondi I, Martin-Eauclaire MF, De Lima ME, Pimenta AM (2006) Moving pieces in a taxonomic puzzle: venom 2D-LC/MS and data clustering analyses to infer phylogenetic relationships in some scorpions from the Buthidae family (Scorpiones). Toxicon 47: 628-639

Nevalainen TJ, Peuravuori HJ, Quinn RJ, Llewellyn LE, Benzie JA, Fenner PJ, Winkel KD (2004) Phospholipase A2 in cnidaria. Comp Biochem Physiol B Biochem Mol Biol 139: 731-735

Nguyen HM, Goldin AL (2010) Sodium channel carboxyl-terminal residue regulates fast inactivation. J Biol Chem 285: 9077-9089

Noda M, Ikeda T, Suzuki H, Takeshima H, Takahashi T, Kuno M, Numa S (1986) Expression of functional sodium channels from cloned cDNA. Nature 322: 826-828

Noda M, Shimizu S, Tanabe T, Takai T, Kayano T, Ikeda T, Takahashi H, Nakayama H, Kanaoka Y, Minamino N, et al.. (1984) Primary structure of Electrophorus electricus sodium channel deduced from cDNA sequence. Nature 312: 121-127

Norton RS (1991) Structure and structure-function relationships of sea anemone proteins that interact with the sodium channel. Toxicon 29: 1051-1084

Norton RS, Olivera BM (2006) Conotoxins down under. Toxicon 48: 780-798

Norton TR, Shibata S, Kashiwagi M, Bentley J (1976) Isolation and characterization of the cardiotonic polypeptide anthopleurin-A from the sea anemone Anthopleura xanthogrammica. J Pharm Sci 65: 1368-1374

Nüchter T, Benoit M, Engel U, Özbek S, Holstein TW (2006) Nanosecond-scale kinetics of nematocyst discharge. Current Biology 16: R316-R318

Oliveira JS, Redaelli E, Zaharenko AJ, Cassulini RR, Konno K, Pimenta DC, Freitas JC, Clare JJ, Wanke E (2004) Binding specificity of sea anemone toxins to Nav 1.1-1.6 sodium channels: unexpected contributions from differences in the IV/S3-S4 outer loop. J Biol Chem 279: 33323-33335 
Oliveira JS, Zaharenko AJ, Ferreira WA, Jr., Konno K, Shida CS, Richardson M, Lucio AD, Beirao PS, de Freitas JC (2006) BcIV, a new paralyzing peptide obtained from the venom of the sea anemone Bunodosoma caissarum. A comparison with the Na+ channel toxin Bclll. Biochim Biophys Acta 1764: 1592-1600

Olivera BM (2006) Conus peptides: biodiversity-based discovery and exogenomics. J Biol Chem 281: 31173-31177

Oshiro N, Kobayashi C, Iwanaga S, Nozaki M, Namikoshi M, Spring J, Nagai H (2004) A new membrane-attack complex/perforin (MACPF) domain lethal toxin from the nematocyst venom of the Okinawan sea anemone Actineria villosa. Toxicon 43: 225-228

Pallaghy PK, Nielsen KJ, Craik DJ, Norton RS (1994) A common structural motif incorporating a cystine knot and a triple-stranded beta-sheet in toxic and inhibitory polypeptides. Protein Sci 3: 1833-1839

Pallaghy PK, Scanlon MJ, Monks SA, Norton RS (1995) Three-dimensional structure in solution of the polypeptide cardiac stimulant anthopleurin-A. Biochemistry 34: 3782-3794

Pardo LA, Heinemann SH, Terlau H, Ludewig U, Lorra C, Pongs O, Stuhmer W (1992) Extracellular K+ specifically modulates a rat brain K+ channel. Proc Natl Acad Sci U S A 89: $2466-2470$

Patton DE, Isom LL, Catterall WA, Goldin AL (1994) The adult rat brain beta 1 subunit modifies activation and inactivation gating of multiple sodium channel alpha subunits. J Biol Chem 269: 17649-17655

Payandeh J, Scheuer T, Zheng N, Catterall WA (2011) The crystal structure of a voltage-gated sodium channel. Nature 475: 353-358

Peng F, Mellor IR, Williamson MS, Davies TG, Field LM, Usherwood PN (2009) Single channel study of deltamethrin interactions with wild-type and mutated rat $\mathrm{Na}(\mathrm{V}) 1.2$ sodium channels expressed in Xenopus oocytes. Neurotoxicology 30: 358-367

Perozo E, Cortes DM, Cuello LG (1999) Structural rearrangements underlying K+-channel activation gating. Science 285: 73-78

Pettersen EF, Goddard TD, Huang CC, Couch GS, Greenblatt DM, Meng EC, Ferrin TE (2004) UCSF Chimera--a visualization system for exploratory research and analysis. $J$ Comput Chem 25: 1605-1612

Pongs O (1992) Molecular-Biology of Voltage-Dependent Potassium Channels. Physiological Reviews 72: S69-S88

Prendini L (2000) Phylogeny and classification of the superfamily Scorpionoidea Latreille 1802 (Chelicerata, Scorpiones): An exemplar approach. Cladistics 16: 1-78.

Ramachandran GN (1963) Protein Structure and Crystallography. Science 141: 288-291

Ramakrishnan C, Ramachandran GN (1965) Stereochemical criteria for polypeptide and protein chain conformations. II. Allowed conformations for a pair of peptide units. Biophys J 5: 909-933

Raman IM, Bean BP (2001) Inactivation and recovery of sodium currents in cerebellar Purkinje neurons: evidence for two mechanisms. Biophys J 80: 729-737

Rathmayer W (1979) Sea anemone toxins: tools in the study of excitable membranes. Adv Cytopharmacol 3: 335-344

Rees BB, A. (1993) Three-Dimensional Structures of Neurotoxins and Cardiotoxins. Chemical Research in Toxicology 6 
Rettig J, Heinemann SH, Wunder F, Lorra C, Parcej DN, Dolly JO, Pongs O (1994) Inactivation properties of voltage-gated $\mathrm{K}+$ channels altered by presence of beta-subunit. Nature 369: $289-294$

Rogers JC, Qu Y, Tanada TN, Scheuer T, Catterall WA (1996) Molecular determinants of high affinity binding of alpha-scorpion toxin and sea anemone toxin in the S3-S4 extracellular loop in domain IV of the Na+ channel alpha subunit. $J$ Biol Chem 271: 15950-15962

Rothberg BS, Shin KS, Phale PS, Yellen G (2002) Voltage-controlled gating at the intracellular entrance to a hyperpolarization-activated cation channel. J Gen Physiol 119: 83-91

Roux B, MacKinnon R (1999) The cavity and pore helices in the KcsA K+ channel: electrostatic stabilization of monovalent cations. Science 285: 100-102

Rudy B, C. K, E. V-SdM (1991) Families of potassium genes in mammals: toward an understanding of the molecular basis of potassium channel diversity. Molecular and Cellular Neuroscience 2: 89-102

Sali A, Blundell TL (1993) Comparative protein modelling by satisfaction of spatial restraints. J Mol Biol 234: 779-815

Salkoff L, Butler A, Scavarda N, Wei A (1987a) Nucleotide sequence of the putative sodium channel gene from Drosophila: the four homologous domains. Nucleic Acids Res 15: 8569-8572

Salkoff L, Butler A, Wei A, Scavarda N, Giffen K, Ifune C, Goodman R, Mandel G (1987b) Genomic organization and deduced amino acid sequence of a putative sodium channel gene in Drosophila. Science 237: 744-749

Salles HC, Volsi EC, Marques MR, Souza BM, dos Santos LD, Tormena CF, Mendes MA, Palma MS (2006) The venomous secrets of the web droplets from the viscid spiral of the orbweaver spider Nephila clavipes (Araneae, Tetragnatidae). Chem Biodivers 3: 727-741

Sanchez-Rodriguez J, Zugasti-Cruz A, Burnett JW (2001) Cutaneous stings from Bartholomea annulata. Contact Dermatitis 44: 314-315

Sanner MF (1999) Python: a programming language for software integration and development. J Mol Graph Model 17: 57-61

Sanz L, Gibbs HL, Mackessy SP, Calvete JJ (2006) Venom proteomes of closely related Sistrurus rattlesnakes with divergent diets. J Proteome Res 5: 2098-2112

Savarin P, Guenneugues M, Gilquin B, Lamthanh H, Gasparini S, Zinn-Justin S, Menez A (1998) Three-dimensional structure of kappa-conotoxin PVIIA, a novel potassium channelblocking toxin from cone snails. Biochemistry 37: 5407-5416

Schreibmayer W, Wallner M, Lotan I (1994) Mechanism of modulation of single sodium channels from skeletal muscle by the beta 1-subunit from rat brain. Pflugers Arch 426: 360-362

Schrodinger, LLC. (2010) The PyMOL Molecular Graphics System, Version 1.3r1.

Schumacher MA, Rivard AF, Bachinger HP, Adelman JP (2001) Structure of the gating domain of a Ca2+-activated $\mathrm{K}+$ channel complexed with Ca2+/calmodulin. Nature 410: 11201124

Schweitz H, Bruhn T, Guillemare E, Moinier D, Lancelin JM, Beress L, Lazdunski M (1995) Kalicludines and kaliseptine. Two different classes of sea anemone toxins for voltage sensitive K+ channels. J Biol Chem 270: 25121-25126 
Schweitz H, Vincent JP, Barhanin J, Frelin C, Linden G, Hugues M, Lazdunski M (1981) Purification and pharmacological properties of eight sea anemone toxins from Anemonia sulcata, Anthopleura xanthogrammica, Stoichactis giganteus, and Actinodendron plumosum. Biochemistry 20: 5245-5252

Seibert AL, Liu J, Hanck DA, Blumenthal KM (2003) Arg-14 loop of site 3 anemone toxins: effects of glycine replacement on toxin affinity. Biochemistry 42: 14515-14521

Seibert AL, Liu J, Hanck DA, Blumenthal KM (2004) Role of Asn-16 and Ser-19 in anthopleurin B binding. Implications for the electrostatic nature of $\mathrm{Na}(\mathrm{V})$ site 3. Biochemistry 43: 7082-7089

Sheets MF, Kyle JW, Kallen RG, Hanck DA (1999) The Na channel voltage sensor associated with inactivation is localized to the external charged residues of domain IV, S4. Biophys $J$ 77: 747-757

Shen NV, Pfaffinger PJ (1995) Molecular recognition and assembly sequences involved in the subfamily-specific assembly of voltage-gated K+ channel subunit proteins. Neuron 14: 625-633

Shevchenko A, de Sousa MM, Waridel P, Bittencourt ST, de Sousa MV, Shevchenko A (2005) Sequence similarity-based proteomics in insects: characterization of the larvae venom of the Brazilian moth Cerodirphia speciosa. J Proteome Res 4: 862-869

Shiomi K, Honma T, Ide M, Nagashima Y, Ishida M, Chino M (2003) An epidermal growth factor-like toxin and two sodium channel toxins from the sea anemone Stichodactyla gigantea. Toxicon 41: 229-236

Sigworth FJ (1994) Voltage gating of ion channels. Q Rev Biophys 27: 1-40

Smith JJH, J. M.; Little, M. J.; Nicholson, G. M.; King, G. F. \& Alewood, P. F. (2011) Unique scorpion toxin with a putative ancestral fold provides insight into evolution of the inhibitor cystine knot motif. Proceedings of the National Academy of Sciences of the United States of America 108: 10478-10483

Smith MR, Goldin AL (1997) Interaction between the sodium channel inactivation linker and domain III S4-S5. Biophysical Journal 73: 1885-1895

Smith TJ, Lee SH, Ingles PJ, Knipple DC, Soderlund DM (1997) The L1014F point mutation in the house fly Vssc1 sodium channel confers knockdown resistance to pyrethroids. Insect Biochem Mol Biol 27: 807-812

Song W, Liu Z, Tan J, Nomura Y, Dong K (2004) RNA editing generates tissue-specific sodium channels with distinct gating properties. J Biol Chem 279: 32554-32561

Spagnuolo A, Zanetti L, Cariello L, Piccoli R (1994) Isolation and characterization of two genes encoding calitoxins, neurotoxic peptides from Calliactis parasitica (Cnidaria). Gene 138: 187-191

Spassova M, Lu Z (1998) Coupled ion movement underlies rectification in an inward-rectifier K+ channel. J Gen Physiol 112: 211-221

Stuhmer W, Conti F, Suzuki H, Wang XD, Noda M, Yahagi N, Kubo H, Numa S (1989) Structural parts involved in activation and inactivation of the sodium channel. Nature 339: 597603

Tamura K, Peterson D, Peterson N, Stecher G, Nei M, Kumar S (2011) MEGA5: molecular evolutionary genetics analysis using maximum likelihood, evolutionary distance, and maximum parsimony methods. Mol Biol Evol 28: 2731-2739 
Tan J, Liu Z, Nomura Y, Goldin AL, Dong K (2002a) Alternative splicing of an insect sodium channel gene generates pharmacologically distinct sodium channels. J Neurosci 22: 5300-5309

Tan J, Liu Z, Tsai TD, Valles SM, Goldin AL, Dong K (2002b) Novel sodium channel gene mutations in Blattella germanica reduce the sensitivity of expressed channels to deltamethrin. Insect Biochem Mol Biol 32: 445-454

Tapper AR, George AL, Jr. (2001) Location and orientation of minK within the I(Ks) potassium channel complex. J Biol Chem 276: 38249-38254

Thomsen WJ, Catterall WA (1989) Localization of the receptor site for alpha-scorpion toxins by antibody mapping: implications for sodium channel topology. Proc Natl Acad Sci U S A 86: 10161-10165

Trott O, Olson AJ (2010) AutoDock Vina: improving the speed and accuracy of docking with a new scoring function, efficient optimization, and multithreading. J Comput Chem 31: 455-461

Tseng TT, McMahon AM, Johnson VT, Mangubat EZ, Zahm RJ, Pacold ME, Jakobsson E (2007) Sodium channel auxiliary subunits. J Mol Microbiol Biotechnol 12: 249-262

Turk T, Kem WR (2009) The phylum Cnidaria and investigations of its toxins and venoms until 1990. Toxicon 54: 1031-1037

Turlapaty P, Shibata S, Norton TR, Kuchii M (1973) Effects of a central stimulant substance isolated from the sea anemone Stoichactis kenti on brain monoamines of the mouse. Eur J Pharmacol 24: 359-365

Ulbricht W (2005) Sodium channel inactivation: molecular determinants and modulation. Physiol Rev 85: 1271-1301

Vais H, Atkinson S, Eldursi N, Devonshire AL, Williamson MS, Usherwood PN (2000) A single amino acid change makes a rat neuronal sodium channel highly sensitive to pyrethroid insecticides. FEBS Lett 470: 135-138

Vincent JP, Balerna M, Barhanin J, Fosset M, Lazdunski M (1980) Binding of sea anemone toxin to receptor sites associated with gating system of sodium channel in synaptic nerve endings in vitro. Proc Natl Acad Sci U S A 77: 1646-1650

Wallace AC, Laskowski RA, Thornton JM (1995) LIGPLOT: a program to generate schematic diagrams of protein-ligand interactions. Protein Eng 8: 127-134

Wallner M, Meera P, Toro L (1996) Determinant for beta-subunit regulation in highconductance voltage-activated and $\mathrm{Ca}(2+)$-sensitive $\mathrm{K}+$ channels: an additional transmembrane region at the $\mathrm{N}$ terminus. Proc Natl Acad Sci U S A 93: 14922-14927

Wang L, Ou J, Peng L, Zhong X, Du J, Liu Y, Huang Y, Liu W, Zhang Y, Dong M, Xu AL (2004) Functional expression and characterization of four novel neurotoxins from sea anemone Anthopleura sp. Biochem Biophys Res Commun 313: 163-170

Wanke E, Restano-Cassulini R (2007) Toxins interacting with ether-a-go-go-related gene voltage-dependent potassium channels. Toxicon 49: 239-248

Warmke JW, Reenan RA, Wang P, Qian S, Arena JP, Wang J, Wunderler D, Liu K, Kaczorowski GJ, Van der Ploeg LH, Ganetzky B, Cohen CJ (1997) Functional expression of Drosophila para sodium channels. Modulation by the membrane protein TipE and toxin pharmacology. J Gen Physiol 110: 119-133 
Watanabe E, Fujikawa A, Matsunaga H, Yasoshima Y, Sako N, Yamamoto T, Saegusa C, Noda M (2000) $\mathrm{Na}(\mathrm{v}) 2 / \mathrm{NaG}$ channel is involved in control of salt-intake behavior in the CNS. Journal of Neuroscience 20: 7743-7751

Welsh JS (1964) Composition and mode of action of some invertebrate venoms. Annual Rev Pharmacology: 293-304

West JW, Patton DE, Scheuer T, Wang Y, Goldin AL, Catterall WA (1992) A cluster of hydrophobic amino acid residues required for fast $\mathrm{Na}(+)$-channel inactivation. Proc Natl Acad Sci U S A 89: 10910-10914

Whelan S, Goldman N (2001) A general empirical model of protein evolution derived from multiple protein families using a maximum-likelihood approach. Mol Biol Evol 18: 691699

Whittington HB. (1985) The Burgess Shale. Yale University Press, New Haven, CT.

Williamson MS, Martinez-Torres D, Hick CA, Devonshire AL (1996) Identification of mutations in the housefly para-type sodium channel gene associated with knockdown resistance (kdr) to pyrethroid insecticides. Mol Gen Genet 252: 51-60

Wu L, Nishiyama K, Hollyfield JG, Wang Q (2002) Localization of Nav1.5 sodium channel protein in the mouse brain. Neuroreport 13: 2547-2551

Yang N, George AL, Jr., Horn R (1996) Molecular basis of charge movement in voltage-gated sodium channels. Neuron 16: 113-122

Yellen G (2002) The voltage-gated potassium channels and their relatives. Nature 419: 35-42

Yellen G, Sodickson D, Chen TY, Jurman ME (1994) An engineered cysteine in the external mouth of a $\mathrm{K}+$ channel allows inactivation to be modulated by metal binding. Biophys J 66: 1068-1075

Yeung SY, Thompson D, Wang Z, Fedida D, Robertson B (2005) Modulation of Kv3 subfamily potassium currents by the sea anemone toxin BDS: significance for CNS and biophysical studies. J Neurosci 25: 8735-8745

$\mathrm{Yu} \mathrm{FH}, \mathrm{Catterall}$ WA (2003) Overview of the voltage-gated sodium channel family. Genome Biol 4: 207

Zagotta WN, Hoshi T, Aldrich RW (1990) Restoration of inactivation in mutants of Shaker potassium channels by a peptide derived from ShB. Science 250: 568-571

Zaharenko AJ, Ferreira WA, Jr., de Oliveira JS, Konno K, Richardson M, Schiavon E, Wanke E, de Freitas JC (2008a) Revisiting cangitoxin, a sea anemone peptide: purification and characterization of cangitoxins II and III from the venom of Bunodosoma cangicum. Toxicon 51: 1303-1307

Zaharenko AJ, Ferreira WA, Jr., Oliveira JS, Richardson M, Pimenta DC, Konno K, Portaro FC, de Freitas JC (2008b) Proteomics of the neurotoxic fraction from the sea anemone Bunodosoma cangicum venom: Novel peptides belonging to new classes of toxins. Comp Biochem Physiol Part D Genomics Proteomics 3: 219-225

Zaharenko AJ, Picolo G, Ferreira WA, Jr., Murakami T, Kazuma K, Hashimoto M, Cury Y, de Freitas JC, Satake M, Konno K (2011) Bunodosine 391: an analgesic acylamino acid from the venom of the sea anemone Bunodosoma cangicum. J Nat Prod 74: 378-382

Zheng J, Sigworth FJ (1997) Selectivity changes during activation of mutant Shaker potassium channels. J Gen Physiol 110: 101-117 
Zhou M, Morais-Cabral JH, Mann S, MacKinnon R (2001a) Potassium channel receptor site for the inactivation gate and quaternary amine inhibitors. Nature 411: 657-661

Zhou W, Chung I, Liu Z, Goldin AL, Dong K (2004) A voltage-gated calcium-selective channel encoded by a sodium channel-like gene. Neuron 42: 101-112

Zhou Y, Morais-Cabral JH, Kaufman A, MacKinnon R (2001b) Chemistry of ion coordination and hydration revealed by a K+ channel-Fab complex at 2.0 A resolution. Nature 414: $43-48$

Zhu S, Darbon H, Dyason K, Verdonck F, Tytgat J (2003) Evolutionary origin of inhibitor cystine knot peptides. Faseb J 17: 1765-1767

Zhu S, Li W, Jiang D, Zeng X (2000) Evidence for the existence of insect defensin-like peptide in scorpion venom. IUBMB Life 50: 57-61 